\title{
Yis languages
}

\section{Theoretical and Methodological \\ Approaches to the Sociolinguistic Integration of Migration}

Edited by Florentino Paredes García and María Sancho Pascual Printed Edition of the Special Issue Published in Languages 
Theoretical and Methodological Approaches to the Sociolinguistic Integration of Migration 



\section{Theoretical and Methodological Approaches to the Sociolinguistic Integration of Migration}

Special Issue Editors

Florentino Paredes García

María Sancho Pascual 
Special Issue Editors

Florentino Paredes García

University of Alcalá

Spain
María Sancho Pascual

Complutense University of Madrid

Spain

\section{Editorial Office}

MDPI

St. Alban-Anlage 66

4052 Basel, Switzerland

This is a reprint of articles from the Special Issue published online in the open access journal Languages (ISSN 2226-471X) (available at: https://www.mdpi.com/journal/languages/special_ issues/sociolinguistic_migration).

For citation purposes, cite each article independently as indicated on the article page online and as indicated below:

LastName, A.A.; LastName, B.B.; LastName, C.C. Article Title. Journal Name Year, Article Number, Page Range.

ISBN 978-3-03936-192-2 (Hbk)

ISBN 978-3-03936-193-9 (PDF)

Cover image courtesy of Florentino Paredes García and María Sancho Pascual.

(C) 2020 by the authors. Articles in this book are Open Access and distributed under the Creative Commons Attribution (CC BY) license, which allows users to download, copy and build upon published articles, as long as the author and publisher are properly credited, which ensures maximum dissemination and a wider impact of our publications.

The book as a whole is distributed by MDPI under the terms and conditions of the Creative Commons license CC BY-NC-ND. 


\section{Contents}

About the Special Issue Editors $\ldots \ldots \ldots \ldots \ldots \ldots \ldots$ vii

Preface to "Theoretical and Methodological Approaches to the Sociolinguistic Integration of

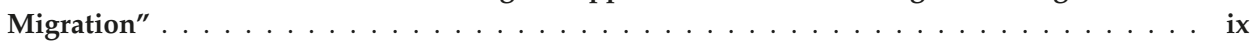

\section{María Sancho Pascual}

The Sociolinguistic Integration of Immigrant Populations: Reflections on Its Study

Reprinted from: Languages 2019, 4, 35, doi:10.3390/languages4020035 . . . . . . . . . . . . . . .

\section{Yara Pérez Cantador}

An Approach to Studying the Sociolinguistic Integration of Romanian Immigrants Residing in the Community of Madrid

Reprinted from: Languages 2020, 5, 3, doi:10.3390/languages5010003 . . . . . . . . . . . . 13

\section{María Cecilia Ainciburu and Irene Buttazzi}

"Esa no soy Yo": Self-Image and Name Change from the Perspective of Female Immigrants

Reprinted from: Languages 2019, 4, 83, doi:10.3390/languages4040083 . . . . . . . . . . . . . 25

Adil Moustaoui Srhir, Gabriela Prego Vázquez and Luz Zas Varela

Translingual Practices and Reconstruction of Identities in Maghrebi Students in Galicia

Reprinted from: Languages 2019, 4, 63, doi:10.3390/languages4030063 . . . . . . . . . . . . . 47

\section{Giovanna Mapelli}

The Identity Construction of Migrants on Facebook

Reprinted from: Languages 2019, 4, 52, doi:10.3390/languages4030052 . . . . . . . . . . . . 65

Olga Ivanova

"My Child Is a Perfect Bilingual": Cognition, Emotions, and Affectivity in Heritage Language Transmission

Reprinted from: Languages 2019, 4, 44, doi:10.3390/languages4020044 . . . . . . . . . . . . . 8

\section{Rosana Ariolfo}

The Use of the Present Perfect (pretérito perfecto compuesto) with Aoristic Value in the Speech of Latin American Students

Reprinted from: Languages 2019, 4, 32, doi:10.3390/languages4020032 . . . . . . . . . . . . . 101

\section{Antonio-Manuel Ávila-Muñoz}

Revisiting the Use of the Proximity Lexicon in the Classroom for Immigrant Populations at Risk of Social Exclusion: Does It Really Help?

Reprinted from: Languages 2019, 4, 43, doi:10.3390/languages4020043 . . . . . . . . . . . . . 115 



\section{About the Special Issue Editors}

Florentino Paredes García Ph. Doctor, is professor at the University of Alcala and develops his research activity in sociolinguistics, dialectology, history of language and Spanish teaching. He currently coordinates the project "The Migrant Population in the Community of Madrid: Linguistic, Communicative, Cultural and Social Factors in the Integration Process and Linguistic Resources for Intervention (INMIGRA3-CM)", financed by the Community of Madrid, and co-directs the PRECAVES XXI project for the study of attitudes towards the cultured varieties of Spanish. His recent publications include Patrones sociolingüísticos de Madrid (Peter Lang 2015) and La lengua hablada en Madrid (Corpus PRESEEA- Distritos de Vallecas) (3 vols. UAH, 2020).

María Sancho Pascual holds a PhD in Spanish Studies at the University of Alcalá (Madrid, Spain). She is an Assistant Professor in the Spanish Linguistics and Literary Theory Department at Complutense University of Madrid (Spain). Her research and teaching activity focuses on sociolinguistics and the study and teaching of Spanish varieties. She has been a member of the research groups "Applied Linguistics", "PRESEEA-Madrid" and "INMIGRA" of the University of Alcalá. She has published several works about the sociolinguistic integration of Spanish-speaking immigrants in Spain. She has been the editorial assistant of the international journal Language and Migration / Language and Migration between 2010 and 2019. 



\section{Preface to "Theoretical and Methodological Approaches to the Sociolinguistic Integration of Migration"}

The history of humanity involves a long series of migratory movements. From the origin of the human species to the contemporary world, a large proportion of the major events in world history are related to displacements of population from one region to other, for economic reasons, because of war, or merely for reasons of survival. The movement of people from one region to another is a process with a wide variety of economic, social, political, psychological, cultural, and linguistic consequences for individuals and societies alike. Migratory movements have reached unprecedented levels in the twentieth and twenty-first centuries, in both quantitative and proportional $t$ erms: a ccording to the World Migration Report 2018, 740 million people had migrated within their own country of birth, while there were 244 million international migrants. However, figures a side, it is essential to study migration insofar as it has been linked to the phenomenon of globalization, and has therefore become a cornerstone of today's society.

This Special Issue, entitled "Theoretical and Methodological Approaches to the Sociolinguistic Integration of Migration", provides a forum for debate and analysis in the study of the relations between language and society when linguistic contact takes place as a result of migratory movements; it focuses particularly on how migration develops or favours the process of sociolinguistic integration. The volume contains a series of studies that contain theoretical approaches, models, and applications related to linguistic and sociolinguistic processes which place certain situations in contact as a consequence of migration.

The chapter that opens the volume, "The Sociolinguistic Integration of Immigrant Populations: Reflections on I ts S tudy", b y M aría S ancho P ascual, is a reflection on th e ro le th at th e linguistic dimension plays in the process of migrants' sociolinguistic integration, based on the INMIGRA project to study the migrant population in the community of Madrid. Language plays a fundamental role in the process of constructing and redefining personal identity in the new c ontext. The models must also consider the population of the receiving society, which is generally the first determining factor in the process, in order to identify the changes caused by linguistic and cultural contact and to analyze them in depth.

The study by Yara Pérez Cantador, "An Approach to Studying the Sociolinguistic Integration of Romanian Immigrants Residing in the Community of Madrid", implements the models used in the INMIGRA project mentioned above. The author describes the methodology she uses to examine the process of sociolinguistic integration among the population of Romanian immigrants living in Madrid. The process is analyzed from a twofold perspective: semi-directed interviews and attitude questionnaires are used with the Romanian immigrant population, while attitude surveys are simultaneously performed on the population of Madrid. These two perspectives show acculturation processes followed by the two social groups in contact, and identify the factors that facilitate the process as well as anticipating those that hinder it.

The next three studies specifically examine the role of language in the c reation of identity in migratory contexts. The study by María Cecilia Ainciburu and Irene Butazzi, "Esa No Soy Yo ("That's not $\mathrm{me}^{\prime \prime}$ ): Self-Image and Name Change from the Perspective of Female Immigrants", focuses on a defining a spect of personal i dentity: a n individual's own $n$ ame. In s ituations of migratory 
contact, a migrant's name is very often modified, which can also lead to changes in the individual's self-perception. The research examines interviews with Peruvian and Chinese migrants living in Italy. The situations range from changes against the migrant's will (such as phonetic modifications and names that are not the same as the person's birth name) or voluntary name changes to adapt them to Western norms (typical among the Chinese population). The results show that there is a correlation between the desire to integrate in the host country and the positive reactions to the image created by the modified name.

In the chapter "Translingual Practices and Reconstruction of Identities in Maghrebi Students in Galicia", Adil Moustaoui Srhir, Gabriela Prego Vázquez and Luz Zas Varela analyze the linguistic variety that arises from migratory contact situations in the process of identity reconstruction. In specific terms, they study what happens to young adolescents of Moroccan and Algerian origin living in Galicia, using a multimodal corpus made up of spoken and written interactions and a group chat on WhatsApp. The results show that these young people's linguistic repertoire is deeply rooted in Moroccan Arabic as their family language, but it incorporates characteristics of the Spanish and Galician languages of the receiving society; it is also shaped by multimodal translation practices associated with transnational histories and the local education process.

The fifth chapter, "The Identity Construction of Migrants on Facebook," by Giovanna Mapelli, presents an analysis of 150 posts published between 2017 and 2019 in five Facebook groups belonging to Latin American migrants residing in Italy: Uruguayans, Argentines, Colombians, Peruvians and Venezuelans. The comments and dialogues that take place in these social networking forums highlight the user's individual identity and position with respect to others. The individual's role in the migratory process is determined in this study, as well as the way in which the digital environment affects relations between migrants, and how the identities of migrants are negotiated and (re)defined in discursive practice, in order to build a shared conception of the deterritorialised collective identity using links of solidarity.

The affective dimension associated with language in the migratory process and in the transmission of language within the family is linked to the process of constructing identity. The study by Olga Ivanova, "My Child Is a Perfect Bilingual: Cognition, Emotions, and Affectivity in Heritage Language Transmission," focuses on this issue. The author analyses the factors which foster the intergenerational transmission of the heritage language, and most obviously encourage its acquisition among second generation speakers. Using a scalar questionnaire which examines the linguistic practices, attitudes, and motivations of first-generation speakers, the study analyses the effect of self-classification, attitudes toward the usefulness of the heritage language, and strategies for intergenerational transmission of the heritage language.

The seventh chapter, "The Use of the Present Perfect with Aoristic Value in the Speech of Latin American Students," by Rosana Ariolfo, studies a specific characteristic of the speech of Latin American students residing in Genoa: use of the past simple or compound verb forms. The author examines the results of a corpus of semi-directed interviews, taking into account its characteristics, the syntactic environment in which it is used, combinations with other verb forms, adverbial complements, temporal expressions, the deixis and its communicative context. According to the author, the speaker's discourse strategies and the desire to converge with or diverge from the local language (Italian) are involved in the selection of one variant or another.

The volume ends with a specific teaching approach for the immigrant population. In "Revisiting the Use of the Proximity Lexicon in the Classroom for Immigrant Populations at Risk of Social 
Exclusion: Does It Really Help?" Antonio-Manuel Ávila-Muñoz advocates the usefulness of the dialectal and local lexicon in the process of teaching second languages, in order to facilitate the integration of socially vulnerable groups of immigrants. The author argues that this local lexicon is often more closely associated with meanings of community membership than the general lexicon, and is therefore a powerful tool for social inclusion. This hypothesis is demonstrated by empirical work in the classroom, involving two samples of students: the dialectal strategy was used in a conscious and programmed way in one group, while the model was not followed in the other control group. The results show that the group to which the proposed system was applied presented higher levels of social well-being, satisfaction and adaptation.

This volume is part of the work of the research project "La población migrante en la Comunidad de Madrid: factores lingüísticos, comunicativos, culturales y sociales del proceso de integración y recursos lingüísticos de intervención". The migrant population in the Community of Madrid: linguistic, communicative, cultural and social factors in the integration process and linguistic resources for intervention (INMIGRA3-CM; ref.: H2019/HUM-5772), financed by the Community of Madrid (Spain) and the European Social Fund.

Florentino Paredes García, María Sancho Pascual Special Issue Editors 

Article

\title{
The Sociolinguistic Integration of Immigrant Populations: Reflections on Its Study
}

\author{
María Sancho Pascual \\ Department of Linguistics and Oriental Studies, Faculty of Language Studies, \\ Complutense University of Madrid, 28040 Madrid, Spain; maria.sancho@ucm.es
}

Received: 25 April 2019; Accepted: 6 June 2019; Published: 7 June 2019

\begin{abstract}
Taking as its main point of departure the research carried out in the Madrid context by the Hispalin-UAH team of the IN.MIGRA2-CM project, the goal of this article is to reflect on the role of the linguistic dimension within the process of the social integration of migrant populations. It trains its sights on the need to work from a cognitive angle which may help to show how those involved in the process construct and re-define the new context, and on the need to consider the host population - as the prime conditioner of the process-and to identify and analyse in depth the components of identity that are modified as a result of cultural contact.
\end{abstract}

Keywords: cognitive sociolinguistics; migration; sociolinguistic integration; cultural contact; city of Madrid

\section{Introduction}

The goal of this article is to offer some general reflections about the study of the sociolinguistic integration of the immigrant population. More specifically, on the basis of the results of the Hispalin-UAH team of the IN.MIGRA2-CM project ${ }^{1}$, I shall consider certain aspects of the Madrid context, which, unlike other Spanish contexts, is officially monolingual. This fact explains the lack of any literature relating to multiculturality and plurilingualism, or to attitudes towards the plurilingual realities constructed by individuals belonging to this context. ${ }^{2}$ What is more, Madrid is held to represent what is regarded to be normative or standard Spanish (Alvar 1982; Alvar 1986; Moreno Fernández 2012b, 2012c; Cestero and Paredes 2018; Sanz Huéscar 2008; Sancho Pascual 2014, for the immigration context in Madrid), a fact that shapes the transmission of certain linguistic ideologies.

We should point out that when talking about the immigrant population, we are referring specifically to economic migration from less developed countries than the host country. Due to its unique socioeconomic situation, this group generally has to undergo an integration process with a level of complexity greater than that of individuals who start off from situations of less vulnerability. Although in this paper we will generally be referring to this group, we should bear in mind that each person's situation as an individual and as a member of certain social groups will affect specifically issues that we are going to address here, and subsequently influence their own process. In this sense, key factors include the source country (and, consequently, the source language, which will or will not

1 IN.MIGRA2-CM (The migrant population of the Madrid Region: a multidisciplinary study and tools for sociolinguistic integration-ref. H2015/HUM3404) is a project carried out by three universities from Madrid: the University of Alcalá (UAH), the Nebrija University and the European University of Madrid (UEM). Its goal is the study of the sociolinguistic immigration of the Madrid region's migrant population and the design of instruments to facilitate that process. An interdisciplinary project, it pursues four research lines: sociolinguistics, communication media, translation, and Teaching Spanish to Immigrants. The Hispalin-UAH team conducts the project's sociolinguistic studies.

2 Although Madrid is officially a monolingual and monodialectal region, given its sociolinguistic complexity, it cannot in fact be regarded as such. The arrival of people of diverse Spanish or national origins make it a meeting point for a multitude of accents and languages which are common in the streets and, therefore, part of Madrilenians' daily lives (Sáez Rivera 2014). 
be shared by the host community), the age of arrival, the length of residence or the size of the source group in the host community, among many others (including, as we pointed out, purely individual factors) (Caravedo 2014). As regards the age of arrival, the difference between first-, second- and third-generation individuals is fundamental. Seeing as they join the educational system of the host country, second and third generations will find it easier to integrate into the host society. Their insertion into the group structure of the host community will, therefore, have different characteristics to that of first-generation members. This will affect the value system of these individuals, which will—entirely or partially - be developed in the host community, with the consequences that this will have from a social and linguistic point of view (Caravedo 2014). As we mentioned, this paper does not set out to dissect the aspects that are going to be proposed according to each of these factors. However, the study and analysis of specific situations and contexts do require the incorporation of these elements.

In the course of this article I will commence by explaining social integration before introducing the sociolinguistic dimension and, finally, focusing on two of the aspects involved in the process which I think call for particular attention in order to re-think approaches to them. These are: the analysis of the host community, and the components that are modified in the acculturation process.

I shall adopt a cognitivist perspective with a view to underlining the importance of starting from the perceptions of those involved in the process in order to analyse and interpret the dynamic spaces and linguistic identities which they themselves construct (Moreno Fernández 2012a; Caravedo 2014; Bürki 2019) and use in inter-group relations. My aim, then, is to highlight the need to change the starting-point of research into this phenomenon in order to avoid imposing researchers' own perspectives, which are usually developed from their own perceptions and, therefore, give their research a subjective bias (Caravedo 2014).

\section{Social and Sociolinguistics Integration}

When dealing with integration, our starting-point is Berry's acculturation model (Berry 1990, 1997, 2001) devised on the basis of transcultural psychology. Although the model's original scheme has been revised and extended, ${ }^{3}$ it is a good place to start if we wish to define integration. The importance of Berry's model lies in its significant advances on earlier ones, and we shall refer to two of them. In the first place, it does not take acculturation as a synonym of assimilation; rather, assimilation is one of the process's possible solutions. Acculturation sets in when two different cultures come into contact and is defined as "the process by individual change, both by being influenced by contact with another culture and by being participants in the general acculturative changes under way in their own culture" (Berry 1990, p. 204). It follows that the context in which acculturation happens should be redefined through the adoption of various strategies, as we shall see.

The second important innovation in Berry's model is its assumption that the process is bidirectional and, therefore, involves both the immigrant and host populations at all their respective structural levels (Gugenberger 2007; Moreno Fernández 2009). Consequently, the full weight of responsibility for the process does not fall solely on the immigrant population.

In line with Berry's model, acculturation is measured by means of two independent attitudinal dimensions which, depending on how they combine, give rise to a range of possible solutions (Figure 1). One of the dimensions has to do with the subordinate group's (in our case, the group composed of migrants) maintenance of its cultural identity, the other with the extent to which relations with other group(s) are valued and maintained. Given that the process is taken to be bidirectional, both

3 While Berry's acculturation model has been applied widely, above all (though not exclusively) in US and Canadian contexts, later valuable proposals have attempted to refine it with the addition of a greater number of explanatory variables. See the Interactive Acculturation Model (Bourhis et al. 1997) and the extended relative acculturation model (ERAM) (Navas Luque et al. 2004; Navas Luque and Rojas Tejada 2010). As it is not our objective to analyse the acculturation process, we shall not discuss Berry's model here but merely take its basic principles, namely, the existence of different acculturation strategies and its consequent definition of integration, as the starting-point for our study. 
dimensions are present in both groups, that is to say, in the dominant group (the host society) and the subordinate group. Thus, Berry's model takes into account, on the one hand, the desires of the minority group with respect to the two dimensions and, on the other, the preferences shown by the majority group with regard to immigrants. Viewed in this light, the concept of acculturation assumes that cultural changes occurring as a result of contact will affect both minority and majority groups, albeit to a lesser degree in the case of the latter (Berry 1990).

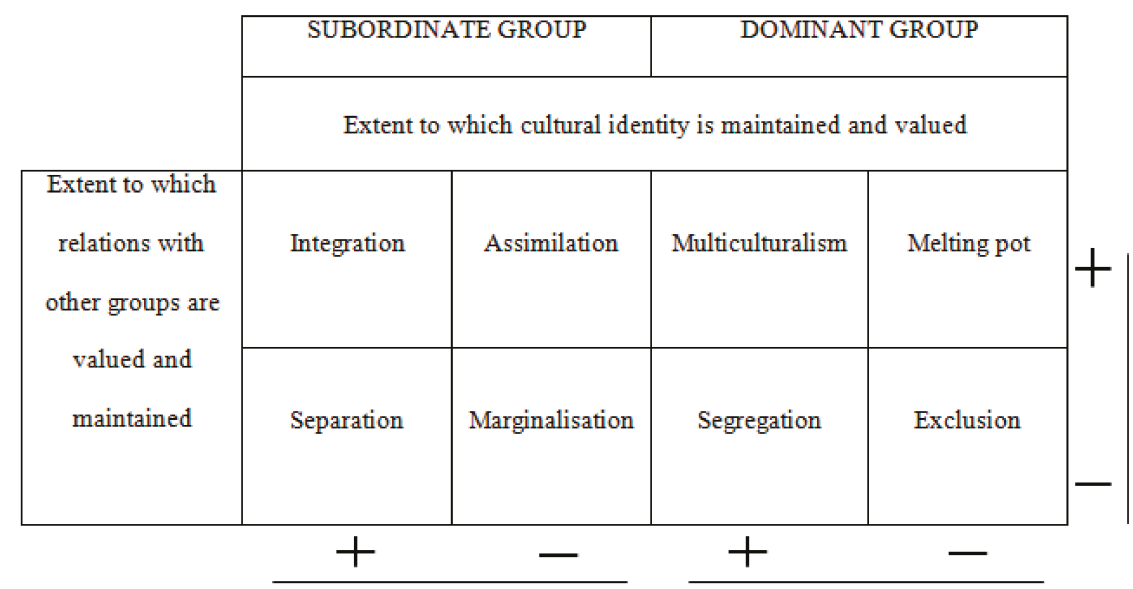

Figure 1. Berry's acculturation model. Source: Berry (2001, p. 618).

Thus, when we talk about integration, we mean the desire to preserve one's own cultural identity and also to strike up relations with other groups. From the point of view of the host community, the desire that migrants forge relations with other groups further implies a search on its own part for such relations. In this regard, Moreno Fernández (2009, p. 131) defines integration as the "process of mutual adjustment on the part of an immigrant community and of a resident population which enables the intersubjective construction of the social reality of both populations and leads them to share certain values, whether those of the resident population or of the resident and immigrant populations".

As far as the process's bidirectionality is concerned, it should be pointed out that the host community becomes the powerful group both macro- and microsocially, thereby controlling the creation and maintenance of the asymmetrical relations that arise by definition when there is a migratory movement. In this sense, regardless of the desires of the subordinate group —or, at least, over and above them-integration can only be achieved successfully if the dominant group has an open and inclusive attitude towards cultural contact and the preservation of different identities. In other words, the real prospects of integration depend on the stance of the majority group (Berry 1990, 1997; Bourhis et al. 1997; Navas Luque and Rojas Tejada 2010). Consequently, as Berry (2001, p. 619) points out, integration depends on finding a society with multicultural (or intercultural) values, free of prejudices, with low discrimination levels, positive attitudes towards cultural contact and a predisposition to identify with different groups.

Moreno Fernández (2009) has proposed a model for the study of sociolinguistic integration which treats the analysis of the linguistic dimension as a function of the process of social climbing and also in parallel to it. For Moreno Fernández, social integration is a process—and therefore dynamic —-with four phases (Figure 2). 


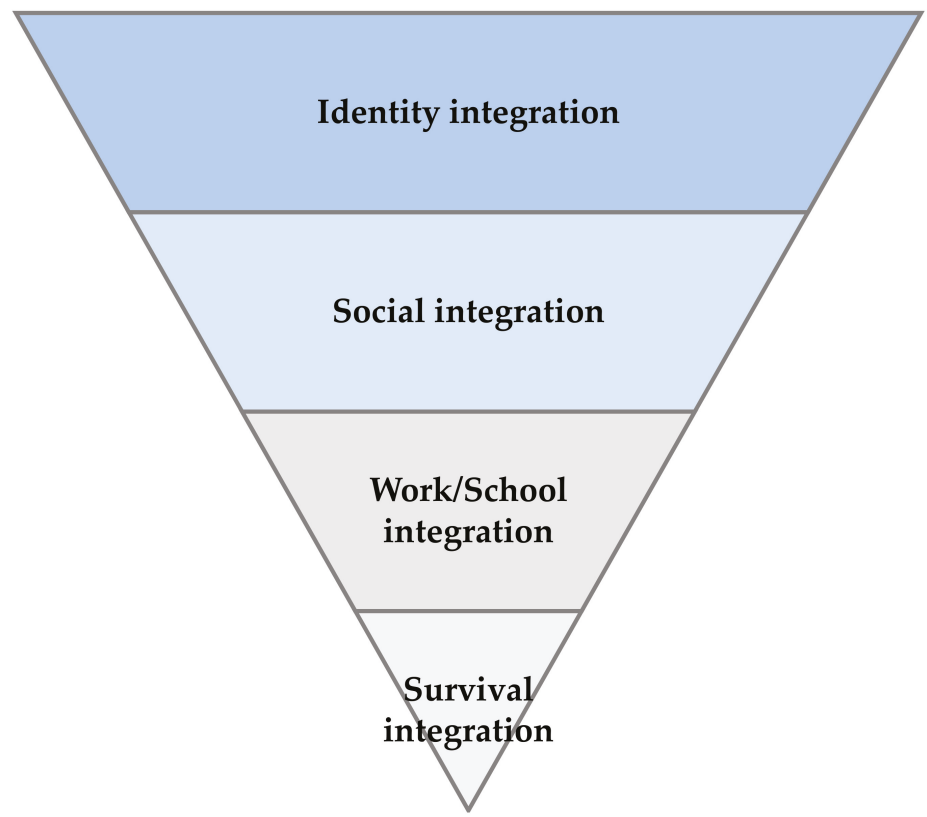

Figure 2. Integration process pyramid. Source: Moreno Fernández (2009, p. 133).

The survival and work/school phases refer to individuals' covering their basic vital needs and their employment or schooling needs, respectively. For its part, social integration entails the presence of the individual in society as such and as a member of a social group tied to his or her national, ethnic, linguistic or racial origin. In this phase, the individual is still identified as belonging to the category of "immigrant". Finally, the phase of integrated identity implies that the host society recognises the immigrant as one of them "in social, cultural and affective terms" (Moreno Fernández 2009, p. 133). This does not mean any loss of original identity, but rather that the individual can shuffle multiple identities. ${ }^{4}$ As the process advances, different phases of integration will be completed, always in tandem with changes on the linguistic plane (133 ff.). That is to say that what happens socially is reflected linguistically.

Through these different phases runs a continuum in which social contacts and, in short, interpersonal relations between immigrants and natives, are projected ever more frequently. As a result, the components of the psychosocial spheres of both groups must be incorporated into the study. In other words, the migrant's passage through the different phases entails a shift from maintaining simple relations with members of the host community to the establishment of more complex ones (Sancho Pascual 2019). Completion of the integrated identity phase carries with it the de facto disappearance of the immigrant category and, therefore, a recategorization of the community's social reality, that is, a recategorization of the groups that make up the community in terms of the feeling of belonging, on the part of the immigrants, and of the perception that the immigrants belong to other groups than that of the immigrants, on the part of the host society.

4 This way of viewing integrations agrees in part with Gugenberger's hypothesis (Gugenberger 2007, 2008). By introducing the concept of linguistic hybridity, Gugenberger revamps Berry's model to overcome the rigidity caused by its binary nature. For Gugenberger, the resolution of acculturation need not be found in any one of Berry's four strategies; instead, individuals may draw on elements with some points in common with each of the various solutions in accordance with their communicative needs. 
In short, the further the advance of integration, the greater and, in interpersonal terms, the closer the contact between different groups; and as this contact grows, the new context will acquire a negotiated re-definition in terms of shared values. On the basis of Tajfel's theory (Tajfel 1984) of social identity, and in view of the relation between language and identity (Tabouret-Keller 1997; Moreno Fernández 2006; Coupland 2007), theories of communicational accommodation and ethnolinguistic identity (Giles and Jonhson 1981; Giles et al. 1991; Viladot i Presas et al. 2007) highlight the importance of the linguistic plane in the process of group categorization, where its role is crucial as a defining attribute of group identity. Thus, we take as our hypothesis that, as the integration processes advance and intersubjective relations are established between residents and arrivals, thereby leading to social recategorization—as, then, social identities come closer to each other (group limits are diluted) - the linguistic practices of members of the group will come closer together since, if the group is redefined, its defining characteristics will be modified, its linguistic ones among them. Thus, from the point of view of sociolinguistics, the changes produced in group configurations will be reflected in the speech communities' linguistic patterns, which will be modified pari passu with the configurations.

Integration is a complex process involving various elements of different kinds. The IN.MIGRA2-CM project proposes a holistic model of sociolinguistic integration which encompasses them all (Figure 3). The sphere of the individual is affected by factors related to origin society, host society, social context and the linguistic phenomena resulting from contacts between languages or language varieties. By analysing these factors, we shall be able to see how they impact the process and, therefore, to describe how the acculturation process happens.

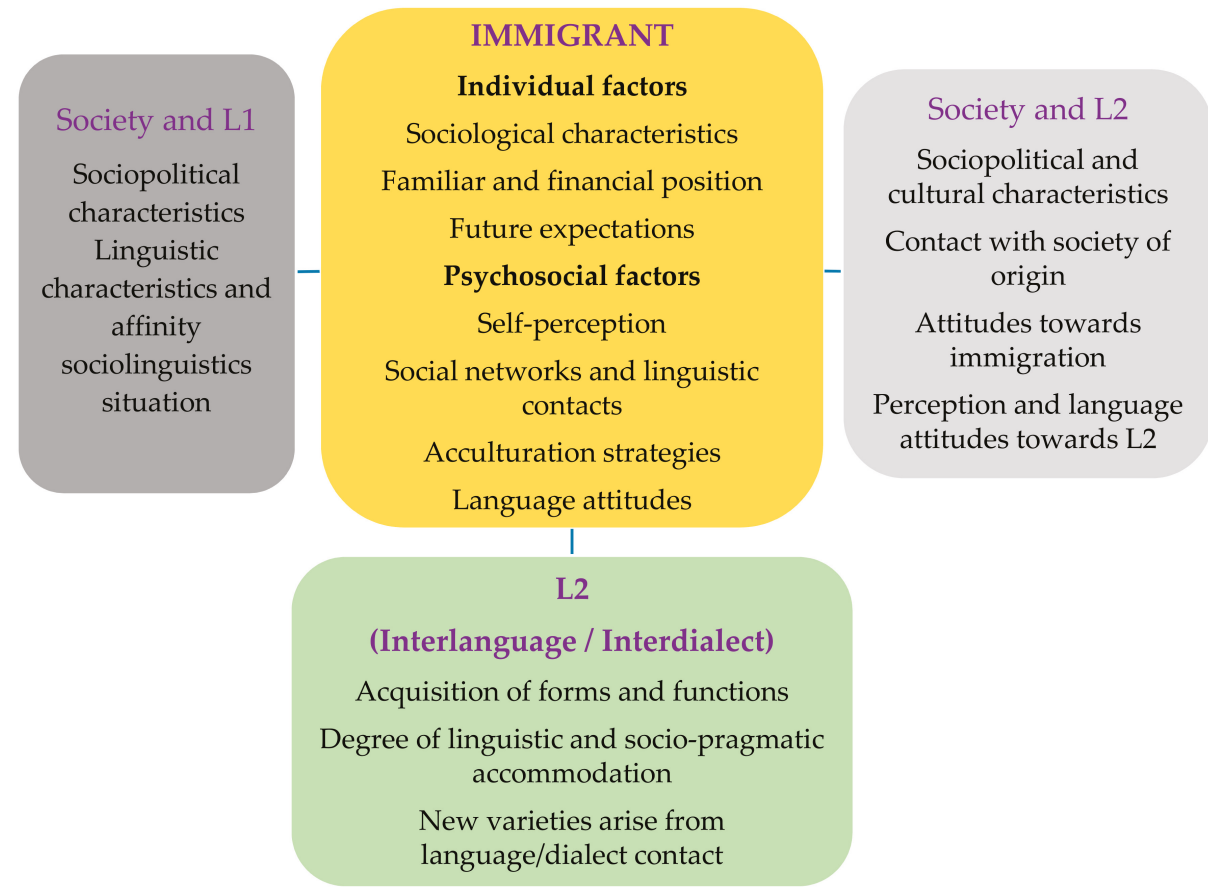

Figure 3. Holistic model of the sociolinguistic integration of immigrants. (Paredes García).

Generally speaking, we need to point out two significant biases in research conducted into integration from different academic disciplines. Firstly, studies of acculturation have mainly focused on analysing acculturation strategies (whether preferred or actually carried out), and chiefly those of the minority groups (thereby ignoring studies about the host population). Secondly, the aspects of culture 
and identity that are modified on contact have received little attention to date, particularly once again in relation to dominant groups. One outcome of that is that changes arising in the psycho-social sphere of individuals and the ensuing subjective perceptions of the process on the part of those involved in it have been pushed into the background (González-Rábago 2014, p. 204).

Thus, by working on the microsocial plane, which is where inter-group communication takes place and where, therefore, the new shared values mentioned earlier are negotiated, and by considering the linguistic dimension, we may turn our attention to two aspects: the study of the perception of individuals forming part of the host community and the study of the linguistic elements which are modified in the process of that intersubjective construction of the new shared reality. When it comes to the first of the elements, as we have pointed out, the real possibilities of the migrants will be limited by the desires, attitudes and behaviours of the host population. In this respect, in order to gain a full insight into how acculturation is taking place, it is vital to know the position of the host community and the way in which its attitudes and actions have an impact on those of the immigrant population and adjust them. As for the second aspect, the changes that take place in the cultural elements of the various groups in contact will shape a new shared reality, along with their cultural and social values. Therefore, it will be necessary to identify the linguistic changes taking place as a consequence of cultural contact and to determine the social significance that they are taking on within the community. In other words, the study of the acculturation process requires characterising, describing and interpreting the new reality constructed among the individuals that make up the community.

\section{Reflections on the Analysis of Two Factors Involved in the Process of Acculturation}

\subsection{Perspective of the Host Community}

As far as the perspective of the host community is concerned, the analysis of their attitudes and behaviour vis-à-vis the acculturation process is essential for the real prospects of the migrants depend on them, as we've just mentioned. González-Rábago (2014) indicates a paradox regarding the roles residents and arrivals assume in the process that could play a part in determining the attitudes each group develops towards it. The full weight of responsibility is shouldered by the migrants, who are regarded as the active subjects in the process, yet they do not have-or do not always have-the capacity to make decisions about what they want and how they want to achieve it. This state of affairs is complemented by the view that the residents are passive parties to the process when in fact, as we have said, it is they who may either facilitate or hamper the process since they enjoy higher status and, consequently, wield more power. This interpretation also has a bearing on the degree of awareness residents possess of the implications of acculturation.

Since the linguistic dimension advances in parallel with the social one and evolves as a function of the needs generated in it, when analysing sociolinguistic integration from the viewpoint of the host population, some correspondence is expected between social attitudes and behaviour and linguistic ones. However, the work carried out in Madrid by the team of sociolinguists from the IN.MIGRA-CM project showed, on the basis of questionnaires, how there are favourable attitudes towards social issues related to immigration and integration, but that these attitudes are not echoed in the dimensions relating to modifications in linguistic practice (Sancho Pascual 2019). Therefore, it might be expected that these favourable attitudes towards social elements were reflected in behaviour oriented towards integration and would consequently redound in progress in terms of integration. As pointed out, that would entail a recategorization of the groups and the consequent redefinition of the identity-related elements that characterize them. However, the majority of Madrilenians claim to hold the view that communicational convergence-which would imply some degree of modification to their language use-is not necessary for social integration to happen. As stated, that is what they claim, but, as I will explain shortly, we need to ascertain what they really think, how they use language, and how far that use is being modified or otherwise by cultural contact. 
At the same time, we might ask how Madrilenians understand the term "integration". According to IN.MIGRA2-CM data, the majority (76.7\% of a sample of 1534 respondents) do indeed believe that integration entails immigrants' maintaining their origin culture and adopting Spanish cultural traits (Pérez Cantador 2019). That said, the doubt remains whether Madrilenians are aware that integration also implies a degree of change to their own cultural traits and signs of identity.

Furthermore, when dealing with a such a socially sensitive subject as immigration, studies of opinion and attitudes run the risk of obtaining socially acceptable responses (Ramos de Oliveira et al. 2005). That makes it necessary to ascertain whether we are dealing with real or only apparent attitudes (Sancho Pascual 2019). In our opinion, not even the use of anonymous surveys can guarantee honest answers because even when they are sure they are not being observed, it is unlikely that individuals will admit to racist attitudes or to being less than tolerant. In this regard, we need to employ a qualitative methodology which will allow us to explore and learn more about residents' views regarding all that integration implies and how they stand in relation to it. Life-stories, in-depth interviews or discussion groups can provide information about how those involved perceive reality and the integration process.

At the same time, in questionnaires sent out by the internet, the Hispalin-UAH team has found out how, as indicated above, a majority of the people willing to participate in this declare a positive attitude towards immigration, a fact which may influence the results. In other words, people with a more positive attitude are more willing to take part in this sort of study. Thus, methodological steps should be taken with respect to this population in order to find and achieve a sample that represents all the opinions present in society.

As for the role of the linguistic dimension in acculturation processes, various studies in different contexts have shown that immigrant populations use language knowingly as a strategy of approximation and/or distancing in intergroup dynamics (Giles et al. 1977; Giles and Jonhson 1987; Sanz Huéscar 2008; Sancho Pascual 2014, 2016, for the Madrid context). Therefore, there needs to be exploration of the way the host society, for its part, modifies its own linguistic practice to set limits and differentiate between groups. In this regard, the transmission of linguistic ideologies may be used as a source of power in order to perpetuate asymmetrical relations. In this context Preston's popular language theory assumes importance (Preston 2004). This theory works from the speaker's own perception to explain how the individual categorizes both what is regarded as his/her language and what are regarded as varieties (Moreno Fernández 2012a; Caravedo 2014), and how, in the Madrid context (which Madrilenians consider to be monolingual and represent the "exemplary language" of Preston's model), this favours the transmission of linguistic ideologies (Sancho Pascual) on the basis of the "ideology of the standard language" (Milroy and Milroy 1985; Milroy 2001; Moreno Fernández 2017). In order to remain distinct from the immigrant, then, Madrilenians may be shoring up their own identity by transmitting attitudes which confer on their linguistic practice greater prestige than on that of the immigrants. Those attitudes would, in part, be composed of ideas concerning correctness, normativity or exemplarity.

Finally, as far as the host population is concerned, we need to study whether its linguistic practice is being modified in some degree as a result of the acculturation process and, if that is the case, what uses are changing and what significance they acquire via-à-vis the acculturation process. In the Madrid context, that would call, on the one hand, for the creation of corpora to complement those already available for studying speech in Madrid $^{5}$ and, on the other, as we shall see in the next section, the inclusion of perception tests.

\subsection{Analysis of the Linguistic Features Modified in the Acculturation Process}

As for the analysis of the linguistic features modified in the acculturation process, two levels of analysis are defined which need to be considered. On the one hand, the study of sociolinguistic acculturation needs to analyse the sociolinguistic corpora of the spoken language in order to characterize

5 See: http://preseea.linguas.net. 
the real speech of those involved in the process. Comparison of the speech of the different groups would enable us to observe the effect of linguistic contact in migratory contexts (accommodation, levelling out, language learning and phenomena deriving from it, transfer, etc.).

On the other hand, from a cognitivist standpoint, the subjective perception of linguistic practices by those involved would have to be tackled in order to explore the significance acquired by particular language uses in the integration process (Moreno Fernández 2012a; Caravedo 2014). If we work on the assumption that integration implies social recategorization and that, therefore, there will be modifications to the signs of identity which define social groups, we must suppose that the social indexing of linguistic uses may vary, that new signs of group identity may appear (because there will be new groups), as will, consequently, new noticeable and marked features from the social point of view.

In our first studies of the sociolinguistic integration of Madrid's immigrant population, we proposed the following model to explain the process of linguistic accommodation (Figure 4 ). ${ }^{6}$

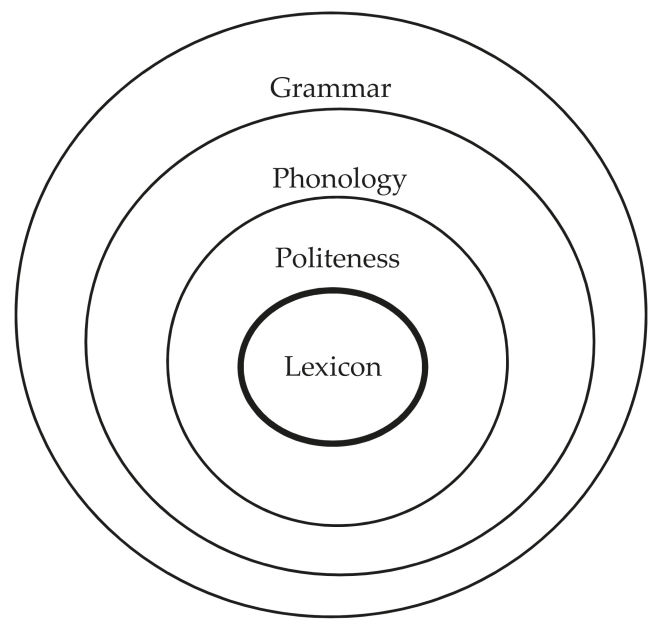

Figure 4. Process of linguistic accommodation (Sancho Pascual 2014, p. 189).

As shown in the figure, linguistic modifications commence with lexical adaptation; thereafter, for a variety of reasons, the process seems to slow down. While we believe that that is actually the case (although we need to perform more studies to confirm the model), the key issue is how the accommodation processes are interpreted. In our studies of the speech patterns of Madrid's migrant population, we have of confirmed that there are cases of divergence from and convergence with Madrilenian speech patterns (Sancho Pascual 2015; Paredes García 2017; Cestero Mancera; Olímpio de Oliveira Silva 2019). Divergence is always found at the pragmatic level and is associated with cultural

6 The proposed hypothesis is taken from the results of research carried out on the Ecuadorian community in the city of Madrid based on the discourse of the respondents from the sample used. Lexical adaptation would in the first place occur due to a question of communicative effectiveness and, generally, only in intercultural interactions, as foreseen by the communication accommodation theory (Giles et al. 1991). From there, accommodation may or may not occur, or may take place more slowly. When it comes to issues related to courtesy, the pragmatic aspects are directly related to cultural aspects and, in situations of cultural contact, their evolution is linked to the development of sociolinguistic attitudes, as Lambert, Gardner and their collaborators pointed out in their pioneering studies on attitudes in Canada (Lambert et al. 1968). As for phonetic-phonological and grammatical levels, the degree of sociolinguistic awareness will have a different impact on them. The lower level of awareness of grammatical variation will cause grammatical variables to arrive later at a level of consciousness that fosters change. However, phonetic features are important signs identified more as linguistic elements belonging to certain social groups, so their accommodation will be linked to the progress of social integration (Giles et al. 1995; Caravedo 2014). 
issues. Viewed unilaterally and ethnocentrically, cases of divergence could be interpreted as factors hindering sociolinguistic integration since they amount to movements away from host community uses. However, on the assumptions as stated above, namely that the shared system of values has to be redefined and negotiated between immigrants and residents, we cannot expect there ever to be full convergence towards the speech patterns of the host community or that the linguistic patterns of the new context can be interpreted from the static viewpoint of the host community. As we have said, the linguistic uses that emerge in the new context will have to acquire a new social value. In short, what we try to show is that it will not be enough to carry out descriptive analyses of a variationist nature, but that it will be necessary to use complementary methods that identify the social meaning of the linguistic uses of the speech communities.

In this respect, the analysis of the perception and of linguistic attitudes towards languages or varieties of Spanish in the Madrid context, or towards particular linguistic features, may yield valuable information. The value placed on the linguistic dimension on the cognitive and affective planes will provide information about the place this plane occupies in the individual's psychosocial sphere. The value placed on this dimension on the affective plane may indicate identification with the linguistic features at stake and, consequently, a feeling of belonging to the groups that manifest those uses since the groups share the system of values, beliefs and attitudes that underlies their forms of behaviour, one of which is linguistic. As far as the cognitive component is concerned, it may imply asymmetrical relations since variables like correctness or open prestige come into play. As both are elements related to status and power, the way this component's linguistic dimension is evaluated may give us information about how those involved in the process perceive this group asymmetry.

\section{By Way of Conclusion: The Researcher as Member of the Host Community}

As Caravedo (2014) has emphasised, I would not like to end without mentioning the importance of the figure of the researcher. As far as methodology is concerned, we must take stock of some of the ideas set out above. Firstly, we have to be aware that, as an individual, the researcher is one more actor in the host community, which has its system of values, beliefs, attitudes and also its own categorizations of social reality. In this regard, the researcher needs to perform a considerable exercise of estrangement if his or her own beliefs are not to affect the research at both the design and the interpretation phases. If we wish to know how the process is evolving and whether or not integration is occurring, we cannot analyse the phenomena from our own point of view, in other words, by fitting the data into a series of categories which appear to be valid but are, in fact, of our own ethnocentric and subjective fabrication. As stated, the study of sociolinguistic integration must enable us to understand what significance and what interpretation the actors in the process give to the new array of linguistic uses defining the new reality which is being built dynamically and progressively by intersubjective contact. From the very instant that we find particular respondents for our research and call them immigrants, we are transferring to them our categorization and identifying them by means of an attribute which does not define them, but which has to do with a particular circumstance of their life. At the same time, we are shoe-horning them into belonging to a particular group which need not coincide with their own perception or sense of belonging to that or to any other group.

In short, that the process is complex is obvious, so too that it has many components, among them an element of individuality which is difficult to systematize, including as it does individuals' wills and capacities to manage their own realities and their own conflicts of identity, whenever these arise as a by-product of migratory movement and cultural contact. Accordingly, there is no simple way to approach the process. Our work needs to be interdisciplinary in its combination of diverse qualitative and quantitative methods which will permit us to form an overview of the process after analysing the different variables impacting on it. It will also be necessary to introduce a cognitivist approach that trains its sights on how those involved in the process perceive it, as well as on inter-group and inter-subjective interactions. In our opinion, the first step to be taken if we wish to understand and explain the process must be that the researchers themselves take stock of this complexity so that 
they may then understand, identify and interpret the psychosocial elements that are at stake in a process of this nature. There can be no integration without a reorganization of pre-ordained social categories. There will be no reorganization until the initial ethnocentric perspectives of all involved are deconstructed. This entails a constant self-reflection and questioning of our social normality, which is acquired from the first stages of socialisation based on the development of perception as a cognitive tool of reality (Caravedo 2014). As a result, re-socialisation—within the acculturation process—is not just the responsibility of the migrant population, but also of the host population. Therefore, the researcher must assume these premises and handle them appropriately when approaching the study of sociolinguistic integration. In this respect, we are facing a social issue of enormous psychosocial sensitivity that calls for an interest and a realistic engagement on the researcher's part. In this sense, it is crucial to learn how to self-question one's own prejudices and know how to recognise and control them when dealing with the study of sociolinguistic integration. Only then will the researcher be able to comply with the principle of debt incurred (Labov 1982, p. 173) in pursuit of a fairer and more egalitarian society (Moreno Fernández 2009, p. 153).

Funding: This article was written as part of the research project La población migrante de la comunidad de Madrid: estudio multidisciplinar y herramientas para la integración sociolingüística (The migrant population of the Madrid Region: a multidisciplinary study and tools for sociolinguistic integration) (IN.MIGRA2-CM) (ref. H2015/HUM3404), funded by the Madrid Region and co-funded by the European Social Fund, and of the research project Estudio complementario de los patrones sociolingüísticos y procesos de integración sociolingüística en Madrid (Complementary study of the sociolinguistic patterns and processes of sociolinguistic integration in Madrid) (ECOPASIS_MAD) (Ref. FFI2015-68171-C5-4-P), funded by the Ministry of Economy and Competitiveness.

Conflicts of Interest: The author declares no conflict of interest.

\section{References}

Alvar, Manuel. 1982. La norma lingüística. In La Lengua Como Libertad. Edited by Manuel Alvar. Madrid: Instituto de Cooperación Iberoamericana, pp. 37-55.

Alvar, Manuel. 1986. Hombre, Etnia, Estado. Actitudes Lingüísticas en Hispanoamérica. Madrid: Gredos.

Berry, John W. 1990. Psychology of Acculturation. In Cross-Cultural Perspectives: Nebraska Symposium on Motivatio. Edited by John J. Berman. Lincoln: University of Nebraska Press, pp. 201-34.

Berry, John W. 1997. Immigration, acculturation and adaptation. Applied Psychology: An International Review 46: 5-68. [CrossRef]

Berry, John W. 2001. A psychology of immigration. Journal of Social Issues 57: 615-31. [CrossRef]

Bourhis, Richard Y., Léna Céline Moïse, Stéphane Perreault, and Sacha Senécal. 1997. Towards an Interactive Acculturation Model: A Social Psychological Approach. International Journal of Psychology 32: 369-86. [CrossRef]

Bürki, Yvette. 2019. Connecting Micro and Macro Sociolinguistic Processes through Narratives. A Glotopolitical Gaze. Special issue. Journal of Multilingual and Multicultural Development. [CrossRef]

Caravedo, Rocío. 2014. Percepción y Variación Lingüística. Enfoque Sociocognitivo. Madrid: Iberoamericana, Frankfurt: Vervuert.

Cestero, María M., and Florentino Paredes, eds. 2018. Creencias y actitudes hacia las variedades cultas del español actual: El proyecto PRECAVES XXI. Special issue. Boletín de Filología 53: 11-43. Available online: https://boletinfilologia.uchile.cl/index.php/BDF/article/view/51940 (accessed on 3 June 2019).

Cestero Mancera, Ana M. Forthcoming. Apéndices interrogativos de control de contacto en el habla de inmigrantes colombianos en madrid: Hacia la convergencia con la comunidad de acogida. Sociolinguistic Studies.

Coupland, Nikolas. 2007. Style: Language Variation and Identity. Cambridge: CUP.

Giles, Howard, and Patricia Jonhson. 1981. The role of language in ethnic commitment, and interethnic language behavior. In Intergroup Behavior. Edited by John C. Turner and Howard Giles. Oxford: Basil Blackwell, pp. 199-43.

Giles, Howard, and Patricia Jonhson. 1987. Ethnolinguistic identity theory: A social psychological approach to language maintenance. International Journal of the Sociology of Language 68: 69-99. [CrossRef] 
Giles, Howard, Richard Y. Bourhis, and Donald M. Taylor. 1977. Towards a theory of language in ethnic group relations. In Language Ehtnicity and Intergroup Relations. Edited by Howard Giles. London: Academic Press, pp. 307-48.

Giles, Howard, Justine Coupland, and Nikolas Coupland, eds. 1991. Contexts of Accommodation. Cambridge: CUP.

Giles, Howard, Angie Williams, Diane M. Mackie, and Francine Rosselli. 1995. Reactions to anglo- and hispanicamericanaccented speakers: Affect, identity, persuasion, and the English-only controversy. Language $\mathcal{E}$ Communication 15: 107-20.

González-Rábago, Yolanda. 2014. Los procesos de integración de personas inmigrantes: Límites y nuevas aportaciones para un estudio más integral. Athenea Digital 14: 195-220.

Gugenberger, Eva. 2007. Aculturación e hibricidad lingüísticas en la migración: Propuesta de un modelo teórico-analítico para la lingüística de la migración. Revista Internacional de Lingüística Iberoamericana 5: 21-45.

Gugenberger, Eva. 2008. El castellano y las lenguas regionales en España: Bilingüismo e hibridación. In La España Multilingüe. Lenguas y Políticas Lingüísticas de España. Edited by Max Doppelbauer and Peter Cichon. Viena: Praesens Verlang, pp. 31-52.

Labov, William. 1982. Objectivity and commitment in linguistic science. Language in Society 11: 165-201. [CrossRef]

Lambert, Wallace E., Robert C. Gardner, R. Olton, and K. Tunstall. 1968. A Study of the roles of attitudes and motivation in second-language learning. In Readings in the Sociology of Language. Edited by Joshua A. Fishman. The Hague: Mouton, pp. 473-91.

Milroy, James. 2001. Language ideologies and the consequences of standardization. Journal of Sociolinguistics 5: 530-55. [CrossRef]

Milroy, James, and Lesley Milroy. 1985. Authority in Language. Investigating Language Prescription and Standardization. London: Routledge.

Moreno Fernández, Francisco. 2006. Medias Lenguas e Identidad. Paper presented at the III Congreso Internacional de la Lengua Española, Rosario, NM, 17 November 2004; Available online: http://cvc.cervantes.es/obref/ congresos/rosario/ponencias/aspectos/moreno_f.htm (accessed on 28 October 2018).

Moreno Fernández, Francisco. 2009. Integración sociolingüística en contextos de inmigración: Marco epistemológico para su estudio en España. Lengua y Migración/Language and Migration 1: 121-56.

Moreno Fernández, Francisco. 2012a. Sociolingüística Cognitiva. Principios, Escolios y Debates. Madrid: Iberoamericana, Frankfurt: Vervuert.

Moreno Fernández, Francisco. 2012b. Percepciones de la lengua Española. Boletín de la Academia Cubana de la Lengua 17: 5-20.

Moreno Fernández, Francisco. 2012c. La percepción global de la similitud. In Les Variations Diasystématiques et Leurs Interdépendances dans les Langues Romanes. Edited by Kirsten Jeppesen Kragh and Jan Lindschouw. Special issue. Éditions de linguistique et de Philologie. pp. 217-37.

Moreno Fernández, Francisco. 2017. Variedades de español y evaluación. Opiniones lingüísticas de los anglohablantes. Informes del Observatorio/Observatorio Reports. [CrossRef]

Navas Luque, Marisol, Pablo Pumares Fernández, Juan Sánchez Miranda, M. Carmen García Fernández, Antonio J. Rojas Tejada, Isabel Cuadrado Guirado, Matilde Asensio García, and Juan Sebastián Fernández Prados. 2004. Estrategias y Actitudes de Aculturación: La Perspectiva de Los Inmigrantes y de Los Autóctonos en Almería. Sevilla: Dirección General de Coordinación de Políticas Migratorias. Consejería de Gobernación. Junta de Andalucía.

Navas Luque, Marisol, and Antonio J. Rojas Tejada, eds. 2010. Aplicación del Modelo Ampliado de Aculuración Relativa (MAAR) a Nuevos Colectivos de Inmigrantes en Andalucía: Rumanos y Ecuatorianos. Sevilla: Junta de Andalucía.

Olímpio de Oliveira Silva, M. Eugênia. 2019. The Phraseology of Immigrants: A Descriptive Study. , . Microsoft Word file. Unpublished manuscript, last modified April 4. Microsoft Word file.

Paredes García, Florentino. 2017. Uso y adquisición de recursos elativos como indicadores de integración sociolingüística en Madrid. In La Adquisición de la Lengua Española: Aprendizaje, Enseñanza, Evaluación. Estudios en Homenaje a Marta Baralo Ottonello. Edited by Claudia Esther Fernández and María Cecilia Ainciburu. Buenos Aires: Autores de Argentina, pp. 57-71.

Paredes García, Florentino. Forhcoming. Un modelo dinámico de análisis de la integración sociolingüística de la programación inmigrante. In Teorías y Métodos en la Sociolingüística de la Migración. Edited by Florentino Paredes García and María Sancho Pascual. Special issue. Lengua y migración/Language and Migration. 
Pérez Cantador, Yara. 2019. An Approach to Studying the Sociolinguistic Integration of Romanian Immigrants Residing in the Community of Madrid. Unpublished manuscript, last modified April 16. Microsoft Word file.

Preston, Dennis. 2004. Language with an Attitude. In The Handbook of Language Variation and Change. Edited by Jack Chambers, Peter Trudgill and Natalie Schilling-Estes. Oxford: Blackwell, pp. 40-66.

Ramos de Oliveira, Diana, Elza-M. Techio, Dario Páez, and Karmele Hernanz. 2005. Factores predictores de las actitudes ante la inmigración. Revista de Psicología Social 20: 19-32. [CrossRef]

Sáez Rivera, Daniel M. 2014. El Madrid plurilingüe y pluridialectal: Nueva realidad, nuevos enfoques. In Prácticas y Políticas Lingüísticas. Nuevas Variedades, Normal, Actitudes y Perspectivas. Edited by Klaus Zimmerman. Madrid: Iberoamericana, Frankfurt am Main: Vervuert, pp. 403-40.

Sancho Pascual, María. 2014. Integración sociolingüística de los inmigrantes ecuatorianos en Madrid. Alcalá de Henares: Servicio de Publicaciones de la Universidad de Alcalá.

Sancho Pascual, María. 2015. Integración sociolingüística de los inmigrantes ecuatorianos en Madrid: datos sobre el diminutivo según los corpus ISPIE-Madrid y PRESEEA-Madrid. In Patrones sociolingüísticos de Madrid. Edited by Ana M. Cestero Mancera, Isabel Molina Martos and Florentino Paredes García. Bern: Peter Lang, pp. 155-76.

Sancho Pascual, María. 2016. Ecuatorianos de segunda generación en Madrid: percepción y actitudes lingüísticas en su proceso de integración. In Migraciones hispánicas: discurso, sociedad y cognición. Edited by Rocío Caravedo and Francisco Moreno Fernández. Special issue. Cuadernos AISPI. vol. 8, pp. 119-44. [CrossRef]

Sancho Pascual, María. 2019. Integrating the immigrant population into the city of Madrid (Spain): preliminary data about the sociolinguistic attitudes of the host community. Special issue. Journal of Multilingual and Multicultural Development. [CrossRef]

Sancho Pascual, María. Forthcoming. Conflicto y acomodación intergrupal entre ecuatorianos y madrileños en la ciudad de Madrid: efectos glotopolíticos. Anuario de Glotopolítica.

Sanz Huéscar, Gema. 2008. Actitudes Lingüísticas de los Inmigrantes Rumanos en Alcalá de Henares. Alcalá de Henares: Universidad de Alcalá, Unpublished supervised research work.

Tabouret-Keller, Andrée. 1997. Language and identity. In The Handbook of Sociolinguistics. Edited by Florian Coulmas. Oxford: Blackwell, pp. 315-26.

Tajfel, Henri. 1984. Grupos Humanos y Categorías Sociales. Barcelona: Editorial Herder.

Viladot i Presas, Ma Àngels, M. Esteban, José Nadal García, and Howard Giles Howard. 2007. Identidad, percepción de vitalidad etnolingüística y comunicación intergrupal en Cataluña. Revista de Psicología Social Aplicada 17: 223-47.

(C) 2019 by the author. Licensee MDPI, Basel, Switzerland. This article is an open access article distributed under the terms and conditions of the Creative Commons Attribution (CC BY) license (http://creativecommons.org/licenses/by/4.0/). 
Article

\title{
An Approach to Studying the Sociolinguistic Integration of Romanian Immigrants Residing in the Community of Madrid
}

\author{
Yara Pérez Cantador \\ Department of Philology, Communication and Documentation, University of Alcalá, \\ 28054 Alcalá de Henares (Madrid), Spain; yara.perez@edu.uah.es
}

Received: 9 October 2019; Accepted: 19 December 2019; Published: 2 January 2020

\begin{abstract}
Grounded in different theoretical approaches of sociolinguistics, this study aims to examine the sociolinguistic integration process of the Romanian immigrant population that resides in Madrid. Semi-guided interviews are carried out with Romanian immigrants in order to obtain qualitative information regarding different aspects of the sociolinguistic integration of the immigrant population; additionally, questionnaires are administered to the same informants, with the objective of obtaining quantitative information on attitudes. Furthermore, questionnaires on attitudes were administered to 1534 informants of Spanish origin who reside in Madrid to analyze their attitudes with regard to the Romanian immigrant population living in Madrid. The analysis performed thus far indicates that the Romanian informants seem to have a good attitude toward the speech of Madrid and, in general, seem highly predisposed to integrating into their host community. The most significant conclusions drawn from the preliminary phase of analysis presented here are that although the Romanian informants perceive their integration positively, the host community does not perceive it in the same way.
\end{abstract}

Keywords: sociolinguistics; sociolinguistic integration; Romanian immigration; Community of Madrid

\section{Introduction ${ }^{1}$}

\subsection{Why Study the Romanian Community?}

According to data from the Immigration Observatory of the Community of Madrid (2018), the Romanian community is the largest migrant group in the Community of Madrid, as can be seen in Figure 1. Specifically, $21.67 \%$ of the foreign population residing in the Community of Madrid is of Romanian origin. These data demonstrate the importance of studying this migrant community, as it can be assumed that there will be greater contact between the host community ${ }^{2}$ and this population than other nationalities and also because this group will have a strong presence in different spheres of Madrid society.

1 This paper is part of the research project's activities "A complementary study of the sociolinguistic patterns and the processes of sociolinguistic integration in the Spanish of Madrid" (ref. FFI2015-68171-C5-4-P), financed by the Ministry of Economy and Competitiveness of Spain, and "The migrant population in the Autonomous Community of Madrid: interdisciplinary study and tools for sociolinguistic integration" (ref. IN.MIGRA2-CM), cofinanced by the Autonomous Community of Madrid (Spain) and the European Social Fund.

2 In this case with the madrileños. Madrileño is the demonym for Madrid natives. 


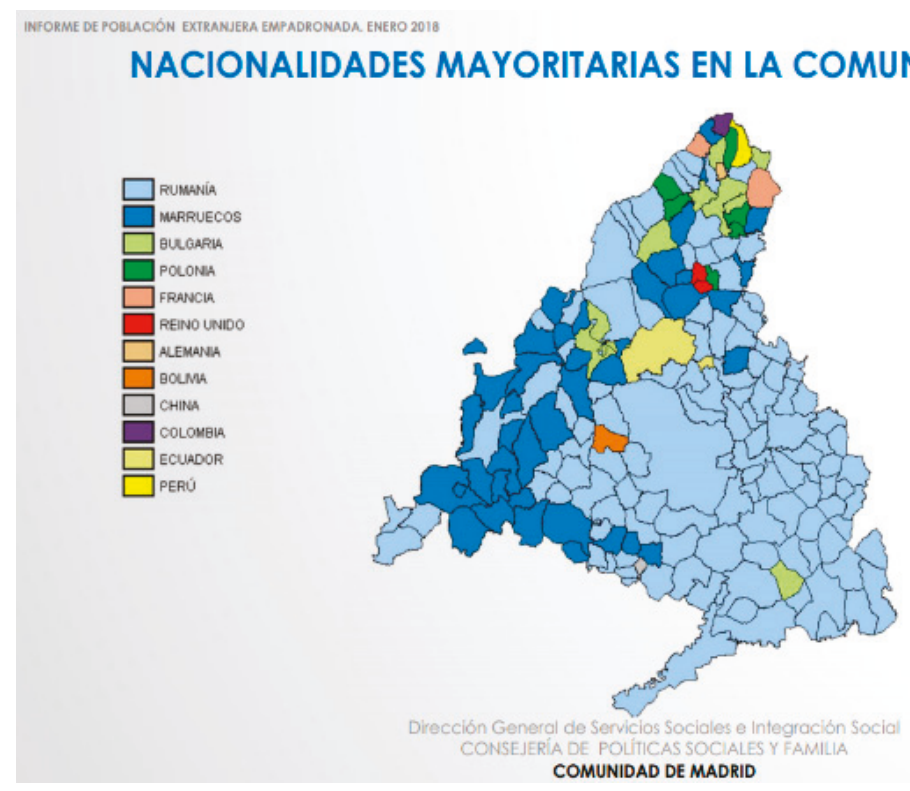

Figure 1. Map of the majority nationalities of the foreign population in the Community of Madrid, by town (Immigration Observatory-Research and Data Centre 2018).

\subsection{Context of the Research}

This study is part of the research project The Migrant Population of the Community of Madrid: Multidisciplinary Study and Tools for Sociolinguistic Integration (IN.MIGRA2-CM) and, more specifically, its subgroup UAH-HISPALIN at the University of Alcalá. This study will examine the sociolinguistic integration process of the Romanian immigrant population living in Madrid, on the basis of different theoretical approaches from sociolinguistics, such as cognitive sociolinguistics, variationist linguistics, different theories regarding language attitudes, and so forth. In this sense, it is necessary to emphasize that, in spite of the fact that all the aforementioned theoretical approaches will be used for the realization of this study, for the moment, studies on linguistic contact have been used especially.

It is expected that the results of the project will significantly enrich research into the sociocultural characteristics of the migrant population living in the Community of Madrid and, therefore, may be of great use in studying phenomena of language contact.

The general objective of this study is to understand and analyze the sociolinguistic integration process of the Romanian immigrant population living in the Community of Madrid, both from the immigrants' perspective (Romanians) and from the perspective of the host community (madrileños).

Additionally, several specific objectives are established under this general objective, such as: contribute to the IN.MIGRA2-CM project by adding a series of semi-guided interviews and questionnaires on language attitudes to the speech corpus; create an independent speech corpus composed of semi-guided interviews with Romanian immigrants living in different areas of the Community of Madrid, including the transcription and coding of the data obtained, as well as organizing the results. Other objectives include: qualitatively analyze different aspects of the sociolinguistic integration (language attitudes, perception, opinion of the language as it relates to the general integration process, communication accommodation) of the Romanian population living in Madrid; quantitatively analyze certain dependent variables that are important to the study; and determine the attitudes of informants from the host community. 


\subsection{Theoretical Framework}

One can speak of sociolinguistic integration when language is seen as a factor determining integration or rejection (Moreno Fernández 2013). Similarly, it should be remembered that sociolinguistic integration "is social and involves a process of adaptation that is influenced by several factors" (Moreno Fernández 2013, p. 73), such as the linguistic repertoire of migrants and host communities, the social and linguistic consequences of language contact, and the way social coexistence is organized in accordance with the use of languages.

Integration is a social issue; however, it unfolds at an individual level and therefore the individuals become the bearers of the conflicts inherent to migration, such as issues of identity, learning, accommodation, or social relations (Moreno Fernández 2013). Thus, the best approach for this research was determined to be one with an interdisciplinary perspective, considering different theories from sociolinguistics, linguistics, psychology, and sociology, so as to provide a framework capable of analyzing the different aspects involved in the integration process.

Social integration is a complex, dynamic process carried out by individuals or societies "through which different groups come to share certain values and establish interdependent socioeconomic relationships" (Paredes García and Pascual 2018, p. 42).

According to the perspective of the sociology of migration, the linguistic dimension is a key variable of the many that are involved in the migrant population's adaptation process (Moreno Fernández 2009). Social integration must be approached by taking into account different aspects related to the coexistence of languages in the host community and the integration process must be explained in relation to language use (Moreno Fernández 2013). However, social integration-and, consequently, sociolinguistics—is a bidirectional process that affects both the migrant population and the host community (Berry 2001; Moreno Fernández 2009). Thus, the immigrant group's real possibilities of integration are going to be directly conditioned by the attitudes and behaviors of the receiving community (Berry 2001). Likewise, the hypothesis is that integration will be less difficult the closer the languages in contact and the less complex the host community (Moreno Fernández 2009). In the specific case that this research occupies, and following the idea of the aforementioned author, Romanians should find fewer difficulties in environmental learning of Spanish, since the linguistic distance between the languages is not very large (their L1 is a Romance language, the same as for Spanish).

Berry (2001) proposes an acculturation model (see Miras Páez and Sancho Pascual 2017) for more on the concept of acculturation) based on the fact that integration is a mutual process that affects two groups, and therefore the cultural changes that occur in one group will have an impact on both. As explained by Miras Páez and Sancho Pascual (2017), Berry's model is based on two independent attitudinal dimensions of acculturation; one refers to the degree to which the groups value and wish to maintain their cultural identity, and the other refers to the degree to which they value and seek relationships with other group(s). These dimensions are found in both the dominant and subordinate group, and their combination gives rise to different attitudinal and/or behavioral spaces in which the groups can move. Continuing with Berry's model (2001), the author argues that, from the point of view of the immigrant groups, integration will occur when there is a desire to relate with the other group and, at the same time, an intention to maintain one's own cultural identity. Assimilation will occur when the individual or group seeks contact with the other groups and does not wish to maintain the cultural values of the in-group. Separation will occur if the immigrants value their own culture but do not intend to interact with others. Finally, marginalization will occur if the attitudes or behavior in terms of both dimensions are negative. As can be imagined, the most tolerant and enriching option is integration; however, as Berry (2001) indicates, even if the subordinate group has a great desire to integrate, this will only be possible if the dominant group has an integrating attitude.

Thus, language attitudes are one of the most important aspects of this study, given that, as asserted by García Marcos (2015), speakers and social groups judge languages and varieties that share the same social space. Furthermore, said judgments are shown not only through positive or negative opinions, but can also be inferred through actions and behaviors. In this sense, another hypothesis that is part of 
the study is that if the immigrant has a favorable attitude toward the language and the dialectal variety of the receiving society, the process is facilitated (Moreno Fernández 2009).

Additionally, the importance of the concept of identity will be considered. Languages not only convey purely linguistic meanings (Moreno Fernández 1998); rather, the language spoken by an individual is part of their identity as a subject and as a member of a social group (Sancho Pascual 2013a). This fact reinforces the importance of studying identity in the linguistics of migration, as identity will, to a greater or lesser extent, have an impact on immigrants' integration process.

\subsection{Previous Studies}

Now, to focus on the subject of the study and to offer a brief summary regarding research on linguistic issues related to Romanian immigrants, the work by Sanz Huéscar (2008), Roesler (2011), Muñoz Carrobles (2013), and Buzilă (2016) is of particular interest.

Sanz Huéscar (2008) studied the influence of different extralinguistic elements of a social nature on the configuration and adoption of language attitudes. Thus, this research-which was based on the study of the Romanian immigrant population living in Alcalá de Henares-focused on contributing knowledge that would help understand the social integration process of immigrants in host communities from a sociolinguistic perspective and, more specifically, understand the language attitudes adopted by Romanian immigrants living in the city of Alcalá, as a determining element of this group's integration into the host community. Of particular note in the findings of this research is the idea "that the language attitudes adopted by Romanian immigrants reveal the complex interrelation between the competence, value and instrumental dimensions of language attitudes and the person's other social and psychosocial systems" (Sanz Huéscar 2008, p. 354). The author argues that as a result of this interrelation, Romanian immigrants living in Alcalá have adopted positive language attitudes and that these positive attitudes are due mainly to the value dimension.

The study carried out by Roesler (2011) aimed to research the Spanish spoken by Romanian immigrants in Castellón de la Plana. To analyze the immigrants' Spanish competency, the author carried out 30 interviews in 2008 with informants who had immigrated to Spain between 1995 and 2007. This research was focused on studying the influence of the immigrants' native language on Spanish, as well as the influence of the intensity of contact with Spanish speakers and the geographic variety of Spanish they first entered into contact with. According to Roesler (2011), these seem to be important factors that affect the specific characteristics of the Spanish spoken by Romanians.

Another study of note was carried out by Muñoz Carrobles (2013), who undertook to analyze the synchronous situation of language contact between Romanian and Spanish within the Romanian community established in Madrid. Some of the conclusions more emphasized by this author in his study are that, on the one hand, the economic factor is a heavy reason for the Romanians to stabilize in Madrid. On the other hand, this author points out that, of the four strategies framed within Berry's model (2001), in the Romanian community of Madrid, mainly assimilation and integration take place. Muñoz Carrobles (2013, p. 384) reports that "the Romanian community of Madrid tries to make an effort to adapt to the culture of the host society". Now, on the linguistic level, this author points out that the use of the Romanian language due to the loss of areas of communication could be the starting point of a future process of linguistic substitution. Muñoz Carrobles (2013) details that a diglossic scenario is taking place in Madrid, which could negatively affect the language with a lower status (the Romanian language).

Another contribution to the topic of this study was the work done by Buzilă (2016), who performed a sociolinguistic analysis of how Romanian immigrants living in Spain speak. This author argues that, at least from a quantitative perspective, there is not a new linguistic code spoken by this migrant group, which some authors have coined rumañol. This author explains in his study that the variables such as sex, training level, and residence time in Spain do not influence the amount of interference of the Romanian language in the Spanish language. However, they do seem to influence in some way the place of origin of the Romanians and the place of residence. In addition, the author states that 
the two factors that most influence the interference of the Romanian language into Spanish are age and bilingualism.

\section{Methods}

This section provides a brief explanation of the methodology followed in this study. It should also be noted that the results presented below in this article are in a first phase of analysis and therefore are not conclusive.

It should be underlined that the selection of the sample, data collection, and the organization of interviews and questionnaires were based on the precepts established by the IN.MIGRA2-CM project; thus, the same interview and questionnaire structure used in said project were applied here. This is because it was considered necessary to employ a single data collection method so as to be able to compare the results of this study to others carried out in parallel by the different members of the IN.MIGRA2-CM project; in this manner, it will be possible to carry out a comprehensive study on the sociolinguistic integration of different migrant groups living in the Community of Madrid in the future.

\subsection{Data Collection}

In this study, data were always collected from the Romanian informants directly and in person (i.e., the researcher was responsible for recording the interviews and administering the questionnaires). Semi-guided interviews were carried out with Romanian immigrants in order to obtain qualitative information regarding different aspects involved in the sociolinguistic integration of the immigrant population, as well as to extract the necessary data to compare them with the information obtained from the qualitative analysis of language attitudes. Additionally, linguistic information can be extracted from these interviews, which could be used to analyze errors in different linguistic aspects that are important to consider when determining the level of integration of the Romanian immigrants living in Madrid. Moreover, using the interviews, it will be determined whether the attitudes the informants project correspond to their linguistic usage (this objective cannot be carried out until all the interviews are carried out). To that end, questionnaires will be administered to the same informants with the objective of obtaining quantitative information on attitudes.

The questionnaire administered to the Romanian population, as mentioned above, was the same used in the IN.MIGRA2-CM project (Paredes García and Pascual 2018). It consists of different issues related to attitudes and is divided into three parts: (1) a section that provides information on the informant's contact with both the host community as well as their compatriots (whether in Madrid or their countries of origin) and immigrants of other nationalities; (2) an attitude questionnaire comprising 32 statements for which the respondent must indicate to what extent they agree or disagree on a four-point Likert scale that ranges from "Strongly disagree" to "Strongly agree". These items are organized into eight topical blocks that allow for an understanding of the different components of attitude (cognitive, affective, and conative) and the possible factors behind said attitudes; and (3) the questionnaire ends with a question that seeks the respondent's opinion of the speech of Madrid as compared to their own through a six-point semantic differential scale.

The questionnaire administered to the host community also consists of three different parts: (1) questions related to their contact with the Romanian population; (2) an attitude questionnaire comprising 29 statements, following the same structure as the questionnaire applied to the Romanian immigrants; and (3) a final question on what madrileños understand by integration.

Thus far, of the 72 informants planned for the study, a total of 48 Romanian informants were interviewed already (the sample will be described in further detail below) between October 2016 and November 2018 through various methods of contact (the researcher visited different associations, Orthodox churches, closed social networks where Romanians living in Madrid come together, local stores with Romanian products, etc.).

The questionnaire on the attitudes of informants of Spanish origin who reside in Madrid was administered in order to analyze their attitudes with regard to the Romanian immigrant population 
living in Madrid. In this case, the questionnaires were administered online by disseminating them through social networks. Responses that did not meet the previously established requirements were eliminated; these requirements were that respondents must be older than 18, be of Spanish origin, and reside in any town in the Community of Madrid. A total of 1534 questionnaires were collected from madrileño informants.

Data collection for the complete sample of informants will be carried out in three ways:

- 72 semi-structured interviews with Romanian immigrants living in different areas of Madrid (center, northwest, south, and east). The northern and western areas of Madrid had to be combined into a single area, the northwest, due to the low percentage of Romanian immigrant population living in this part of the Community of Madrid.

- 72 questionnaires on language attitudes administered to the same informants.

- Questionnaires on attitudes administered to madrileños living in Madrid.

Additionally, a prestratified sample was selected based on sex (variable divided into two groups: "men" and "women") and on the informants' length of residence in Spain (also divided into two groups: "more than four years residing in Spain" and "less than four years residing in Spain"), as these were considered to be determining factors.

Moreover, other poststratified variables were taken into account, such as the area of residence, social network, and whether or not the informant planned to stay in Spain, as these are possible factors that may influence the sociolinguistic integration process.

It is important to note that the link between madrileños and Romanians is only that of the place they share; there are no interpersonal relationships between the interviewees, at least not that they have been specifically sought. But for that reason, it is important to detect the attitudes of these two groups (i.e., whether the interviewees or respondents knew each other, which would surely influence the results).

\subsection{Coding and Data Extraction}

In order to reflect all of the results extracted from the data, a coded figure has been created that includes the informants' profile, as well as all of the coded answers from the questionnaires administered. Subsequently, the statistics computer program SPSS was used to perform a quantitative analysis of the data and thus favor the means to perform a descriptive statistical analysis.

For the next phase of analysis, the qualitative phase, all of the interviews will be transcribed into the corpus, following the conventions of the TEI (Text Encoding Initiative), which are also the criteria followed by the PRESEEA project (Cestero et al. 2003). The transcription will be performed manually with the assistance of different computer programs, such as Transcriber. At the moment, there are a total of four transcribed interviews, so it is still too early to make an analysis in this regard.

\subsection{Description of the Sample}

Below are the data regarding the sample collected thus far, as can be seen in Figures 2-5. In them, the following coding appears: $\operatorname{sex}(\mathrm{H}=$ men, $\mathrm{M}=$ women $)$; residence time in Spain $(+4=$ more than 4 years, $-4=$ less than 4 years). The $\mathrm{X}$ represents the informants interviewed in each box.

Given these data, it can be seen that the established number of Romanian informants who have been living in Spain for more than four years has been interviewed in all areas. However, the established sample of informants who have lived in Spain for less than four years has not been completed yet. Specifically, 48 of the expected 72 interviews have been carried out in total; 36 of these correspond to informants who have been living in Spain for over four years and 12 to those who have lived in Spain for less than four years. Thus, 24 interviews must still be conducted to complete the sample.

The sample has not been completed because of the great difficulty in finding Romanian informants who have been in the country for a short period of time. This difficulty is due, in large part, to the economic downturn Spain has experienced in recent years, which has caused a large number of 
Romanians to return to their country of origin and has also translated to a lower number of arrivals (Buzilă 2016).

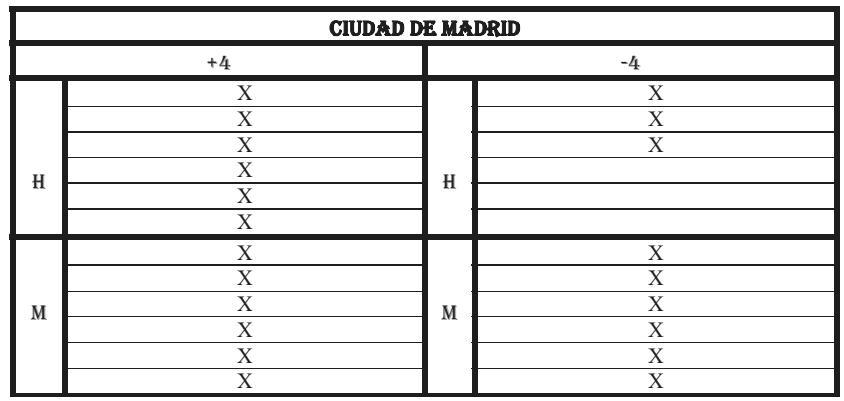

Figure 2. Data on the informants surveyed in the city of Madrid.

\begin{tabular}{|c|c|c|c|}
\hline \multicolumn{4}{|c|}{ ESTE DE MADRID } \\
\hline & +4 & & -4 \\
\hline \multirow{4}{*}{$\mathrm{H}$} & $\mathrm{X}$ & \multirow{4}{*}{$\mathrm{H}$} & $\mathrm{X}$ \\
\hline & $X$ & & \\
\hline & $\mathrm{X}$ & & \\
\hline & $\mathrm{X}$ & & \\
\hline \multirow{4}{*}{ M } & $\mathrm{X}$ & \multirow{4}{*}{ M } & $\mathrm{X}$ \\
\hline & $\mathrm{X}$ & & \\
\hline & $\mathrm{X}$ & & \\
\hline & $\mathrm{X}$ & & \\
\hline
\end{tabular}

Figure 3. Data on the informants surveyed in the eastern area of Madrid.

\begin{tabular}{|c|c|c|c|}
\hline \multicolumn{3}{|c|}{ SUR DE MADRID } \\
\hline & +4 & & \\
\hline & $\mathrm{X}$ & & -4 \\
\hline & $\mathrm{X}$ & \multirow{3}{*}{$\mathrm{H}$} & $\mathrm{X}$ \\
\hline & $\mathrm{X}$ & & \\
\hline & $\mathrm{X}$ & & \\
\hline & $\mathrm{X}$ & & \\
\hline & $\mathrm{X}$ & \multirow{2}{*}{$\mathrm{M}$} & \\
\hline & $\mathrm{X}$ & & \\
\hline & $\mathrm{X}$ & & \\
\hline
\end{tabular}

Figure 4. Data on the informants surveyed in the southern area of Madrid.

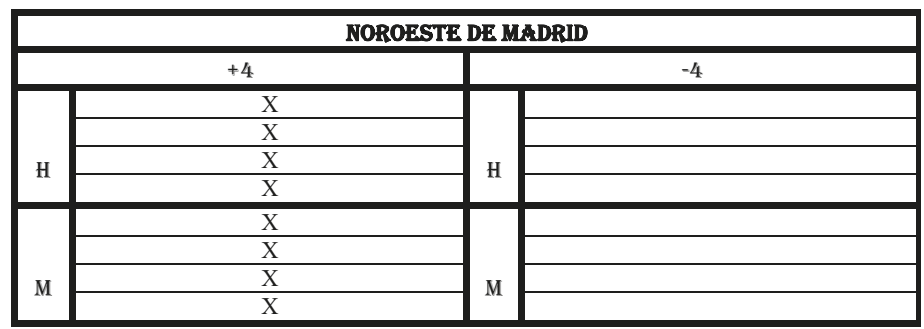

Figure 5. Data on the informants surveyed in the northwest area of Madrid.

Closely examining the above figures, it can be seen that the areas with the lowest number of -4 informants are the south and northwest of the Community of Madrid. This is related to the lower number of Romanian immigrants living in these areas. 


\section{Results}

This section will present some of the most representative results from the analysis that has been carried out in the study's first phase. It should be clarified that the results presented below have been extracted from an analysis of the SPSS statistical software, as stated above. According to the results of this program, only significant values have been selected.

\subsection{Characteristics of the Sample: Reasons for Coming to Spain and Future Expectations}

The data provided below come from the questionnaires applied to the informants. Specifically, they were in a multiple-choice question format where the informants had to choose the answer closest to their reality.

Figure 6 presents the results related to Romanian immigrants' reasons for coming to Spain. As can be seen, the main reason Romanian immigrants come to Spain is to improve their economic prospects. This may be related to the socioeconomic circumstances experienced in Romania in the 1990s, when the transition to capitalism took place, triggering a series of important changes in society (Buzilă 2016). According to the author quoted, the country's economic situation worsened considerably as the privatization process began, resulting in many lost jobs, leading to a rise of Romanian emigration to Western Europe. Consequently, salaries in Romania dropped sharply and unemployment increased; immigration was the only way out of this difficult situation for many Romanians (Buzilă 2016). Additionally, Spain's economic situation drew many Romanian immigrants to the country, given that beginning in 2000, the country's economic development created a large number of jobs. Moreover, a decisive factor for Romanians choosing Spain as their preferred country of immigration is the language (Buzilă 2016). This can be related to what has already been explained above about the linguistic distance between Romanian and Spanish (Moreno Fernández 2009). So, since the Romanian and Spanish languages are two nearby languages because they belong to the same linguistic family, this can be seen by migrants as a great advantage when choosing the destination country.

REASONS FOR COMING TO

SPAIN

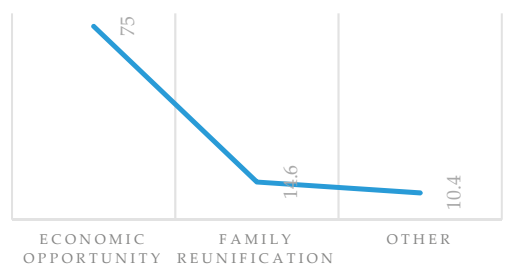

Figure 6. Results for "reasons for coming to Spain".

Figure 7 shows that the majority of Romanian informants expressed their wish to remain in Spain definitively. This result coincides with Buzilă's findings (2016); in his study, he argues that there is a certain degree of interest in returning to Romania, but few people actually do so, and the majority return to Spain because they find it difficult to reintegrate into the Romanian job market or because they are unable to readapt to Romanian society. This author presents several reasons why the majority of Romanian immigrants decide to stay in Spain (e.g., they purchase a home in Spain, the Romanian economy is not good enough, or the Spanish economy, in spite of the recession, is better than the Romanian economy). 


\section{FUTURE EXPECTATIONS}

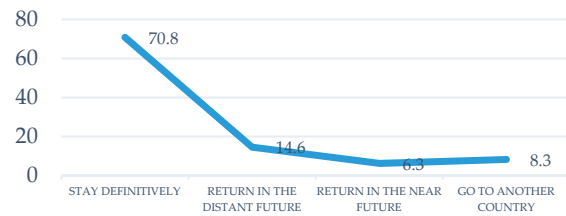

Figure 7. Results for "future expectations".

\subsection{Attitudes of Romanian Informants toward the Speech of Madrid}

As can be observed in Figure 8, the Romanian informants present fairly positive attitudes toward the variety of Spanish spoken in Madrid. This is important, as it can be assumed that this will largely favor their sociolinguistic integration process. Furthermore, it may reflect a strong desire to integrate into the host community.
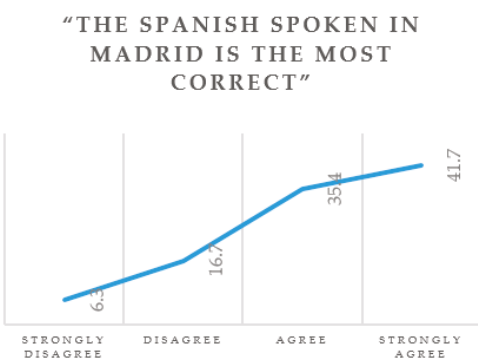

(a)
"I LIKE THE SPANISH SPOKEN IN MADRID"

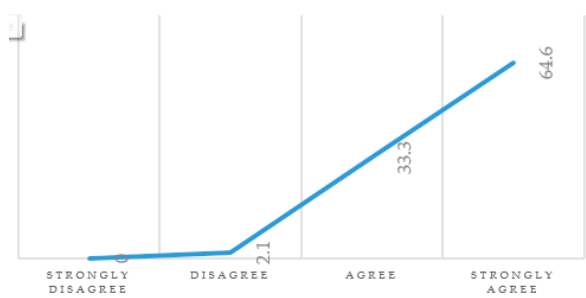

(b)

Figure 8. Results from Romanian informants on their attitudes toward the speech of Madrid. (a) Results of the item "The Spanish spoken in Madrid is the most correct". (b) Results of the item "I like the Spanish spoken in Madrid".

\subsection{The Identity Issue}

As can be seen in Figure 9, a little over half of the Romanian informants surveyed stated that they would not like to maintain their way of speaking as an identifying trait. The identity issue should be taken into consideration; as Sancho Pascual (2013b) indicates, language is an important element of the identity of individuals and social groups, and therefore it can become both an element of inclusion and exclusion with regard to the host society (Sorolla Fernández, 2011, quoted in Sancho Pascual 2013b). Given these results, special emphasis should be put on a subsequent analysis of whether it is possible that there is a type of linguistic disloyalty that would favor linguistic convergence with the host community. If so, this would have a direct impact on the sociolinguistic integration of Romanian immigrants; however, it is too soon to assert this fact. 

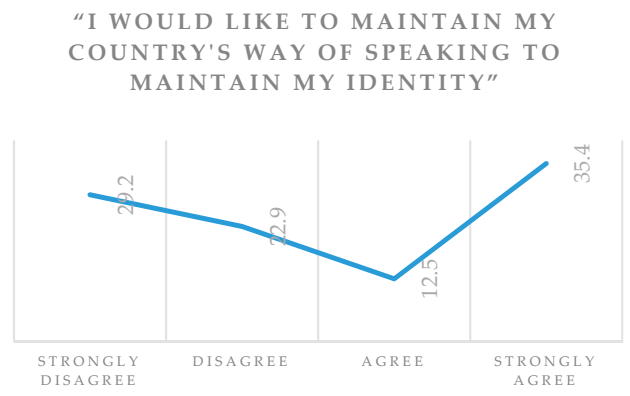

Figure 9. Results of the item "I would like to maintain my country's way of speaking to maintain my identity".

\subsection{Madrileños' View on Integration}

In the question on the questionnaire asking about integration, four possible responses are provided: (1) To me, integration means immigrants retain their cultural standards of behavior, and also adopt those of Spaniards; (2) To me, integration means immigrants adopt Spaniards' standards of behavior; (3) To me, integration means immigrants maintain the cultural standards of behavior of their country of origin and do not adopt those of Spaniards; and (4) Other. In the option "Other", there was no response different from those already given in the other options, only nuances by the people of Madrid regarding the options given above. In spite of this, these data must be analyzed more thoroughly in the future.

Figure 10a shows that the majority of madrileño informants (almost 76\%) agree with the idea of integration proposed by Berry (2001), that is, that immigrants must maintain their cultural standards of behavior, but they must also adopt those of Spaniards. The second most frequently chosen option (17.6\%), although with much lower numbers than the first, is the idea of assimilation proposed by the same author, that is, that immigrants should adopt Spaniards' standards of behavior. The idea of separation proposed by Berry (2001)—that integration consists of immigrants maintaining the standards of cultural behavior of their country of origin and not adopting those of Spaniards-is an option that is hardly chosen $(0.6 \%)$. These results must be analyzed in greater depth in order to be able to understand what aspects influence these responses.

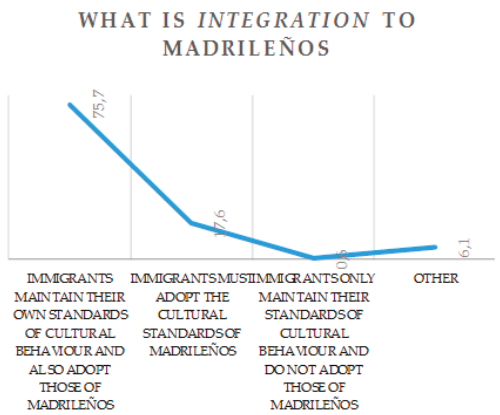

(a)

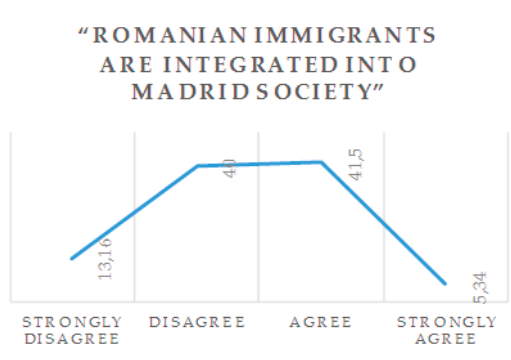

(b)

Figure 10. Results from the madrileño informants on issues related to integration. (a) Results of the item "What is integration". (b) Results of the item "Romanian immigrants are integrated into Madrid society".

According to Figure 10b, the perception of a little more than half (53.16\%) of madrileño informants is that Romanian immigrants are not fully integrated into Madrid society. While it is true that the 
percentage of madrileño informants that believe this is not too high (on the total population surveyed), further analysis of the aspects that may contribute to this perception in the host community is required.

These results offer a glimpse into the host community's view of the migrant group under study, and are considered to be particularly representative given that, as mentioned above, the social (and sociolinguistic) integration process is bidirectional; therefore, the responses of the host community must be considered in order to understand how this integration process is unfolding.

\subsection{Romanian Informants' Self-Perception of Integration}

Figure 11 clearly shows that Romanian informants feel very integrated into the host community. This can be related to the results in Figures 6-9, which demonstrate the strong desire for integration into the host community of the Romanian immigrants surveyed, given their different personal characteristics and attitudes toward the speech of Madrid.

“I BELIEVE I AM VERY INTEGRATED INTO SPAIN"

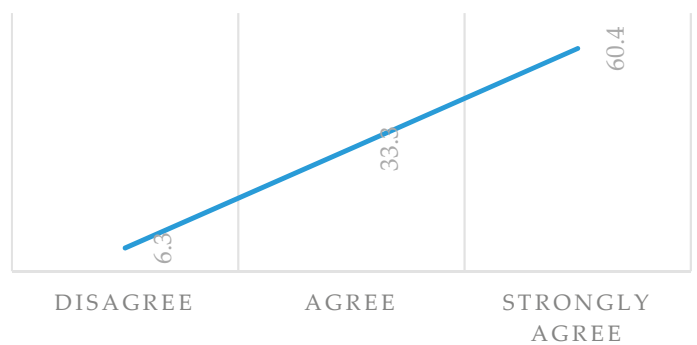

Figure 11. Results from Romanian informants for the item "I believe I am very integrated into Spain".

At the same time, as can be seen by comparing these results to those in Figure 10b, the perceptions of madrileños and Romanians differ in terms of Romanians' level of integration; therefore, further analysis is required to determine what other aspects or variables influence these responses.

\section{Discussion}

From all the information presented above, some conclusions can be drawn in this first phase of the study.

First, according to the preliminary data, Romanian immigrants seem to show a good attitude toward the speech of Madrid - which Sanz Huéscar (2008) confirmed in her study-and they also believe that they have a high degree of integration into the host community. This could indicate that Romanian immigrants would have a strong desire to integrate into the host community, facilitating this process of integration in this regard. In addition, the identity issue is an aspect that can have an impact on the sociolinguistic integration process. In this regard, further analysis is required on the different variables that may affect this issue in order to determine to what extent identity may affect the sociolinguistic integration process of the Romanian community living in Madrid, both positively and negatively.

Second, the madrileños surveyed seem to show a relatively positive attitude toward the integration of the Romanian population; however, although the Romanian immigrants perceive their integration in Madrid very positively, it seems that the host community does not see it in the same way. These topics must also be studied carefully, taking into account the multiple variables and aspects that could influence these issues; additionally, the full sample must be collected in order to obtain complete results.

Lastly, and due to the fact that the results presented in this article are fairly general and the established sample size still has not been reached, a more exhaustive analysis of the results collected 
must be carried out in order to offer more realistic, objective data. For all of these reasons, the second phase of the study is expected to continue by completing data collection and, of course, by transcribing the corpus. Then, sufficient information will be obtained to offer more precise data regarding the sociolinguistic integration process of the Romanian community living in the Community of Madrid.

Funding: This article was written as part of the research project La población migrante de la comunidad de Madrid: estudio multidisciplinar y herramientas para la integración sociolingüística (The migrant population of the Madrid Region: a multidisciplinary study and tools for sociolinguistic integration) (IN.MIGRA2-CM) (ref. H2015/HUM3404), funded by the Madrid Region and cofunded by the European Social Fund, and of the research project Estudio complementario de los patrones sociolingüísticos y procesos de integración sociolingüística en Madrid (Complementary study of the sociolinguistic patterns and processes of sociolinguistic integration in Madrid) (ECOPASIS_MAD) (Ref. FFI2015-68171-C5-4-P), funded by the Ministry of Economy and Competitiveness.

Conflicts of Interest: The author declares no conflict of interest.

\section{References}

Berry, John Widdup. 2001. A Psychology of Immigration. Journal of Social Issues 57: 615-31. [CrossRef]

Buzilă, Paul. 2016. El Rumano Hablado en España. Bucureşti: Editura Universităţii din Bucureşti.

Cestero, Ana María, Molina Isabel, and Paredes Florentino. 2003. Metodología del Proyecto para el estudio sociolingüístico del español de España y de América. Available online: http://www.linguas.net/LinkClick. aspx?fileticket=\%2FthWeHX0AyY\%3D\&tabid=474\&mid=928 (accessed on 11 February 2019).

García Marcos, Francisco. 2015. Sociolingüística. Madrid: Síntesis.

Immigration Observatory of the Community of Madrid (Observatorio de Inmigración-Centro De estudios y Datos de la Comunidad de Madrid). 2018. Available online: http://www.comunidad.madrid/servicios/asuntossociales/observatorio-inmigracion-centro-estudios-datos (accessed on 5 February 2019).

Miras Páez, Elizabeth, and María Sancho Pascual. 2017. La enseñanza de ELE a niños, adolescentes e inmigrantes. In Manual del Profesor de ELE. Edited by Ana María Cestero and Inmaculada Penadés. Alcalá de Henares: Servicio de Publicaciones de la Universidad de Alcalá, pp. 865-912.

Moreno Fernández, Francisco. 1998. Principios de Sociolingüística y Sociología del Lenguaje. Barcelona: Ariel.

Moreno Fernández, Francisco. 2009. Integración sociolingüística en contextos de inmigración: marco epistemológico para su estudio en España. Lengua y Migración 1: 121-56.

Moreno Fernández, Francisco. 2013. Lingüística y migraciones hispánicas. Lengua y Migración 5: 67-89.

Muñoz Carrobles, Diego. 2013. Lenguas y Culturas en Contacto en Contexto Urbano: El caso de la Comunidad Rumana de Madrid. Ph.D. dissertation, Universidad Complutense de Madrid, Madrid, Spain.

Paredes García, Florentino, and María Sancho Pascual. 2018. Influencia de las expectativas de permanencia o retorno en la integración sociolingüística de la población migrante en la Comunidad de Madrid. Revista Internacional de Lingüística Iberoamericana 16: 41-67.

Roesler, Patrick. 2011. Características generales del español hablado por inmigrantes rumanos en Castellón de la Plana. RedELE: Revista Electrónica de Didáctica ELE 22: 65-86.

Sancho Pascual, María. 2013a. Integración Sociolingüística de los Inmigrantes Ecuatorianos en Madrid. Ph.D. dissertation, Universidad de Alcalá, Alcalá de Henares, Spain.

Sancho Pascual, María. 2013b. Introducción: lengua y migraciones en el mundo de la globalización. Lengua y Migración 5: 5-10.

Sanz Huéscar, Gema. 2008. Actitudes lingüísticas de los inmigrantes rumanos en Alcalá de Henares. Alcalá de Henares: Universidad de Alcalá.

(C) 2020 by the author. Licensee MDPI, Basel, Switzerland. This article is an open access article distributed under the terms and conditions of the Creative Commons Attribution (CC BY) license (http://creativecommons.org/licenses/by/4.0/). 


\title{
Article \\ "Esa no soy Yo": Self-Image and Name Change from the Perspective of Female Immigrants
}

\author{
María Cecilia Ainciburu ${ }^{1, *}$ and Irene Buttazzi ${ }^{2}$ \\ 1 Department of Applied Languages, Nebrija University 1, 28015 Madrid, Spain \\ 2 Department of Modern Languages, Literatures and Cultures, Università di Bologna, 40124 Bologna, Italy; \\ irene.buttazzi2@unibo.it \\ * Correspondence: ainciburu@unisi.it
}

Received: 24 April 2019; Accepted: 21 October 2019; Published: 31 October 2019

\begin{abstract}
The given name by which we call ourselves in our native language contains a series of phonetic, social, and cultural elements that determine its value in any given context. When people migrate, these elements change and, consequently, so does the individual's self-perception. This research consists of an analysis of focused interviews with Peruvian and Chinese migrants carried out in Spanish and Italian. The most common phenomenon identified in the interviews was the use of names that do not correspond to birth names, either because they are not pronounced correctly or because - as in the case of most of the Chinese informants-the name was changed to adapt to Western standards. We attempt to categorize the nonconformity of the version of the name used by the host population and the emotional reactions that this provokes. The results demonstrate that there is a correlation between the desire to integrate into the host country and positive reactions to the image given to them by the foreign name.
\end{abstract}

Keywords: first name; self-image; immigrants; emotional reactions; second language

\section{Introduction}

This research aims to investigate the phenomenon of self-perception in the appellative use of given names that do not correspond to birth names or the names people are accustomed to being called in familiar environments. This phenomenon usually occurs when people emigrate and their own names are difficult to pronounce for the host population.

A number of legal studies have been undertaken on the impact of emigration on people's names. The issue emerged when bureaucratic processes relating to the issue of certificates of permanent residence in a country led to the officers in charge misunderstanding migrants' name and misspelling them (for example in the US; (Fermaglich 2015)). Ways of registering foreign visitors and migrants are constantly being updated (passport, scanner, fingerprint reader, etc.), with the result that it is now easier to register names correctly. Consequently, the legal changing of a name has largely been reduced to cases in which national names are imposed on individuals, as in Israel and other Middle Eastern countries. In recent decades, name change has also taken on other connotations (Portolés 1998) and research has focused on ways in which individuals can voluntarily change their own names to make it easy for them to be pronounced in the language of the new community they are entering, especially in view of the need for integration and adaptation to a work environment in the host community (Arai and Skogman-Thoursie 2009).

The study is based on 71 interviews conducted with a view on analyzing the experiences of two groups-a group of immigrant women from Peru and China who currently reside in Tuscany (Italy) and a group of Chinese immigrants in Madrid. Neither of the two host countries encourages new residents to change their names. However, the difficulty encountered in pronouncing their first names correctly could have an impact on the self-image of the immigrants-specifically, a psychological 
impact resulting in a feeling of alienation-which should be prioritized above the urgency to integrate into society (Aksholakova 2014; Stojanovic-Zezovic 2016; Schlote 2018).

The primary research tries to understand: (1) what relationship the immigrant has with her original given name, (2) whether she recognizes herself in the name currently used in the host country, and (3) whether the degree of positive or negative identification with her "new" name is related to the willingness to reside in the host country in the long term.

\section{Name and Identity}

There are various aspects of the subject of the given name that deserve attention: forename, calligraphy/orthography and alphabet, early literacy development, meanings and origins, the personal history of each name with a view on achieving individual uniqueness, multilingualism, and exchange. There is no doubt that the given name is a crucial part of identity: it evokes the expectations, omens, and future hopes of the individual's parents who gave it. In that sense, it represents inheritance, family geography, and identity with a particular social group. The name is the metonymical "face" of the person and, as such, it defines the person in her or his uniqueness and singularity. Moreover, a person's name is a benchmark in subjective development.

Identity (as a logical principle and complementary to noncontradiction) is a notion that has concerned Western philosophy for centuries. First, Descartes theorized about the so-called duality of mind and body (Descartes[1637] 2004, p. CXII), which he believed to be a contrast between res cogitans and res extensa. Locke later criticized this duality and provided one of the first definitions of identity (Locke [1690] 1956, p. 29), namely the search for "what substance individuality is, on what is founded and maintained in time, through experiences, even distant and overcome in which we may not recognize ourselves". This paper further examines whether memory and recognition are the two factors that constitute the conceptualization of identity. For Locke, memory is the power of the mind "to revive perceptions, which it has once had, with this additional perception annexed to them, that it has had them before" (Locke [1690] 1956, p. 98)—with no memory, there is no identity. Locke's concept of identity has been criticized; indeed, it is mental and subjective and does not necessarily encompass biological or individual corporeality. This limitation was overcome in the twentieth century when philosophers such as Hume theorized that humanity's understanding of the world is exclusively mediated by our senses and that there is no such thing as an inherent identity. Moreover, the successive integration of new psychological models that postulate the existence of multiple personalities reduces the scope of the concept of identity. Thus, William James concludes that a person's self is "the sum of all that he can call 'his', not only his body and his psychic faculties, but also his clothes and his house and also his wife, his friends, his children and his money in the bank" (James[1890] 1994, p. 67). On this basis, the elements that constitute the "self" may be presented as set out in Figure 1 below.

According to this model, the name by which a person is identified is for social use and may also be tangentially associated with all the enunciated forms of the self (body, clothes, family, house, peer recognition, preferences, desires, and memory). Many twentieth century psychologists were inspired by James's theory, in particular by his construction of the social self, which is why he is considered as the pioneer of the more modern conceptions of the self (for a review of the works of this author, see (Fierro 2013)).

In linguistic use, the notion of the self is usually counterposed with the form "My name is ... " In normal interactions between natives, this may include the use of a nickname (i.e., "My name is Jerome, but everyone calls me Pepo.") or some kind of variant of the name (for example, using the second name instead of the first or dropping part of a compounded name, as in the case of "Pilar" instead of "María del Pilar"). Social identity is the part of the self that is built and defined by/from daily interactions with members of a social community. Social identity can influence intergroup behavior, and therefore, a nickname can reflect intergroup relationships that are established within a specific reality. 


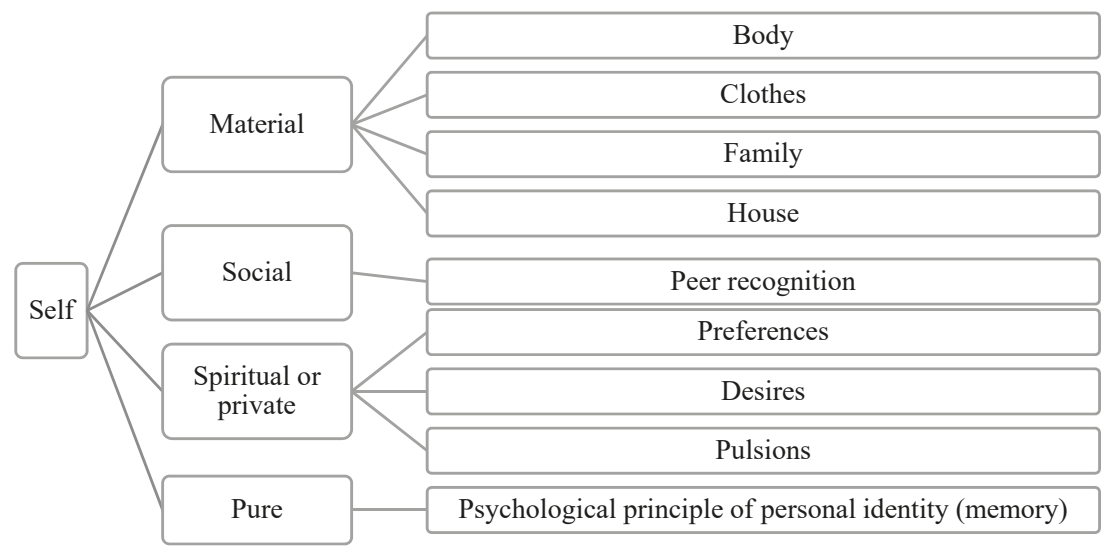

Figure 1. Structure of the self, according to William James (personal elaboration).

In twentieth century literature, the self is complemented by the perception of self. Behavioral psychology sustains the duality between a "phenomenal self", a self of which the subject is aware, and an "inferred self", perceived by the external observer. In this model, behavioral aspects focus on the inferred self, since the phenomenal self (the idea one has of oneself) can be altered by the unconscious. In this structure, the given name is part of the sphere of behavior because it is connected to other people's speculation of our own identity: giving, using, or changing a name is a behavioral act.

The cognitive approach does not emphasize being in itself but rather the ideas through which we perceive ourselves, namely what we would like to be or should be when dealing with our image of ourselves (convictions, what we are capable of doing, ideas about who we are, or beliefs that dominate our decisions). Neisser (1988) defines cognition and the processes of self-perception in an ecological perspective in which the knowledge that a person has of himself or herself derives from the information he or she possesses or is able to process. He identifies a structure of five subsystems that articulate with each other, as presented in Figure 2.

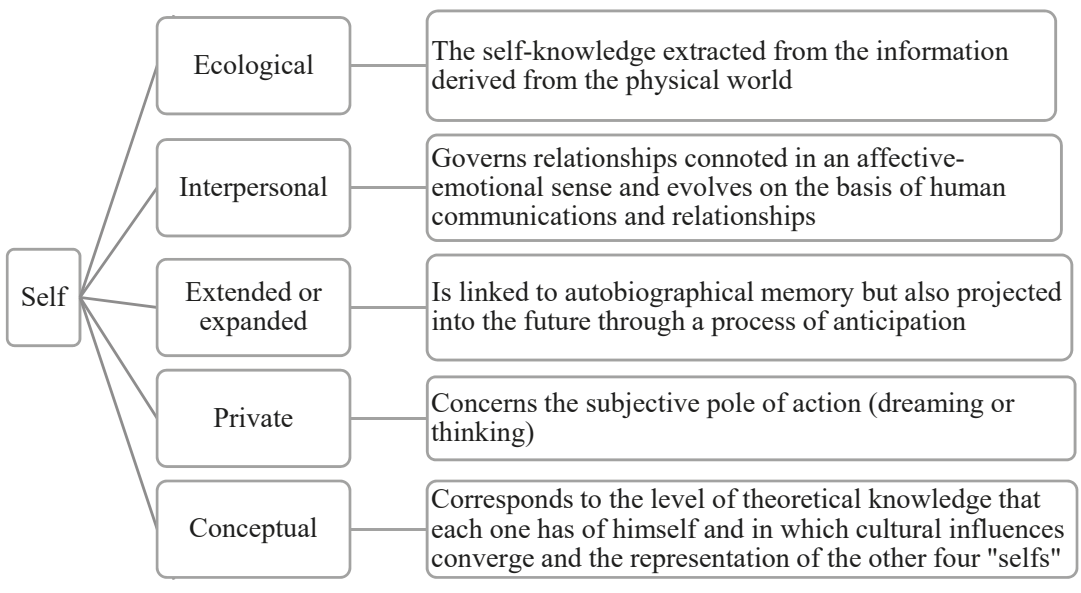

Figure 2. Structure of the self, according to Ulric Neisser (personal elaboration).

In terms of James's theory, the use of the given name can be placed among the information coming from the interpersonal self. The finding of this cognitive model lies in linking the interpersonal 
self-subsystem to the affective and emotional sphere. Thanks to these advances in the field of psychology, cognitive linguists are concerned with the concept of the self, which entails the use of personal pronouns, the grammatical indication of belonging, and the more general linguistic process of nomination.

The concepts of "current self" (online self) or "crystallized self" (offline self) that characterize Neisser's (Neisser 1988) explanation of the expanded self coexist in the theory of "possible selves" (Markus and Nurius 1986). According to this theory, the "ideal self" (Dörnyei and Ushioda 2009) channels the motivation of an individual and can, therefore, be easily connected to learning processes and, more specifically, to linguistic acquisition.

Dörnyei and Ushioda (2009) proposed the L2 motivational self-system that leads to differentiation between the ideal L2 self and the ought-to L2 self. On the one hand, he developed the idea that the ideal L2 self is a vision of oneself in the future and promotes the personal approach of the student to study. In this way, it focuses on a more distant perspective. On the other hand, the ought-to L2 self represents the vision of one having the attributes that should be possessed, which would influence the avoidance of negative results. Thus, Dörnyei provides a tripartite model of motivation that relates to inner desires, the social pressures exerted by significant people in the environment, and the experience of learning process.

Markus and Nurius (1986, p. 954) argue that possible selves represent ideas of what individuals might become, what they would like to become, and what they are afraid of becoming. They provide a conceptual connection between cognition and motivation and represent imaginary future states of the self, including the expected and feared results. Consequently, possible selves can function as a strong incentive in behavior regulation (Oyserman and Markus 1990, p. 113).

Thus far, we have tried to approach the concept of self by appealing to the two dimensions that characterize human beings and the attribution of meaning: an interior one, understood as self-recognition (identity), and an exterior one-our alterity - that involves either the environment in which we live and interact with a form of social self (James[1890] 1994) or the interpersonal self (Neisser 1988). It has been established that the latter may be considered the core of human emotions, since interaction with the outside world constantly modifies the psychological state of the subject. Based on this assumption, this paper investigates the dynamics between the expressions "my name is" and "they call me" (interpersonal self) and the emotional reactions these expressions elicit, with a view of being able to link them with the participants' degree of social integration in the host population.

\section{Personal Identity and Degree of Integration}

Historically, the change of personal names or surnames arose either against or in accordance with the immigrant's will. In the first case, the name is changed because of the host community's lack of knowledge of the emigrant's native language and, in the second, for the convenience of those who prefer to adapt quickly to the context of arrival (Fermaglich 2015). Bertrand and Mullainathan (2004), for example, demonstrate that there is a negative correlation in the US labor market between African last names and the way that employers regard such job applicants, whereas this is not the case when the applicant has a typically US surname, such as Johnson or Smith. A similar situation occurs when names denote that an individual belongs to an ethnic minority; it has been demonstrated that such individuals will receive a more severe penalty from judges than others for the same offense (Bielen et al. 2018). It is therefore understandable why immigrants choose to change their names when allowed to do so by their host country. Changing one's name can represent a form of integration. In some cases, when the new name is assigned regardless of the person's wishes, the change consists of the original name's graphic or phonetic adaptation to the language of the host country. When the change occurs in accordance with the person's wishes, there are convenience factors linked to greater work possibilities, better access to bank loans, or avoidance of being socially identified as belonging to a minority group (Handri 2008; Arai and Skogman-Thoursie 2009). In this case, "intention to integrate" does not imply a positive or negative bias of the decision in moral or anthropological terms. 
Studies on imposed change of name for immigrants tend to concentrate on historically massive immigrations, such as the migratory flow of Jews and Italians to the US in the early 1900s or the flow of Italians to South America in the same years (Bertrand and Mullainathan 2004; Handri 2008). Today, these types of studies have fallen into disuse because there are more efficient techniques of identification and the correct information is retrieved electronically.

Arai and Skogman-Thoursie (2009) studied the effects of the voluntary change of surnames of immigrants in Finland for over a decade (1991-2000). The study focuses on adults between the ages of 20 and 60 who renounced the use of a surname marked by origin in favor of a typical Finnish or neutral surname; for example, changing the surname "Mohammed" or a Slavic surname ending in "-vic" to one ending in "-en" or "-nen", which is the local patronymic, or to one from a list of Finnish "sonanan" surnames provided by the government (www.prv.se). This leads to a progressive endogeneity of names in a given community (Arai and Skogman-Thoursie 2009, p. 40). In Italy, which is the current country of residence of most of the immigrants studied for this research, there is no legislation that encourages immigrants to change their original names. Indeed, the only way that residents can have their given name or surname changed is through the intervention of a judge, who often decides such cases for reasons of decorum or for judicial protection. The situation is similar in Spain, although different when it comes to changing a first name. It is relatively easy in Spain for residents to change their first name- especially when the person is known by a name other than that which appears on the birth certificate. In Italy, by contrast, first names are seldom changed. These countries have similar laws relating to the changing of a given name, and receive few annual applications from foreigners, primarily due to very strict policies that originate from nationalist linguistic patterns instituted under Francoism and fascism (for details, see (Walkowiak 2016, p. 235)).

In specific terms, this research analyzes the names by which the people of the host country call the participants, namely Peruvian and Chinese immigrants. We are interested in the emotional reactions that are provoked by this change or mispronunciation of the individual's birth name. The change of name is a radical response to this situation. However, what happens when it is not possible or the person has no desire to change his or her name?

Unfortunately, the scant research available relates to countries in which it is possible (or even incentivized) to change one's name voluntarily. Nevertheless, two central factors are covered in this research, namely how the immigrants feel in relation to a wrong pronunciation of their names and their degree of social integration in the host country. It is useful to analyze the results of the existing research with a view to evaluate how they differ from those obtained in this study.

In questionnaires completed by 34 bilingual Estonians residing in Canada, $78 \%$ of the participants stated that they have to repeat their names more than three times before they are pronounced correctly (Lehiste 1975, p. 32), while the remaining $22 \%$ do not do so-not because they do not feel annoyed but because they consider it a waste of time. When an attempt was made to contrast the use of the two languages, English as the rational one and Estonian as the personal, intimate, and affective one, only one third of the group acknowledged that the sound of their mother tongue elicited emotions. The author concludes that:

A person's identity is inextricably linked to their name. A name distortion is a violation of self-image. In that order, in order to preserve his identity, the person must keep his name-protect it against mispronunciation-, keep it inviolable. An individual can maintain his identity as long as those around him respect the integrity of his environment. (Lehiste 1975, p. 35)

Although somewhat dated, the research is still relevant because it assigns percentages to the spectrum of different reactions of bilinguals to hearing their name. These data are not easily retrievable in this type of research, probably because reactions tend to be categorized only as positive or negative, simplifying the analytical detail or even focusing exclusively on negative attitudes, as dealt with later in the article. 
We agree with the authors cited above that the attention to a person's given name is a very important sign of respect and of the disposition to coexist in a foreign country. Aksholakova (2014) states that "if a name is mispronounced or misspelled, this can be considered as a distortion of identity in the sense of a man's personality" (Aksholakova 2014, p. 465). We are not sure to what extent having one's name mispronounced harms the individual's personality, but it certainly may cause some kind of humiliation. Nevertheless, the results indicate that the person's identity and integration process into the host society will be affected. Other recent studies describe this phenomenon as "microaggression", as in the context of a classroom when the teacher does not pronounce the foreign name correctly (Kohli and Solórzano 2012). When asked for their opinions, immigrants often describe their struggle between the desire to belong to a society that pressures them to assimilate and the desire to remain faithful to their own identities and to their linguistic and cultural origins. "Immigrants often express this in opposite terms: they feel that they do not belong [to the community] when their names are mispronounced, misspelled, avoided, forgotten or ridiculed" (Pennesi 2016, p. 47). de Pina-Cabral (2015, p. 183) explains that "people whose names somehow do not conform to the norm, feel significantly incomplete or absent, are likely not to feel 'normal' people, even to experience a 'stigma'" (Pennesi 2016, p. 48).

There have also been studies on the mispronunciation of names in relation to languages that are spoken in countries that were part of the former USSR. Thus, although she focuses predominantly on surnames, Aksholakova (2014) indicates that her students of Russian origin prefer the pronunciation of the first name "Laura" with the accent in the " $u$ ", while the Cossacks prefer the accent on the final " $a$ ". The results demonstrate that a wrong pronunciation elicits irritation in the students.

In cases of more recent immigration, Daniel Stojanovic-Zezovic's study on Swedish immigrants demonstrate that first names represent an important aspect of the experience of one's own identity (Stojanovic-Zezovic 2016). Since names are linked to attitudes and identity, they reflect what society represents to the individuals that belong to it. Moreover, Zezovic's study also highlights, as noted above, that having a non-Swedish name can be both positive and negative: on the one hand, it may be an important sign of ethnic and cultural conservation; on the other, it can also be a form a stigma, accentuated by the fact that mispronunciation causes individuals to feel different. The analysis considers the results of 9 interviews and 11 autobiographical accounts in Swedish of young immigrants (primarily between the age of 20 and 30) from the former Yugoslavia (Serbia, Bosnia), Turkey (Kurdistan), Vietnam, Greece, Poland, and Colombia. The results indicate that the majority of informants feel stigmatized by the way their name sounds in Swedish and have been able to request a name change. This step is considered very significant among immigrants and raises concerns about the risk of losing both their personal identity and their ethnic group identity. Their first names, according to their statements, are deeply rooted in their life histories and even their personal qualities. Colombian informant Camilo explains that he likes his name because it is the name of the greatest revolutionary in Cuba (Stojanovic-Zezovic 2016, p. 28). He also explains that the name was very popular in his country in the 1970s, when the singer Camilo Sesto was famous (Stojanovic-Zezovic 2016, p. 42). He describes what happens when Swedes try to pronounce his name:

[They] fail completely. It's supposed to be pronounced just like Camilla, which is a Swedish name, but nobody understands it, nobody. [ . . . ] It's been 10 years now, so I'm used to it, it makes me laugh sometimes because sometimes they're very close, sometimes it's completely fucked up what they say. Sometimes it doesn't make sense, but it's a problem for people who are really close to me. My closest friends get madder than me when people mispronounce my name, because everyone does it. But my identity has played an important role too, it has forced me to be flexible about it, because if I was going to fight all the time about how to pronounce my name, I would have to do it 10 times a day, it's not worth it. (Stojanovic-Zezovic 2016, p. 42)

We decided to focus on the case of Camilo because he is South American and because, after 10 years, he has not decided to change his name. Moreover, he demonstrates that mispronunciation is not 
always a form of microaggression, as mentioned above, and it is not always perceived as a stigma or as something painful. Thus, Camilo's interview demonstrates that he associates mispronunciation with the ignorance of his fellow citizens, and it helps him to frame people. Mispronunciation thus becomes a metaphor for how Camillo feels in Sweden: "I'm here, but I'm not completely here." (Stojanovic-Zezovic 2016, p. 45).

A recent doctoral thesis in Canada, based on 19 interviews, categorizes the social phenomenon of the identification and naming of a foreign person according to thematic and ritual axes that arise spontaneously in conversations: the reaction of the immigrant and of others and aspects related to the given name itself. These criteria are further broken down into subthemes, as presented in Figure 3 below (Schlote 2018).

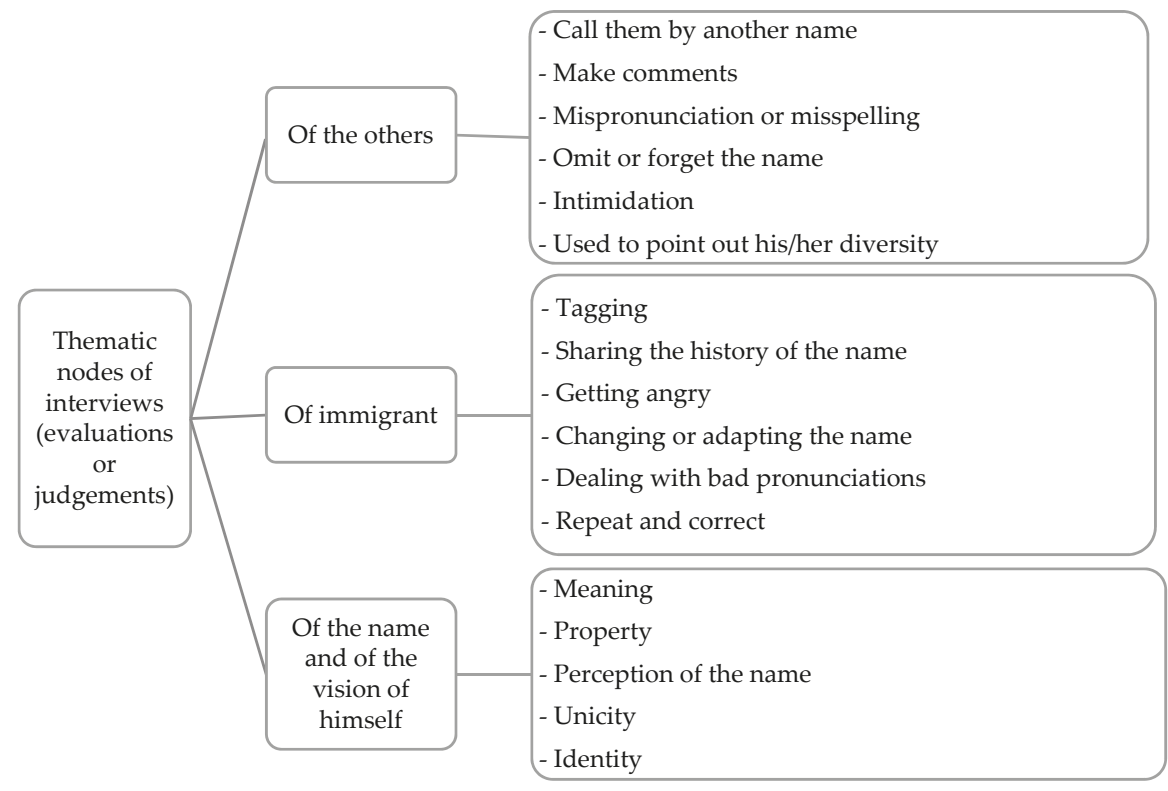

Figure 3. Thematic nodes associated with given names in immigrant interviews (based on Schlote (2018, p. 28)).

The names of the 19 interviewees are primarily marked by their origin (Godswill, Henok, Raneem, or Shiruq), but it is striking that none of the thematic options related to "the others" include positive attitudes, such as pronouncing the name correctly, making an effort to do so, or asking to be taught the right way. It is possible that the dynamics of the interview will lead to certain types of responses. The results of the research are probably biased because participants were selected among young immigrants who have decided not to change their name. The only exception that the research considers is the fact that some immigrants have chosen to alter the pronunciation of their given name. This strategy of best pronunciation as opposed to correct pronunciation demonstrates the resigned attitude of the participants, an attitude similar to Camilo's statements that were presented and transcribed earlier. Four of the 19 cases studied by Schlote $(21 \%)$ are examined below.

Examining isolated items that have been used to exemplify certain subtopics (see Figure 3), the attitude towards the social group of the host country is not always negative. Indeed, when people migrate, their name can sometimes be a mark of their uniqueness. Maha, for example, says that her name is quite common in Dubai while, in Canada, "it is special" and that this is positive because in "most classes, like at home, I am the only Maha" (Schlote 2018, p. 81). We understand that the fact 
of being unique is not the property of the participants but of the name. This is the same participant who has adapted the pronunciation of the vowel of her name to the "best possible pronunciation". Although the above thesis does not contain the complete transcriptions, this example demonstrates an attitude of greater integration than in the case of other participants. It seems impossible that the "of the others" category in Figure 3 does not even contain one positive evaluation. Interestingly, in Canada, there is a paid service for teachers to learn to pronounce the name of their students (NameCoach, $\$ 500$ per year). It is therefore anomalous that there are no positive attitudes when people are willing to pay for such services.

A special phenomenon relating to the changing of names exists-both from a social and linguistic point of view-in the case of Chinese immigration. There is a consistent bibliography about the difficulties experienced by Chinese communities to integrate, associated with a distinctive phenomenon in terms of identity that we call the use of the "fictitious name" that Chinese immigrants choose when they move to Western countries. Fictitious names do not appear in documentation, so there is no legally processed change of names. This makes them similar to nicknames or aliases, which means that they are unstable in terms of lexical placement ("Anita Ling Pao", "Ling Anita Pao", "Anita L. Pao", etc.). This is how one is known, but it is usually an individual choice rather than a social one (such as in the case of "Pepa", "Tiger", or "Skinny"). However, this is not necessarily an effect of immigration because it can be found in former Western colonies. For example, in Hong Kong, the chosen name was introduced in official documents using both modes of writing (Li 1997, p. 505).

Liao (2011) studied the experiences and perceptions of Chinese immigrants in the US in order to understand why they decided to change their birth names. Liao interviewed 10 Chinese immigrants to understand the meaning of their names in Chinese culture and the positive or negative perception that Chinese people have of Chinese and Western names. The first part of the study focuses on the family's attitude towards the imposition of names because they are strongly symbolic and add something to a person's characterization. In this sense, changing the given name can be seen as a lack of respect towards the family because of the negative perception of its transliteration in Latin characters. Thus, "some Chinese immigrants refuse to commit themselves and adapt to these changes, adopting a Western name to use in the English context, while keeping their Chinese names to use within the Chinese circle, seems to be a primordial option for them" (Liao 2011, p. 65). The results demonstrate that 8 out of the 10 participants feel misidentified and frustrated when they hear their name mispronounced, while the remaining two have no experience of mispronunciation with their names since they have almost exclusively used their Western names from a young age (Liao 2011, p. 67).

The positive and negative effects of perceptions of the Western and Chinese names are presented in Figure 4 below.

Recent studies on Chinese immigrants are focused primarily on the double identity of the second generation (American Chinese). The phenomenon takes a very different turn in second-generation immigrants because they have a higher degree of integration in the educational system. It is the parents or teacher of these individuals who decide what name they should go by, so the effects of their adoption or self-representation change substantially compared to the first generation. Currently, the phenomenon has extended to exchange students (Kim 2017) and to immigrants from Korea or Taiwan, who also seem to adopt the practice of taking on a local name (Chen 2016; Kim 2017).

In their analysis of immigrants' given names, the studies reviewed thus far do not consider the linguistic differences between names, nicknames, or affective forms of family use (Portolés 1998). Moreover, these studies do not relate to Italy or Spain, the countries this research is concerned with. Therefore, this paper attempts to apply the above linguistic categories with a view on deepening the analysis of the identification of immigrants in the host society.

The present investigation involves groups of Peruvian and Chinese immigrants in Italy and Spain where, as has already been seen, it is not possible to change one's name legally, except in serious cases in which only a judge can decide. The official data for Italy (ISTAT 2017) indicates that preferences in relation to assigning traditional names of the culture of origin depends loosely on nationality. Unlike 
Arab parents who prefer to assign names belonging to their own tradition, Romanians, Albanian, and Chinese parents often choose both names frequently used in Italy and names in use in their own country. For example, the names most frequently given to children born in 2016 were Kevin, Matteo, Kimi, William, and Alessio. The most frequent girls' names were Sofia, Emily, Gioia, Angela, and Jessica.

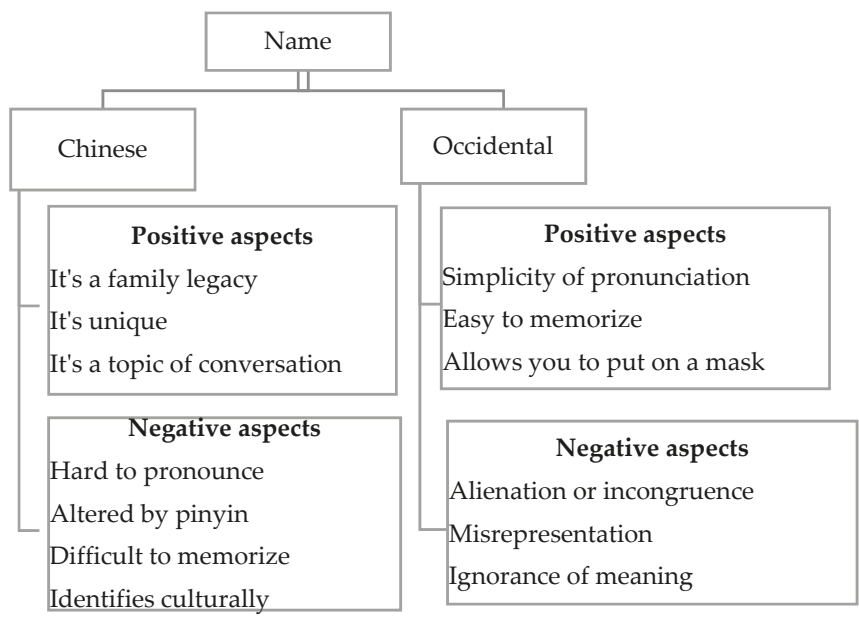

Figure 4. Reactions to the use of Western and Chinese names (from Liao 2011, pp. 92-103).

In Spain, the National Statistics Institute (INE) publishes an annual list of the most frequent names and surnames according to the local geolectal preferences of parents residing in Spain (INE 2017). It observes the frequency of names based on the province of residence, but it does not provide information on whether they are the preferences of autochthonous Spanish families or of immigrant families.

\section{The Question of One's Own Name in Personal Interviews with First-Generation Immigrants}

The aim of this research is to answer to the following questions:

1. Is there an explicit relationship between the immigrants' proper name and their community of origin (meaning, personal satisfaction, and family uses)?

2. Does that name correspond to the name currently used in the new host community? If not, what linguistic forms are proposed in substitution?

3. Does the degree of self-identification of immigrants with the name de facto assigned to them by the host community relate to their willingness to reside in the host country in the future?

The answers to these questions come from personal interviews conducted between 2017 and 2018 with two groups of women immigrants from Peru and China residing in Tuscany (Italy) and a group of Chinese women immigrants in Madrid. In Italy, the interviewees were 45 full-time Peruvian home care workers (colf or badanti, in Italian) and 14 Chinese saleswomen; in Madrid, the interviewees were 12 women who were working in Chinese shops. All subjects gave their informed consent for inclusion before they participated in the study. The study was conducted in accordance with the Declaration of Helsinki, and the protocol was approved by the Ethics Committee of INMIGRA-2 [H2015/HUM-3404; Comunidad de Madrid and European Social Found]. The selection of informants does not respond to criteria of demographic and origin representativeness. According to the Tuscany regional administration, on 1 January 2018, there were 408,463 foreign residents, 191,659 of whom were men and 216,804 of whom were women. Figure 5 presents the composition of immigrants according to their origin. 


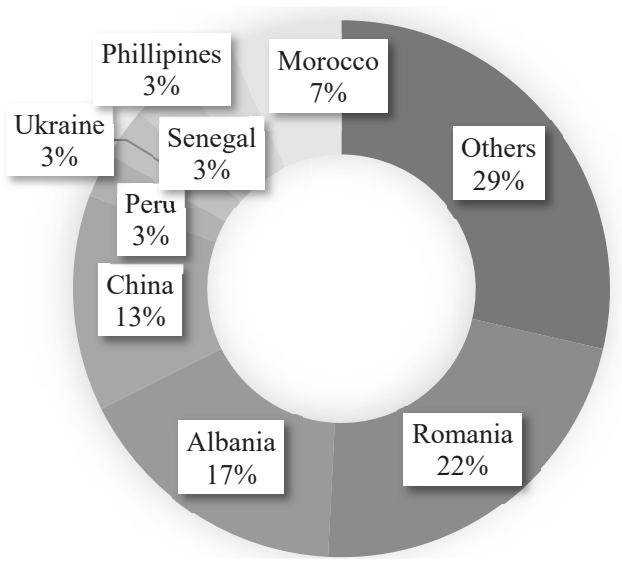

Figure 5. Origin of immigrants in Tuscany (data are taken from "Progetto PAeSI, Pubblica Amministrazione e Stranieri Immigrati").

Therefore, the results obtained by our sample do not necessarily extend to the entire population of immigrants of the region. The same is true for the Madrid sample.

The semi-structured interviews were conducted in Italian or in Spanish with a view to study the influence of noninstitutional learning of these two languages. Each interview lasted between one hour and $90 \mathrm{~min}$ (an average of 11,614 words per sample). The present research analyzes only those fragments that answer the research questions set out above (an average of 1678 words per participant).

The first part of the interviews is divided into three sections corresponding to the two nuclei used by Schlote (2018) and an additional question: my name and myself; my name and the others; and a third question on the perspective of residence, which attempts to collect data on the future self of the informants.

a. What does your name mean? Do you like it? Do you know why they gave it to you? Is that what they call you at home or in your family?

b. What should I call you? What do they call you in Italy (or Spain)? Why do they call you that? Tell me about it. How does it sound to you when Italians (or Spaniards) pronounce your name? Which name do you prefer and why?

c. Where will you live in 10 years? In Italy (or Spain)? Will you ever move back to Peru (or China)?

All the interviewees answered the above three questions. The answers to the first two questions were more extensive and were used to extract the examples analyzed in Sections 4.1 and 4.2. Subsequently, in order to illustrate the relevance of the phenomenon, the responses that demonstrate emotional attitude towards the pronunciation of the name by the host population were placed on a scale of 4 positions: positive, predominantly positive, more negative than positive, and negative. The part of the third question relating to future residence in the host country received very brief answers. Therefore, since this implied a dichotomous answer, it served indirectly to assess immigrants' degree of future family integration. A statistical test was used to determine whether there were significant differences between the intention to remain in the host country and the emotional attitude towards the pronunciation of the name by the host population.

Peruvian immigrants conducted interviews half in Spanish and half in Italian, randomly alternating between one language and the other. Chinese immigrants were interviewed in Spanish or Italian according to the country in which they resided. The interviews were transcribed in the CLAN system to be integrated later in the Nebrija-INMIGRA corpus (https://slabank.talkbank.org/access/Spanish/ 
Nebrija-INMIGRA.html). To facilitate their reading, the fragments selected for the exemplification do not contain marks.

In order to avoid linguistic distortions caused by recent immigration, only informants who had been in the host country for longer than seven years were interviewed (Table 1):

Table 1. Years of residence in the (host) country of the interviewed participants.

\begin{tabular}{cccc}
\hline & $\begin{array}{c}\text { 7-9 Years of } \\
\text { Residence }\end{array}$ & $\begin{array}{c}\mathbf{1 0 - 1 4} \text { Years of } \\
\text { Residence }\end{array}$ & $\begin{array}{c}\mathbf{2 1 5} \text { Years of } \\
\text { Residence }\end{array}$ \\
\hline Peru (Italy) & 4 & 21 & 20 \\
China (Italy) & 5 & 8 & 1 \\
China (Spain) & 5 & 7 & 0 \\
\hline
\end{tabular}

All the women (aged between 27 and 57) have children in their country of residence or in their countries of origin. Not all of them have legal residence in the host countries, and all have consented to the interviews being transcribed for the study of their linguistic output in exchange for anonymity. They were informed that, since the research involves first names, the surname and public identification information (identity document, residence, etc.) would remain anonymous. Each example contains an identification code that includes the initial sample number, the informant's acronym (P for Peru and $\mathrm{Ch}$ for China), and the time location of the fragment in the recording. The place of residence of Chinese immigrants is not indicated in the codes of the examples because the language in which they express themselves (Italian or Spanish) provides guidelines on which subgroups they belong to. The quantification of the analyzed phenomena always takes account the country of residence into account.

\subsection{Myself and My Name}

The first result of the analysis clearly demonstrates that all the Chinese informants know the meaning of their names, while this is not so for $70 \%$ of the Peruvian group. Examples of responses are given below.

4. Como nací el 25 de diciembre me pusieron Nacimiento. En Brasil es de hombre, pero yo me llamo Nacimiento, de mujer (16P, 4'2").

"Since I was born on December 25, I was called Nacimiento. In Brazil it is a man's name, but my name is Nativity, a woman's name."

5. Sono Cori perchè in "kichwa" è "d'oro", ma i documenti sono Corina perché non lasciavano. (28P, 3'11").

"I'm Cori because, in Quechua, it means 'golden', but in the documents, I'm Corina because they did not permit [the Quechua name]."

6. Mi nombre es Bertilde y mi madre me contó que me lo puso mi papá y que ni en el almanaque estaba ¿cómo voy a saber [qué significa]? Mis abuelas se llamaban Berta y Matilde, pero eso no es significado ¿no? $\left(34 \mathrm{P}, 1^{\prime} 8^{\prime \prime}\right)$.

"My name is Bertilde, and my mother told me that my father gave it to me and that it wasn't even in the almanac... How would I know [what it means]? My grandmothers' names were Berta and Matilde, but they don't have a meaning do they?"

7. Ying Lián. Así [escribe 英 莲] “flor de loto". Fácil. Ying flor, Lián, loto (3Ch, 12'2”).

“Ying Lián. Like this, [writes 英莲] 'lotus flower'. Easy. Ying [is] flower; Lián, [is] lotus."

8. Jin Yin Hua è fiore. Molto bello. Non italiano, di fiori Bach 'honeysuckle'. Conosci? Tutte donne, fiori in Cina [ride] (9Ch, 2'26"). 
"Jin Yin Hua is a flower. [A] very nice [one]. Not Italian, of Bach flowers 'honeysuckle'. Do you know? All women [are] flowers in China [laughs]."

In Peru, most names are "borrowed" (from the Bible, from the almanac, or from the family) and usually come from foreign languages. Therefore, they tend not to have an obvious meaning for a Spanish speaker (e.g., from Latin, Lucia "who has light" or, from Hebrew, Daniela "God is my justice"). The situation is not homogeneous, and in some cases, there is an influence of the Quechua substrate that is transparent for the she-immigrant (example 2). On the other hand, it is not possible to ignore the meaning of the given name in Chinese because the name's formants have meaning in Mandarin, as is the case of examples 4 and 5 . The flower in example 5 is Lonicera caprifolium, which is used to manufacture the group of perfumes known as "Fiori di Bach", which the interviewee mentions.

While all the interviewees in the Chinese group say that they like their name, in the Peruvian group, the answers vary and, sometimes, their tone of voice manifests a certain bewilderment, as if the question was not appropriate.

9. Nunca me gustó. Cuando niña en la escuela la maestra me llamaba Juli y me encantaba. Judith es bien feo. $\left(33 \mathrm{P}, 5^{\prime} 16^{\prime \prime}\right)$.

"I never liked it. When I was a little girl at school, the teacher called me Juli and I loved it. Judith is really ugly."

10. Bueno, todas nos llamamos María y todas usamos el segundo nombre. Aquí Fiorella suena bien, pero en Perú, no. La gente no sabe de la doble ele (22P, 4'43").

"Well, we all call ourselves Mary and we all use the middle name. Fiorella sounds good here but not in Peru. People don't know about the [pronunciation of the] double el."

11. Il nome mio regalo del padre. Molto importante. Molto buono. I nomi cinesi sono fortunati (14Ch, 3'56").

"My name is my father's gift. Very important. Very good. Chinese names are lucky."

In the Peruvian group, $45 \%$ said they did not like their name, 23\% said they liked it, and $32 \%$ said they were indifferent or did not answer the question. There seems to be no correlation between whether the interviewee liked the name and whether she knows its meaning. There is a proportionately similar number of people who did not know the meaning of their name in each group. Whether an immigrant likes or dislikes her name may influence whether she wants to change it, including whether she prefers to use other forms of names such as nicknames (example 6). However, the data do not make it possible to arrive at any strong conclusions in this respect.

Nicknames (literally "additional names") or hypocoristics (affectionate, family, or euphemistic names used to replace real names, for example, Susi for Susana and Josema for José María) affect the two groups almost equally, with a distribution of $26 \%$ in the Peruvian group and $22 \%$ in the Chinese group. Although this use is verified in other transcriptions-as in example 6, for example-an additional example is given for each group.

12. Mi chiamo Adriana e in famiglia sono Adri per tutti. No, per li amici, no, solo en casa. (26P, 9'55").

"My name is Adriana, and I am Adri for everyone in the family. No, for friends, no, just at home."

13. Cuando pequeña mis padres llamaba Xiao Lin, 'chuoming' nombre pequeño (sobrenombre). Xiao es 'pequeña'. Mi padre me llama ahora, aquí, en casa. Eso. En China un niño no tiene nombre cuando bebe. Los padres piensan y lo llaman 'niño' o 'bonito'. Después miran bien, mucho, y ponen el nombre. No enseguida. 100 días para poner nombre. En la estuala no Xiao Lin, Lin-lin. Solo niña (9Ch, 5’51"). 
"When I was a little girl, my parents called me Xiao Lin-'chuoming', little name (nickname). Xiao is 'little'. My father calls me that now, here, at home. That's it. In China, a child doesn't have a name when [it is] a baby. The parents think about [the name for a time] and [in the meantime] call him 'boy' or 'pretty'. They take quite some time before actually giving the name, not right away. It takes 100 days to give a name. At school, they don't use Xiao Lin, only Lin-lin-little girl."

Nicknames in China change according to the age of the individual concerned, and they are also regarded as forms of respect (Liao 2011). That explains why, in example 10, they call the informant "Lin-lin" at school, which apparently is a name that is commonly used for children. We have not investigated this subject because it diverged from the objective of this research. However, this different conception in the modality of assigning different names for different ages deserves further investigation in the case of immigrants who grow up in perfectly bilingual contexts.

The data demonstrate that there is an explicit relationship between the proper name of the immigrants and their community of origin, a relationship that is different for the Peruvian and Chinese communities observed in this study. Peruvian immigrants often do not know the meaning of their name, do not like it, or regard it simply as an imposition: their identification with it is thus rather weak. By contrast, Chinese immigrants regard their name as a private gift, related to what the family was expecting for them, as it apparent from example 10. At no time do they feel free to say that their name is ugly or that they do not like it. This could explain their inclination to protect it from distorted use by the host community and to treasure it within the family and in private reality. The answers make it clear that the relationship between the original name given by the family and the immigrants' identification with it has specific cultural traits.

While the results of the Chinese informants are consistent with the patterns indicated by Liao (2011, pp. 92-103), those of the Peruvian women — not analysed by the previous literature-can be partially associated with those obtained by Schlote (2018) for Middle Eastern and Asian (non-Chinese) populations. However, comparing Peruvian and Middle Eastern data could result in distortion because Middle Easterners are induced to evaluate their proper name as a unique identity in countries in which idioms are based on Latin.

\subsection{My Name and the Others}

The results demonstrate that most of the participants do not have the same perception of the difference between their name and what others call them. This discrepancy occurs in $56 \%$ of the group of Peruvian women and $100 \%$ of the group of Chinese women. There are manifestations of different entities within these figures: from the imposition of a diminutive to the acceptance of the naturalization of the foreign name, as presented in Table 2.

Table 2. Forms of disparity between the documented name of the immigrant and the one used in the host country.

\begin{tabular}{ccccc}
\hline $\begin{array}{c}\text { Origin } \\
\text { (Residence) }\end{array}$ & $\begin{array}{c}\text { Participants with } \\
\text { Name Discrepancy }\end{array}$ & $\begin{array}{c}\text { Name } \\
\text { Mispronounced }\end{array}$ & $\begin{array}{c}\text { Hypocoristic or } \\
\text { Nickname }\end{array}$ & $\begin{array}{c}\text { Fictitious } \\
\text { Name }\end{array}$ \\
\hline Peru (Italy) & 25 & 18 & 7 & - \\
China (Italy) & 14 & - & $2^{*}$ & 13 \\
China (Spain) & 12 & - & - & 12 \\
\hline
\end{tabular}

A case of double disparity in the use of a fictitious name with truncation problems is indicated with an asterisk in Table 2 and is detailed in the transcription of example 16, which presents the qualitative analysis of the fragments of one of the two Chinese informants.

In both groups, the discrepancy between the name on the identification document and the name in social use exceeds the expected coincidence value. In the case of the two groups of immigrants from 
China, one encounters the phenomenon of the Western name corresponding to the nationality of the groups rather than to that of the host country. The various types of dissimilarity require qualitative treatment and are discussed in more detail in the following three sections.

\subsubsection{The Mispronounced Name}

Having their names mispronounced is more common in the Peruvian than in the Chinese group. This is unexpected because we may assume that Italian has a more similar pronunciation to Spanish than Spanish to Chinese. Nevertheless, we base our conclusions on the responses that were received. This phenomenon is produced either by the complete Italianization of the name when the corresponding Italian exists (Lucía pronounced "Luchía") or by the reading of names written in Spanish in an "Italian way" ("Iulia" for Julia and not "Giulia", due to the custom of Italians to read the jota as "i").

14. Para mí es más fácil decir directamente 'Luchía' y se acabó. En Toscana si no terminan diciendo algo que me suena rarísimo (6P, 2'17").

"It's easier for me to say 'Luchía' directly, and that's it. Otherwise, in Tuscany, they end up saying something that sounds very strange to me."

15. La signora mi chiama Iulia e come non può dire bene 'Julia', io la lascio. Viviamo sola, noi due e non ci si confondono. Meglio che 'chica', come mi chiamavano nell'altra casa (8P, 4'8").

"The lady calls me "Iulia", and as she cannot say 'Julia' properly, I leave her. We live alone, the two of us, and we do not get confused. It's better than 'chica', as they called me in the other house."

The habit of mispronouncing names is not detected in the group of Chinese informants because the imposition of a Western name implies a priori the impossibility of pronouncing the original name correctly.

16. Mi chiamo Alice Xiao-Chen. Xiao-Chen è nome, XXXX cognome. Qua Alice, come 'delle Meraviglie' (ride) (7Ch, 1'22").

"My name is Alice Xiao-Chen. Xiao-Chen is [my Chinese] first name, XXXX surname. Here, Alice, as 'in Wonderland' (laughs)".

It is obvious that the informant's name is constantly mispronounced, even if she does not state this explicitly. Subsequently, since all informants answer the question about how they feel when their name is mispronounced, they must have tried to use it in the host country.

Mispronunciation is the factor that emerges most prominently in the interviews conducted by previous researchers (Aksholakova 2014; Stojanovic-Zezovic 2016; Schlote 2018), and one that causes the most negative reactions. Such reactions have been described as "feeling rejected", "humiliated", or "sad" (Stojanovic-Zezovic 2016) or, on a social level, as the feeling of "being ridiculed", "being rejected", or "being stigmatized" (Pennesi 2016, p. 48). The fact that Chinese informants seldom comment negatively on name mispronunciations may attract attention but we believe this reveals only that mispronunciation by the host population is taken for granted, without assigning any negative evaluation to it.

\subsubsection{Use of Hypocoristics or Nicknames}

We have placed a range of different cases in the category of nicknames or hypocoristics-the only common element being that the subject does not decide on them, their being, rather, the results of social use (Portolés 1998). Consequently, the performative effect to which they allude and which they evoke in the real world as well as the associated idea they activate do not depend on the choice of the subject (Walkowiak 2016). Indeed, the subject has no control over the intention with which these 
names are assigned. A shortened name may have a different second meaning in the mother tongue or in a foreign language, and awareness of the connotations can be crucial in interpreting or ignoring that meaning. We therefore consider examples in which the hypocoristic can be derogatory and unpleasant for the receiver:

a. the reduction of compound names to the first name

17. Cuando le dieron mi pasaporte a mi señora para que el hijo escribiera los datos el hijo le dijo 'es 'Maria de los Anjiles [ay 'xi les]', es más fácil María, María como la señora anterior' (4P, 3’11”).

"When they gave my passport to my lady employer so that her son could write down the information, the son told her 'it's Marïa de los Anjiles [an 'xi les]', [only] Mary is easier. Mary like the previous maid."

b. hypocoristic forms, with shortening of given names

18. Mi chiamo Lorena ma la mi signora mi chiama 'Lori'

- $\quad$ E non ti chiamavano così in Perú? in Argentina si fa...

- $\quad$ No. A casa mi chiamano Lili come la pellicola e a scuola 'Lorena' (12P, 9'34")

My name is Lorena, but my lady [employer] calls me 'Lori'.

And they didn't call you that in Peru? In Argentina, they do it ...

- No, they didn't. At home, they call me Lili, as in the film, and, at school, 'Lorena'."

c. truncations of given names that are considered too long, with elimination of syllables (initial, final, or both)

19. Se dico 'Bing-Qing' dicono 'Bin' e mi chiama 'Bin' o 'King' come re, d'uomo. 'Bing-Qing' è come 'giacchio bianco' o 'Biancaneve', ma 'Bin' è come 'spiaggia'. Bello, ma non tanto bello per me. $\left(4 \mathrm{ChIt}, 6^{\prime}\right)$

"If I say 'Bing-Qing,' they say 'Bin' and they call me 'Bin' or 'King,' as king of man. 'Bing-Qing' is like 'white ice' or 'Snow White', but 'Bin' is like 'beach'. Nice, but not so nice for me."

d. the imposition of unused nicknames in the country of origin.

20. Y el niño me dijo 'Tati' y como Lidovina era complicado para ellos, todos me llaman 'Tati' (11P, $\left.8^{\prime} 12^{\prime \prime}\right)$

"And the kid called me 'Tati', and since Lidovina was complicated for them, they all call me 'Tati'."

In the corpus as a whole, there are other examples of the use of nicknames that have not been considered because they were already used in the country of origin. This is the case of the following informant:

21. Adelina, who is called "Lina" both in Peru and in Italy.

Given the above analysis, it is likely that - from a pragmatic point of view-the category needs to be specified in more detail. Human beings create and attribute meaning from the model of representation they have of the world and from the information that constantly updates this model. Thought systems are interiorized representations of reality and of the outside world. Hypocoristics constitute a re-elaboration of given names used by native speakers, with predominantly affectionate intentions, as is probably the case in example 15. They refer to images and evoke memories that are 
associated with the person in question. Nicknames, on the other hand, can be perceived as positive or negative (Portolés 1998), especially in the case of immigrants or foreigners because they can be based on stereotypes. In terms of the cause-effect relationship, it is possible to explain the reasoning by the connection that always exists between an action and the feelings that it elicits. Thus, "Tati" can be positive and affectionate or negative, since it limits the individual to the occupation for which she is hired (the interviewee considers it positive). Something similar can happen with the use of the double or simple name, which is generally quite neutral, but, in the case of example 14, is negative. Although the immigrant is not fluent in the host language, it is evident that she was irritated. Indeed, in Italy, the association between Chinese nationality and "beach" carries a negative connotation that automatically activates the stereotypical idea of a Chinese immigrant working illegally, doing massages on the beach, and consequently reduces social prestige. Moreover, this amplifies a stereotype of nationality that people are constantly fighting to eradicate. Cultural stereotypes come from the tendency that human beings must assume that reality is determined by their subjective experience, which creates their biased expectation.

This category was not assessed by the authors of the reviewed literature. The quantitative relevance of the phenomenon is contained in our analysis, and it was therefore not considered appropriate to examine it in greater detail for the purposes of this research.

\subsubsection{Fictitious Names}

Fictitious names or Western names (as defined in Section 3) are present for all the Chinese informants who have a Western name and use it on authorization forms as their first name (67\%) or as a middle name (33\%). In 56\% of cases, fictitious names were chosen during childhood (for example, by the mother, father, or teacher), while the remaining $44 \%$ chose it for themselves. When required to justify this second "Western baptism", all responses resemble example 16. Such a baptism prevents the effects of mispronunciation and, as already mentioned, is consistent with the results found by Li (1997) in Hong Kong and by Liao (2011) in the US.

The three previous sections indicate that the bad pronunciation emphasized by Lehiste (1975), Aksholakova (2014), or Schlote (2018) is not the only aspect that should be analyzed because of the relevance of the phenomena described in Section 4.2.2, which refer both to the name in its original version (in the population of origin) and to the one that the immigrant uses in the host country. As the following section argues, these aspects should be studied in relation to the reactions that they may provoke in the immigrant population.

\section{Reaction to Different Ways of Being Called and Perspectives of Permanent Residence: Incidence of Language}

The question concerning the emotions or reactions of immigrants was quite general: "How does it sound to you when the Italians (or Spaniards) say your name?" This question overlooks the fact that Chinese informants call themselves by their fictitious name. Considering the fragments that have been studied, the results demonstrate that a good pronunciation of the name causes positive reactions, while-as expected - a bad pronunciation is associated with negative emotions. These results coincide with those reported by Pennesi (2016) and Schlote (2018) for other immigrant groups from different countries (see Section 3).

Each reaction has been classified on a scale of four possibilities (positive, predominantly positive, more negative than positive, and negative). Table 3 below presents the different reactions linked to their forms of disparity and nomination pointed out in the previous section ( $\mathrm{P}$ is Peruvian and $\mathrm{CH}$ is Chinese group). The two Chinese groups are not separated because both use Western names. 
Table 3. Reaction to different ways of being called.

\begin{tabular}{|c|c|c|c|c|c|c|c|c|}
\hline & \multicolumn{2}{|c|}{ Correct Name } & \multicolumn{2}{|c|}{$\begin{array}{l}\text { Mispronounced } \\
\text { Name }\end{array}$} & \multicolumn{2}{|c|}{$\begin{array}{l}\text { Hypocoristic or } \\
\text { Nickname }\end{array}$} & \multicolumn{2}{|c|}{ Western Name } \\
\hline & $\mathrm{P}$ & $\mathrm{CH}$ & $\mathrm{P}$ & $\mathrm{CH}$ & $\mathrm{P}$ & $\mathrm{CH}$ & $\mathrm{P}$ & $\mathrm{CH}$ \\
\hline Positive & 20 & & & & & & & 20 \\
\hline Prevalently positive & & & & & 2 & 2 & & \\
\hline $\begin{array}{l}\text { More negative than } \\
\text { positive }\end{array}$ & & & 10 & 4 & 2 & & & \\
\hline Negative & & & 10 & & 1 & & & \\
\hline
\end{tabular}

As presented in Table 3 above, the people who react positively are those who are called by their own name- - either the birth name or the Western name-while bad pronunciation generates the highest degree of negativity, followed by the imposition of nicknames or hypocoristics.

When asked about the possibility of maintaining their residence in 10 years' time, all the Chinese interviewees hoped to continue living in the host country—Italy or Spain — while $60 \%$ of the Peruvian women thought of returning to Peru and did not consider the possibility of reuniting their family in Italy, which was allowed by the existing law. Combining the information from the participants' personal records with the data collected in the interview, it appears that the family situation of the two immigrant groups is diametrically different. Chinese immigrants reside with husbands and children, while $83 \%$ of Peruvian women share a domicile with the elders that they care for and $72 \%$ live separately from their children who are in Peru in the safekeeping of the rest of the family.

We investigated whether temporary immigration and the use of their own language for the Peruvian women (of the 45 interviews, 23 Peruvian women completed this first fragment in Spanish and 22 in Italian), could have influenced the outcome of the research. Combining the data demonstrates that, although there was no difference in the case of well-pronounced names, the negative attitudes of the group with "name differentiation" indicated a sensitivity to the use of the language. In other words, if the analyzed segment of the interview was carried out in Spanish, the negative attitudes towards bad pronunciation were strengthened. Conversely, when it was carried out in a foreign language (Italian), the subjects seemed to be more tolerant towards the attitudes of the host population. We compared the proportions between groups divided by language (independent groups) and by positive or negative attitudes (dichotomous variable), and applying the Fisher test, the difference is significant $(2 \times 2, p=0.023)$. Since this research is conducted on a small sample, the results should be regarded with caution. However, the incidence of language in the expression of feelings has been confirmed by studies with larger samples, and this assumption may generally be regarded as accurate: the immigrant tends to judge the attitude of the host population more harshly in the case of Spanish speakers than Italian speakers.

\section{Concluding Remarks}

This research was carried out with the objective of obtaining data about the perception that Peruvian and Chinese immigrant women have of their own name. For this purpose, three questions were presented as part of a broader interview, relating to three thematic areas: the relationship of the name with the culture of origin, with the host culture, and with the intention of residing in the host country in the future (Schlote 2018). In terms of perception, emotional reactions to different ways of "being called" are underlined, especially when these do not coincide with the name given by the parents.

The results of the first thematic focus, "Myself and my name", demonstrate that the relationship with one's own name is different according to one's culture of origin. Half of the Peruvian immigrants do not like their name of origin, while all the Chinese women are happy with their Chinese name. The ritual imposition of the name, characteristic of the culture of origin, seems to skew the result of the Chinese sample regardless of their residence in Madrid or in Prato. In fact, for reasons of linguistic transparency, Chinese names often represent the aspirations of the parents and they are often given to the child as a good omen (Liao 2011, p. 65). Therefore, consistently, none of the Chinese immigrant 
women have expressed disagreement with her name. This contrast brings consideration of the identity of given names from the category of "social use" (James[1890] 1994) or "interpersonal use" (Neisser 1988; Fierro 2013) to a more elaborate one of "cultural use" (Dörnyei and Ushioda 2009) that does not appear clearly in the studies on the name of immigrants.

As far as the first research question is concerned, i.e., whether there is a manifest relationship between the use of the immigrants' given name in the host country, the results suggest that the significant relationship is related to nationality rather than to the perspective of roots and place of origin. It is possible to observe a remarkable difference between the attitudes of the two groups (see Section 4.1). In fact, among the Peruvians, there is a general acceptance of the bad pronunciation or foreignization of the own name, which does, however, produce a negative attitude when the distortion implies a negative connotation. For the Chinese group, the adoption of a new Westernized or fictitious name implies a positive attitude because it signals their will to integrate into the host community.

In relation to the second research question concerning the name that immigrants receive in the host country (see Section 4.2), two phenomena are prevalent: the mispronunciation of the original name (the "Italianization" of the pronunciation for $56 \%$ of Peruvian names) and the use of Western "new" names (the Western baptism of all Chinese immigrants). These two categories are also present in previous research, although these studies examined the same phenomenon in other countries (Handri 2008; Costa-Scottini 2011). An intermediate category of given names-hypocoristic names or nicknames-which has been previously studied but only in relation to their native use in Spain and Italy (Portolés 1998), has been created in order to group phenomena that cannot be included in the two main categories of mispronunciation and Westernization. The results of previous qualitative analyses of the native use of nicknames have been confirmed by our quantitative analysis for immigrants. From a pragmatic point of view and given the spectrum of reactions it elicits-positive or negative depending on the reaction of each immigrant-hypocoristics might deserve to be investigated further by asking different questions in the interviews. The present research indicates that it is possible to observe hypocoristics within the framework of cultural stereotypes and the attitudes of host communities towards immigrants based on the effects they produce and the causes that generate them.

With regard to the reactions of immigrants upon hearing their own names as spoken by foreigners (third research question), the majority of informants whose names are pronounced correctly or who use fictitious names, manifested positive attitudes, while bad pronunciation tended to be the more irritating (see Table 3). The intermediate category of shortened names presents a diversified landscape, with a tendency to negative rather than positive reactions, which are not excluded, however. In some cases, it is possible that the interpretation of a nickname requires a linguistic competence that the immigrant does not have. Therefore, P39 does not feel annoyed if her employer, who knows a bit of Spanish, sometimes calls her "Cari" and sometimes "Caracol", without understanding that calling someone a snail has a different illocutive force in Italian (metaphorically in Italian, "very slow").

Just as has been demonstrated that the degree of the immigrant's competence in the second language has an impact when interpreting her host's discourse (P39), it is possible that the language chosen for the interview also has an impact on the results. In fact, Peruvian immigrants had more positive reactions when the interviews were in Italian and were more severe when the interviews were in Spanish. The results could be in line with the conclusions that were reached by other authors, taking into account, however, that our interviews were not conducted in the mother tongue (Li 1997; Liao 2011; Aksholakova 2014) or in languages other than Spanish or Italian (Costa-Scottini 2011; Stojanovic-Zezovic 2016; Schlote 2018). The results show that, from a linguistic point of view, "bad pronunciation" (Schlote 2018) is not the only phenomenon that should be studied and that a study of other phenomena such as nicknames or hypocoristics should be extended to host populations with non-Latin linguistic uses. On the other hand, from the methodological point of view, it would be hard to obtain more useful information, given the difficulty that would be entailed in conducting the interview in a bilingual format or in repeating the same questions after a long period of time. 
Although the results obtained from questions that are akin to those asked by Schlote (2018) confirm the existence of similarities in the response possibilities for the three thematic nodes, our two groups show different preferences and evaluations (see Figure 3). Specifically, Chinese immigrants made judgments and assessments about the use of their name from the perspective of "Of the name" and "Of the vision of himself", that is, guided by the categories "Meaning", "Property", "Unicity", or "Identity". Differently, Peruvian immigrants expressed evaluations guided by judgments based on the subcategory "To others" ("Mispronunciation or misspelling", "Omit or forget the name", "Intimidation", and "Used to point out his/her diversity") or the subcategory "Of immigrant" "Get angry" and "Dealing with bad pronunciations"). The difference in the choice of the arguments by the the two groups in the first two questions seems directly related to the emotional reaction and to immigrants' expectations about their future (Oyserman and Markus 1990). Unfortunately, the research on the immigrants' given names obtain results on multiethnic groups with up to 12 different nationalities (Stojanovic-Zezovic 2016; Schlote 2018) or of a single nationality (Lehiste 1975; Aksholakova 2014; Li 1997; Liao 2011). In order to obtain more solid results, it would be interesting for future research to consider at least three groups of immigrants of different nationalities.

The question about the possibility of stable residence in the host country demonstrates the same difference in behavior with respect to the social use of the name: $60 \%$ of Peruvian immigrants want to return to their country within ten years, while Chinese immigrants have come to stay. The phenomenon shows an almost dichotomous behavior, since it is not clear whether the remaining $40 \%$ who answer that they wish to stay in Italy for the next ten years are young and intend to stay only until retirement age. This representation of the possible selves, if we accept the proposals of Markus and Nurius (1986) and of Oyserman and Markus (1990) as a conceptual connection between cognition and motivation, could function as a strong incentive in the regulation of present behavior: imagining oneself back in one's own country within 10 years could diminish the desire to integrate into the host country and increase the impact of "microaggressions" (Kohli and Solórzano 2012). Clearly the perception of one's own name cannot be the cause of the lack of integration of a group of immigrant women, since this is a complex and multifactorial phenomenon (Handri 2008; Arai and Skogman-Thoursie 2009). It could be a symptom of a situation of marginalization and should influence the motivation to learn the language of the host country (Dörnyei and Ushioda 2009).

In conclusion, the results seem to indicate that, when the sound and meaning of one's own name used by the host community is related to family use and to the community of origin (as in the case of the new European proper names used daily in Chinese families), it gives rise to a favorable attitude that provokes identification and personal satisfaction with the new environment. By contrast, when the pronunciation of the proper name sounds foreign or the meaning is associated with a negative self-image or stereotype, an alteration of the self-image and a lack of identification may result, producing demotivation and personal dissatisfaction.

Author Contributions: Conceptualization, M.C.A. and I.B.; methodology, M.C.A. and I.B.; formal analysis, M.C.A.; writing — original draft preparation, M.C.A.; writing—review and editing, I.B.; supervision, M.C.A.

Funding: This article was written as part of the research project La población migrante de la comunidad de Madrid: estudio multidisciplinar y herramientas para la integración sociolingüística (The migrant population of the Madrid Region: a multidisciplinary study and tools for sociolinguistic integration) (IN.MIGRA2-CM) (ref. H2015/HUM3404), funded by the Madrid Region and co-funded by the European Social Fund.

Conflicts of Interest: The authors declare no conflict of interest.

\section{References}

Aksholakova, Asem. 2014. Given name as a clue symbol of identity. Procedia-Social and Behavioral Sciences 112: 465-71. [CrossRef]

Arai, Mahmood, and Peter Skogman-Thoursie. 2009. Renouncing personal names: An empirical examination of surname change and earnings. Journal of Labor Economics 27: 127-47. [CrossRef] 
Bertrand, Marianne, and Sendhil Mullainathan. 2004. Are Emily and Greg more employable than Lakisha and Jamal? A field experiment on labor market discrimination. American Economic Review 94: 991-1013. [CrossRef]

Bielen, Samantha, Peter Grajzl, and Wim Marneffe. 2018. Blame Based on One's Name? Extralegal Disparities. Criminal Conviction and Sentencing. Available online: https://ssrn.com/abstract $=3185444$ (accessed on 27 October 2018). [CrossRef]

Chen, Yi-An Jason. 2016. English name transition from Taiwan to the United States: A case study of Taiwanese international students. International Journal of Applied Linguistics and English Literature 5: 58-64.

Costa-Scottini, Lucas. 2011. O que o Nome nos Ensina? Padrões Sociais e Raciais de Nomes e Sobrenomes e Performance Escolar em São Paulo. Ph.D. dissertation, Universidade de São Paulo, São Paulo, Brazil, November. Available online: http://www.teses.usp.br/teses/disponiveis/12/12138/tde-30112011-192644/ publico (accessed on 20 October 2018).

de Pina-Cabral, Joao. 2015. Towards an Ecumenical Anthropology. In Who are 'We'?: Reimagining Alterity and Affinity in Anthropology. Edited by Liana Chua and Nayanika Mathur. New York: Berghahn Books, pp. 2017-232.

Descartes, René. 2004. Discurso del Método. Buenos Aires: Ediciones Colihue SRL. First published 1637.

Dörnyei, Zoltán, and Ema Ushioda, eds. 2009. The L2 motivational self system. In Motivation, Language Identity and the L2 Self. Bristol: Multilingual Matters, pp. 9-42.

Fermaglich, Kirsten. 2015. "Too Long, Too Foreign ... Too Jewish": Jews, Name Changing, and Family Mobility in New York City, 1917-1942. Journal of American Ethnic History 34: 34-57. [CrossRef]

Fierro, Catriel. 2013. Principios: la relevancia de William James en la enseñanza de la historia de la psicología. Eureka en Línea 10: 96-104.

Handri, N. H. 2008. La Identidad Mutante. La Construcción de la Identidad en los hijos de Inmigrantes. Documentación Social 151: 35-48.

INE. 2017. Nombres y Apellidos más Frecuentes. Madrid: Instituto Nacional de Estadística.

ISTAT. 2017. Natalità e fecondità della popolazione residente. Statistica Report. November 27. Available online: https://www.istat.it/it/files/2017/11/Report-Nascite-e-fecondità.pdf (accessed on 19 September 2018).

James, William. 1994. Principios de Psicología. México: Fondo de Cultura Económica. First published 1890.

Kim, Harris Hyun-Soo. 2017. In-Group and Out-Group Networks, Informal Social Activities, and Electoral Participation Among Immigrants in South Korea. Journal of International Migration and Integration 18: 1123-48. [CrossRef]

Kohli, Rita, and Daniel G. Solórzano. 2012. Teachers, please learn our names!: Racial microagressions and the K-12 classroom. Race Ethnicity and Education 15: 441-62. [CrossRef]

Lehiste, Ilse. 1975. The attitudes of bilinguals toward their Personal Names. American Speech 50: 30-35. [CrossRef]

Li, David. 1997. Borrowed identity: Signaling involvement with a Western name. Journal of Pragmatics 28: 489-513. [CrossRef]

Liao, Wenting. 2011. Defining and Negotiating Identity and Belonging: Ethnic Name Change and Maintenance among First-Generation Chinese Immigrants. Ph.D. dissertation, University of British Columbia, Vancouver, BC, Canada, October.

Locke, John. 1956. Ensayo Sobre el Entendimiento Humano. Mexico City: Fondo de Cultura Económica. First published 1690 .

Markus, Hazel, and Paula Nurius. 1986. Possible selves. American Psychologist 41: 954-69. [CrossRef]

Neisser, Ulric. 1988. Five kinds of self-knowledge. Philosophical Psychology 1: 35-59. [CrossRef]

Oyserman, Daphna, and Hazel Rose Markus. 1990. Possible selves and delinquency. Journal of Personality and Social Psichology 59: 112-25. [CrossRef]

Pennesi, Karen. 2016. "They can learn to say my name": Redistributing Responsibility for Integrating Immigrants to Canada. Anthropologica 58: 46-59. [CrossRef]

Portolés, J. 1998. Nombres, adjetivos y xenofobia. Mugak 2: 17-21.

Schlote, Nadja. 2018. "Too Hard to Pronounce"-Examining Immigration Ideologies in the Treatment of Newcomer Youths' Names. Ph.D. dissertation, University of Western Ontario, London, ON, Canada, April. Available online: https://ir.lib.uwo.ca/cgi/viewcontent.cgi?article=7324\&context=etd (accessed on 10 October 2018). 
Stojanovic-Zezovic, Daniel. 2016. Ett Förnamn är Aldrig Betydelselöst-Icke Svenskklingande Förnamns Betydelse för Individers Upplevelser av Personlig Identitet och Grupptillhörighet. Master's thesis, Lund University, Lund, Sweden. Available online: https://lup.lub.lu.se/student-papers/search/publication/8878986 (accessed on 20 October 2018).

Walkowiak, Justyna. 2016. Names as covert affirmation of identity: On some propagandistic urbanonyms of the post-war western borderlands in Poland. Acta Onomastica 60: 138-49.

(c) BY

(C) 2019 by the authors. Licensee MDPI, Basel, Switzerland. This article is an open access article distributed under the terms and conditions of the Creative Commons Attribution (CC BY) license (http://creativecommons.org/licenses/by/4.0/). 

Article

\title{
Translingual Practices and Reconstruction of Identities in Maghrebi Students in Galicia
}

\author{
Adil Moustaoui Srhir ${ }^{1, *}$, Gabriela Prego Vázquez ${ }^{2, *}$ and Luz Zas Varela ${ }^{2, *}$ \\ 1 Department of Linguistics and Oriental Studies, Universidad Complutense de Madrid, 28040 Madrid, Spain \\ 2 Departmento de Lingua e Literatura Españolas, Teoría da Literatura e Linguística Xeral, \\ Universidade de Santiago de Compostela, 15782 Santiago de Compostela, Spain \\ * Correspondence: adil.moustaoui@pdi.ucm.es (A.M.S.); gabriela.prego@usc.es (G.P.V.); \\ luz.zas@usc.es (L.Z.V.)
}

Received: 8 May 2019; Accepted: 10 August 2019; Published: 15 August 2019

\begin{abstract}
In this article, we explore the emergence of a new translingual repertoire among young adolescents of Moroccan and Algerian origin in Galicia and the role it plays in reconstructing the transnational identity of young people within the Maghrebi diaspora. The data include a multimodal corpus with spoken and written interactions, collected as part of a classroom action research project, in which each student reconstructed their family and school language repertoire, as well as a WhatsApp group chat set up with the same young people. The results of our analysis reveal how the intercrossing of parental and adolescent agency plays a crucial role in dealing with the new multilingual translingual repertoire. The findings also indicate how this repertoire is deeply rooted in Moroccan Arabic as the family language and the incorporation of local languages, namely Spanish and Galician, and relies heavily on translingual multimodal practices, associated with transnational trajectories and the local schooling process of these young people.
\end{abstract}

Keywords: translingual multimodal practices; multilingualism; identities; Maghrebi students in Galicia and diaspora

\section{Introduction}

In this article, we explore how a new translingual repertoire has emerged among young adolescents of Moroccan and Algerian origin in Galicia and the role of the new communicative repertoire in addressing issues of identity (Moustaoui Srhir 2016, 2019a; Pereiro et al. 2017). The research was conducted in Arteixo, a rurban municipality located on the outskirts of the city of A Coruña (Galicia, Spain). Arteixo has traditionally been a bilingual Spanish/Galician community ${ }^{1}$. However, over the last few decades, migratory trends have led to the emergence of a new multilingual and multicultural ecology (Prego Vázquez and Varela 2015, 2018, 2019; Zas Varela and Prego Vázquez 2018). In the 1960s, the municipality's population was less than 11,000 inhabitants, and there was a strong outbound migratory flow abroad. This contrasts sharply with the 2018 data for the municipality released by the Galician Statistics Institute (IGE, based on its Spanish initials), which revealed a population of 31,917, $5 \%$ of whom were of foreign origin. It must be remembered that this percentage does not include those who have been granted Spanish citizenship, foreigners not registered on the municipal census, or, in the case of adolescents, those that were born in Galicia but are of foreign descent.

This new multilingual ecology, positioned on the limits of superdiversity (Vertovec 2007; Mutsaers and Swanenber 2012; Wang et al. 2014), provides a space shared by speakers of varieties of Galician

1 Spanish and Galician are co-official languages in Galicia. 
and Spanish (Galician, Venezuelan, Uruguayan, Argentinean, or Colombian Spanish), Moroccan and Algerian Arabic, Amazigh, French, Wolof, Russian, Romanian, and Portuguese, amongst other languages. These languages and varieties form symbolic frames of self-identification and self-affirmation (Bourdieu 1977) and are of particular relevance amongst young people of Maghrebi origin, some of whom, although they were born in Galicia, comprise a strong allochthonous group within the community and the educational environment, both in terms of their number and social visibility.

Students of Maghrebi origin account for around $0.8 \%$ of the total school community. The data obtained from the sociolinguistic survey that we conducted during the 2018-2019 school year ${ }^{2}$ (Rodríguez Neira et al. 2019) reveal that 78 pupils aged between 12 and 17 years of age claim to have a knowledge of Arabic. Moreover, 52 of these students indicated that they have an intermediate or advanced mastery of Moroccan Arabic, compared with 26 who believed that they have a low level of competency. A total of 46 of 78 believed that they have an intermediate or advanced mastery of Modern Standard Arabic, and 32 believed they have a low level of competency. This contrasts with other varieties of Arabic and Amazigh, for which the language skills of the respondents are lower: 18 respondents claimed to have an intermediate/advanced knowledge of other Arabic varieties-a number that drops to just 13 in the case of the Amazigh language.

Within this educational context, the Maghrebi group can be considered to form a community of practice (Wenger 2001), in which its members forge a network of dense, multiple social relationships (Milroy 1980), in which young people of Moroccan origin exert a strong leadership. In this sense, the Moroccans not only outnumber the Algerians, but the group has also adopted the Moroccan Arabic variety used in the central-southern region of Tadla-Azilal for their group conversations, as we observed in our ethnographic research project that targets the educational community of this municipality and that has been ongoing since 2016 .

This research, which falls within the frame of critical ethnographic sociolinguistics, focuses on this community of practice made up of young students of Maghrebi origin in Arteixo (Galicia, Spain) and aims to provide the answer to the following research questions based on a corpus of multi-sited data:

What are the translingual resources used by this community of practice, and to what degree are they relevant to identity issues?

What are the linguistic ideologies underpinning these practices, and how do they affect various forms of language resistance and maintenance?

What are the underlying processes involved in addressing this new translingual repertoire?

\section{Methodological Considerations ${ }^{3}$}

This research was conducted within a multidisciplinary frame, combining critical ethnographic sociolinguistics (Fairclough 1990, 1999; Heller 2002; Martín Rojo 2010), interactional sociolinguistics (Gumperz 1982), and an educational approach called critical language awareness (García 2008; Hawkins 1984, 1992). The methodology employed included frame analysis (Goffman 1981). The concepts of translanguaging (García 2009) and translanguaging moments (Wei 2018) were also included in order to address hybrid practices and the emergence of this new multilingual and translingual repertoire (Corona et al. 2013; García et al. 2018; Llompart 2016; Rampton 1995). Bourdieu's concepts of agency and habitus (Bourdieu 1977) are also pertinent to the interpretation of the results obtained.

The data include a multimodal corpus with spoken and written interactions, collected as part of a classroom action research project, in which each student was invited to reflect on their family and school language repertoire, based on the personal reconstruction of their language biography

2 The sociolinguistic survey universe included all pupils enrolled in the municipality's secondary and baccalaureate schools. We are currently analyzing the data collected.

3 All subjects gave their informed consent for inclusion before they participated in the study. 
as well as on a WhatsApp group chat we set up with the same young people. The multi-sited and multimodal ethnographic collection of data allowed for the creation of a corpus containing data from various contexts, which in turn was intended to reconstruct the emic vision of the social actors in light of these new multilingual realities.

Multimodality is of particular relevance in our study due to adolescents' continued use of varying repertoires and semiotic systems in their interactions (Kress 2010). As we will show, they deploy a mix of simplified script, various alphabets, and semiotic systems. WhatsApp is a new, delocalized, multimodal space positioned on the boundary between orality and literacy in which translingual practices emerge spontaneously. This multi-sited corpus allows us not only to contrast meta-communicative practices in formal and informal contexts but also to observe the divergence between metalinguistic awareness and the practices actually employed. The following types of data complement the corpus:

1. Discussion groups, based on the Jigsaw technique (Aronson 1978), in which language trajectories are constructed in a group format;

2. The reconstruction of family language biographies based on an activity known as 'the Language Tree', in which participates record the languages of their ancestors in a genealogical tree format, together with the languages used in their family environment, both in Galicia and their country of origin;

3. Longitudinal interviews;

4. A discussion group set up via a WhatsApp chat (Dud@sxlingu@s), providing the respondents with a forum for reflection on the various languages included in their family trajectories;

5. A quantitative sociolinguistic survey (Rodríguez Neira et al. 2019).

The data selected for the qualitative analysis of this article focus on students of Maghrebi origin: 28 pupils ( 18 males and 10 females) aged between 12 and 17 years of age. The activities were carried out within the framework of the Arabic classes developed in the program of this school, entitled "Arabic Language and Moroccan Culture". Three researchers and the Arabic teacher also participated in the activities. One researcher and the Arabic teacher are Moroccan and male. The other two researchers are women and Spanish. None of the three researchers belongs to the local Maghrebi community. The three researchers hold three different positions with respect to this community. The Moroccan researcher connects with them because of their culture of origin but lives in Madrid (far from Arteixo). One of the researchers lives in the same village as the pupils, and she also has a life trajectory linked to migration. The third researcher lives in another locality in Galicia and has had different types of experiences (research and teaching) with migrants of Maghrebi origin from other networks in Galicia.

\section{Results of Our Analysis}

Our analysis shows that the translingual repertoire involved in addressing the identity of young people within the Maghrebi diaspora is the result of parental and adolescent agency intercrossing within the community of practice forged by these young students. In this sense, we observed three key agentive processes (Bourdieu 1977) that intercrossed to form a transnational (Guarnizo 1997) habitus (Bourdieu 1977): (a) parental agency in maintaining the language of origin; (b) adolescent agency in handling family multilingualism; and (c) adolescent agency in handling new forms of language resistance within the context of digital discourse.

\subsection{Parental Agency in Maintaining the Family Language}

Parental agency plays a crucial role in transmitting and maintaining languages of origin. The language socialization of young Maghrebis takes place mainly in the language varieties of origin within the family context. At home, they watch television programs broadcast from Morocco or other Arab countries and use social media to maintain an ongoing flow of communication with friends and relatives in their places of origin, where, in turn, they visit practically every summer with their parents. 
The families also encourage activities aimed at the acquisition of Arabic language skills and cultural knowledge. Families pass on their religious practices and attend the local mosque, which acts not only as a place of worship but also as a space in which to learn and reproduce the language and cultural practices of their countries of origin. The municipality has two Maghrebi cultural centers that organize religious activities and courses in Modern Standard Arabic, which are attended by the majority of children and young people.

Families also enroll their children in the program entitled "Arabic Language and Moroccan Culture" (PLACM, based on its Spanish initials). Set up following the signing of a cultural cooperation agreement between the governments of Spain and Morocco, the principal aim of this program is to teach Arabic and Moroccan culture to Moroccan students enrolled in junior and secondary schools in Spain, although it is also open to non-Moroccan pupils and teaching staff. A total of 47 pupils at the school were enrolled in this program during the 2018-2019 school year; the majority were of Moroccan origin, although the program was also utilized by Algerian pupils. No autochthonous students and teachers or those of any other nationalities signed up. Practically all the Moroccan and Algerian pupils at the school take part in this activity.

Parental agency is therefore of particular relevance in ensuring the lingual vitality of the languages of origin amongst young Maghrebis and guaranteeing sociolinguistic cohesion within their families and language communities (Moustaoui Srhir 2019a, 2019b). The following fragment is an example of the parental agency process and highlights the importance of the family context as the hub in which this transnational habitus unfolds (Bourdieu 1977).

Example 1. ¿Qué lengua o quélenguas son las más importantes?

1. INV: ¿Qué lengua o qué lenguas de las que habéis señalado cada uno en su árbol es la más importante?

2. INV: Para vosotros.

3. (Todos los alumnos contestan a la vez y no se entiende)

4. INV: No vamos a hablar así, que cada uno diga una idea ivale?

5. (0.72)

6. INV: Vamos a empezar por aquí.

7. SR: Eh, árabe

8. INV: XXX

9. (0.52)

10. INV: ¿Por qué $x x x$ ?

11. SR: Porque es la que más se usa en Marruecos.

12. CG: $x x x x$.

13. INV: Estamos hablando no solo de Marruecos, sino de Marruecos, España, la familia, el barrio, la escuela, todo.

14. (0.20)

15. INV: Todo vuestro entorno.

16. (Niño 3 asienta con la cabeza)

17. INV: ¿Vale?

18. (2.03)

19. INV: ¿Vale? árabe.

20. (0.65)

21. SR: Eh, ¿cómo, qué de qué?

22. INV: ¿Por qué es la más importante para ti?

23. SR: Porque es la que yo uso y considero más importante.

24. INV2: ¿Tú la usas?

25. (0.42) 
26. SR: Sí, $x x x x$.

27. (Todos los alumnos se ríen y no se escucha lo que dice el alumno que está interviniendo)

28. INV: $x x x x$

29. INV: ¿Sí?

30. (1.33)

31. INV: árabe ¿con la familia, no?

32. SR: Sí, con la familia, pero $x x x x$.

33. INV: Vale, ¿XX?

34. SM: Dariya.

35. INV: ¿Dariya también?

36. (1.21)

37. INV: ¿Por qué?

38. $(0.60)$

39. SM: Porque es la que nos enseñan nuestros padres y nos la siguen enseñando.

40. (0.42)

41. SM: Para

42. INV: Uhu.

43. (0.66)

44. INV: Y ¿pensáis que la vais a transmitir a vuestros hijos también?

45. SM: Sí.

46. INV: ¿La tenéis que aprender porque solamente porque la hablas todos los días o porque es algo muy importante y tenéis que mantenerla y luego transmitirla...?

47. (0.31)

48. INV: ¿No?

49. (0.38)

50. INV: ¿Por qué?

51. $(0.26)$

52. INV: árabe ¿qué pensáis los demás?

53. CG: Dos.

54. CR árabe.

55. INV: árabe.

56. (0.53)

57. CG: Yo dos el español y el, y el, el árabe.

58. CG: Dariya.

59. INV: Dariya.
a. $\quad(0.49)$

60. INV: Son muy importantes, ¿por qué?

61. CG: ¿Por qué? Porque yo las uso las dos para hablar en casa con los amigos, todo.

b. $\quad(0.25)$

62. CG: La familia, el cole.

63. (0.36)

64. CG: Es que, es que es la que más uso con todo.

65. INV2: ¿El gallego no $x x x x$ ?

66. CG: A ver.

67. (0.82) 
68. CG: En español entra el gallego, pero yo no hablo gallego solo en clase de gallego.

69. (0.75)

70. CG: Sabes, yo yo como personalmente yo el gallego no lo uso.

71. (0.85)

72. (N5 gesticula con las manos y encoge los hombros)

73. CG: ¿Sabes?

74. (2.30)

75. INV: O sea, en términos de uso crees que el español y el dariya son los más importantes porque los usas más.

76. CG: Para mí, sí.

77. INV: Para ti.

78. (0.19)

79. INV: Si, si, para ti $x \times x$.

80. (1.30)

80. CG: Parati.

82. (N5 le pone la mano en el hombro a su compañero de al lado mientras lo mira)

83. INV: ¿Quién, quién quiere hablar, opinar?

84. CR: Yo.

85. (0.28)

86. (N5 señala a N6 con el dedo)

87. CR: Yo.

88. INV: $x x x x$.

89. CR Yo, dariya.

90. INV: ¿También?

91. CR: Sí.

92. (0.57)

93. CR: Porque, porque yo soy de una religión que está en ese idioma.

94. (0.39)

95. INV: ¿La religión está en este idioma?

96. (0.66)

97. INV: ¿Y crees que por ser musulmán tienes que hablar esta lengua?

98. (0.35)

99. CR: Hombre, sí.

[Which language or languages are the most important?

1. REA: Which language or languages that you marked on your individual trees are the most important?

2. REA: To you.

3. (All the pupils answer at the same time, and therefore, their responses are unintelligible)

4. REA: Let us not do it that way; each person should put forward their idea, OK?

5. (0.72)

6. REA: Let us start with you.

7. SR: Er, Arabic

8. REA: XXX

9. (0.52)

10. REA: Why $x x x$ ?

11. SR: Because it is the one spoken most in Morocco.

12. CG: $x x x x$. 
13. REA: We are not just talking about Morocco, but Morocco, Spain, the family, the neighborhood, school, everywhere.

14. (0.20)

15. REA: Your environment as a whole.

16. (Child 3 nods)

17. REA: OK?

18. (2.03)

19. REA: OK? Arabic.

20. (0.65)

21. SR: Eh, like, like what?

22. REA: Why is it the most important one for you?

23. SR: Because it is the one I speak, and I consider it to be the most important.

24. REA2: So, you speak it?

25. (0.42)

26. SR: Yes, $x x x x$.

27. (All the pupils laugh, and it is impossible to make out what the pupil who is speaking is saying)

28. REA: $x x x x$

29. REA: So?

30. (1.33)

31. REA: Arabic, with the family, right?

32. SR: Yes, with the family, but $x \times x x$.

33. REA: $O K$, ¿XX?

34. SM: Dariya.

35. REA: Dariya as well?

36. (1.21)

37. REA: Why?

38. (0.60)

39. SM: Because that is the one our parents taught us, and they still do.

40. (0.42)

41. SM: For

42. REA: Uh-huh.

43. (0.66)

44. REA: And do you think you will pass it on to your kids as well?

45. SM: Yes.

46. REA: Do you have to learn it just because you speak it every day or because it is important and something you should maintain and then pass on ...?

47. (0.31)

48. REA: Is that not the case?

49. (0.38)

50. REA: Why?

51. (0.26)

52. REA: Arabic. What do the rest of you think?

53. CG: Two.

54. CR Arabic.

55. REA: Arabic.

56. (0.53)

57. CG: In my case two: Spanish and, and Arabic. 
58. CG: Dariya.

59. REA: Dariya.
a.
(0.49)

60. REA: Why are they so important?

61. CG: Why? Because I speak both languages at home, with my friends, everyone.
$b$.

62. CG: Family, school.

63. (0.36)

64. CG: And it is like the one I use most, for everything.

65. REA2: Don't you speak Galician $x \times x x$ ?

66. CG: Well.

67. (0.82)

68. CG: Galician and Spanish go together, but I do not just speak Galician in Galician language lessons.

69. (0.75)

70. CG: You know, personally, I, I do not speak Galician.

71. (0.85)

72. (Child 5 gesticulates and shrugs his shoulders)

73. CG: You know what I mean?

74. (2.30)

75 REA: In other words, in terms of usage, you think that Spanish and Dariya are more important because you use them more.

76. CG: In my case, that is true.

77. REA: In your case.

78. (0.19)

79. REA: Yes, yes, in your case $x x x$.

80. (1.30)

81. CG: In your case.

82. (N5 places his hand on the shoulder of the classmate sitting next to him and turns to look at him)

83. REA: So, who would like to say something and give their opinion?

84. CR: Me.

85. (0.28)

86. (Child 5 points to Child 6)

87. CR: Me

88. REA: $x x x x$.

89. CR In my case, Dariya.

90. REA: So, you agree?

91. CR: Yes.

92. (0.57)

93. CR: Because that is the language of my religion.

94. (0.39)

95. REA: Religion is in that language?

96. (0.66)

97. REA: So, you think that because you are a Muslim, you have to speak that language?

98. (0.35)

99. CR: Basically, yes.] 
This episode is a multi-party interaction (Lerner 1996) in which the researcher uses glances, gestures, and references to a second party to single out the various respondents or encourage self-selection. The respondents forge an informal interactional frame (Goffman 1981), as shown in the jocular byplays (Goffman 1981) reflected in lines 27,82 , and 86 . The researcher initiates the first part with an adjacency pair (lines 1-2) by posing the following question: "Which language or languages are the most important?" The various respondents complete the pair with references to Dariya/Moroccan Arabic $^{4}$ (lines 7, 19, 23, 26, 31, 34, 35, 52, 54, 55, 57, 58, and 59), amongst others. All the pupils except one, CG, claim that for them, Dariya/Moroccan Arabic is the most important language. It is worth noting that CG, the only boy who considers Spanish to be equally as important as Dariya, comes from a mixed family comprising a Galician mother and a Moroccan father-a situation that is still relatively rare in the community under study. In contrast, Galician, the language of Galicia, does not hold a position of relevance amongst the children's preferences.

The responses provided by these students reflect a leaning towards their culture of origin from the anchor point of the "here and now in Galicia". Together, they construct a chronotope (Bakhtin 1989) that neutralizes the sense of opposition between here (Galicia) and there (Morocco). In this sense, Dariya is important to SR, because it is the language spoken in Morocco (line 9), and it is also the language he uses most in Galicia (line 18) with his family and friends. Dariya indexicalizes a key 'delocalized' and transnational chronotope that positions these young people in a territorialized space between Galicia and Morocco, which they use to construct a new 'territory' based on their identity and translingual practices.

When the researcher asks for reasons that justify this response (lines 10, 22, and 37), the respondents jointly evoke key aspects of their identity: Morocco, their place of origin (lines 11 and 13); the frequent use of this language when interacting with friends and relatives (lines 23 and 29); their upbringing and transmission from family members (lines 39, 44, and 45); their own role in transmitting the language (lines 44 and 45); and the religion of Islam and its association with the language (lines 93-95; "Because that's the language of my religion"). In this sense, language-Dariya/Moroccan Arabic; place of origin-Morocco; and the sense of Muslimness that is often associated with the Arabic language act as creatively effective indexical elements (Silverstein 1976), intended to reconstruct key aspects of the sense of identity of being a young Moroccan within the diaspora.

Essentially, the family provides a space for transnational habitus, encouraged by parental agency, which stems from the creation of a delocalized space that connects here (Galicia) and there (Morocco) through a series of social, linguistic, religious, economic, and political practices (Giddens 1991; Guarnizo 1997; Ostergaard Nielsen 2003; Vertovec 2007). Factors related to religion, cultural heritage, and socio-communicative elements, mediated through parental agency, forge positive ideologies associated with Arabic, and Dariya in particular, due to its mother tongue status. Such ideologies are favorable for the capitalization of the languages of origin in the diaspora and promote their transmission and maintenance within the family context.

\subsection{Adolescent Agency in Handling Family Multilingualism}

Our analysis of both the 'Language Tree' activity and the 'sociolinguistic survey' has shown that varieties of Galician and Spanish are also included in the communicative repertoire of these young people. Socialization within the context of school and other spaces outside their family environment is crucial to their acquisition of these two languages. School is of particular importance in that it provides a regular meeting point for both autochthonous and allochthonous groups. One of the results of this situation is that the young Moroccans introduce this new multilingual repertoire into the family space, and consequently, they change the home sociolinguistic regime and its interactional order. Adolescents are essential in articulating families' multilingual profiles in the sense that their agency is crucial for

4 Dariya is the term commonly used to refer to Moroccan and Algerian Arabic. 
the introduction of new linguistic varieties at home and is involved in competition with the parental agency. Our analysis has revealed that Dariya/Spanish/Galician/French translingual practices are fairly common among these young people. Indeed, and as we will illustrate in Section 3.3, they admit to using what they refer to as "el mezclado" (the mix) - a kind of Galician Spanish translanguaging of Galician/Dariya/French.

The following two examples, taken from classroom activities intended to reconstruct the language biography, depict adolescent agency in family multilingualism in the case of two families. Example 2 corresponds to a family in which both parents are of Moroccan origin, who moved to Galicia with their children several years ago. In contrast, Example 3 illustrates a mixed family with a Galician mother and a Moroccan father-a family unit that is still relatively uncommon in the community.

Example 2. Multilingualism in a 1.5 generation family:

1. INV: A VER FTM (Voz más alta para propiciar el turno de participación)

2. FTM: Con mis padres hablo en árabe

3. INV: ¿En árabe marroquí?

4. FTM: $S \hat{i}$

5. (..)

6. FTM: Con con mis hermanos en español

7. (..)

8. INV: ¿Siempre en español con tus hermanos?

9. (...)

10. FTM: No siempre, a veces

11. MART: $[x x x]$

12. FTM: Con mis vecinos en gallego

13. (...)

14. FTM: ¡Ei! [Pausa] Con los amigos, en castellano

1. [REA: SO, LET US SEE FTM (Speaks louder to encourage turn taking)

2. FTM: I speak to my parents in Arabic.

3. REA: In Moroccan Arabic?

4. FTM: Yes

5. (...)

6. FTM: And I speak to my brothers and sisters in Spanish.

7. (..)

8. REA: Do you always speak to your brothers and sisters in Spanish?

9. (...)

10. FTM: Not always, sometimes.

11. MART: [ $x x x$

12. FTM: I speak Galician to the neighbors.

13. (..)

14. FTM: Hey! [Pause] And Spanish to my mates.]

Example 2 features a girl, FTM, a member of the 1.5 generation. Even though neither she nor her siblings were born in Galicia, both Spanish and Galician form part of their communicative repertoire. FTM reconstructs her language uses through her language biography: Moroccan Arabic with her parents, (occasionally) Spanish with her siblings and friends, and even Galician with her neighbors.

In contrast, Example 3 reveals that for CG, both Spanish and Dariya are transmission languages in the family context: 
Example 3. Multilingualism in a 1.5 generation family:

1. CG: Eh os voy a decir esto. Mi abuelo materno habla español y gallego.

2. CG: Mi abuela materna habla español y gallego. Mi abuela paterna habla árabe y dariya.

3. CG: Mi abuelo paterno habla árabe, francés y dariya. Mi madre habla español y gallego, y marroquí ( ... ) ah no mucho a ver.

4. CG: Mi padre español, gallego, francés, dariya, chleuh y tamazight.

5. CG:Y yo hablo español, gallego, francés, inglés, árabe y chleuh..poco.

6. CG:Y mis hermanos español la mayoría, árabe, francés, inglés y el gallego.

1. [CG: Hey, let me say this. My maternal grandfather speaks Spanish and Galician.

2. CG: My maternal grandmother speaks Spanish and Galician. My paternal grandmother speaks Arabic and Dariya. My paternal grandfather speaks Arabic, French, and Dariya.

3. CG: My mother speaks Spanish and Galician, and Morocco (... ) but only a bit, you know.

4. CG: My father, Spanish, Galician, French, Dariya, Shelha, and Tashelhyt.

5. CG: As for me, I can speak Spanish, Galician, French, English, Arabic, and a bit of Shelha.

6. CG: And my brothers and sisters Spanish, most of them, Arabic, French, English, and Galician.]

\subsection{Adolescent Agency in Handling New Forms of Language Resistance in Digital Discourse}

Social media use plays a key role in young people's interactional habits. According to the Spanish General Media Study (EGM, based on its Spanish initials) for the period between April 2018 and March 2019 (AIMC 2019), instant messaging, mainly WhatsApp, was a regular form of communication amongst adolescents. Digital conversations are playing an increasingly relevant role in their network of relationships and have therefore become a major agent of socialization in the contemporary world. Technologies have modified habits, and young people today maintain delocalized online relationships regardless of their place of residence. These circumstances are of particular importance in the case of adolescents that maintain a network of relationships in their places of origin, which, as we shall show, provides an insight into new forms of resistance in which multimodal creativity plays an essential role.

As stated above, our ethnographic research included a discussion group in which the respondents reflected on the various languages included in their family trajectories. One of the issues discussed in this group was the way the respondents write when using the WhatsApp chat (Dud@sxlingu@s) we activated in order to share metalinguistic reflections on the respondents' repertoires. Example 4 shows how they applied Arabizi (Allehaiby 2013), the digital encoding of Arabic using the Latin alphabet, to their written digital practices.

Example 4. Digital script:

1. Inv: ¿Cuándo escribís dariya en el chat con alfabeto latino?

2. ¿cómo lo hacéis de izquierda a derecha o de derecha a izquierda?

3. Ou: NORMAL

4. Inv: ¿Qué es normal?

5. (Se inicia una discusión sobre la dirección en la que escriben. Acompañan con gestos [tienen que pensarlo)

6. Fd: Cuando escribimos en alfabeto árabe de derecha a izquierda y en dariya en el chat

7. con alfabeto latino y números de izquierda a derecha.

8. In: ¿Quién os enseñó a escribir así?, ¿aprendistéis aquí?

9. Ou, Mr, Fd [al mismo tiempo] Nos enseñaron en Marruecos a usar el alfabeto latino

10. con los números

11. (...)

12. MR: Por ejemplo yo tuve que aprender los números en el teclado francés (muestran la pantalla del teléfono que reproducimos en la figura 1) 
13. y además lo que significaba por ejemplo: co que es ça va

14. In: ¿Hace tres años en Marruecos utilizabas WhatsApp?

15. Ou: Sí, sí y allí ya cambió

16. In: ¿Lo usáis igual que en Marruecos?

17. Al mismo tiempo varias: Sí, no $x x x$ (Dudan)

18. Inv: ¿Estáis en redes con chicos y chicas de Marruecos y otros lugares de Europa?

19. Ou, Mr: Sí sí, de diferentes lugares

1. [Rea: When you use the Latin alphabet to write in Dariya on the chat?

2. How do you do it? From left to right or from right to left?

3. Ou: NORMAL

4. Rea: What does normal mean?

5. (A discussion starts up regarding the direction in which they write. This is accompanied by gestures, and they have to visualize it)

6. Fd: When we use the Arabic alphabet from right to left and from left to right when we

7. use Dariya in the Latin alphabet on the chat.

8. Rea: Who taught you how to write like that? Did you learn that here?

9. $\mathrm{Ou}, \mathrm{Mr}, \mathrm{Fd}$ [all at the same time]: We learned to use the Latin alphabet with numbers

10. in Morocco

11. (...)

12. Mr: For instance, I had to learn how to use numbers with the French keyboard [they show the screen of the phone that we reproduce in Figure 1] as well as what they meant, I mean like 'cv' is ça va.

13. Rea: Did you use WhatsApp in Morocco three years ago?

14. $\mathrm{Ou}, \mathrm{Mr}, \mathrm{Fd}$ : Yes, yes, it had already changed there

15. Rea: Do you use it in the same way as in Morocco?

16. Several members speak at the same time: Yes, No $x x x$ (They are unsure)

17. Rea: Are you in contact via social media with young people from Morocco and other parts of Europe?

18. Ou, Mr: Yes, yes, from different places]

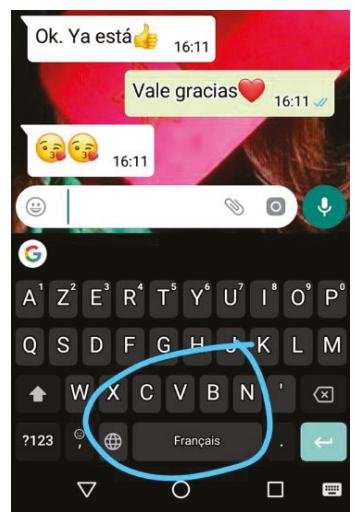

Figure 1. Digital Script.

It is therefore evident that their network of relationships enables them to introduce multimodal resources into their digital practices that provide identity marks for their group. They use French and Arabizi but also include the new languages acquired in Galicia. Arabizi is used extensively as an 
alternative for Arabic script in digital technology contexts and social media spaces. This is attributable to the fact that Arabic script lacks the necessary technological tools and online resources. The solution is to use the Latin alphabet but include the change of writing direction and the numbers as an alternative to certain graphemes (Allehaiby 2013). Figure 1 shows the extent to which these resources are used in digital communication.

Various authors have addressed the question of the multimodal features of this type of discourse. One of the key aspects is the inclusion of script, orality, and other semiotic resources (Alcántara 2014; Mancera 2016; Mancera and Pano 2013; Martín Gascueña 2016; Vázquez-Cano et al. 2015). Figure 1 shows that the conversation comprising this brief interaction took place in Spanish, interspersed by emoticons, although the French keyboard was used, together with the use of numbers due to the need to adapt to the Latin script when using Arabic.

We will now consider two examples taken from the WhatsApp chat referred to above. The Dud@sxlingu@s group comprised two researchers and eight adolescents, six of whom belong to the 1.5 generation and two who had moved to Arteixo (Galicia) about two years ago. The respondents' languages were as follows: Moroccan Arabic, Modern Standard Arabic, French, Spanish, and Galician. As Examples 5 and 6 reveal, the adolescents constantly interacted in several languages and semiotic systems. They mixed various types of simplified scripts, alphabets, and icons and employed translation and self-correction tools.

One of the most striking aspects was the construction of narratives that identify the profiles of each participating adolescent. Figures 2 and 3 include some of these young people's profiles. With one exception, they all featured some form of reference to Morocco: either a flag, phrase, or, in the case of the girls, a semiotic element associated with their traditional clothing. As in the previous sections, these communicative practices were part of the co-construction of the deterritorialized transnational space in which these young people position themselves:

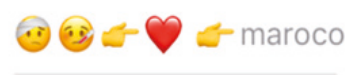

Figure 2. Example 5.

\section{DimaMaroc}

Figure 3. Example 6.

Figure 3 (translation): The text in Moroccan Arabic and French "DimaMaroc" translates to "Always Morocco".

The examples provided in Figures 4 and 5 show the role of hybrid practices in constructing the delocalized spaces that constitute translanguaging spaces (Wei 2011). As Wei (Wei 2011, p. 1223) explains,

"[T]ranslanguaging space is particularly relevant to multilinguals not only because of their capacity to use multiple linguistic resources to form and transform their own lives, but also because the space they create through their multilingual practices, or translanguaging, has its own transformative power informal. It is as space where the process of what Bhabha (1994) calls "cultural translation" between traditions takes place; it is not a space where different identities, values and practices simply co-exist, but combine together to generate new identities, values and practices": 


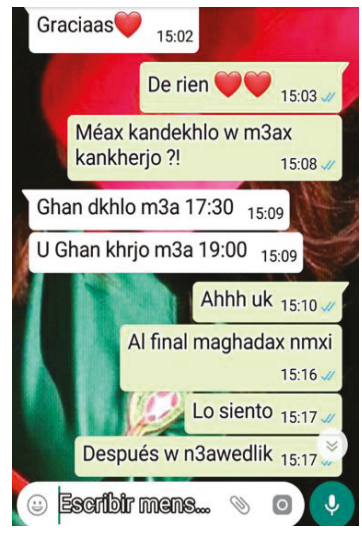

Figure 4. Example 7.

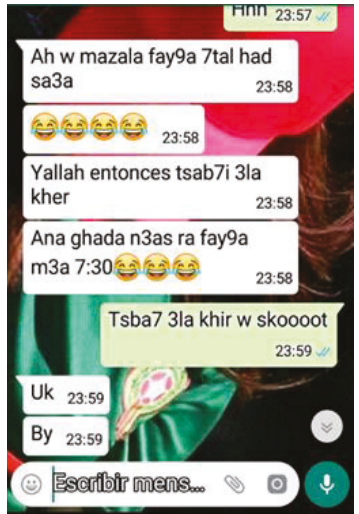

Figure 5. Example 8.

Figure 4 (translation): WhatsApp chat

Thanks

Not at all!

What time do we start and finish?

We start at 17:30

We finish 19:00

Ah. OK.

I'm not going in the end

Sorry about that

I tell you later

Figure 5 (translation): WhatsApp chat.

Ah, so you're still awake this late.

Sleep well then

I'm going to sleep now; tomorrow I've got to wake up at 7:30

So stop talking and sleep well.

Ok

Bye 
Both of these examples contain what we consider to be "translanguaging moments" (Wei 2018). Arabizi, an alternative writing system that uses the Latin alphabet to encode Arabic, was used in both examples. Furthermore, we can observe how language boundaries became blurred during the course of the interactions. The first example began with an adjacency pair (appreciation/minimization), in which A expressed thanks in Spanish and B responded in French before continuing in Dariya. The remainder of the exchange was mainly in Dariya, although Spanish was introduced in the time markers ("in the end" and "later") and for the expressive speech act of apology ("Sorry about that"). The second example was similar in that it unfolded mainly in Dariya, with the inclusion of Spanish in the time marker ("then"). Essentially, it represents a translanguaging "mix" that challenges the monolingual standards of schools and institutions, as well as the political, geographical, territorial, and linguistic boundaries of the community or nation state they inhabit.

Spontaneous multilingual communicative practices, such as these, are creative forms of language resistance to the use of Modern Standard Arabic and Spanish. They are actions with an embedded indexical value used to address the so-called "translanguaging spaces" (Wei 2011) in which the identities of young Moroccans/Maghrebis in the diaspora are forged.

\section{Conclusions}

In this article, we have shown how young people of Maghrebi origin form a visible community of practice within the school context, generating new knowledge through shared experiences that enables them to cooperatively acquire and create new hybrid communicative practices, such as Arabizi and the so-called el mezclado ("mix"). In this sense, we have observed their widespread use in digital communicative practice of Arabizi, a non-standardized script system that consists of using the Latin alphabet to write Arabic or Dariya. Moreover, this "mix", a Spanish/Galician/Dariya/French translanguaging, reveals these young people's creative skills, which in turn constitutes a major language resistance resource. Our data show that the translingual repertoire of this community of practice comprises a continuum in which the boundaries between languages merge into "translanguaging moments" (Wei 2018), namely indexical spaces for the new identities and values associated with young Moroccans/Maghrebis in the diaspora.

The results of our analysis indicate that these young people also introduce the official languages of the host country into their everyday interactions, namely Spanish and, albeit to a lesser extent, Galician. Local schooling plays a key role in this process. We have also seen how these young people identify closely with Moroccan and Modern Standard Arabic. Cultural, socio-communicative, and religious factors, as well as parental ideology, all contribute to the way this sense of belonging and legacy are associated with the two varieties of Arabic: Moroccan and Modern Standard. Capitalizing on the languages of origin in the diaspora, therefore, creates a favorable setting for the transmission and maintenance of these languages within the family context. As a result, anyone who ceases to speak the language is essentially shunning their identity, moving into the mainstream group, and would consequently lose their cultural and linguistic legacy.

Our ethnographic work and the results of our analysis have enabled us to identify the role played by the various types of habitus and agency (Bourdieu 1977), as processes underlying the emergence of this multilingual repertoire. As discussed in Section 3, this multilingual translingual repertoire stems from the intercrossing of parental and adolescent agency. Indeed, three key processes were observed that converge to form a transnational habitus: (a) parental agency reflected in the transmission and maintenance strategies of the language of origin; (b) adolescent agency in addressing family multilingualism and their language repertoires; and (c) adolescent agency in expressing and highlighting new forms of language resistance in digital discourse.

In conclusion, the data analyzed reveal that deploying translingual multimodal practices is a means of reconstructing the identity of young Maghrebis in the diaspora. Furthermore, these practices can be used to negotiate the tensions produced by various forms of belonging. 
Author Contributions: All three authors contributed equally to collecting, processing, and analyzing the data, as well as the writing of this article.

Funding: The data analyzed and discussed in this paper come out of a research project financed by FEDER/Ministerio de Ciencia, Innovación y Universidades-Agencia Estatal de Investigación. FI2016-76425-P.: Project I + D + I Superdiversidad lingüística en áreas periurbanas. Análisis escalar de procesos sociolingüísticos y desarrollo de la conciencia metalingüística en aulas multilingües.

Acknowledgments: We would like to extend our thanks to the anonymous reviewers for their careful reading of our manuscript and for their useful comments.

Conflicts of Interest: The authors declare no conflicts of interest.

\section{References}

AIMC. 2019. Audiencia de Internet en el EGM. Abril 2018/marzo 2019. Madrid: Asociación para la Investigación en Medios de Comunicación, Available online: https://www.aimc.es/egm/audiencia-internet-egm/ (accessed on 8 August 2019).

Alcántara, Manuel. 2014. Las unidades discursivas en los mensajes instantáneos de wasap. Estudios de Lingüística del Español 35: 223-42.

Allehaiby, Wid H. 2013. Arabizi: An Analysis of the Romanization of the Arabic Script from a Sociolinguistic Perspective. Arab World English Journal 4: 52-62.

Aronson, Elliot. 1978. The Jigsaw Classroom. Beverly Hills: Sage.

Bakhtin, Mijail. 1989. Las formas del tiempo y del cronotopo en la novela. Ensayos sobre Poética Histórica. In Teoría y estética de la novela. Translated by Helena Kriukova, and Vicente Cazzarra. Madrid: Taurus, pp. 237-410.

Bhabha, Homi K. 1994. The Location of Culture. New York: Routledge.

Bourdieu, Pierre. 1977. Outline of a Theory of Practice. Cambridge: University Press.

Corona, Victor, Luci Nussbaum, and Virginia Unamuno. 2013. The emergence of new linguistic repertoires among Barcelona's youth of Latin American Origin. International Journal of Bilingual Education and Bilingualism 16: 182-94. [CrossRef]

Fairclough, Normand. 1990. Critical Language Awareness. London: Longman.

Fairclough, Normand. 1999. Global capitalism and critical awareness of language. Language Awareness 8: 71-83. [CrossRef]

García, Ofelia. 2008. Multilingual language awareness and teacher education. In Encyclopedia of Language and Education, 2nd ed. Edited by Jasone Cenoz and Nancy Hornberger. Berlin: Springer, vol. 6, pp. 385-400.

García, Ofelia. 2009. Education, multilingualism and translanguaging in the 21st century. In Multilingual Education for Social Justice: Globalising the Local. Edited by Ajit Mohanty Minati Panda, Robert Phillipson and Tove Skutnabb-Kangas. New Delhi: Orient Blackswan (former Orient Longman), pp. 128-45.

García, Ofelia, Kate Seltzer, and Daria Witt. 2018. Disrupting linguistic inequalities in US urban classrooms: The role of translanguaging. In The Multilingual Edge of Education. Edited by Piet Van Avermaet, Stef Slembrouck, Koen Van Gorp, Sven Sierens and Katrija Marijns. London: Palgrave Macmillan, pp. 41-66.

Giddens, Anthony. 1991. Modernity and Self Identity: Self and Identity in the Late Modern Age. Cambridge: Cambridge University Press.

Goffman, Erving. 1981. Forms of Talk. Oxford: Blackwell.

Guarnizo, Luis Eduardo. 1997. The Emergence of a Transnational Social Formation and the Mirage of Return Migration among Dominican Transmigrants. Identities 4: 281-322. [CrossRef]

Gumperz, John. 1982. Discourse Strategies. Cambridge: Cambridge University Press.

Hawkins, Eric. 1984. Awareness of Language: An introduction. Cambridge: Cambridge University Press.

Hawkins, Eric. 1992. Awareness of language/knowledge about language in the curriculum of England and Wales. An historical note on twenty years of curricular debate. Language Awareness 1: 5-17. [CrossRef]

Heller, Monica. 2002. Éléments d'une Sociolinguitique Critique. Paris: Didier.

Kress, Gunter. 2010. Multimodality. A Social Semiotic Approach to Contemporary Communication. London: Routledge. Lerner, Gene. 1996. On the Place of Linguistic Resources in the Organization of Talk-in-Interaction: 'Second Person' Reference in Multi-Party Conversation. Pragmatics 6: 281-94. [CrossRef] 
Llompart, Julia. 2016. Enseñar lengua en la superdiversidad: De la realidad sociolingüística a las prácticas de aula. Signo y Seña 29: 11-32.

Mancera, Ana. 2016. Usos lingüísticos alejados del español normativo como seña de identidad en las redes sociales. Bulletin of Spanish Studies 93: 1469-93. [CrossRef]

Mancera, Ana, and Ana Pano. 2013. El español coloquial en las redes sociales. Madrid: Arco Libros.

Martín Gascueña, Rosa. 2016. La conversación guasap. Soprag 4: 108-34.

Martín Rojo, Luisa. 2010. Constructing Inequality in Multilingual Classrooms. Berlin: Mouton de Gruyter.

Milroy, Lesley. 1980. Language and Social Networks. Oxford: Blackwel.

Moustaoui Srhir, Adil. 2016. Tú serás el responsable ante Dios el día del juicio si no le enseñas árabe (a tu hijo-a): lengua árabe, identidad y vitalidad etnolingüística en un grupo de marroquíes en Madrid. Lengua y Migración 8: 51-79.

Moustaoui Srhir, Adil. 2019a. Política lingüística en familias de origen marroquí: ideologías, prácticas y desafíos. In Transmissions. Estudis sobre la trasmissió lingüística. Edited by Mónica Barrieras and Carla Ferrerós. Vic: Editorial Eumo, pp. 179-210.

Moustaoui Srhir, Adil. 2019b. Making Children Multilingual: Language Policy and Parental in Transnational and Multilingual Moroccan Families in Spain. Journal of Multilingual and Multicultural Development 40: 1-13. [CrossRef]

Mutsaers, Paul, and Jos Swanenber. 2012. Super-diversity in the margins? Youth language in North Brabant, The Netherlands. Sociolinguistic Studies 6: 65-89. [CrossRef]

Ostergaard Nielsen, Eva. 2003. The Politics of Migrants: Transnational Political Practices. International Migration Review 37: 760-86. [CrossRef]

Pereiro, Carmen, Gabriela Prego, and Luz Zas. 2017. Traxectorias lingüísticas de mulleres marroquíes en Galicia. In Muller inmigrante, Lingua e sociedade. Edited by LauraRodríguez Salgado and Iria Vázquez Silva. Vigo: Galaxia, pp. 189-212.

Prego Vázquez, Gabriela, and Luz Zas Varela. 2015. Identidades en los márgenes de la superdiversidad: prácticas comunicativas y escalas sociolingüísticas en los nuevos espacios educativos multilingües en Galicia. Discurso y Sociedad 9: 165-96.

Prego Vázquez, Gabriela, and Luz Zas Varela. 2018. Paisaje lingüístico. Un recurso TIC, TAC, TEP para el aula. Lingue Linguaggi 25: 277-95.

Prego Vázquez, Gabriela, and Luz Zas Varela. 2019. Unvoicing practices and the scaling (de)legitimization process of linguistic 'mudes' in classroom interaction in Galicia (Spain). International Journal of the Sociology of Language 257: 77-107.

Rampton, Ben. 1995. Language crossing and the problematisation of ethnicity and socialisation. Pragmatics 5: 485-513. [CrossRef]

Rodríguez Neira, Modesto, Gabriela Prego Vázquez, and Luz Zas Varela. 2019. Encuesta sociolingüística para las nuevas realidades multilingües en los centros educativos: Datos cuantitativos y cualitativos cara a cara. Unpublished manuscript, May 29.

Silverstein, Michael. 1976. Shifters, Linguistic Categories and Cultural descriptions. In Meaning in Anthropology. Edited by Keith H. Basso and Henry A. Selby. Alburquerque: University of New Mexico, pp. 11-56.

Vázquez-Cano, Esteban, Santiago Mengual-Andrés, and Rosabel Roig-Vila. 2015. Análisis lexicométrico de la especificidad de la escritura digital del adolescente en Whatsapp. Revista de Lingüística Teórica y Aplicada (RLA) 53: 83-105. [CrossRef]

Vertovec, Steven. 2007. Super-diversity and its implications. Ethnic and Racial Studies 30: 1024-54. [CrossRef]

Wang, Xuan, Max Spotti, Kasper Juffermans, Leoni Cornips, Sjaak Kroon, and Jan Blommaert. 2014. Globalization in the margins: Toward a re-evaluation of language and mobility. Applied Linguistics Review 5: $23-44$. [CrossRef]

Wei, Li. 2011. Moment Analysis and translanguaging space: Discursive construction of identities by multilingual Chinese youth in Britain. Journal of Pragmatics 43: 1222-35. [CrossRef]

Wei, Li. 2018. Translanguagins as a Practical Theory of Language. Applied Linguistics 39: 9-30. [CrossRef] 
Wenger, Etienne. 2001. Comunidades de práctica: aprendizaje, significado e identidad. Barcelona: Paidós.

Zas Varela, Luz, and Gabriela Prego Vázquez. 2018. A view of Linguistic Landscapes for an Ethical and Critical Ed Srhirucation. In Galician Migrations: A Case of Emerging Super-Diversity. Edited by Renée DePalma and Antía Pérez-Caramés. Dordrecht: Springer, pp. 249-64.

(c)

(C) 2019 by the authors. Licensee MDPI, Basel, Switzerland. This article is an open access article distributed under the terms and conditions of the Creative Commons Attribution (CC BY) license (http://creativecommons.org/licenses/by/4.0/). 
Article

\title{
The Identity Construction of Migrants on Facebook
}

\author{
Giovanna Mapelli \\ Dipartimento di Scienze della Mediazione e di Studi Interculturali, Università degli Studi di Milano, Piazza I. \\ Montanelli, 1-20099 Sesto San Giovanni, Milano, Italy; giovanna.mapelli@unimi.it
}

Received: 8 May 2019; Accepted: 1 July 2019; Published: 4 July 2019

\begin{abstract}
Social network sites, such as Facebook, allow access to a series of resources or discursive forms that constitute a multimodal and dialogical system that transcends barriers of time and space, favouring transnational communication, something particularly important to migrants. In addition, the comments and dialogues that take place in such socialisation spaces allow us to develop a greater knowledge of the identity and positioning of the user with respect to others. With this work we analyse, from a qualitative point of view, 150 posts each containing at least five comments, published between 2017 and 2019, in each of five Facebook groups of Latin American migrants living in Italy: Uruguayans, Argentinians, Colombians, Peruvians and Venezuelans. We determine their role in the migratory process and how the digital environment affects the relationships between migrants. In addition, we investigate how the identities of migrants are negotiated and (re)defined in discursive practice. Results shows that social network sites are "transnational social spaces", in which a community is based on bonds of solidarity that derive from a shared conception of collective identity, and they forge deterritorialised "community of feeling".
\end{abstract}

Keywords: social networks sites; immigration; identity; transnationalism; Facebook groups

\section{Latin Americans in Italy}

After Spain, Italy is one of the main destination countries of the Latin American diaspora in Europe. The number of migrants from Central and South America has remained constant since 2015: according to the ISTAT data for $2017^{1}$, almost 350,000 Latin Americans (hereafter: LAs) are registered in Italy, representing just under $8 \%$ of the foreign migrant population; to these should be added about 10,000 such migrants without legal status, along with those who have entered the country as descendants of European citizens and those who have obtained Italian citizenship.

For some years now, Peruvians, numbering almost 100,000 and resident Ecuadorians, almost 80,000 , are the most represented nationalities. As for the other nationalities of interest to this study, there are almost 18,000 Colombians, the sixth most numerous group of residents of American backgrounds; Uruguayan migrants are the seventeenth most numerous group with 1200 residents, whilst Argentinians and Venezuelans constitute somewhat lower numbers (occupying the tenth and eleventh positions) with 8000 and 6000 residents respectively. The majority of LAs reside in the northern part of Italy, with the specific epicentre being Lombardy.

It should also be noted that the LA presence in Italy is predominantly female. Indeed, women represent more than $60 \%$ of residents and are, in many cases, the first link in the migration chain, due to their ease in finding work (Caselli 2009). Another relevant aspect of LA migration is the clear tendency towards transnationalism, that is, the simultaneous participation in the family and economic life of their country of origin as well as that of the host country (Boccagni 2009). In addition, these groups tend to be deeply rooted, with very high rates of employment. Their social lives centre around

1 Istituto Nazionale di Statistica (www.istat.it). 
the businesses they establish in the areas of commerce, transport, construction and renovation work, as well as in the sectors of care working and communications (Caselli 2009). In particular, ethnic media and social network sites (SNS) (Chiesi and Zucchetti 2003; Caselli 2009; Mapelli 2010, 2014; Mariottini 2014) give migrants a voice, which allows them to play an active role as protagonists within the information system.

In addition, although the LA presence is not confined to a specific geographical area, there are different urban spaces that represent defined meeting points for ethnic groups and become centres for social contact within the LA communities, such as parks, squares, and churches (Bonomi 2018). In these contexts, Spanish-speaking LA migrants come together to recreate and preserve their customs and traditions and to dialogue in their own language. We also see the formation of very solid SNS that are founded upon a socio-cultural identity deeply rooted in the world of music, dance and gastronomy. These networks, especially when they become highly organised and fully developed, catalyse the process of social integration amongst migrants ${ }^{2}$. Through such groupings migrants are able to develop both socially and intellectually, which facilitates the negotiation of their participation and their effective integration (Garrreta Bochaca 2016). In fact, these associations offer migrants "a sense of belonging and a social significance, helping them, therefore, to position and locate themselves in the new place" (Ferrer et al. 2014, p. 569).

Also, today there are new ways of interrelating people within the digital environment, i.e., SNS, which enable the exchange of experiences and information between peers and represent a fundamental resource for the migrant, since they allow him/her both to create ties between different communities and within the collective itself, and to integrate him or herself within the new social context, avoiding the risks of marginalisation and discomfort.

\section{Theoretical Framework: Identity and Social Network Sites}

This study is based on a theoretical approach that considers identity as a discursive construction and SNS as discursive practices. In this regard, Benwell and Stokoe (2006) state that:

[ ... ] identity has been relocated: from the 'private' realms of cognition and experience, to the 'public' realms of discourse and other semiotic systems of meaning-making. Many commentators therefore argue that rather than being reflected in discourse, identity is actively, ongoingly, dynamically constituted in discourse. (Benwell and Stokoe 2006, p. 4)

Thus, identity is not a static concept, but rather something flexible and dynamic that is constructed within discourse, in our case, in a virtual space. Thus, identity is constantly negotiated, both in interaction and in the narration of personal experiences, in which the speaker signals her positioning in the world and her attitude towards others (De Fina 2006; De Fina et al. 2006). It is something that varies over time, according to a given context and to social relationships (Yus Ramos 2014).

In the new migratory contexts, identities are negotiated and configured (Calvi 2015b). They are often fluctuating, diasporic (Mera 2010) and transnational (Melella 2013), since they go beyond the borders of nation states and promote a constantly hybridised sense of the self. Migrants use identity to negotiate with others and establish closer links within groups.

New technologies mediate social life and migrants have taken advantage of them to shorten distances and build new ways of relating, both with the destination community and with their community of origin. In this way, the internet has fostered a 'connected presence' (Licoppe 2004) in the context of diaspora, in the sense that a new form of 'presence' is possible, which negates distances and the fragmentation that they cause (Diminescu 2008), in favour of an immediate communication.

SNS are fundamental tools with which actors, in this case migrants, constitute and test out their own identities. For example, opening a profile, selecting the profile photo and publishing news,

2 Clearly there is another aspect to such associations: they might complicate the process of migrants' integration into the host community, given the risk of becoming ethnic ghettos leading to ethnic isolation (Leurs and Ponzanesi 2018). 
are all actions that contribute to the creation of an interactive identity that amounts to the fusion of social and personal identities. Likewise, the comments and dialogues that emerge in these socialising environments allow to know better the identity and positioning of the user with respect to others (Yus Ramos 2014).

In addition, SNS, such as Facebook, grant access to a series of discursive forms that constitute a multimodal and dialogical system, which facilitates the interconnections between users located in different nations or continents, favouring transnational communication (Vertovec 1999; Boccaglia 2011), something that can be very useful in the case of migrants. In this regard, according to Ambrosini, there are three sectors of transnational activity:

- $\quad$ Economic: represented by the initiatives of transnational entrepreneurs who initiate contacts across borders in search of markets, forms of capital and suppliers;

- $\quad$ Political: in which we place the action of politicians seeking to acquire power;

- Sociocultural: in which we find different categories orientated towards strengthening a sense of national identity abroad or aimed at the collective realisation of cultural events and products that evoke the country of origin (Ambrosini 2008).

\section{Aims and Methodology}

We looked daily at the posts and their corresponding comments published between 2017 and 2019 in five closed Facebook groups ${ }^{3}$ : Uruguayos en Italia (URenIT), Argentina en Italia (ARGenIT), Colombianos en Italia (COLenIT), Venezolanos en Italy (VENenIT) and Peruanos en Italia (PEenIT). We chose different nationalities in order to investigate recurrent linguistic phenomena, rather than the peculiarities related to a given nationality, an aspect that we will explore in future. We built up manually a corpus of 150 posts from each group, and each post contained at least five comments, allowing us to observe the interactive character of the communication. We then carried out a qualitative analysis of the material collected. In this study, we do not systematically consider multimodal aspects of the communications, since they are primarily verbal in nature, to the point where, in most cases, we only see written text. Within a sociolinguistic analytical framework, our objective was to determine the role of these groups in the migratory process. In addition, through the migrant voice, considered as a heuristic tool allowing us to understand the meanings that other people formulate about the world (Hymes 1996), we investigate how identity is negotiated and (re)defined in discursive practice (Knauer 2005) and how relationships between migrants change in the digital environment.

In line with Busso (2016), we define a group as "closed" not so much because it selects the people who access it ${ }^{4}$, but rather because it is a virtual space that is defined by common interests and a sense of collectivity (Jankowski 2006), as bringing people together, which facilitates the establishment of transnational networks and links that reinforce their own identities as Argentinians, Uruguayans, Colombians, etc.

The use of SNS in the area of migration has been addressed mainly in the field of digital communication and, in particular, digital migration (Diminescu 2008; Komito 2011; McGregor and Siegel 2013; Busso 2016; Leurs and Ponzanesi 2018), or in anthropology (Zijlstra and Liempt 2017), psychology (Chen 2010; Ferrer et al. 2014) and sociology (Damian and Ingen 2014). Within the framework of sociolinguistics, studies have focused mainly on semi-directed interviews (with specific

3 Although there are groups bringing together Latin Americans in general, regardless of their nationalities, such as Somos Latinos en Italia and Latinos en Italia (with 5000 and 3000 members, respectively), there is greater interaction within groups of individual nationalities. Also, there are other groups from these communities, but we chose those that, on 15 June 2017 , had more followers: PEenIT have more than 11,000 members; VENenIT more than 8000; ARenIT and COLenIT around 3500 each; URenIT 1500. We excluded the group Ecuadorians in Italy, despite theirs being one of the largest Latin American communities in Italy, because there was no dialogue apparent between the members.

4 In fact, when I applied for membership, they granted me entry within a few days, without asking who I was or why I wanted to join the group. 
regard to Spanish speakers in Italy, see Bonomi 2010, 2018; Calvi 2015a, 2015b among others) and on ethnic media (Mapelli 2010, 2014; Mariottini 2014). However, research on virtual communities is still scarce (Vincent 2015; Kluge 2015). We want to show how migrants forge or (re)construct an identity through discursive practices and to discover whether SNS might be considered transnational social spaces, which tie the country of origin to that of destination, breaking down borders so that two or more nation-states become part of a single social space in which ideas, symbols and cultural material circulate as much as people themselves (Ambrosini 2008). This is an initial approach to how migrants exploit SNS to renegotiate their identities in a new territory, and we leave the analysis of cyberpragmatic aspects (Yus Ramos 2011) for future research.

\section{Analysis of the Facebook Groups}

\subsection{Cover Photo and Information}

Despite not adopting a multimodal perspective, in this article it seems important to consider the cover photo that the administrator chooses to present the group, something the addressee will use to form a hypothesis about the nature of the group in question and the content of the page (Vela Delfa 2014), given that this is the first element with which the user comes into contact.

Uruguay, Venezuela and Argentina opt for their flag and their national colours as a mark of identity; Peru chooses a photo of the World Heritage Site, Machu Picchu; whilst, Colombia displays a famous personality, the cyclist Nairo Quintana, who made history in 2014 as the first Colombian (or, indeed, Latin American) to win the Giro d'Italia.

In the Information section, the target readers and group objectives are defined. In the Peruvian group, for example, it highlights the idea that the group is aimed at Peruvians who "want to share something", whilst the Argentinian page specifies that the group is for "Argentinians who want to meet to share things, help each other, become informed and feel close to home":

1. All Peruvians in Italy who want to share something in common with us all $\because \cdot$ :) and so remember our lovely PERU !!!!!!!!!!!!!!!!!!!!!!! (PEenIT) $)^{5,6}$

2. For whatever reason, whether long ago or recently, whether alone or accompanied, we all came to Italy from different parts of Argentina. And we meet in a group (as is our custom) to share things, help each other, get informed and feel close to "home", let's make this small space something truly ours. Let's not discuss politics or religion, we know that almost never ends well. Let's not publish things that, rather than helping, annoy others. Let's look after our space together, let's decide what we want to see and what we don't, the group belongs to all its members. Thanks and kisses (ARGenIT)

The Argentinian group has already declared in this section that it is better to avoid discussions about politics or religion, or messages that might offend or annoy other users. It is similarly not uncommon in the other groups to find messages that bring up this topic and invite members to avoid rude language and to respond in a polite manner:

3. Sorry but [ ... ] This group is to "help each other" as Colombians to settle any doubt so to insult or mistreat people who are just looking for information???? Please, if someone asks a question it

5 Footnotes herein give the original examples verbatim.

6 Todos los peruanos que se encuentran en italia y quieren compartir algo en comun con todos nosotros $\because$ :) asi recordar nuestro lindo PERU!!!!!!!!!!!!!!!!!!!!!!!!!!

7 No importa el motivo, si hace mucho o poco tiempo, si solos o acompañados, llegamos a Italia desde diferentes lugares de Argentina. Y nos reunimos en un grupo (como es costumbre bien nuestra) para compartir cosas, ayudarnos, informarnos y sentirnos cerca de "casa", hagamos entre todos de este pequeño espacio algo bien nuestro. No discutamos de política o de religión, sabemos que casi nunca se llega a buen puerto. No publiquemos cosas que en vez de ayudar, molestan. Cuidemos entre todos nuestro lugar, decidamos que queremos ver y que no, el grupo es de todos sus miembros. Besos y gracias. 
is because they do not know or want to know more about the subject [ ... ] They don't expect people to come out with rudeness [ ... ] If you know the answer, reply courteously, if not, just move on ... Thank you very much! (COLenIT) ${ }^{8}$

4. Colombians in Italy should be a group of brothers and sisters with mutual respect ... for a convivial moment ... Share beautiful things. Fun things ... that help us escape from some of the sad realities that we live on a daily basis (COLenIT) ${ }^{9}$

The Venezuelan group in Italy has the Italian subtitle "Tutto Venezuela" and, as we shall see later, the use of the language of the host country marks a hybrid identity. This group presents itself as a portal to access Italian services and information; it affirms that here it is possible to find "everything related to Venezuela":

5. Tutto Venezuela where you will find everything related to our country and that only we can offer you in Italy, such as: Gastronomy, National Television Live, the National Press, Events, Photo Galleries, Chat and more (VENenIT) ${ }^{10}$

The case of Uruguay is peculiar because it indirectly criticises both the Uruguayan and the Italian governments; indeed, it claims that people have had to leave their homeland to come to Italy "because of people like those who govern Italy today":

6. People who left their homeland because of people, like those who govern Italy today, in this group we only accept transparent people, people with no information in their profile are not accepted and I would add that this group is for Uruguayans in Italy and not Uruguayans in the rest of the world (URenIT) ${ }^{11}$

The Colombian group opts for an ironic tone to describe certain situations, customs or characters that they see as typically Italian and that they might meet with-("[people who] have been faced with one or more "tamarros"12"; "have wanted to string up the occasional official at the Questura (Police headquarters)", etc.) or certain beliefs amongst the Colombians ("think that Turin belongs to France"; "have gone to Monza or the San Marino Grand Prix to see Montoya ... "; "are surrounded by the best wines in the world but they just guzzle beer", etc.):

7. For anyone who has ever: faced one or more 'tamarros'. dreamt about stringing up the occasional official at the Questura. [ . . been] surrounded by the best wines in the world, but just guzzles Irish beer. gone to Monza or the San Marino GP to see Montoya before sunset with a straw hat on. realised that the Tuscan landscape is just like Boyacá. loved the majesty of Rome, the action of Milan, the elegance of Turin, the freshness of Bologna or the beauty of Florence. thought that Turin belongs to France. thought it's at least a little strange that the Italians call themselves Latinos, even though. [ ... ] thought that in Italy male hair removal should be banned (COLenIT) ${ }^{13}$

8 Perdón pero ... Este grupo es para "ayudarnos" como colombianos a resolver alguna duda o para insultar o tratar mal a las personas que no saben de alguna información???? Por favor, si alguien hace una pregunta es porque no sabe o quiere profundizar en el tema ... No es para que le salgan con groserias [ ... ] Si usted sabe, responda educadamente, si no, siga derecho ... Muchas gracias!

9 Colombianos en italia debe ser un grupo de hermandad de respeto reciproco ..de un momento de relax .... . Comparte cosas bellas. Divertentes. ... que logren alejarnos de algunas tristes realidades que vivimos cotidianamente.

10 Tutto Venezuela donde encontraras todo lo relacionado con nuestro país y que solo nosotros te podemos ofrecer en Italia como: Gastronomía, Televisión Nacional en Vivo Prensa Nacionales, Eventos, Galerías de fotos, Chat y algo más.

11 Gente que a dejado su patria. por culpa de gente, como aquella que hoy govierna en italia ,en este gruppo se aceptano solo personas trasparentes, personas que no tienen informacion en el perfil no son aceptadas y agrego este grupo es para los uruguayos en Italia y no los uruguayos en el resto del mundo.

12 'Tamarro' is an Italian colloquial term meaning 'loutish', 'uncouth' or 'ill-mannered', which is used by young people. In this case it has been pluralised by using a Spanish suffix.

13 Para todos los que alguna vez: Le han frenteado a uno o más tamarros. Han querido en sus sueños ahorcar a una funcionaria de la Questura. [ . . . ] Tienen a disposición los mejores vinos del mundo, pero se ponen a jartar cerveza irlandesa. Han ido a Monza o al GP de San Marino ver a Montoya antes de su ocaso con un sombrero vueltiao puesto. Se dan cuenta de que el 


\subsection{Assessment of the Migratory Experience and of the Host Country}

If we read the posts, we realise that the 'wall' is a place where internet users publish their personal concerns and questions about visas, citizenship, residence permits, working, renting, etc. Above all we find requests for practical information and suggestions about living in Italy or about going to Italy; the answers, however, are laid out as accounts of personal migratory experiences, in which migrants use the space autobiographically. These are discursive productions in the first-person singular (Atkinson 1998), in which the subjects construct narratively how they lived certain experiences and how they solved problems related to their arrival in the new country. The use of the first-person singular highlights the active role of the speaker in the narrated events (there are many verbs expressing actions) and their evaluations of situations ("nothing was missing", "it's not easy", "it seems too much"). According to Bauman, there is a tendency to feel able to express more intimate and personal information on Facebook than we would naturally communicate in face-to-face situations; this phenomenon is called "extimacy", which is the constant externalisation of privacy (Bauman 2011). With this approach, persons XXX and ZZZ whose comments aim to demonstrate solidarity with their compatriot, provide relevant answers that demonstrate how he or she has managed to tune in to the host society:

8. $Y Y^{14}$ : Hello friends, good morning, sorry for the inconvenience, out of curiosity I started to look into the process of gaining my citizenship and they told me that they are offering chances to apply in about 5 to 7 years' time at the consulate in Córdoba, which seems too long, honestly, but if I go with all the papers to Rome or wherever necessary in Italy, the process is faster, right? Thank you in advance!

XXX: In 2012 at the consulate in Rosario they gave me the number 18654, as of December 31, 2017 they are going to deal with number 14600 , so I still have to wait about 4 or 5 years before they look at my documents.

In Italy, I arrived and applied for residency on February 20 and by June 8 I had my electronic ID in my hand.

ZZZ: I'll tell you my experience, I brought all my documentation complete, there was absolutely nothing missing, it took me 20 days to find a flat to establish my residence, it is not easy to get a contract for just a few months (it has to be totally legal and rubber stamped), then I waited for the time to pass, (between 7 and 45 days), then you present the documentation and wait for them to assess it

In terms of money there were 2 stamp duties of 16 euros, 22.21 euros for the electronic ID card and almost 120 euros for the passport

Of course there is the cost of rent and maintenance because during that time you are not allowed to work.

I carried out the process in Asti, the rent was 350 euros per month plus service charges. (A flat just for me, I did not share with anyone)

The conversion of my driving licence was a bit more expensive because there were several stamp duties and a trip to the consulate in Milan to get the translation done (this is mandatory), in total something like 160 euros in total.

The Tessera Sanitaria [health card] is processed in the hospital, you don't pay anything and it is

paisaje toscano es igual al boyacense. Aman la majestuosidad de Roma, la acciòn de Milán, la elegancia de Turín, la fescura de Bologna o la belleza de Florencia. Piensan que Turín pertenece a Francia. Piensan que es al menos un poco extraño que los Italianos se llamen latinos, aunque tengan la razón. [ . . . ] Piensan que en Italia se debería prohibir la depilación masculina.

14 In order to maintain privacy, names of individuals have been omitted. Letters appear when interactions involve multiple participants, in order to distinguish the different comments. 
sent by post to your house.

This is just my experience at the moment (ARGenIT) $)^{15}$

It is very common to find messages that show the migrants' determination to face the migratory process. In (10) and (11) there is an attempt to reassure ("you need to relax") the person who is arriving in Italy, by using periphrasis of deontic modality, encouraging them not to give up over administrative procedures ("keep going"). The use of the adversative conjunction "but" mitigates a negative judgment previously expressed ("it's not immediate, but it will happen"; "you can't gain permanent residence straight away but at least you get here") as in (9) and (10):

9. [ . . ] while you are looking for a place to rent you can stay in a room or hostel that you can book from Argentina. From there you can't gain a permanent residence straight away but at least you can get here with an assured bed, nobody can stop you from being a tourist during the time you need until you can rent something (ARGenIT) ${ }^{16}$

10. I arrived on February 2 and started looking, on the 15th I signed a contract with the estate agent, they need to get it stamped and on the 20th I was able to go to the public registry and establish my residence. It is not immediate, but it will happen. If you get that far you need to relax and stick with it (ARGenIT) ${ }^{17}$

11. Keep going in your work a Colombian brother wishes you the best of luck (COLenIT $)^{18}$

Examples (12)-(15) underline the wish not to disturb the dreams of those who want to start a new life. The social network in this case plays the role of attracting people. Those who are already in Italy feel an obligation to be honest with their compatriots, explaining that living in another country is not easy, but try not to discourage them. The important thing is each person's faith and determination to emigrate and, above all, his or her ability to adapt to the new context:

12. No matter what happens, the faith to go on, that everything can be resolved, even if reality shows us something to the contrary. People can tell you a thousand things but only you can live your own experiences, whatever we might tell you, or suggest, is irrelevant if you hang on to the conviction that you will achieve what you want to. Good luck (PEenIT) ${ }^{19}$

13. If you are strong you will achieve everything, I wish you the best of luck from the bottom of my heart (COLenIT) $)^{20}$

15 YYY: Hola amigos, buen día, disculpen la molestia, por curiosidad me puse a averiguar para tramitar mi ciudadanía y me dijeron que están dando turnos para dentro de 5 a 7 años en el consulado de Córdoba y me parece demasiado, honestamente, pero si yo voy con todos los papeles a Roma o dónde sea necesario allá en Italia es más rápido el proceso, no? Muchas gracias desde ya! XXX: En el año 2012 en el consulado de Rosario me dieron el número 18654, al 31 de diciembre de 2017 van a atender el 14600, o sea todavía me faltan aproximadamente 4 ó 5 años para que me reciban la carpeta. En Italia, llegue e hice residencia el 20 de febrero y el 8 de junio ya tenía mi DNI electrónico en la mano. ZZZ: Yo cuento mi experiencia, traje mi documentación completa, no faltaba absolutamente nada, demore 20 días en conseguir piso para fijar residencia, no es fácil hacer un contrato por pocos meses (debe ser totalmente legal y estar sellado), luego espere que pase el vigile, (entre 7 y 45 días), después presentar la documentación y esperar que ellos evalúen. Con respecto al dinero fueron 2 sellados de 16 euros, 22.21 euros la carta de identidad electrónica y casi 120 euros el pasaporte. Por supuesto esta el gasto del alquiler y la manutención porque en ese lapso de tiempo no podes trabajar. Yo hice el trámite en Asti, el alquiler fueron 350 euros por mes mas gastos de servicios. (Un piso para mi sola, no compartía con nadie). La conversión del registro de conducir me salio un poco mas cara porque fueron varios sellados y un viaje a Milano al consulado para que hagan ellos la traducción (es obligatorio), en total algo así como 160 euros en total. La tessera sanitaria se gestiona en el hospital, no se abona nada y te llega por correo a tu domicilio. Esto es estrictamente mi experiencia en este momento.

$16[\ldots]$ mientras buscás un lugar para alquilar podes parar en una habitación o albergue que podes reservar desde Argentina. Por ahí no podrás fijar residencia inmediatamente pero al menos llegas con una cama segura, nadie te puede impedir que estés como turista el tiempo que necesites hasta poder alquilar algo.

17 Yo llegue el 2 de febrero y empecé a buscar, el 15 hice el contrato en la inmobiliaria, deben sellarlo y el 20 pude ir al comune y fijar residencia. No es inmediato, pero se consigue. Si venís a eso tenés que relajarte y ser constante.

18 Sigue adelante en tu trabajo un hermano colombiano te desea mucha suerte.

19 Pase lo que pase la fe por delante que todo se puede solucinar aunque la realidad nos muestre todo lo contrario. Cada uno te puede decir mil cosas pero tus experiencias solo las puedes vivir tu, lo que podamos decirte, sugerirte es irrelevante si tienes la convicción de que lo que te propones lo vas a lograr. Suerte.

20 Si eres fuerte logras todo, buena suerte te deseo de corazón. 
14. Having no-one else is a difficult situation but if your dream is here, come (URenIT) ${ }^{21}$

15. In terms of work it's not easy either but if you adapt to doing anything (care worker, babysitter, kitchen assistant, bar worker, I mean humble things) you might get work! (URenIT) ${ }^{22}$

The trip to Italy or the obtention of citizenship require a long wait. Example (16) betrays a certain emotional intensity, by relating the mood of a young woman on the day she leaves Argentina. There are emotive vocabulary ("dreams" and "emotions"), or words that evoke strength and resistance ("never lower our sights"):

16. Fulfil your dreams if you are strong enough [ ... ] friends, the day has arrived, Italy awaits me, I take a suitcase full of dreams and mixed emotions, I hope we can all achieve our dreams never lower our sights! (ARGenIT) ${ }^{23}$

Nevertheless, some emphasise their identity of origin and their love for their homeland, noting that the feeling for the motherland does not change:

17. A document does not change your feeling for your country, but it does make life easier (I'm thinking of the bureaucratic aspect) (PEenIT) $)^{24}$

LA migration is characterised by good integration into the receiving community (Calvi 2011; Bonomi 2018); in fact, a positive vision emerges of Italy and the Italians. Again, negative evaluations are always mitigated, in (18)-(20), through the oppositional conjunction "but":

18. The situation will be difficult but better here than in Venezuela (VENenIT) ${ }^{25}$

19. It's not easy but it's not impossible either [ . . . ] (URenIT) ${ }^{26}$

20. These days, Italy is not the best country for migrants but probably anything is better today than Venezuela (VENenIT) ${ }^{27}$

Moreover, it should be pointed out that LA migrants do not look down on the Italian people, their discontent stems from the crisis that the country is going through, something that also affects the Italians themselves:

21. People gave me a warm welcome (ARGenIT) ${ }^{28}$

22. It's not the Italians' fault but the crisis that's affecting Italy (URenIT) ${ }^{29}$

23. It's not the best time. Italy is not good at the moment the Italians have no work so imagine the immigrants (COLenIT) $)^{30}$

Italy's natural and cultural beauty is also appreciated: on the Facebook wall, users publish pictures of the Italian landscape, with which immigrants of various nationalities "fall in love". This is another sign of their transnational identity, which is divided between their love for their country of origin and that for their destination country:

24. The sunset today, less than an hour ago, at the Spiaggia Le Ghiaie, in Portoferraio. I fell in love with the Isle of Elba $\bigcirc \bigcirc\left(\right.$ ARGenIT) ${ }^{31}$

21 Sin tener a nadie es una situación difícil pero si es tu sueño aquí véngase.

22 A nivel de trabajo tampoco es facil pero si te adaptas a hacer cualquier cosa (badante, babysitter, ayudante de cocina, mesonero, bueno cosas humildes) puede ser que consigas trabajo!

23 Cumple sus sueños quien resiste ... amigos llegó el día Italia me espera, me llevo una valija llena de sueños y mezclas de emociones, espero que todos podamos lograr nuestros sueños a no bajar los brazos!

24 Un documento no te cambia un sentimiento por tu patria, pero te hace la vida más fácil (hablo siempre de un aspecto burocratico).

25 La situación será fea pero mejor aquí que en Venezuela.

26 No es fácil pero tampoco es imposible.

27 Italia no es hoy el mejor pais para el inmigrante pero seguramente cualquier cosa es mejor hoy que Venezuela.

28 La gente me acogió muy bien.

9 No es culpa de los italianos sino de la crisis que afecta a Italia.

30 No es el mejor momento. Italia esta mal en este momento no tienen trabajo los italianos imagínese inmigrantes.

31 El atardecer de hoy, hace menos de una hora, en la Spiaggia Le Ghiaie, en Portoferraio. Me enamoré de la Isla de Elba. 


\subsection{Assessment of the Active Participation in the Destination Country}

Another aspect that should be highlighted here is that the 'wall' serves as a bulletin board to advertise restaurants, shops selling typical products, and travel agencies run by LAs, which emphasises the business success achieved in the host country and, therefore, the LA migrants' transnational identities.

Likewise, members of the LA community who have reached important positions and that give rise to national pride are celebrated. At the same time, there is also praise for the Italians ("lovely recognition on the part of the citizens") who have given such LAs the opportunity to reach these positions (Council candidate in the local elections, tram driver):

25. Today [ ... ] our compatriot Liliana Bermudez is participating in the local elections as a candidate for the council. This is a lovely example of recognition from the citizens of this welcoming and picturesque little town of Verona. COLOMBIAN Pride (COLenIT) $)^{32}$

26. Peruvian Pride in Florence ITALY: FIRST PERUVIAN TRAM DRIVER IN ITALY (PEenIT) ${ }^{33}$

Highlighting the active participation of LA migrants in the social life within the local context, we see publicity for initiatives linked to the culture of the country of origin ("In Imperia we are celebrating the Feast of the National Flag", "Inti Raymi, Festa del Sole"). Sometimes, the group members themselves are seeking information about cultural or sporting events in order to "reconnect with their roots". Once again, we observe a need to maintain an identity of origin, despite the geographical distances:

27. Hello, where can I find a celebration for the 28th (for the Independence Day) recommendations please, I need to reconnect with my roots. Thanks (PEenIT) $)^{34}$

28. Is there a bar in Milan to see the Boca match? (ARGenIT) ${ }^{35}$

\subsection{The Value of Our Roots}

The importance of the country of origin is especially evident in the comments about daily news, which often include complaints and a deep discontent over the serious economic, political and social situation; social media allow a virtual participation in the political life of the country of origin. In (29)-(30) we see the use of vocabulary with negative connotations for the country of origin ("corruption", "poverty", "theft", "laziness"), with the aim of encouraging people to improve the situation, as seen in (31):

29. Corruption and laziness don't allow these regions to progress they are given a great deal of aid. But the leaders steal it all (VENenIT) $)^{36}$

30. This referendum will barely solve anything of the problems in Peru, and it certainly won't end the corruption!! (PEenIT) ${ }^{37}$

In this regard, we note that at times of elections or referendums, several messages are published with information on how to vote from abroad.

Despite living in another country, migrants feel a need to exercise their rights and remain emotionally involved. Expressions such as "pure blood" and "all strength to Peru" give away the Peruvians' sense of pride:

32 Hoy [ ... ] nuestra compatriota Liliana Bermudez participa a las elecciones comunales como candidato al consejo. Este es un lindo ejemplo de reconocimiento de parte de los ciudadanos de este acogedor y pintoresco pueblito verones. Orgullo COLOMBIANO.

33 Orgullo Peruano en Florencia ITALIA: PRIMERA CONDUCTORA PERUANA DE TRANVIA EN ITALIA.

34 Hola, donde habra fiesta por 28 ( $x$ el dia de la independencia)? recomendaciones por favor, Necesito reencontrarme con mis raices. Gracias.

35 Hay algún bar en Milán dónde ver el Partido del Boca?

36 La corrupción y la pereza no dejan progresar esas regiones ayudas se dan y muchas. Pero los lideres se la roban.

37 Con dicho referendum no se solucionara casi nada de los problemas que tiene Perú ni mucho menos se acabara la corrupción!! 
31. It is time to exercise our rights as true- and ancestrally-blooded Peruvians, so now, more than ever, all strength to Peru (PEenIT) ${ }^{38}$

There are also some examples of economic transnationalism (Portes et al. 1999), since some LA businessmen or entrepreneurs seek partners in Italy; this shows that some business activities transcend borders and no longer require a physical infrastructure, but take advantage of digital networks in order to sell products or for consultations, for example. We also note the proliferation of shops selling food and ethnic products, which are advertised in these groups. Similarly, we find publicity for the sale or rental of flats in certain Latinamerican cities:

32. Business opportunity. I am looking for a partner in Rome. Someone who likes Sales, either in person or through social media [ ... ] send me a WhatsApp (Colombian telephone number) $(\text { COLenIT })^{39}$

33. You are invited to get to know my holiday apartment in $\mathbf{X X}, \mathbf{X X}$ available for families and groups of up to eight people [... ] (COLenIT) ${ }^{40}$

Food has an important role in the construction of identity (De Fina 2007). The LAs who write in these groups also want to know where they can find certain typical products from their homelands or express their happiness at seeing restaurants serving traditional food, since this is a way in which they can recreate in Italy the social practices of their countries of origin and feel as if they were back home:

34. Where can I find PAN ${ }^{\circledR}$ flour? $(\text { COLenIT })^{41}$

35. How lovely to know that I can taste the delights of my homeland (PEenIT) $)^{42}$

Migratory transnationalism is above all related to the sphere of the family (Boccagni 2009); an important issue emerging from the posts is that of the social ties with family members who have remained in the country of origin, as shown by remittances and the exchanges of goods (36)-(37) as well as the sporadic visits or the decision to return permanently (38):

36. Hello friends, I am currently in Rosario, and I am returning to Italy on July 25, if someone needs me to bring over anything, any documents I can do that ... let me know and we'll fix it up $(\mathrm{ARGenIT})^{43}$

37. Has anyone sent money to Colombia with small World? (COLenIT) ${ }^{44}$

38. XXX: I'm going to return to Colombia and I want to send at least one suitcase by courier YYY: I'm also going back!!! Decision made (COLenIT) ${ }^{45}$

\subsection{Social Identification}

In terms of relationships with compatriots, we observe that there is a maintenance of a marked ethnic identity, which is manifested in a constant search for fellow countrymen and women living nearby. The use of adjectives that indicate nationality is very frequent: "Any Argentinians in Messina?"; "Any Colombians in Monza?"; "Any Venezuelan friends in Milan?" It is interesting to note that within these groups, the sense of national identity is very strong and they are never subsumed under the

38 Es tiempo de reclamar nuestros derechos como peruanos de sangre pura y milenaria por eso más que nunca fuerza Perú.

39 Oportunidad de negocio. Busco socio en Roma. Que le gusten las ventas, en persona y por redes sociales [ ... ] envíame un whatsapp (telefono colombiano).

40 Los invito a conocer mi apartamento de vacaciones en XX, XX disponible para familia y grupos de hasta ocho personas [... ].

41 ¿Dónde puedo encontrar harina PAN?

42 Que bello saber que podré ir a saborear las delicias de mi tierra.

43 Hola amigos, yo ahora estoy en Rosario, y vuelvo a italia el 25 de julio, si a alguien le sirve algo que le lleve alguna cosa, algun documento yo lo puedo hacer... me avisan y arreglamos.

44 Alguien ha enviado dinero a Colombia con small World?

45 XXX: Me voy a regresar a Colombia y quiero enviar al menos una maleta por courrier; YYY: Yo también me devolvi!!! Decision acertada. 
supranational label "Latino" (Calvi 2015a; De Fina 2014; Kluge 2015), which is used exclusively in posters advertising some of the activities publicised in the various groups: Rutas Latinas Envio (cargo distribution network from Italy to Latin America), Aventura Latina (travel agency), used in order to reach a wider audience ${ }^{46}$.

Sometimes, the reference to compatriots is indirect, for instance, when someone mentions a cultural element (e.g., "mate" — a popular infusion shared in Argentina): "Good People! How goes it? Anyone in Savona around to drink some mates?" It is interesting to note that "mate" is a very recurrent cultural symbol in the posts of Argentinians, as we will also see in Example (39) and reveals the importance of the past and the country of origin. Moreover, it should be noted that it also appeared for a while in the group's cover photo, as a symbol of the country.

The formulas that migrants use to address other members of the group are an index of their desire to approach other people in the same situation: they are unifying appellations that emphasise closeness and intimacy, despite the fact that users do not know each other personally.

Thus, some posts include the words friend" or brother, or allude to their shared place of origin, such as a countryman or compatriot. In addition, the use of the participatory we marks group membership and denotes strong emotional involvement and attachment to the country of origin, above all when users talk about Peru or Colombia. There are many expressions like "all of us", "our beautiful Peru", "our beloved Peru", "my lovely homeland", "I love you Peru", "long live our Homeland", and "our beautiful homeland".

In (39)-(40) there is a very strong sense of belonging to the national group. Argentinians, for example, miss the peculiarities of friendship and character that, according to them, Italians do not possess ("Argentinians are unique", "it will never be the same as Argentinian friendship"):

39. ZZZ: Hello everyone, a year ago I came to live in Italy, [ . . ] I don't know about you, but I personally still find it difficult to understand how the Italians relate as friends. Argentinians are unique and I miss my friends [ ... ] If anyone is in this area and wants to have a chat or share a bit, we can fix something up one day. Kisses to everyone!

XXX: It would be good to put on a great barbecue with a really long table and all get together!!!! YYY: You're invited whenever you like bring the mate I don't have any haha ${ }^{-1}$ (ARGenIT) ${ }^{47}$

40. I was lucky enough to meet some very nice guys from Torino who introduced me to more people, but it will never be the same as Argentinian friendship (ARGenIT) ${ }^{48}$

In (41) the collaborative spirit that characterises these communities stands out, an endogroup attitude emerges, for instance in (41), when the speaker expresses that she or he wants a Colombian babysitter (female):

41. Hi, I'm still looking for a nanny, part time I'm offering the possibility to live here in Vercelli YYY: I've seen you looking for a while, I found my babysitter in a group of babysitters here on

46 In Italy, the label latino has not taken on the economic or political significance that it holds in the United States (Dávila 2008), and neither has it acquired a racial connotation (Garcés-Conejos Blitvich and Bou-Franch 2014). For Italians, this term is typically associated with the world of music and popular culture, and only takes on a negative aspect if used to refer to Latino Gangs, which are often associated with crime and violence.

47 ZZZ: Hola a todos, hace un año me vine a vivir a Italia, [ . . . ] No se a ustedes, pero a mí en lo personal me cuesta aún entender a los Italianos en la relación amistad. El Argentino es único y extraño a mis amigos ... Si alguno anda por ésta zona y tiene ganas de hacer una charla o de compartir un rato, algún día se puede organizar algo. Besos a todos! XXX: Estaría bueno hacer un gran asado con una mesa súper larga y juntarnos todos!!!! YYY: Te invito cuando quieras trae el mate yo no tengo jaja

48 Tuve la suerte $\mathrm{d}$ conocer chicos muy buenos de Torino q me presentaron mas personas, pero nunca sera igual a la amistad argentina. 
Facebook $[\ldots]$

XXX: Yes, thank you, I was hoping to find someone from Colombia (COLenIT) ${ }^{49}$

Meanwhile, when events reported in these groups show LAs as protagonists of negative actions in Italy, the comments display a rejection of these compatriots, expressing their desire to distance themselves from "them" and highlighting the positive qualities of the group with the use of the first person plural ("we", in (44)) as opposed to "them" (42), those committing criminal acts:

42. They are criminals (PEenIT) ${ }^{50}$

43. A classic, he should be permanently expelled (PEenIT) $)^{51}$

44. The majority of Colombians in Italy are peaceful, honest, hardworking and we reject the brutality that took place in Milan and all the manifestations of violence [ ... ] let's protect our community and the community that hosts us [ ... ] let's denounce violent people (COLenIT) $)^{52}$

On the other hand, despite obtaining Italian citizenship, which, as we mentioned earlier, is a moment of pride and happiness, these migrants always emphasise their national identity, in line with the transnational condition in which they live:

45. I have Italian citizenship, but I am Colombian (COLenIT) $)^{53}$

\subsection{Language}

Language operates, in its own right, as an identity marker in the tension between maintenance of the mother tongue and language change (De Fina et al. 2006). Code switching, understood as the alternation of more than one language, is a typical phenomenon of bilingual discourse and can be a resource for the negotiation and construction of identity (Dumitrescu 2014). The use of the language of the host country can be considered as an index of the level of integration achieved, of a greater level of attention to the new context and, sometimes, to the interlocutor who may be Italian, as found in semi-directed interviews (Calvi 2011). In the Facebook groups, however, there is greater control of the conversation, perhaps because this is an asynchronous medium and the dialogue is not in real time. In this social network, Spanish is considered to be a marker of identity; it has been suggested that its primacy might stem from the fact that many users post their messages and ask for advice from the country of origin before emigrating, something that is confirmed by a post which states: "[ $\ldots$ ] in the group there are people from all over" (ARGenIT). Moreover, when someone writes in Italian, she or he is immediately asked why she or he does so. In example (46), a university student writes a long post in which she gives information about the linguistic habits of the Spanish speakers living in Italy, she is asked why she does not write in Spanish, since the group is constituted mainly by LAs:

46. I see in your profile that you know Spanish, why are you writing in Italian here? (PEenIT) $)^{54}$

On other occasions the members of the group criticise and make fun of poor use of Italian, suggesting the use of Spanish:

47. Sometimes makes you laugh ... they want to write in Italian on a page in Spanish and what's worse, they write it badly (PEenIT) $)^{55}$

49 Hola sigo buscando ninera empleada, medio tiempo doy la disponibilidad de vivir aca en Vercelli. YYY: Hace rato que te veo buscando, yo encontré mi niñera en un grupo de babaysitters acá en Facebook [ ... ]. XXX: Sí, gracias, mi intención era buscar a alguien colombiano.

50 Son unos delincuentes.

51 Un clasico, deberían expulsarlo definitivamente.

52 La mayoría de colombianos en Italia somos pacíficos, honestos, trabajadores y rechazamos la brutalidad ocurrida en Milán y toda la manifestación de violencia [ ... ] portejamos nuestra comunidad y la comunidad que nos hospita [ ... ] denunciemos los violentos.

53 Tengo ciudadanía italiana, pero soy colombiano.

54 Veo en tu perfil que sabes castellano, por qué escribe en italiano aquí.

55 A veces es como para reirse. quieren escribir en italiano en una pagina en español y para colmo lo escriben mal. 
Nevertheless, it is possible to find some signs of the contact with the Italian language. These hybrid, innovative and creative discursive praxes, also favoured by the grammatical closeness of the two languages that make up the bilingual repertoire of the LAs in Italy, represent a strategy to which speakers resort in an active and conscious way in order to negotiate multiple identities and to create a new social space in which to position themselves. In SNS, we observe a "Spanish in motion" that represents the way in which "the Hispanic-American population relocate their linguistic practices and at the same time affirm their transnational identity and create a new social space" (Bonomi 2018).

We can trace then, some borrowed words that are used to introduce terms related to the areas of work, food, bureaucracy and other realities pertaining to Italy, such as "codice fiscale", "permesso di soggiorno", "badante", "comune", "nulla osta", "Prefettura", "Questura", and "affettati"; likewise, hybrid forms appear, such as "permiso de [Spanish] soggiorno [Italian]" or "salumes", which employs a Spanish plural form applied to the Italian term for "cold cut", a linguistic phenomenon that also takes place in the case of the neologism "badantes" ("old people's care worker"). We find the same practices of codeswitching and borrowed words in the ethnic media (Mapelli 2010,2014) and in the semi-structured interviews (Calvi 2011; Bonomi 2018):

48. To marry in Italy you must reside in a comune, bring her birth certificate from Argentina (stamped), go to the consulate to place the nulla osta [authorisation], legalise it in the Prefettura and then make an appointment. These are presented to the questura along with the marriage certificate and they give you the form to request the permesso di soggiorno (COLenIT) $)^{56}$

49. I want to apply for the permiso de soggiorno, can someone tell me what to do? (ARGenIT) $)^{57}$

50. XXX: I'm going to travel to Colombia and I wanted to know if you can take affettati YYY: Salumes if they are vacuum packed (COLenIT) ${ }^{58}$

The corpus contains other examples of words and phrases in Italian with no particular cultural resonance, but which are very frequent in everyday life ("bellissima", "brutto", "ci sarò") or formulas for greetings, thanks or congratulations ("Buona domenica"; "Buongiorno Padova", "Tanti auguri!", "Bravissima!"), and typical expressions from the field of professions and employment ("pizzaiolo", "mestiere", "lavoro", "con esperienza", "capo", etc.). We also find traces of functional words, such as "mah", "boh", to express doubt, or "cioè" to reformulate. Italian thus serves to emphasise still further the user's level of integration and to reaffirm a plural identity:

51. I've been here for 12 years [ . . . ] Venite a Italia! $E^{\prime}$ bellissima (ARGenIT) $)^{59}$

52. Italy is going through a brutto moment $(\text { COLenIT })^{60}$

53. Ask if your capo will give you a contract (PEenIT) $)^{61}$

54. In your case you would have a better chance in other countries [ . . ] boh I don't know (URenIT) ${ }^{62}$

Sometimes the Italianism is preceded by a translation:

55. You can get a job as an old people's carer (badante) $(\text { PEenIT })^{63}$

The penetration of Italian may also observed in some morphosyntactic structures, such as, for example, the use of the article in front of the possessive adjective $\left({ }^{*} \mathrm{El}\right.$ mío consejo $=$ My advice), the use

56 Para casarse en Italia deben residir en un comune, traer de argentina el acta de nacimiento de ella (apostillada), ir al consulado a colocarle el nulla osta, legalizarlo en la Prefettura y luego sacar turno. Con el acta de matrimonio se presentan a la questura y te dan el formulario para solicitar el permesso di soggiorno.

57 Quiero solicitar el permiso de soggiorno, alguién me puede decir que hacer?

58 XXX: Voy a viajar a Colombia y queria saber si se pueden llevar 'affettati'. YYY: Salumes sì empaquetados al vacío.

59 Llevo aquí 12 años [ ... ] Venite a Italia! E' bellissima.

60 Italia está pasando por un brutto momento.

61 Pregunta si tu capo te hace un contrato.

62 En tu caso tendrías más oportunidad en otros país ... boh no sé.

63 Puedes conseguir trabajo como acompañante de ancianos (badante) 
of the verb "recomendar" with "de + the infinitive" rather than "recomendar que + subjunctive", or the use of the preposition "en" instead of "a" ("*Te recomiendo de no venir en Italia" — "I recommend you don't come to Italy").

Although Spanish is dominant, the importance of learning Italian to find work is underlined. Indeed, we often encounter advice such as: "you'll need to know some Italian"; "I would invest in the language":

56. You should know some Italian so that you can communicate $[\ldots$ ] and go to the police as soon as you arrive (PEenIT) ${ }^{64}$

57. If I were you, I'd invest in the language [Italian] from Argentina, and I'd work on perfecting it on a daily basis (ARGenIT) ${ }^{65}$

It should also be noted that in the group of Argentinians, Italian courses are announced, and the learning of Italian is encouraged through videos and tables explaining some L2 grammar rules, since LA migrants consider that knowing the language favours the integration process and the search for a job. The administrator of the group published, during a period, some videos explaining some grammatical rules of Italian. This is because Argentinians, in many cases, have Italian origins and already know Italian when they arrive in Italy.

\section{Conclusions}

Facebook groups respond to the human need to meet, dialogue, exchange information, and express one's concerns and experiences. Particularly, in the case of migrants, this need is accentuated by a feeling of loneliness and disorientation before and after the trip, when different problems of adaptation need to be addressed and a number of bureaucratic procedures have to be gone through. Such groups provide psychological benefits, offering moral support to many and a magnetic pole for people who wish to emigrate, since they praise the success achieved by the group in Italy or mitigate the narratives about the difficulties encountered; they also provide practical benefits in the form of concrete information about the migration process. In addition, as a discursive practice, Facebook is configured as a privileged space for the negotiation and construction of identity. These groups create a feeling of "community belonging" (Busso 2016) by the fact of being able to share content and personal experiences to create a connection with "friends" both here and over there and by generating trust. In these groups people seek a psychological refuge, an identity based on the sentimental ties that connect people to their country of origin and that are often translated into manifestations of nostalgia towards some cultural or characteristic aspect thereof, with a continuous oscillation between the country of origin and the host nation. The user's sense of identity tends to privilege references to the home country and the use of Spanish to communicate, although we also observe that there is a good level of integration into the new context and that their language is permeable to the influence of Italian.

In addition to this "affiliation" with members of the same group, a "disaffiliation" (Blas Arroyo 2009) is observed with respect to citizens who are stigmatised for having committed a criminal act.

To conclude, we can affirm that, despite the separation of members from their distant places of origin, in migrant Facebook groups, ties with their cultural, political, economic and linguistic roots are not merely unbroken, but are indeed strengthened (De Fina 2014). Thus, SNS become "transnational social spaces" (Faist 1998), that is, fluid environments, without geographical or territorial limits, in which a community reinforces the bonds of solidarity that derive from a shared conception of collective identity, and in which ideas, symbols and cultural materials circulate. The internet and social media forge a deterritorialised "community of feeling". Within SNS, the migrant experiences a

64 Deberías saber algo de italiano para poder comunicar ... e ir a la policía apenas llegas.

65 En tu lugar le metería al idioma [italiano] desde Argentina, e iría a perfeccionarlo en el día a día. 
double-belonging and (re)builds his/her identity, maintaining a strong attachment to his/her country of origin even though he/she makes adjustments, reinterpreting that identity to establish the foundations for a balanced integration, conscious of the fact that he/she will need to adapt to the new context, without forgetting his/her own roots. Migrants thus set themselves up as actors who operate in different political and economic environments that connect different places, intertwining relationships that encompass the country of origin and the host community (Ambrosini 2008).

We therefore share Diminescu's (2008) notion of the 21st century migrant as someone who cannot be defined through ideas of fractured spaces and borders, but rather by concepts of mobility and connectivity, characteristics that change the migratory experience and the management thereof. We will leave for future research the quantitative analysis of linguistic strategies employed in these contexts, as well as the study of multimodal aspects, with the aim of gaining a more complete picture of identity construction in SNS.

Funding: This research received no external funding.

Conflicts of Interest: The author declares no conflict of interest.

\section{References}

Ambrosini, Maurizio. 2008. Un'altra Globalizzazione. La Sfida Delle Migrazioni Transnazionali. Bologna: Il Mulino. Atkinson, Robert. 1998. The Life Story Interview. London: Sage.

Bauman, Zygmunt. 2011. Facebook, L'intimità e L'estimità. Bari: Laterza.

Benwell, Bethan, and Elizabeth Stokoe. 2006. Discourse and Identity. Edinburgh: Edinburgh University Press.

Blas Arroyo, José Luis. 2009. Manifestaciones de la identidad lingüística en el mundo hispánico. In Identidades Sociales e Identidades Lingüísticas. Coordinated by José Jesús Bustos Tovar and Silvia Iglesias Recuero. Madrid: UCM, pp. 119-57.

Boccaglia, Paolo. 2011. Transnazionalismo e percorsi familiari: Profili di genere e di generazione a confronto nell'immigrazione ecuadoriana. Studi di Sociologia 4: 385-404.

Boccagni, Paolo. 2009. Tracce Transnazionali. Vite in Italia e Proiezioni Verso Casa tra i Migranti Ecuadoriani. Milano: FrancoAngeli.

Bonomi, Milin. 2010. Hablamos mità y mità. Varietà linguistiche di immigrati ispanofoni in Italia. In Lingua, Identità e Immigrazione. Prospettive Interdisciplinari. Edited by Maria Vittoria Calvi, Giovanna Mapelli and Milin Bonomi. Milano: FrancoAngeli, pp. 53-69.

Bonomi, Milin. 2018. Mestizos Globales. Transnacionalismo y Prácticas Discursivas en la Población Hispana en Italia. Milano: FrancoAngeli.

Busso, Mariana. 2016. Grupos de migrantes en Facebook: Los reacomodamientos íntimos de la identidad nacional. Inmediaciones de la Comunicación 11: 229-49. [CrossRef]

Calvi, Maria Vittoria. 2011. Aspectos del español hablado por los inmigrados hispanoamericanos en Italia. In Sintaxis y Análisis del Discurso Hablado en Español: Homenaje a Antonio Narbona. Coordinated by José Jesús de Bustos Tovar, Rafael Cano-Aguilar, Elena Méndez García de Paredes and Araceli López Serena. Sevilla: Universidad de Sevilla, vol. 1, pp. 155-72.

Calvi, Maria Vittoria. 2015a. Etiquetas étnicas e identidad en entrevistas a hispanoamericanos en Italia. In Identità e Discorsi. Studi Offerti a Franca Orletti. Edited by Laura Mariottini. Rome: Roma TrePress, pp. 111-30.

Calvi, Maria Vittoria. 2015b. Spagnolo e italiano nelle seconde generazioni di migranti ispanofoni in Italia. Quaderns d'Italià 21: 45-62. [CrossRef]

Caselli, Marco. 2009. Vite Transnazionali? Peruviani e Peruviane a Milano. Milano: FrancoAngeli.

Chen, Wenli. 2010. Internet-usage patterns of immigrants in the process of intercultural adaptation. Cyberpsychology, Behaviour, and Social Networking 13: 387-99. [CrossRef] [PubMed]

Chiesi, Antonio M., and Eugenio Zucchetti, eds. 2003. Immigrati Imprenditori. Milano: Egea.

Damian, Elena, and Erik Van Ingen. 2014. Social Network site usage and personal relations of migrants. Societies 4 : 640-53. [CrossRef]

Dávila, Arlene M. 2008. Latino Spin. Public Image and the Whitewashing of Race. New York: New York University Press.

De Fina, Anna. 2006. Group Identity, Narrative and Self Representations. Edited by Anna de Fina, Deborah Schiffrin and Michael Bamberg. Cambridge: Cambridge University Press, pp. 351-75. 
De Fina, Anna. 2007. Parlando di mangiare. La costruzione interazionale dell'identità. In La Costruzione Interazionale Dell'identià. Repertori Linguistici e Pratiche Discorsive Degli Italiani in Australia. Edited by Anna Ciliberti. Milano: FrancoAngeli, pp. 68-89.

De Fina, Anna. 2014. Spazi transnazionali di costruzione delle identità: I latinos negli Stati Uniti. In Lingue Migranti e Nuovi Paesaggi. Edited by Maria Vittoria Calvi, Irina Bajini and Milin Bonomi. Milano: LED, pp. 215-32.

De Fina, Anna, Deborh Schiffrin, and Michael Bamberg, eds. 2006. Discourse and Identity. Cambridge: Cambridge University Press.

Diminescu, Dana. 2008. The connected migrant: An epistemological manifesto. Social Science Information 47: 565-79. [CrossRef]

Dumitrescu, Domnita. 2014. La alternancia de lenguas como actividad de imagen en el discurso hispanounidense. Pragmática Sociocultural 2: 1-34.

Faist, Thomas. 1998. Transnational social spaces out of international migration: Evolution, significance and future prospects. Archives Européennes de Sociologie 39: 213-47. [CrossRef]

Ferrer, Raquel, Jorge Palacio, Olga Hoyos, and Camilo Madariaga. 2014. Proceso de aculturación del inmigrante: Características individuales y redes sociales. Psicología desde el Caribe 31: 557-76. [CrossRef]

Garcés-Conejos Blitvich, Pilar, and Patricia Bou-Franch. 2014. ¿iHispano y blanco?!: Racialización de la identidad latina en YouTube. DiscursoESociedad 8: 427-61.

Garrreta Bochaca, Jordi. 2016. Asociacionismo e inmigración. El papel de las asociaciones de inmigrantes en España. Intercambio/Échange 1: 164-80.

Hymes, Dell. 1996. Ethnography, Linguistics, Narrative Inequality: Toward an Understanding of Voice. London: Taylor and Francis.

Jankowski, Noam. 2006. Fare comunità con i media: Prospettive storiche, teoriche e di ricerca. In Capire I New Media. Culture, Comunicazione, Innovazione Tecnologica e Istituzioni Sociali. Edited by Leah A. Lievrow and Sonia Livingstone. Milano: Hoepli, pp. 37-66.

Kluge, Bettina. 2015. The Joint Construction of a Supranational Identity in the Latin American Blogging Community in Quebec. In A Sociolinguistics of Diaspora. Latino Practices, Identities, and Ideologies. Edited by Rosina Márquez Reiter and Luisa Martín Rojo. New York and London: Routledge, pp. 181-95.

Knauer, Gabriele. 2005. Lengua y medios de comunicación étnicos: El caso del español en EE. UU. In El Español en América. Aspectos Teóricos, Particularidades, Contactos. Edited by Volker Noll, Klaus Zimmermann and Ingrid Neumann-Holzschuh. Madrid and Frankfurt: Iberoamericana/Vervuert, pp. 133-50.

Komito, Lee. 2011. Social Media and Migration: Virtual Community 2.0. Journal of the American Society for Information Science and Technology 62: 1075-86. [CrossRef]

Leurs, Koen, and Sandra Ponzanesi. 2018. Connected migrants: Encapsulation and cosmopolitanization. Popular Communication 16: 4-20. [CrossRef]

Licoppe, Christian. 2004. 'Connected' presence: The emergence of a new repertoire for managing social relationships in a changing communication technoscape. Environment and Planning D: Society and Space 22: 135-56. [CrossRef]

Mapelli, Giovanna. 2010. Informazione e multiculturalità: Il caso di Expreso Latino. In Lingua, Identità $e$ Immigrazione. Prospettive Interdisciplinari. Edited by Maria Vittoria Calvi, Giovanna Mapelli and Milin Bonomi. Milano: FrancoAngeli, pp. 173-89.

Mapelli, Giovanna. 2014. Il caso Hola mi gente-Ciao amici. Rivista Trimestrale di Scienza dell'Amministrazione 4: 105-18.

Mariottini, Laura. 2014. Spazio latino nei discorsi pubblici mediati: Radio Mambo. RTSA 4: 117-29. [CrossRef]

McGregor, Elaine, and Melissa Siegel. 2013. Social Media and Migration Research. MERIT Working Papers 068, United Nations University-Maastricht Economic and Social Research Institute. Available online: https: //migration.unu.edu/publications/working-papers/social-media-and-migration-research.html (accessed on 10 October 2017).

Melella, Cecilia. 2013. Del Inmigrante Desarraigado al Migrante Conectado. La Construcción de Identidades de los Colectivos Andinos en la Argentina a Través de la Web. Buenos Aires: Instituto de Investigaciones Gino Germani.

Mera, Carolina. 2010. El concepto de diáspora en los estudios migratorios: Reflexiones sobre el caso de las comunidades y movilidades coreanas en el mundo actual. Revista de Historia 12: 1-18. 
Portes, Alejandro, Luis Guarnizo, and Patricia Landolt. 1999. The Study of Transnationalism Pitfalls and Promise of an Emergent Research Field. Ethnic and Racial Studies 22: 217-37. [CrossRef]

Vela Delfa, Cristina. 2014. Estrategias de construcción y mantenimiento de la imagen pública en canales de chat. Aposta. Revista de Ciencias Sociales 63. Available online: http://apostadigital.com/revistav3/hemeroteca/cvela1. pdf (accessed on 20 July 2018).

Vertovec, Steven. 1999. Conceiving and researching transnationalism. Ethnic and Racial Studies 22: 447-62. [CrossRef]

Vincent, Jane. 2015. Stayig in Touch with My mobile Phone in My Pocket and Internet in the Cafés. In $A$ sociolinguistics of Diaspora. Latino Practices, Identities, and Ideologies. Edited by Rosina Márquez Reiter and Luisa Martín Rojo. New York and London: Routledge, pp. 169-80.

Yus Ramos, Francisco. 2011. Ciberpragmática 2.0. Nuevos usos del lenguaje en Internet. Barcelona: Ariel.

Yus Ramos, Francisco. 2014. El discurso de las identidades en línea: El caso de Facebook. Discurso E Sociedad 8: 398-426.

Zijlstra, Judith, and Ilse Van Liempt. 2017. Smart (phone) travelling: Understanding the use of impact of mobile technology on irregular migration journeys. International Journal of Migration and Border Studies 3: 174-91. [CrossRef]

(C) 2019 by the author. Licensee MDPI, Basel, Switzerland. This article is an open access article distributed under the terms and conditions of the Creative Commons Attribution (CC BY) license (http://creativecommons.org/licenses/by/4.0/). 

Article

\title{
"My Child Is a Perfect Bilingual": Cognition, Emotions, and Affectivity in Heritage Language Transmission
}

\author{
Olga Ivanova \\ Spanish Language Department, University of Salamanca, 37008 Salamanca, Spain; olga.ivanova@usal.es \\ Received: 23 April 2019; Accepted: 17 June 2019; Published: 20 June 2019
}

\begin{abstract}
One of the key questions of studies on heritage language (HL) transmission is which factors most likely foster the intergenerational transmission of HL and more saliently favor its acquisition in second-generation speakers. The present study explores the effect of the cognitive and affective disposition of first-generation speakers on the subjective HL proficiency level in the second generation of Russian-speaking immigrants in the town of Salamanca, central Spain. Based on a scalar questionnaire which enquires into the language practices, language attitudes and language motivations of the first-generation speakers, the study analyzes the effect of self-categorization, attitudes towards HL utility, and strategies of HL intergenerational transmission in ten mixed families. The main results of the study show that positive HL affectivity is key to assuring proficient HL acquisition in second-generation speakers, while negative HL affectivity systematically drives unbalanced Spanish-Russian bilingualism in children. The final results are consistent with those of other recent studies on affectivity in HL and suggest the importance of positive attitudes towards HL in its transmission.
\end{abstract}

Keywords: heritage language; bilingualism; Russian language; Spanish language; cognition; self-categorization; assessment; affectivity; attitudes

\section{Introduction}

Heritage language (HL) speakers are assumed to be bilinguals in a non-restrictive sense of the term (Rothman 2007). However, it was already well described in studies on heritage language transmission that achieving full bilingual competence is the exception rather than the rule for second-generation migrants. Bilingualism in heritage speakers is frequently based on misbalanced proficiency of the majority language and heritage language (Montrul 2016) and is usually highly varying among heritage speakers in what concerns their language skills (Chevalier 2004). Despite the level of proficiency in inherited language, heritage speakers are frequently characterised as speakers lacking functional literacy (Rothman 2007), which means they have a restricted stylistic ability to use HL in all contexts. Indeed, it is common for heritage speakers themselves to be aware that their proficiency in the majority language (the language of the host country) is stronger than their skills in the HL (Chevalier 2004).

Unlike other naturalistic bilinguals, heritage language (HL) speakers' bilingualism depends to a higher degree on social circumstances surrounding HL acquisition (Rothman 2007). Considering that heritage speakers are those "whose home language is much less present in their linguistic repertoire than the dominant language of their society" (Scontras et al. 2015), unbalanced HL development is closely linked to environmental factors of language acquisition during childhood.

The HL learner's competence is conditioned by what Brehmer and Kurbangulova (2017) calls "the baseline", or the language input transmitted by the first-generation immigrant to the second-generation speaker. But, apart from the language system itself, sociolinguistic factors like language ideologies, language loyalty, and attitudes to languages play an important role in what is actually transmitted 
from parents to children. At its core, HL is the result of a language shift from first-generation speakers (Polinsky and Kagan 2007), which makes it an essentially sociolinguistic phenomenon. Further, HL transmission directly correlates with language attitudes, one of the key factors in understanding linguistic functionality. Recent studies have put forward that the attitudes from both the first-generation speakers (Au and Oh 2005) and the second-generation speakers themselves (Boon and Polinsky 2015) predict the ultimate success of the latter in HL.

One of the key aspects underlying attitudes to HL is the specific combination of the HL and the majority language (ML), as well as their social values. The higher the prestige and the social value of $\mathrm{HL}$, the more probable its intergenerational maintenance. To mention two illustrative examples, one can focus on two extensive HL communities in the United States: Chinese and Spanish-speaking. While Mandarin speakers share positive attitudes towards both their HL and $\mathrm{ML}$, and consequently support Mandarin in HL promotion and transmission between generations (Wiley et al. 2008), some Spanish speakers in the same country exhibit negative attitudes towards their local varieties of HL (Achugar and Pessoa 2009), which gives rise to the replacement of Spanish by English (Montrul 2018).

The social value of a HL relies on different factors: the economic status and independence of the HL community, usually estimated in terms of professions and the dominating type of work; the social importance and relevance of the HL community, referring to the degree of its self-esteem as a historical entity; and the linguistic status of HL community, which is based on the general perception of HL (Balestra et al. 2008). From these three factors, linguistic status seems to be the most unstable in what concerns its possible impact on HL transmission. This is due to the direct dependence of linguistic status on the cognitive and affective disposition of first-generation speakers.

Starting out from this premise, the present study proposed to explore how the cognitive and affective disposition of first-generation speakers determine the strategies of HL transmission to second-generation speakers and, accordingly, the level of proficiency the latter achieve in HL. For this purpose, the present study focused on the Russian-speaking community living in the town of Salamanca, central Spain, which is characterized by some specific sociolinguistic features. Russian is one of the most numerous minority languages in Spain, with more than 50,000 immigrants living in Spain as of 2019 according to the Spanish National Statistics Institute. The share of the Russian-speaking population, however, is even higher in Spain if one takes into account that many immigrants arriving from post-Soviet countries other than Russia (Ukraine, Belarus, Moldavia, Georgia, etc.) may also be Russian-speaking. Some sources (Riazantsev and Grebeniuk 2014) sustain that immigrants from post-Soviet countries amount to almost a million speakers, and one can only estimate how many of them use Russian as their habitual language.

There have been several waves of immigration from post-Soviet countries to Spain since the dissolution of the USSR. While immediate post-dissolution immigration was characterized by high social and ethnic diversity and followed the purposes of immigration started during perestroika (Kopnina 2005), succeeding migratory waves obeyed purely economic aims first (Tishkov et al. 2005) and both economic and affective aims later. As a result, the Russian-speaking population follows different HL transmission strategies with second-generation learners: from explicitly reinforced maintenance of Russian as a HL (RHL) to total renunciation of this language for being difficult, unpopular, and unnecessary in future (this is a paraphrase of some opinions captured from Facebook pages of Russian-speaking communities in Spain).

In the small town of Salamanca, located two hours to the northwest from Madrid, the members of one of the Russian-speaking communities share many sociolinguistic features. This is a small community of young women who are married to Spanish-speaking men and have been residing in Spain for an average of 13 years. In addition, all of them belong to the same medium-high sociocultural level, assessed from their professions and educational level (for methodological background, see (Ghezzi and Mella 2015)). However, their children vary significantly in what concerns proficiency in RHL: while 
some of them may be easily described as full bilinguals (Russian as heritage language and Spanish as majority language), others have notably limited proficiency in RHL.

Considering this background, in the present study it was hypothesized that HL transmission strategies might depend on the cognitive and affective aspects of first-generation speakers' attitudes. There could be underlying psychological reasons which do not allow first-generation speakers to strongly support HL development in children, and, eventually, these reasons might be identified through a set of sociolinguistic characteristics related to cognition (what kind of speaker am I?), emotions (does my language really serve me for anything?), and affectivity (will my language really serve my children for anything?). The perspective adopted in this work is in line with previous research which showed a strong relationship between positive attitudes towards HL in the family and HL proficiency (Guardado 2018b) and between positive HL attitudes of the second-generation speakers and their language development (Kagan 2012). It goes, however, further in order to explore the link between HL attitudes in the first generation and HL proficiency in the second generation as deeply related factors.

Indeed, the present research could prove this assumption by an attitudes study in the mentioned Russian-speaking community. The members of this community adopt different HL transmission strategies because of the different cognitive, emotional, and affective dispositions they have towards RHL. Accordingly, these psycholinguistic factors seem crucial for understanding both the success and the failure of $\mathrm{HL}$ transmission between generations.

\section{Materials and Methods}

Language loyalty, also known as intergenerational transmission and considered the background for HL maintenance, may be measured as the set of variables of mother tongue, use of language, language proficiency, and attitudes to languages (Rivera-Mills 2012). Following this claim, in this research it was considered that understanding all these aspects is crucial to finding out the strategies of HL transmission in the Russian-speaking community in Salamanca.

In order to collect necessary data, a sociolinguistic questionnaire was designed. The design of the questionnaire did not follow any previously used model. This decision was mainly driven by the needs of the study, which sought to measure three key sociolinguistic parameters: cognitive aspects, emotional aspects, and affective aspects of RHL transmission strategies altogether. Even so, the choice of the items for measuring these parameters relied on both sociolinguistic theory and the results from other studies, as will be described below.

Overall, the questionnaire included 34 scalar items organized into eight sets concerning:

- Personal data (4 items): The collection of these data is conventional in sociolinguistic research and plays a particular role in studies on social networks, where demographic variables refer to attributes of network members (Vetter 2011).

- Data for calculating the sociocultural level (4 items): Here, sociocultural level was considered in terms of a set of static traits which might drive language behavior in HL transmission. In many sociolinguistic studies, as He (2010) reviewed, sociocultural level was taken as a predictor of HL development and the varying degree of proficiency in the second generation. In the present research, sociocultural level was calculated as a variable measured by the profession of the participants, the profession of their parents, and the educational levels of both. This measurement is standard for sociolinguistic research (Ghezzi and Mella 2015).

- Data for calculating the language self-assessment of first-generation speakers (4 items): Self-reporting of language abilities is considered to be a reliable measurement and is consistently used as a standard method of language assessment elsewhere (Kim and Chao 2010). Including language self-assessment is common in research on $\mathrm{HL}$, where several key studies (see, for example, Riehl 2017) have analyzed first-generation language self-assessment and included it as a variable which determines HL transmission strategies.

- Data for calculating characteristics of the social network of first-generation speakers (5 items): Sociolinguistic studies put forward that the structure of the social network may deeply condition 
language uses. Dense social networks usually determine more uniform language practices, while loose (or diffuse) social networks imply non-homogeneous language practices (Blanco Canales 2000). For HL transmission in particular, dense social networks were argued to be responsible for better HL acquisition (see Shively 2018 for an overview).

- Data for analyzing language use in first-generation speakers (6 items): Self-reported language use is a central part of any sociolinguistic questionnaire, since it allows for contextualizing language development. Although many deeper assessment tests may be used for analyzing this aspect (see Polinsky 2017 for an overview), in the present study, self-reported language use in first-generation speakers, in particular, with their children and in the family context was considered sufficient for contextualizing RHL development in the second generation.

- Data for calculating the instrumental and integrative motivation of language use from first-generation speakers to second-generation speakers (4 items): As a key attitudinal factor, motivation is described as predictor of language attainment ( $\mathrm{Lu}$ and $\mathrm{Li}$ 2008), both from the bottom-up perspective of the second generation and from the top-down perspective of the first generation. Frequently, HL parents show more integrative than instrumental motivation for language development in their children (Lindholm-Leary 2001), which might directly influence the way in which HL is transmitted and encouraged.

- Data for calculating the language competence of second-generation speakers (3 items): Proficiency in HL may be assessed in very different ways (see Polinsky 2017 for an overview). Self-reported language proficiency is one of the conventional methods in HL studies, since many studies have found this technique to be highly consistent with real language achievement (Mu 2016). In this research, language proficiency is assessed from reports from first-generation speakers.

- Data for analyzing explicitly stated HL transmission strategies (4 items): Finally, the questionnaire included items concerning HL transmission strategies from the first-generation speakers. Language management strategies proved to be key in the development of language proficiency in the second generation (Brehmer and Kurbangulova 2017) and thus play an important role in understanding language attainment.

The purpose of all included items consisted, on the one hand, of obtaining data for correct sociolinguistics classification of the participants and, on the other hand, of gathering data for cross-analysis of (a.) the cognitive, affective, and emotional characteristics of first-generation speakers and (b.) the RHL proficiency of second-generation speakers. In this way, verification was sought of the correlation between the language self-esteem and motivation of first-generation speakers and HL competence and transmission towards second-generation speakers.

The questionnaire was completed by 10 speakers with similar sociolinguistic profiles: all participants are young women, average age 39, with high education and enrolled in intellectual activity, with a long-term residence in Spain (Table 1). Participants were contacted via a "snowball" technique: new potential participants were found and recruited through social networks (a participant recommends his or her acquaintances to take part in the study), which was previously described as an effective method in sociolinguistic research of small communities (Milroy and Gordon 2003). The selection criteria for participating in the study were (a.) to have Russian as one's mother tongue; (b.) to have a Spanish-speaking partner; (c.) to have been living in Spain for several years; and (d.) to have a child/children exposed to both languages at home. All subjects participated voluntarily and were aware of the purposes of the research and of that they could withdraw from the study at any time. Participation was anonymous and followed the principles of research ethics. 
Table 1. Research sample.

\begin{tabular}{cccc}
\hline Participant & Age & Education Level & Years in Spain \\
\hline 1 & 34 & Tertiary & 11 \\
2 & 35 & Tertiary & 8 \\
3 & 40 & Tertiary & 17 \\
4 & 49 & Tertiary & 3 \\
5 & 39 & Tertiary & 15 \\
6 & 46 & Tertiary & 15 \\
7 & 38 & Tertiary & 20 \\
8 & 42 & Tertiary & 12 \\
9 & 44 & Tertiary & 14 \\
10 & 29 & Tertiary & 16 \\
\hline Average & $39.6( \pm 5.98)$ & & $13.1( \pm 4.86)$ \\
\hline
\end{tabular}

Apart from this, participants share other important sociolinguistic characteristics. All of them are married to Spanish-speaking men, of whom most (a.) either do not speak/do not understand Russian (40\%) or (b.) understand some but do not speak any Russian (40\%). Consequently, the home language policy of the participants is usually based on the simultaneous use of Russian and Spanish, and, in most cases, Spanish is used more frequently than Russian, although all participants started to use RHL with their children from birth.

Before the data are analyzed and discussed, it is necessary to comment on the small sample size used in this research. There are several reasons why only 10 participants took part in the study. First of all, the Russian-speaking community of Salamanca is not the biggest one in Spain; most Russian-speaking migrants live by the Mediterranean coast, while Central Spain has a smaller migrant population originating from post-Soviet countries. Secondly, the sociolinguistic profile this research was looking for-young Russian-speaking women married to Spanish-speaking men-is not the dominant one within the Russian-speaking community in Salamanca. In this respect, the present research resembles other studies on attitudes in HL transmission which were based on small samples (for example, Park and Sarkar 2008).

\section{Results}

On the whole, second-generation speakers are mainly characterized by their mothers as assymetric bilinguals, who share native-like comprehension (listening and reading) but restricted verbal production (speaking and writing) of RHL. In addition, some first-generation speakers underline the presence of a certain foreign accent in their children when speaking Russian. In general, second-generation RHL speakers are dominant bilinguals, some of whom tend to be receptive speakers of Russian. These general results were predictable, since limited exposure to RHL and the lack of formal instruction are hindering factors in HL intergenerational transmission.

Nonetheless, the overall perspective on RHL competence in second-generation speakers can be discussed in terms of internal variation. During their participation in the survey, some first-generation mothers mentioned that their children know Russian as well as their monolingual Russian-speaking peers; others complained that the RHL proficiency of their offspring either started to worsen or did not improve over the years. In order to check the influence of cognitive, affective, and emotional factors on this internal variation between second-generation speakers, their RHL proficiency was analyzed from all three perspectives separately. 


\subsection{Cognitive Characteristics of First-Generation Speakers and Language Competence in the Second Generation}

Applying a cognitive filter to the general perspective on RHL competence in second-generation speakers makes an important difference. Cognition here implies the speaker's understanding of oneself as a speaker and is primarily embodied in self-categorization parameters: an open category which defines the speaker's identity and awareness in interaction (Ziegler 2011).

Four variables from the questionnaire were used for calculating the self-categorization of the first-generation speakers of RHL: (a.) language self-assessment in Spanish (What is your proficiency in Spanish?); (b.) language self-assessment in Russian (Did your competence in Russian change since you moved to Spain?); (c.) language self-assessment as a Russian-Spanish bilingual (What is your language proficiency as a Spanish-Russian bilingual?); and (d.) attitudes towards one's language proficiency as a Russian-Spanish bilingual (Would you change anything in your proficiency as a Spanish-Russian bilingual?). Together, the four parameters make up self-categorization profiles which are based on the participants' assessment of their proficiency in both Russian and Spanish in terms of fossilization and attrition of the mother tongue (Russian), attainment of a second language (Spanish), bilingual competence, and bilingual performance.

According to the obtained scores (maximum 20 points, 5 points maximum for each item), speakers were divided into two groups: a positive self-categorization group and a negative self-categorization group. The positive self-categorization group included speakers who very positively assessed their own proficiency in Spanish and Russian, their bilingual competence, and linguistic self-awareness. These participants achieved scores of 16-20 from 20, or 4 points minimum for each measured variable. The four variables (competence in Russian, competence in Spanish, bilingual Russian-Spanish competence, and attitudes towards one's own language competence) point in the same direction: all of them express positive language ideologies and, thus, positive self-categorization.

The negative or critical self-categorization group included speakers who felt critical about their proficiency in Spanish and Russian, their bilingual competence, and their linguistic self-awareness. These participants achieved scores of 10-15 from 20; that is, from 2 to 3 points for each measured variable. Scores under 10 were not obtained, but if they were, they would point to almost total absence of Russian language maintenance and use in the participant. In this respect, the baseline at 10 points served as a control criterion for assuring a participant's adequacy for research objectives. Their joint characteristics also pointed in the same direction: all of them expressed non-positive language ideologies and, thus, negative self-categorization (Table 2).

Table 2. Sample grouping according to self-categorization.

\begin{tabular}{|c|c|c|c|}
\hline Group & Score Range & Participants & Features \\
\hline Positive self-categorization & $16-20$ & 4 & $\begin{array}{l}\text { - } \\
\text { - }\end{array}$ \\
\hline Critical self-categorization & $10-15$ & 6 & $\begin{array}{l}\text { - } \quad \text { Self-assessed varying proficiency of Spanish (from B1 to C2) } \\
\text { - } \quad \text { Recognition of certain fossilization of native language } \\
\text { - } \quad \begin{array}{l}\text { Critical attitudes towards one's language competence } \\
\text { (self-assessed dominant bilingualism) }\end{array}\end{array}$ \\
\hline
\end{tabular}

Overall, the results showed that belonging to the critical self-categorization group increases the potential of transmitting RHL to a lower level of competence in the second generation. Within the positive self-categorization group, this study found a relatively uniform position in the language competence of the second generation; however, the critical self-categorization group is notably heterogeneous when assessing the same parameters. 
The following illustrative materials summarize the most salient aspects of RHL proficiency dependence on the self-categorization of the first generation (Table 3, Figures 1 and 2). Overall, second-generation speakers have more balanced bilingual competence and more advanced proficiency in RHL if their mothers self-assess positively. Children from such families have better comprehension skills and speaking abilities; they also develop less of a foreign accent in RHL and usually can both read and write in RHL. Contrarily, children of mothers who critically assess themselves may develop highly unbalanced bilingualism in which RHL is the subordinate language. They tend to have less speaking fluency in RHL, in which they also develop a moderate accent; and although all of them read, only few can write.

Table 3. Language competence of the second generation in Russian as a heritage language (RHL) according to first-generation speakers.

\begin{tabular}{ccc}
\hline Aspect of Language Competence & Positive Self-Categorization Parents & Critical Self-Categorization Parents \\
\hline Bilingual competence & $\begin{array}{c}\text { Unbalanced Spanish-Russian } \\
\text { bilingualism }\end{array}$ & $\begin{array}{c}\text { General tendency to unbalanced } \\
\text { Spanish-Russian bilingualism at } \\
\text { different degrees }\end{array}$ \\
\hline Comprehension in RHL & Fully proficient comprehension & Good comprehension \\
\hline Speaking in RHL & Good speaking skills & Moderate speaking skills \\
\hline Accent in RHL & Little accent & From little to noticeable accent \\
\hline Reading skills in RHL & Good reading skills & Good reading skills \\
\hline Writing skills in RHL & Developed writing in most children & Developed writing in few children \\
\hline
\end{tabular}

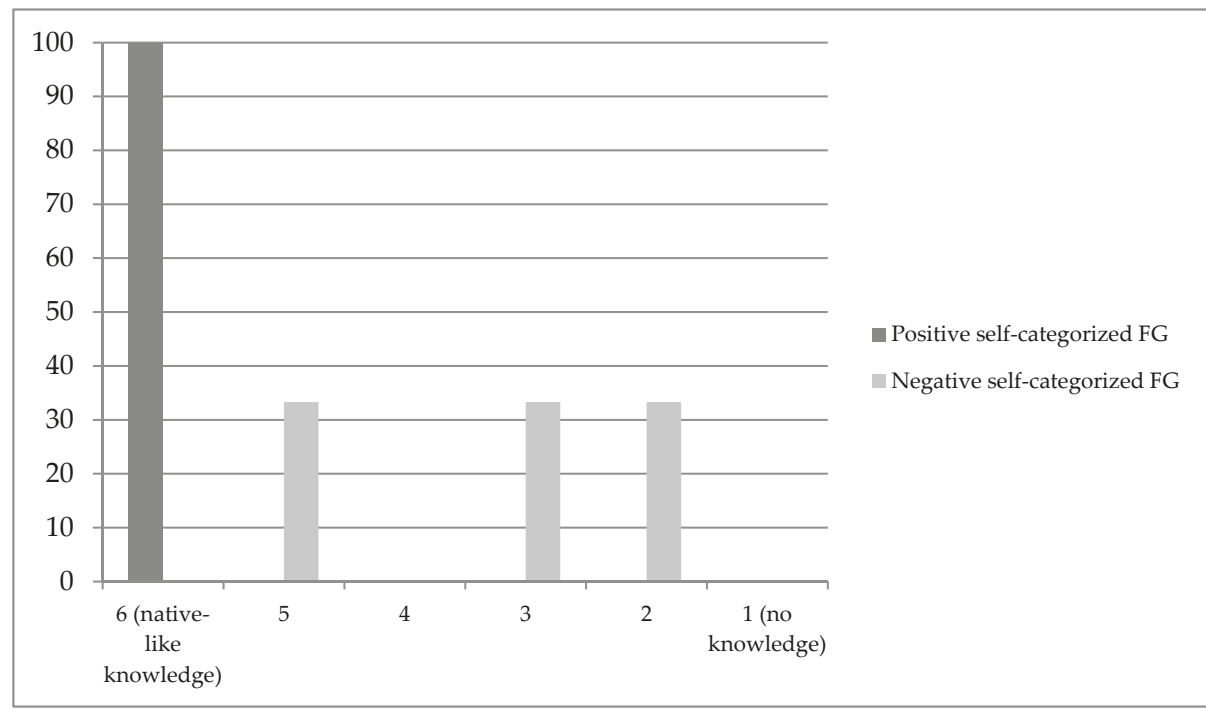

(a)

Figure 1. Cont. 


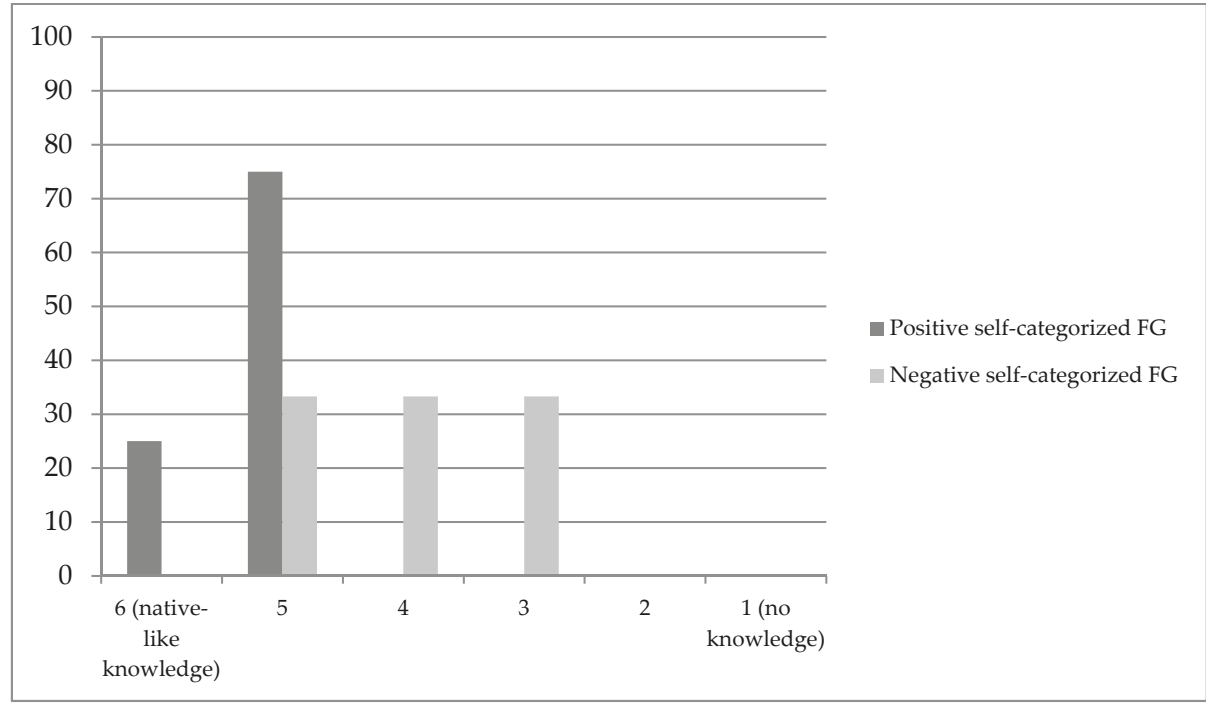

(b)

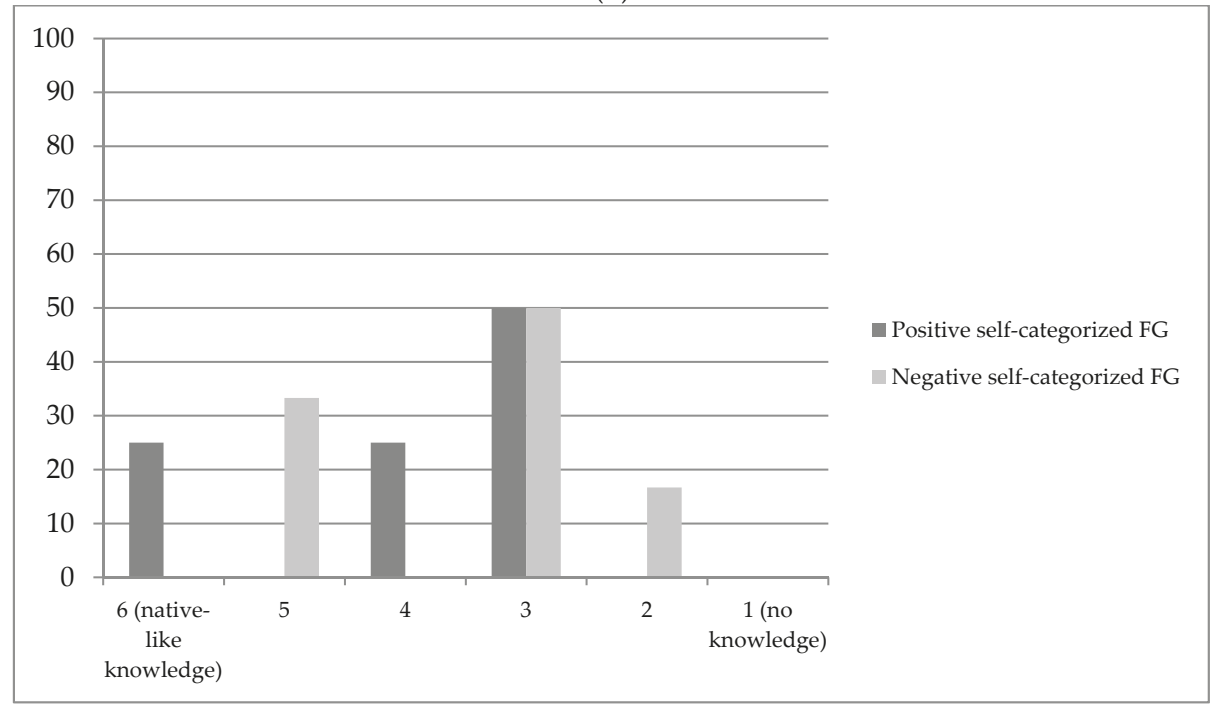

(c)

Figure 1. Cont. 


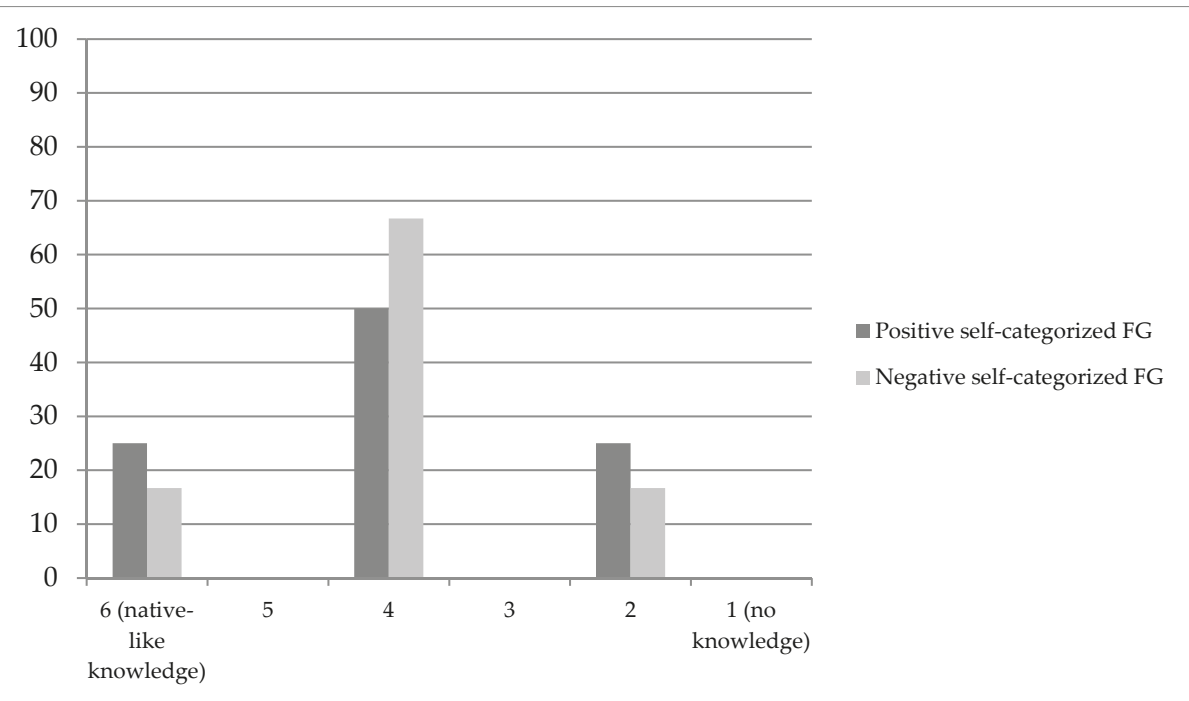

(d)

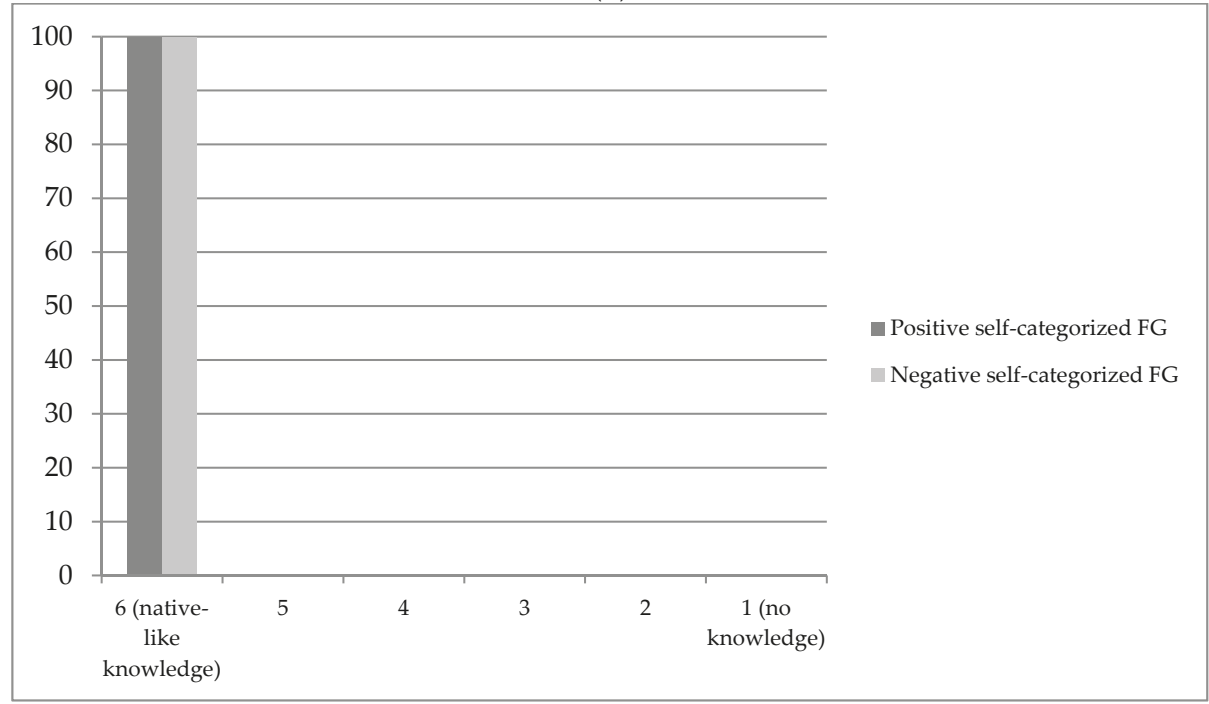

(e)

Figure 1. Cont. 


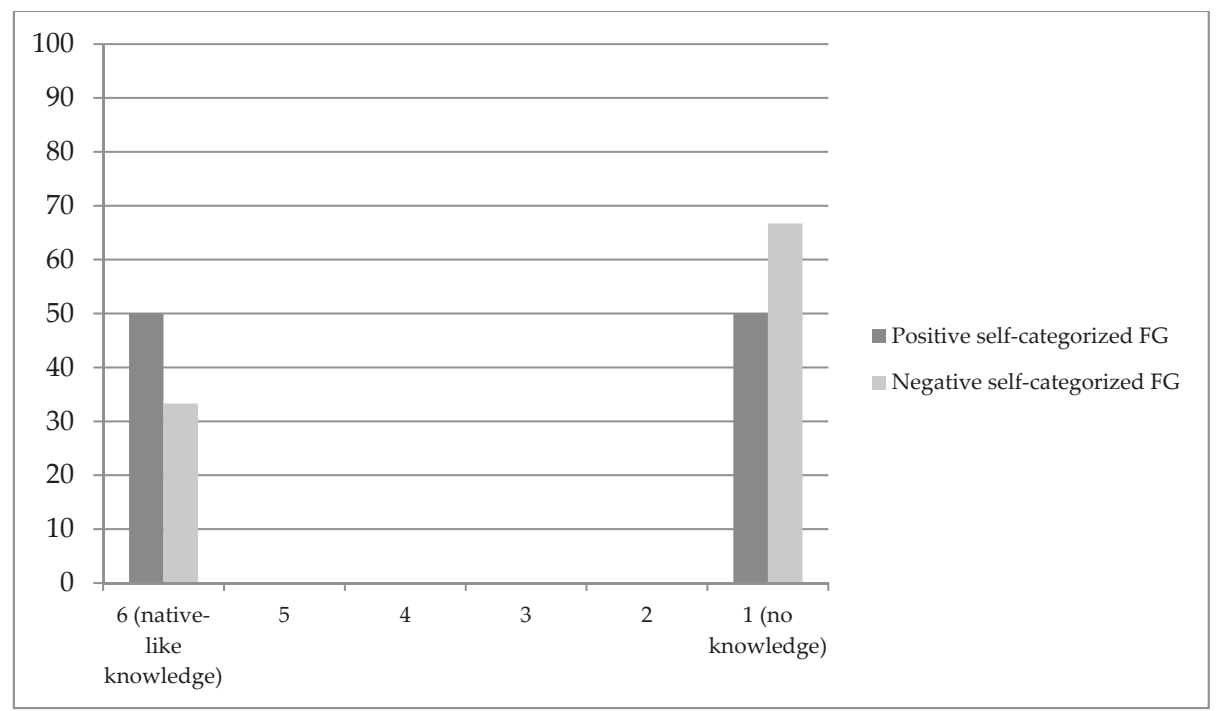

(f)

Figure 1. (a) Bilingual language competence; (b) Comprehension; (c) Speaking; (d) Accent; (e) Reading; (f) Writing. Scalar analysis: 1 means minimal/no knowledge or competence; 6 means native-like knowledge or competence.

\subsection{Emotions and Affectivity of First-Generation Speakers and Language Competence in the Second Generation}

The notion of "language affect" is usually applied to second language learning to describe the set of feelings one has about the target language (Pavlenko 2013). The emotional charge of heritage languages also implies such feelings and refers to different associations the speaking community shares about HL, like its esthetic value (Leedem Shaul 2014) or its value as a bridge to the community's past (Guardado 2018a). As one of the most important affective factors (Mishan 2005), motivation clearly stands out for its direct influence on language acquisition and transmission: positively-oriented affectivity drives better outcomes in language attainment. In this sense, the emotional component is embedded into the motivational angle, and several studies on emotions in L2 acquisition considered their analysis through motivation research (see Oxford 2011 for an overview).

In order to determine to which extent first-generation affectivity and emotional position influence the level of acquisition of RHL in the second generation, the following four variables were analyzed from the questionnare: (a.) the assessed usefulness of RHL for the second generation in the future (Do you believe Russian language will be useful for your children in future?); (b.) the assessed importance of RHL for the second generation (Do you believe Russian language is important for your children?); (c.) the assessed usefulness of RHL in comparison with other foreign languages (Do you believe Russian language is more important for your children than English?); (d.) the assessed expectations for RHL in second-generation speakers (Do you believe your children should know Russian language as well as possible?). These variables refer to both instrumental and integrational motivation: that is, both utilitarian and social and interpersonal motives for language learning (Baker and Jones).

Surprisingly, all participants coincided in considering RHL to be extremely useful and important for second-generation speakers, and they strongly believed that second-generation speakers should know Russian as well as possible. The point of difference between speakers lay in perceptual instrumental motivation concerning the usefulness of Russian against foreign languages, which in the questionnaire explicitly referred to English. 


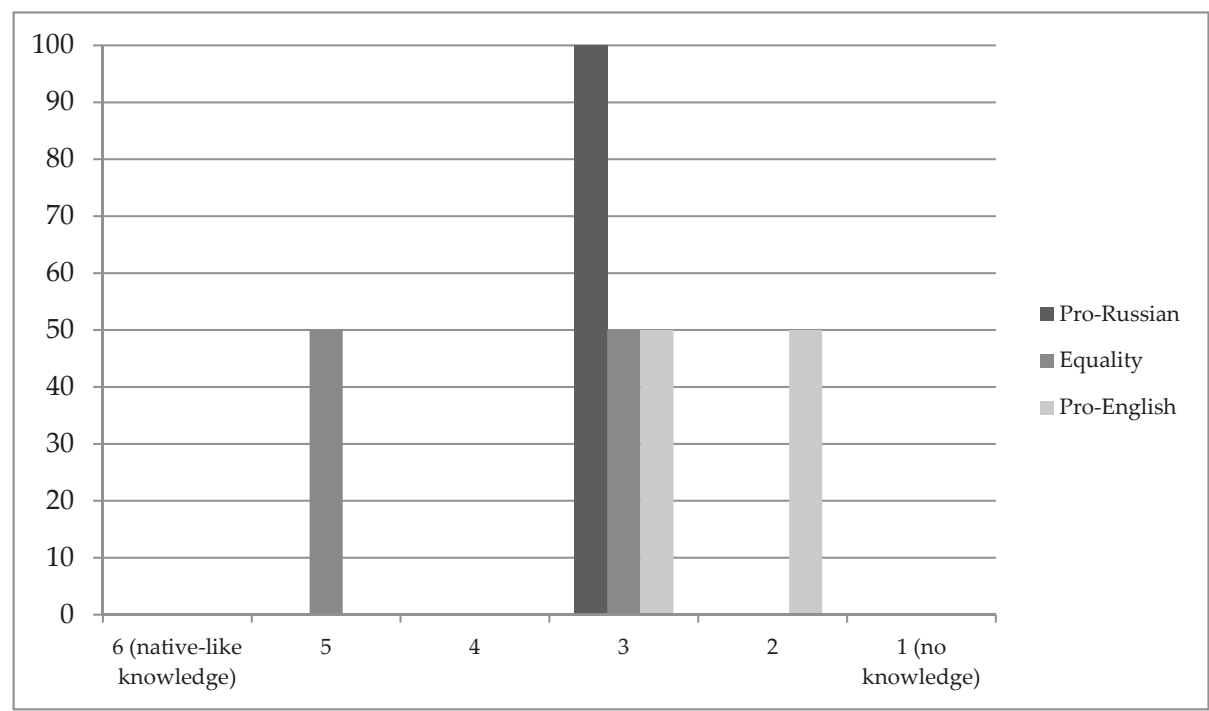

(a)

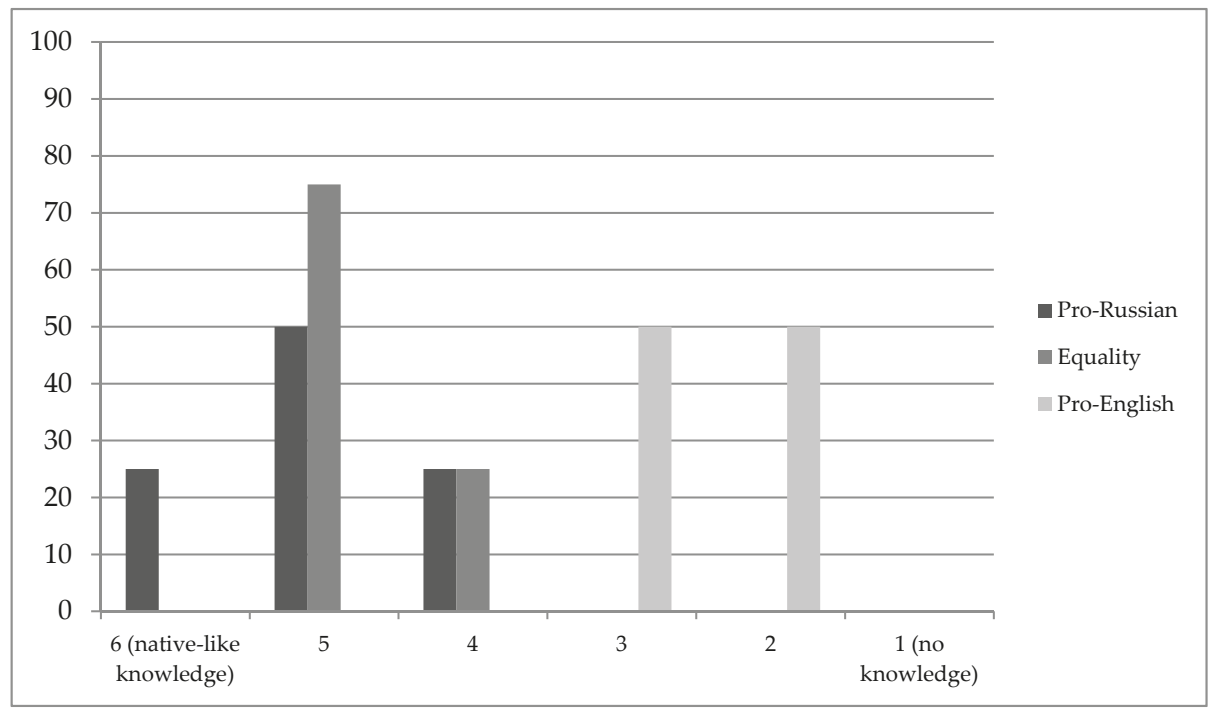

(b)

Figure 2. Cont. 


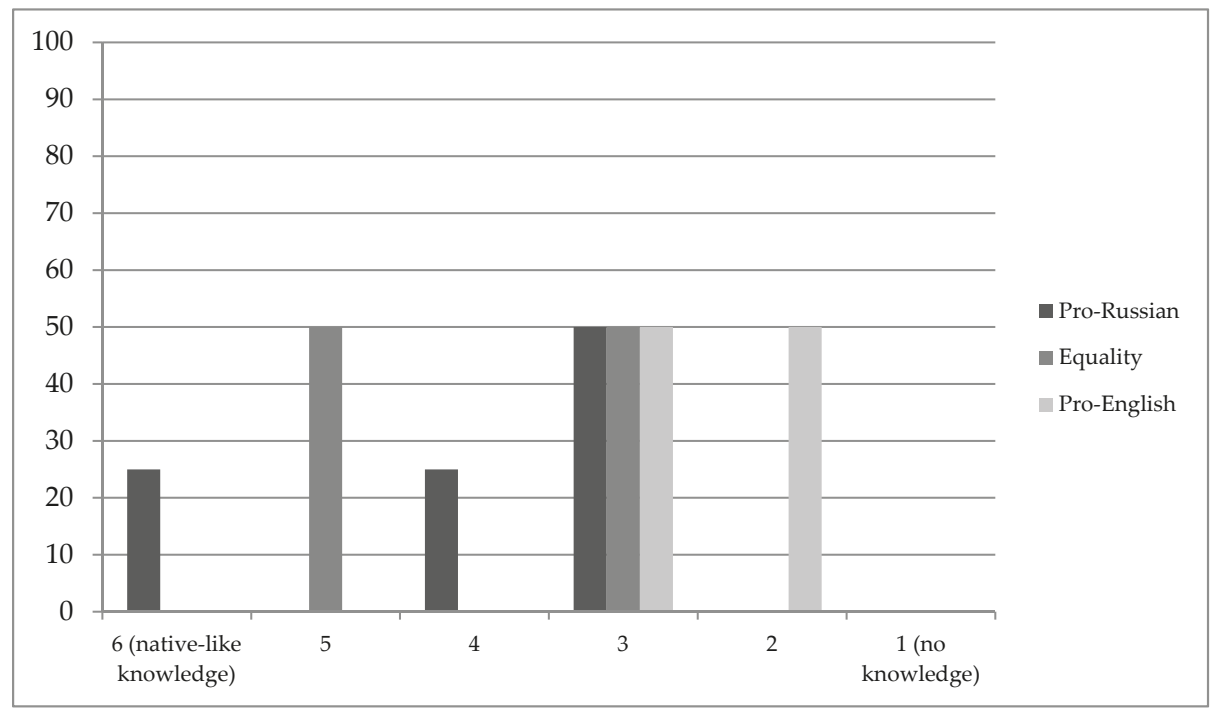

(c)

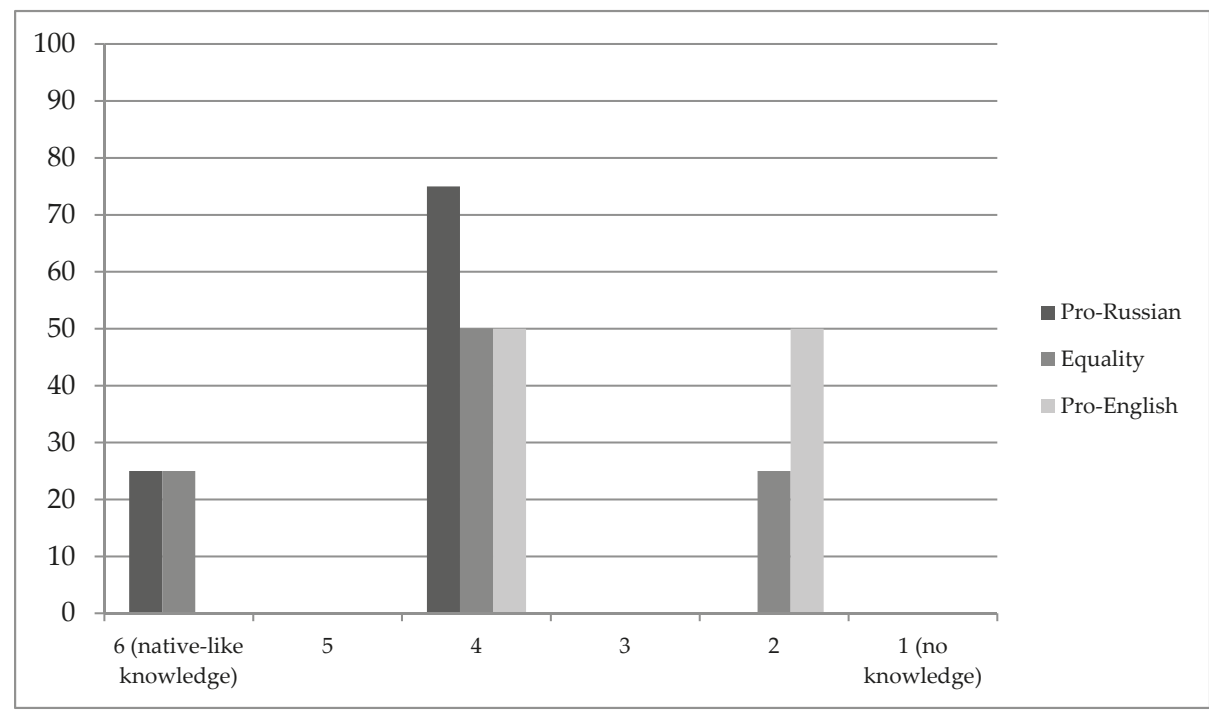

(d)

Figure 2. Cont. 


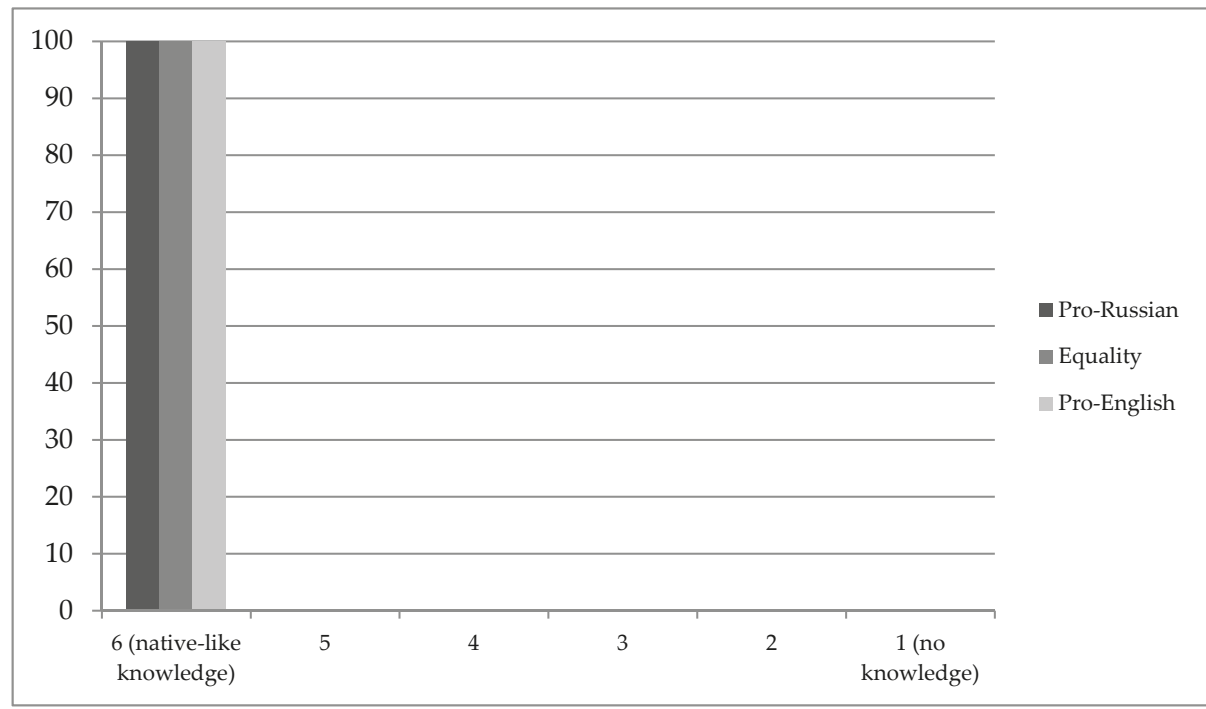

(e)

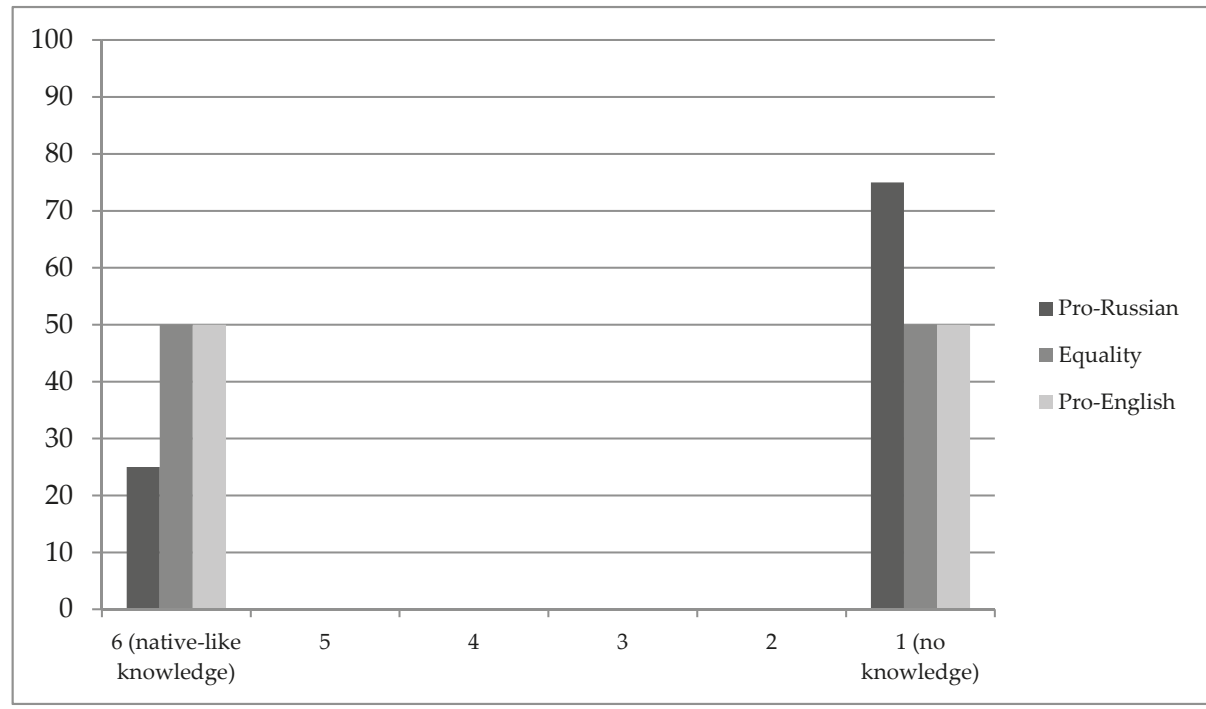

(f)

Figure 2. (a) Bilingual language competence; (b) Comprehension; (c) Speaking; (d) Accent; (e) Reading; (f) Writing. Scalar analysis: 1 means minimal/no knowledge or competence; 6 means native-like knowledge or competence.

According to the obtained scores, speakers were divided into three groups: a pro-Russian motivated group; a pro-English motivated group; and an equality motivated group. The pro-Russian motivated group considered Russian to be more important for the second generation than other languages; the pro-English motivated group considered English to be more important for the second generation than Russian; and the equality motivated group considered both Russian and English to be equally important for second-generation speakers. 
The overall results show that first-generation speakers' positive affectivity towards RHL determines higher levels of assessed language proficiency in the second generation (Table 4). Children from families who believe Russian to be more or as necessary and important as the English language for the second generation are usually assessed by their parents as either balanced or slightly unbalanced bilinguals, with native-like comprehension and reading skills, good speaking abilities with almost no accent, and moderate writing development. Conversely, children proceeding from families who believe Russian not to be so important as English are usually assessed by their parents as true unbalanced bilinguals with none of the skills being at a native-like level: although they have good comprehension and reading skills, their speaking is limited and marked by a noticeable accent, while writing skills are developed in very few of them.

Table 4. Language competence of the second generation of RHL according to first-generation speakers.

\begin{tabular}{|c|c|c|c|}
\hline $\begin{array}{c}\text { Aspect of Language } \\
\text { Competence }\end{array}$ & Pro-Russian Group & Equality Group & Pro-English Group \\
\hline Bilingual competence & $\begin{array}{c}\text { Unbalanced } \\
\text { Spanish-Russian } \\
\text { bilingualism }\end{array}$ & $\begin{array}{c}\text { Balanced and } \\
\text { unbalanced } \\
\text { Spanish-Russian } \\
\text { bilingualism }\end{array}$ & $\begin{array}{l}\text { Unbalanced bilingualism } \\
\text { with prominent } \\
\text { dominance of Spanish }\end{array}$ \\
\hline Comprehension in RHL & $\begin{array}{c}\text { Proficient } \\
\text { comprehension }\end{array}$ & $\begin{array}{c}\text { Proficient } \\
\text { comprehension }\end{array}$ & Good comprehension \\
\hline Speaking in RHL & Good speaking skills & Good speaking skills & Moderate speaking skills \\
\hline Accent in RHL & Little accent & $\begin{array}{c}\text { From little to noticeable } \\
\text { accent }\end{array}$ & Noticeable accent \\
\hline Reading skills in RHL & Good reading skills & Good reading skills & Good reading skills \\
\hline Writing skills in RHL & $\begin{array}{l}\text { Developed writing in } \\
\text { few children }\end{array}$ & $\begin{array}{l}\text { Developed writing in } \\
\text { most children }\end{array}$ & $\begin{array}{l}\text { Developed writing in } \\
\text { few children }\end{array}$ \\
\hline
\end{tabular}

Notably, the pro-Russian group and equality group mostly coincide with the group of positive self-categorization parents. This is a predictable observation, since one may expect positive attitudes to language transmission and learning in every respect.

Figure 2 summarizes the most salient aspects of RHL proficiency dependence on the affective position of the first generation.

\subsection{Who Transmits RHL to Whom and Why}

The participants of this study pointed out the strategies of RHL transmission they usually apply with the second-generation speakers. They were asked about their own practices in Russian language at home (I watch TV/movies in Russian; I read Russian books; I read Russian press; I listen to music in Russian language); about the practices of their children in the Russian language at home (They watch cartoons/movies in Russian; They read/I read them Russian books; They listen to music in Russian language; They play games in Russian language); and about their involvement in the explicit transmission of Russian (Do you teach your children Russian language at home?) and the strategies of such explicit transmission (I read them Russian books; I teach them Russian alphabet for reading; I teach them Russian alphabet for writing; I teach them new words and sentence composition; We describe pictures; We do not have time for learning Russian).

The answers given by the participants allowed us to identify two groups of speakers: (a.) those who make efforts to explicitly transmit RHL to the second generation (overall score from 11 to 20) through different everyday activities and target tasks for contextual maintenance of RHL; and (b.) those whose efforts are weak in transmitting RHL to the second generation (overall score from 0 to 10) since everyday activities and target tasks for contextual maintenance of RHL are random and non-systematic. 
Group (a.) almost completely coincides with the positive self-categorization parents and, thus, with speakers who possess positive affectivity towards RHL and its intergenerational transmission. First-generation mothers who believe themselves to be proficient speakers of Russian as their mother tongue and Spanish as their second language also believe Russian is of high importance for their children and act accordingly by making all efforts in order to assure native-like proficiency in RHL in the second generation. As a result, they assess their children's competence in RHL as totally or almost native-like-some of them referring to it as "My child is a perfect bilingual" — and even equivalent to that of their Russian monolingual peers.

Conversely, Group (b.) coincides with the critical self-categorization parents and, thus, with speakers who do not share positive affectivity towards RHL, but rather consider Russian not as useful as other languages for their children. First-generation mothers who believe themselves to be unbalanced bilinguals and bilinguals with fossilized competence are not always sure whether Russian is of any importance for their descendants, and they do not actually make significant efforts to maintain RHL in the second-generation speakers. As a result, they assess their children's competence in RHL as unbalanced and subordinate to Spanish, with most children being unable to fluently speak and write in their heritage language.

\section{Discussion}

Recent studies on attitudes to heritage languages evidenced the importance of positive cognition and affectivity in understanding why some communities succeed in intergenerational transmission of HL and others do not. Considering HL as a prestigious language and displaying positive attitudes towards HL in the first generation is crucial for avoiding an intergenerational shift to the majority language and for enhancing HL second-generation proficiency (Li 2006). Such proficiency directly correlates with the strength of the parents' positive attitudes towards HL and their involvement in HL transmission (Simpson 2019). Although "one parent, one language" was demonstrated not to be the best context for successful HL intergenerational transmission (Brehmer and Kurbangulova 2017), a positive speaker profile is key for assuring successful HL development in second-generation speakers, even if only one parent is responsible for it.

In this sense, the present study is consistent with other previous research (Park and Sarkar 2008; Pérez-Leroux et al. 2011) which demonstrated the salient importance of language positiveness in the first generation. A small community of Russian-speaking immigrants living in a town in central Spain proves this claim. First-generation speakers with positive self-assessment as Spanish-Russian bilinguals, positive attitudes towards Russian as an ideological and functional tool, and positive motivation for intergenerational transmission of Russian consider their children to be more proficient RHL speakers. Although assessed second-generation RHL proficiency is not homogeneous, positively oriented first-generation speakers are more likely to believe they are raising perfect Russian-Spanish bilinguals with almost no language limitations. Some speakers even believe their children to be fully balanced functional bilinguals, able to natively communicate in RHL as their monolingual peers would do. The family language policy in these cases is based on default language transmission, which is reinforced by conscious and explicit strategies for RHL acquisition in second-generation speakers.

Conversely, first-generation speakers with critical self-assessment as Spanish-Russian bilinguals (usually perceiving themselves as semilinguals: non-native Spanish speakers with fossilized proficiency in Russian) usually share less positive attitudes towards Russian as a functional tool and, as a result, foster RHL intergenerational transmission to a smaller extent. Believing Russian to be less important than English, for example, is more characteristic of critically self-assessed first-generation speakers; consequently, family transmission strategies are more likely to be based on receptive, rather than default, transmission.

In the explanation of these results, the present study does not consider first-generation attitudes to be a misleading variable which would influence the positive assessment of second-generation speakers linearly. Quite the opposite, during surveying, the researcher was surprised to discover that 
positively self-assessed first-generation speakers were more prone to be demanding about their own and their children's HL proficiency. Overall, they tended to comment more on their concerns about RHL maintenance and competence, particularly in the second-generation speakers.

Despite several limitations of this study, it also offers several interesting implications for the scientific comprehension of heritage languages. Certainly, the small size of the sample and its specificity-all participants belong to a reduced community living on a non-typical territory for Russian-speaking immigrants in Spain, most of whom are concentrated on the Mediterranean coast-may influence the final results. Nonetheless, these results highlight an important conclusion about which sociolinguistic context benefits HL intergenerational transmission. First of all, the study puts forward that HL transmission relies on the versatile psycholinguistic profiles of the first-generation speakers, including their cognitive, emotional, and affective predispositions. Although this research shows positivity in cognitive, emotional, and affective factors to coincide in Russian-speaking first-generation immigrants in Salamanca, it may theoretically imply that the three factors should be positively valenced in first-generation speakers to assure successful HL intergenerational transmission.

Either way, the present study highlights positive affectivity towards HL in the first generation to be key to promoting native-like or almost native-like proficiency in HL in the second generation. This idea was also reached by other studies (see Hsieh 2012) which showed the direct dependence of children's proficiency in HL on parents' attitudes to HL. In this respect, and with a focus on future research, it is possible to suggest that first-generation speakers driven to migrate by affective or non-compulsory motives are more prone to transmit their HL successfully. This is a pending task, to which one should add the necessity to compare the results obtained in this study with similar data from other Russian-speaking communities in Spain.

Funding: This research received no external funding.

Conflicts of Interest: The author declares no conflict of interest.

\section{References}

Achugar, Mariana, and Silvia Pessoa. 2009. Power and place: Language attitudes towards Spanish in a bilingual academic community in southwest Texas. Spanish in Context 6: 199-223. [CrossRef]

$\mathrm{Au}$, Terry, and Janet Oh. 2005. Korean as a heritage language. In Handbook of East Asian Psycholinguistics. Part III: Korean Psycholinguistics. Edited by Li Ping. Cambridge: Cambridge University Press, pp. 268-75.

Baker, Colin, and Sylvia Prys Jones. Encyclopedia of Bilingualism and Bilingual Education. Clevedon: Multilingual Matters.

Balestra, Alejandra, Glenn Martínez, and María Irene Moyna. 2008. Recovering the U.S. Hispanic linguistic heritage. In Recovering the U.S. Hispanic Linguistic Heritage: Sociohistorical Approaches to Spanish in the United States. Edited by Alejandra Balestra, Glenn Martínez and María Irene Moyn. Houston: Arte Público Press, pp. 2-74.

Blanco Canales, Ana. 2000. Redes sociales y variación sociolingüística. Revista Española de Investigaciones Sociológicas 92: 115-36. [CrossRef]

Boon, Erin, and Maria Polinsky. 2015. From silence to voice: Empowering heritage language speakers in the 21st century. In Informes del Observatorio/Observatorio Reports. Cambridge: Instituto Cervantes at FAS-Harvard University.

Brehmer, Bernhard, and Tatjana Kurbangulova. 2017. Lost in transmission? Family language input and its role for the development of Russian as a heritage language in Germany. In Integration, Identity and Language Maintenance in Young Immigrants. Russian Germans and German Russians. Edited by Ludmila Isurin and Claudia Maria Riehl. Amsterdam and Philadelphia: John Benjamins, pp. 225-68.

Chevalier, Joan F. 2004. Heritage language literacy: Theory and practice. Heritage Language Journal 2: 1-19.

Ghezzi, Maddalena, and María Sampedro Mella. 2015. Influencia de la variable nivel sociocultural en el uso de las formas de tratamiento. Pragmalingüística 23: 61-78. [CrossRef]

Guardado, Martin. 2018a. Discourse, Ideology and Heritage Language Socialization. Micro and Macro Perspective. Boston and Berlin: De Gruyter Mouton. 
Guardado, Martin. 2018b. Spanish as a minority/heritage language in Canada and the UK. In The Routledge Handbook of Spanish as a Heritage Language. Edited by Kim Potowski. Abingdon and New York: Routledge, pp. 537-54.

He, Agnes Weiyun. 2010. The Heart of Heritage: Dimenions of Heritage Language Acquisition. Annual Review of Applied Linguistics 30: 66-82. [CrossRef]

Hsieh, May H. 2012. From Invisible to Visible. Stories of Taiwanese Hakka Heritage Teachers' Journeys. Bloomington: Xlibris.

Kagan, Olga. 2012. Intercultural competence of heritage language learners: Motivation, identity, language attitudes, and the curriculum. Proceedings of Intercultural Competence Conference 2: 72-84.

Kim, Su Yeong, and Ruth K. Chao. 2010. Heritage Language Fluency, Ethnic Identity, and School Effort of Immigrant Chinese and Mexican Adolescents. Cultural Diversity \& Ethnic Minority Psychology 15: 27-37.

Kopnina, Helen. 2005. East to West Migration: Russian Migrants in Western Europe. Aldershot: Ashgate.

Leedem Shaul, David. 2014. Linguistic Ideologies of Native American Language Revitalization. Doing the Lost Language Ghost Dance. London: Springer.

Li, Guofang. 2006. The role of parents in heritage language maintenance and development. Case studies of Chinese immigrant children's home practices. In Heritage Language Development. Focus on East Asian Immigrants. Edited by Kimi Kondo-Brown. Amsterdam and Philadelphia: John Benjamins, pp. 15-32.

Lindholm-Leary, Kathryn J. 2001. Dual Language Education. Clevedon: Multilingual Matters.

Lu, Xuehong, and Guofang Li. 2008. Motivation and achievement in Chinese language learning: A comparative study. In Chinese as a Heritage Language: Fostering Rooted World Citizenry. Edited by Agnes Weiyun He and Richard Schmidt. Honolulu: University of Hawai'I at Manoa, pp. 89-108.

Milroy, Lesley, and Matthew Gordon. 2003. Sociolinguistics. Method and Interpretation. Oxford: Blackwell.

Mishan, Freda. 2005. Designing Authenticity into Language Learning Materials. Bristol and Portland: Intellect.

Montrul, Silvina. 2016. The Acquisition of Heritage Languages. Cambridge: Cambridge University Press.

Montrul, Silvina. 2018. Morphology, syntax, and semantics in Spanish as a heritage language. In The Routledge Handbook of Spanish as a Heritage Language. Edited by Kim Potowski. London and New York: Routledge, pp. 145-63.

$\mathrm{Mu}$, Guanglun Michael. 2016. Learning Chinese as a Heritage Language. An Australian Perspective. Bristol: Multilingual Matters.

Oxford, Rebecca L. 2011. Teaching and Researching Language Learning Strategies. London and New York: Routledge.

Park, Seong Man, and Mela Sarkar. 2008. Parents' attitudes toward heritage language maintenance for their children and their efforts to help their children maintain the heritage language: A case study of Korean-Canadian Immigrants. Language, Culture and Curriculum 20: 223-35. [CrossRef]

Pavlenko, Aneta. 2013. The affective turn in SLA: From 'affective factors' to 'language desire' and 'commodification of affect'. In The Affective Dimension in Second Language Acquisition. Edited by Danuta Gabrýs-Barker and Joanna Bielska. Bristol: Multilingual Matters, pp. 3-28.

Pérez-Leroux, Anat, Alejandro Cuza, and Danielle Thomas. 2011. Clitic placement in Spanish-English bilingual children. Bilingualism: Language and Cognition 14: 221-32. [CrossRef]

Polinsky, Maria. 2017. Heritage Languages and Their Speakers. Cambridge: Cambridge University Press.

Polinsky, Maria, and Olga Kagan. 2007. Heritage languages: In the 'wild' and in the classroom. Language and Linguistics Compass 1: 368-95. [CrossRef]

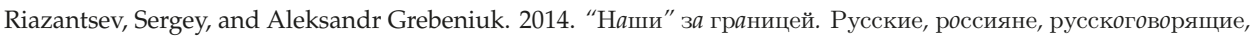
соотечественники: Расселение, интеграция и возвратная миграция в Россию. Москва: ИСПИ РАН, ["The Ours" Abroad. Russians, Russian-Speaking, Compats: Distribution, Integration and Return to Russia. Moscow: ISPI RAN].

Riehl, Claudia Maria. 2017. Russian-Germans: Historical background, language varieties, and language use. In Integration, Identity and Language Maintenance in Young Immigrants. Russian Germans or German Russians. Edited by Ludmila Isurin and Claudia Maria Riehl. Amsterdam and Philadelphia: John Benjamins, pp. 11-40.

Rivera-Mills, Susana V. 2012. Spanish heritage language maintenance: Its legacy and its future. In Spanish as a Heritage Language in the United States: The State of the Field. Edited by Sara M. Beaudrie and Marta Fairclough. Washington, DC: Georgetown University Press, pp. 21-42.

Rothman, Jason. 2007. Heritage speaker competence differences, language change, and input type: Inflected infinitives in Heritage Brazilian Portuguese. International Journal of Bilingualism 11: 359-89. [CrossRef] 
Scontras, Gregory, Zuzanna Fuchs, and Maria Polinsky. 2015. Heritage language and linguistic theory. Frontiers in Psychology 6: 1-20. [CrossRef] [PubMed]

Shively, Rachel. 2018. Spanish heritage speakers studying abroad. In The Routledge Handbook of Spanish as a Heritage Language. Edited by Kim Potowski. Abingdon and New York: Routledge, pp. 403-19.

Simpson, Andrew. 2019. Language and Society. An Introduction. Oxford: Oxford University Press.

Tishkov, Valery, Zhanna Zayinchkovskaya, and Galina Vitkovskaya. 2005. Migration in the Countries of the Former Soviet Union. A Paper Prepared for the Policy Analysis and Research Programme of the Global Commission on International Migration. Geneva: Global Commission on International Migration.

Vetter, Eva. 2011. Social network. In The SAGE Handbook of Sociolinguistics. Edited by Ruth Wodak, Barbara Johnstone and Paul Kerswill. London: SAGE, pp. 208-18.

Wiley, Terrence G., Gerda de Klerk, Mengying Li, Na Liu, Yun Teng, and Ping Yang. 2008. Attitudes toward Mandarin, heritage languages, and dialect diversity among Chinese immigrants and international students in the United States. In Chinese as Heritage Language: Fostering Rooted World Citizenry. Edited by Agnes Weiyun He and Yun Xiao. Honolulu: University of Hawai'i at Manoa, pp. 67-88.

Ziegler, Gudrun. 2011. From the learners to the actor: Categorizations as loci of language acquisition. In Handbook of Multilingualism and Multiculturalism. Edited by Geneviève Zarate, Danielle Lévy and Claire Kramsch. Paris: Éditions des Archives Contemporaines, pp. 29-32.

(C) 2019 by the author. Licensee MDPI, Basel, Switzerland. This article is an open access article distributed under the terms and conditions of the Creative Commons Attribution (CC BY) license (http://creativecommons.org/licenses/by/4.0/). 
Article

\title{
The Use of the Present Perfect (pretérito perfecto compuesto) with Aoristic Value in the Speech of Latin American Students
}

\author{
Rosana Ariolfo \\ Department LeLiA, University of Bari, 70121 Bari, Italy; rosanaariolfo@yahoo.com
}

Received: 25 April 2019; Accepted: 29 May 2019; Published: 3 June 2019

\begin{abstract}
This article focuses on the use of the present perfect (he cantado) with aoristic value, or rather, on pre-hodiernal contexts in which, as a rule, the simple form (canté) should appear. This verbal form is examined on the basis of a corpus of semi-guided interviews provided to Latin American students living in Genoa and taking into account its characteristics, the syntactic environment in which it is used, combinations with other verb forms, adverbial complements, temporal expressions, deixis and the communicative context in which it is inserted. This phenomenon has already been analyzed in several recent studies carried out by Azpiazu, Kempas, Montoro del Arco, Bermejo Calleja and Soto, both in European and American contexts, and has led to the conclusion that it could be related to discursive strategies of the speaker as well as to a convergence towards the local language (i.e., Italian).
\end{abstract}

Keywords: past simple; present perfect; aorist; American Spanish; Latin American immigration; orality

\section{Introduction}

\subsection{Values of the Pretérito Perfecto Compuesto in the Spanish Language in Spain and America}

The functional distribution between the tenses of pretérito perfecto simple (PPS) and pretérito perfecto compuesto (PPC) is a topic that has been studied by several authors (Caravedo and Klee 2012; Escobar 1997; Hurtado 2009; Jara Yupanqui 2009; among others) From an aspectual point of view, the former is associated to the aorist (or perfective), while from a temporal perspective it represents a delimited event with a beginning and end located in a pre-hodiernal past that is sometimes marked by the presence of a temporal locator (TL) which disassociates the event from the present of the speaker (yesterday, two weeks ago, last month). The latter is associated with the perfect aspect and at a temporal level is bound to the moment of enunciation to express events that the speaker considers not accomplished or that have occurred in the immediate past or in the recent hodiernal past (Luisa ha llegado hace un rato $)^{1}$ and is sometimes supported by temporary locators linked to the present (now, today, this week, this year, etc.).

Although the Nueva Gramática de la Lengua Española ('New Grammar of the Spanish Language' (NGLE)) (RAE and ASALE 2009, p. 1721) points out the difficulty of drawing a clear dividing line between the uses and values of the PPS and those of the PPC in Spanish due to the great dialectal variety that the two forms present in this language (especially the latter), it is possible to highlight that European Spanish, with the exception of Galicia and the Canary Islands, tends to develop the compound form to the detriment of the simple, while American Spanish is prone to the reverse

1 The examples in Section 1 belong to the NGLE (2009), pp. 1721-1736. 
phenomenon. In any case, several studies carried out in the Latin American framework have shown that the PPC is used more than what is believed in American Spanish.

The NGLE outlines the uses of the PPC and classifies them by dialectal areas. However, given that the pretérito perfecto compuesto is the verbal form that presents the greatest diatopic variety, its geographical distribution is very complex. The NGLE is very clear in terms of the dialectal values of the compound form in the Spanish spoken in Spain, but not to the same extent as regards the Spanish spoken in America. This could be due to the proposed distribution area being rather generic, and does not reflect all the dialectal nuances of the uses of the PPC.

Taking into account what is stated in the NGLE, only three of the described values are used in a generalized manner throughout Spanish-speaking geographical areas: the experiential value $(\mathrm{Ha}$ viajado muchas veces a Europa), the resultative/evidential value or of verified facts (;Cómo han subido los precios!) and the one related to topical or recent news (Ha resultado herido). The remaining values are used in all dialectal areas, although with different interpretations, or are used exclusively in certain areas.

In addition to the three values mentioned above, the NGLE explains other values of the PPC, such as: continuous value, hodiernal or recent events, evidential narrative, non-resultative evidential, iterative and resultative values.

The PPC with continuous value is used in Spain and Latin America, but the interpretation of the extent of the aforementioned situation varies according to the geographical area in which the compound verbal form is used. Thus, in European Spanish (except in that spoken in the Canary Islands and in the Northwest of the Peninsula), in the Antilles, Andean (especially in Bolivia and Peru) and in the Northwest of Argentina, the sentences Sigo viviendo aquí or Ya no vivo aquí can be deduced from the sentence He vivido aqui treinta años. However, in the rest of the American areas, the interpretation of this sentence with the present perfect continuous tense (Sigo viviendo aquí) is almost forced.

In much of Spain, Peru, Bolivia, Paraguay, northwestern Argentina and part of Central America, the hodiernal PPC (for recent events) is used (limited to the current day: Luisa ha llegado hace un rato) and the extended pre-hodiernal PPC (for facts presented as current) is used without the presence of temporal locators (Luisa me ha regalado este vestido).

The PPC with narrative evidential value is used after the simple past or imperfect tense (Ayer fuimos a una fiesta. ;Cómo nos hemos reído!) in Central America (Nicaragua, Costa Rica and other Central American countries), Peru and several countries in the Caribbean area to bring the events closer to the perspective of the listener or the reader.

The PPC with non-resultative evidential value is used only in part of the Andean area (particularly in Ecuador) to highlight the novelty or surprise of what has just been revealed. It is not related to temporality, and is probably a linguistic calque of the Ecuadorian Quichua. Thus, the phrase Ha sido caro expresses surprise after having discovered the price of a product.

Past tenses either of the resultative and prospective type, or for planning, are also used when it is needed to emphatically express an action as accomplished, even though it has not been carried out yet (Mañana a estas horas, seguro que ya hemos terminado el informe). However, the PPS is preferred in Mexico, some Central American countries, Río de la Plata and Peru.

The PPC shares the usual or iterative interpretation value with the present tense and usually appears with universal quantifiers (cuando, cada vez, siempre, etc.; when, every time, always, etc.), but it is not specified in what geographical areas this use is common (Siempre que han podido nos han fastidiado).

\subsection{Innovative Values of the PPC}

The NGLE's description of the use of the PPC is very detailed, yet it does not reflect all the values that are peculiar to the different dialectal varieties. Reference is made to values and uses of the pretérito perfecto compuesto that are still not very well known, such as evidential, semantic-pragmatic, narrative 
and discursive values ${ }^{2}$, as documented by Montero Cádiz (2015), Bustamante (1991), Pfänder and Palacios (2013), Escobar (1997), Palacios Alcaine (2007), Caravedo and Klee (2012), Jara Yupanqui (2009, 2011, 2013), Moreno Burgos (2015), De Jonge (1999), Rodríguez Louro (2009) and Rodrigues Parrihna (2014) in their studies. Specifically, in works by Caravedo and Klee (2012) and Jara Yupanqui (2011, 2013), the presence of the PPC in narrative clauses is highlighted more in Andean Spanish than in the Spanish of Lima to indicate emotional content, psychological relevance for the speaker, narrative climax, change of theme, specification, comment, reported speech, succession, outcome and summary. On the other hand, Escobar's work (Escobar 1997), also in the area of Peru, underlines the use of the PPC when the speaker wishes to emphasize their protagonism or direct involvement, as a witness or as an agent, in the events they narrate. As far as the area of Ecuador is concerned, however, Palacios Alcaine (2007) gives evidence of the opposite phenomenon-that the speaker selects the compound verbal form when they want to express their detachment from the message they are conveying because they did not personally experience what they expresses in their utterance and are either not sure what has happened, or do not trust the source of information.

In contrast to the general considerations discussed so far, two quite clear trends stand out that are probably due to the influence of contact with other languages. On the one hand, there is resistance to the grammaticalization of the PPC, even with the value of perfecto, for which canté is used indistinctly for both the aorist and the perfecto (Ayer/hoy canté). As indicated above, it is a secondary option in European Spanish, as its use has been located in Galicia, Asturias and the Canary Islands, while it is a primary option in American Spanish. There is another phenomenon that is the aoristicization of the PPC, or rather the use of he cantado in pre-hodiernal contexts that cannot be linked to the moment of speech (Ayer he ido al cine). Literature on the subject shows that there is a tendency towards the consolidation of periphrastic forms to the detriment of simple forms. As mentioned previously, this use exists in some areas of the Andean Spanish spoken on the Peruvian coast, in Argentina and in Bolivia, but is not recognized by the NGLE in European Spanish, although it has been registered in areas of peninsular Spanish and other areas of Latin America.

\subsection{PPC with Aoristic Value}

The NGLE also recognizes the use of the perfective or aoristic PPC in Bolivia, on the Peruvian coast, in Paraguay and in the northwest of Argentina, with temporal expressions peculiar to the past tense (Luisa ha llegado a esta ciudad hace tres años), but no mention is made of its use in other areas of Latin America or in European Spanish. This has been documented in studies by De Mello (1994), Serrano (1994) and Bermejo Calleja (2017) in Madrid, Kempas $(2008,2014)$ in several areas of Spain, Burgo (2008) in the Basque Country, Azpiazu (2012, 2014, 2015) in Salamanca and San Sebastián and Montoro del Arco (2017) in Granada.

The use of pretérito perfecto compuesto (he cantado) in pre-hodiernal contexts, or rather, when the verb designates perfective events (events that occurred a day before the enunciation), occurs in contexts in which the simple verbal form should appear (canté) according to the standard rule. However, if the verb is located in a wide temporal space that in some way includes the enunciation moment (EM), the phenomenon does not cause any perplexity given that, as reported above, such use is considered by the NGLE to be an 'extended present' value normally used in Spain. Nevertheless, as Azpiazu (2012) points out, it is strange when the PPC is used together with temporal locators (TL) that clearly separate the expressed event from the moment of enunciation, or when it is used in narrative contexts located in a past detached from the present. Therefore, Azpiazu (2012) underlines that the sentence Ayer he visto a Pedro paseando con su perro would be considered an incorrect or ungrammatical sequence from the theoretical-descriptive perspective of the standard language. This phenomenon, called 'aoristic drift' (Squartini and Bertinetto 2000), deriva aorística (Azpiazu 2014) or aoristización (Kempas 2008; Azpiazu

2 About the use of the PPC by Latin American speakers in migration contexts see Ariolfo (2018). 
2014), initially arises in colloquial speech and consists of the semantic evolution of aspectual original values of the perfect of the PPC towards aoristic values, typical of pretérito perfecto simple. In Section 1 , it was highlight that the NGLE records the extension of the value of the PPC with aoristic aspect on the Peruvian coast, in Bolivia, in Paraguay and in the northwest of Argentina. As for European Spanish, many of the authors who have studied the subject, both in Spanish and in other languages, point out the functional grammaticalization where the compound form gains values that are typical of the pretérito perfecto simple. However, the author prefers to be more cautious about the phenomenon in the Peninsula because, in her opinion, it deals with

un sistema no asentado, donde el uso real de la lengua no coincide con el estándar representado en la escritura, a lo cual debe añadirse una gran dispersión dialectal, de la que apenas tenemos un conocimiento ordenado. (Azpiazu 2012, p. 333) ('an unsettled system, where the actual use of the language does not coincide with the standard represented in the writing system, characterized as well by a large dialectal dispersion of which we barely have a systematic knowledge.')

Hence, this use of the PPC has been documented and analyzed in Europe by De Mello (1994), Serrano (1994) and Bermejo Calleja (2017) in Madrid, by Kempas (2008) in several areas of Spain, by Burgo (2008) in the Basque Country, by Azpiazu (2012, 2014, 2015) in Salamanca and San Sebastián and by Montoro del Arco (2017) in Granada. In the Latin American scenario, the phenomenon has been studied by Soto (2014) in nine American capitals, Mexico City, San Juan in Puerto Rico, San José in Costa Rica, Caracas, Bogotá, Lima, La Paz, Buenos Aires and Santiago in Chile in contrast to the use of the PPC in Madrid. His study gives rise to interesting considerations. On the one hand, the greatest occurrence of aorist usage occurs in areas where the PPC is more commonly used. On the other hand, the aorist is related to the relevance that the narrated facts have for the speaker, and this expresses the importance of subjectivization. There are three situations regarding the aoristicization of the PPC defined by Soto: in most American capitals, use is made of the resultative, existential or continuative PPC, although possibly with an associated subjective valuation; in Madrid, where hodiernals and sporadic aorist forms exist together with the cases of perfect; and in La Paz and Lima, where aorist values of relevance occur in addition to perfect tenses.

According to Soto (2014), there is a close relationship between PPC frequency, progress in aoristic drift and subjectivization. Although it is not possible to establish a strict causal relationship between these phenomena, it can be assumed that the aoristic drift may be the consequence of a process of gradual subjectivization of the PPC; objective restrictions are eliminated and the speaker's subjectivity prevails, so not only do they relate facts, but they also evaluate the relevance of those facts at the moment of speech.

On the other hand, Bermejo Calleja (2017) states that the use of the aoristic PPC is related to the speaker's strategies. Therefore, in his narrations a fragment of the narrated event is brought closer to the enunciation situation, achieving an expressive, discursive type of effect and sometimes coloring the story with emotional and affective values. In this sense, the use of the aoristic PPC would be a strategy employed in direct speech (Ariolfo 2018) that includes the participation of the speaker and involves the interlocutor.

It is well known that the use of the PPS and the PPC varies greatly throughout Italy, with a marked contrast between the North and the South, as highlighted by Bertinetto and Squartini in 1996. The north of Italy is characterized by a clear, if not exclusive, predominance of the PPC, while, on the contrary, the PPS prevails in the South of Italy, and in Central Italy both forms seem to be more appropriately used or at least more balanced. In addition, Bertinetto and Squartini state that the contrast between the different varieties of Italian is clearly perceptible in the spoken language, but not necessarily reflected in the written, which is influenced by the literary model. Furthermore, the compound form is in continuous expansion, especially in the central and southern areas (Bertinetto and Squartini 1996, pp. 383-84). In another publication, the authors point out that the Italian present perfect can be used to refer to past pre-hodiernal and completely concluded events as well as to narrate past personal 
experiences both in an oral and informal way. As was said before, this use varies according to the regions and speakers; however, we emphasize that it is much more widespread in the north of the country (Squartini and Bertinetto 2000).

\section{Objectives, Corpus and Methodology}

The purpose of this paper is to detect and analyze the appearance of the PPC with aoristic value in the spontaneous speech of a group of high school students from Peru and Ecuador, taking into account the different varieties of American Spanish in the Genoese area. Based on a corpus of 16 semi-guided interviews given to Latin American students living in Genoa, in this research we aim to shed light on the factors that can lead speakers to the use of the PPC with aoristic value. To this end, due consideration is given to the characteristics of this verbal form, the syntactic environment in which it is used, combinations with other verbal forms, adverbial complements, temporal expressions and deixis, as well as the communicative context in which the narrated facts are inserted.

We hypothesize that the aoristic use of the PPC in the Genoese context is due to subjective or pragmatic topics, and therefore bound to the context and intentions of the speaker, to his/her attitude towards the narrated facts and to the situation in which they occurred, as well as the result of a prolonged duration of contact with the northern Italian language.

Table 1 sums up the main characteristics of each interviewee and the number of occurrences of the compound PP found out in their speech.

Table 1. Characteristics of the interviewees and number of occurrences in the PPC. ${ }^{3}$

\begin{tabular}{cccc}
\hline Country of Origin & Migration Age & Years of Residence Italy & PPC \\
\hline Ecuador, Guayaquil & 5 & 13 & 3 \\
Ecuador, Manabí & 16 & 2 & 3 \\
Peru, Lima & 6 & 12 & 23 \\
Ecuador, Guayaquil & 7 & 9 & 30 \\
Peru, Lima & 2 & 13 & 36 \\
Ecuador, Guayaquil & 11 & 7 & 23 \\
Ecuador, Manta & 13 & 5 & 28 \\
Ecuador, Manta & 9 & 5 & 13 \\
Ecuador, Portoviejo & 10 & 8 & 7 \\
Ecuador, Sucumbios & 12 & 6 & 21 \\
Ecuador, Quito & 7 & 13 & 21 \\
Peru, Lima & 8 & 12 & 10 \\
Ecuador, Guayaquil & 16 & 4 & 12 \\
Ecuador, Guayaquil & 16 & 4 & 15 \\
Ecuador, Quito & 11 & 8 & 20 \\
Peru, Lima & 16 & 2 & 101 \\
\hline
\end{tabular}

The interviews had an average duration of one hour, consisting of several parts and concerning personal issues and events that occurred in the life of the interviewees; as a rule, they focused on general topics. Most interviewees provided stories that referred to their lifetimes spanning migration, school life, trips and family life. They used anecdotes of all kinds, as well as dreams and memories. Some responses were structured more in the form of a dialogue, while others were more narrative. The majority of the topics revolved around past events, generating stories of spontaneous orality in which the temporal element was of the utmost importance (Caravedo and Klee 2012). We chose to rely solely on semi-directed interviews, because this method is more natural than other data collection methods, such as the evocation test used by Kempas (2006). The test of evocation consists of a survey in

3 All subjects gave their informed consent for inclusion before they participated in the study. The study was conducted in accordance with the Declaration of Helsinki, and the protocol was approved by DISPO-UNIGE (Project FRA 2016). 
which the informants are provided with certain sentences in which the verb is missing and they must decide which verb to choose and what verbal form to use, relying exclusively on the linguistic context. Basically, these were gapped sentences with adverbial complements that served to locate an event at a certain point in the past that was clearly disconnected from the present-that is, in pre- hodiernal contexts: yesterday, two days ago, last week, at the end of July, and so on, either with hodiernal complements or without them. Although this method can be easier to prepare, since variables can be allegedly kept more under control thanks to the homogeneity of the materials provided to carry out the analysis, this is a test in which the sentences are totally decontextualized, regardless of the actual pragmatic conditions that usually influence choice of verbal form when a speaker structures their speech. When interviewed, the participant is not forced to adapt their verbal form to a speech alien to them. On the contrary, the verbal form becomes the core of the discourse, a nucleus around which the rest of the text is configured. Thus, the information offered by the interview-based corpus shows the real functioning of the language, although it may be scattered and scarce, and this makes it more valuable than the evocation test. On the other hand, in the evocation test the informant is more aware of the academic and formal nature of the test, which can influence their responses by eliminating spontaneity. So when facing a test with these characteristics, they could feel inhibited by the possibility of making mistakes, which would totally degenerate the aim of the test itself.

Such restraint could be even more justified, or understood, if we consider that many of the Latin Americans born in Italy, or who arrived in Italy at preschool age or had very few years of formal education in their countries of origin, do not have a good knowledge of written Spanish. They do not even have a lot of knowledge of grammar and mainly use oral Spanish. In a similar context, bilingualism is often still considered a source of confusion by many teachers who regard it as a sort of suspicious bilingualism (Lorenzo and Vez 2011, pp. 26-27) that is hardly prestigious, and unfortunately puts migrant children and young people at a disadvantage as it is inevitably associated with migration and poverty (Ariolfo 2012, 2014; Ariolfo and Viterbori 2016) and the outcome of the circumstances of life instead of free choice. These perceptions, combined with a lack of adequate tools and strategies to accompany these types of students in their language learning path, have contributed to confounding a part of the teaching staff who continue to advise against the use of the Spanish language even at home, convinced there is a negative correlation between language of origin and difficulties at school.

In the following pages we will outline the corpus and comment on a few fragments from the interviews conducted with respondents belonging to Latin American immigrant communities that use the PPC with aoristic value.

Hence, the aim is to qualitatively scrutinize the cases in which the phenomenon under analysis appears in our corpus, and not to highlight its mainstream uses. This is because such an approach would not be possible, due to the scarce availability of data we can rely on.

We are aware that any possible assumptions that may arise from the analysis of the individual cases should be confirmed by a vast empirical support in future research.

\section{Analysis of the Interviews}

First of all, it is necessary to underline that in this research we will concentrate on the use of the compound form even though the simple verbal form prevails, since the use of the PPS predominates in the discourse of all the respondents. Reference will only be made to the simple form when we consider it useful for the purposes of our study. In the present study, a total of 207 occurrences of the PPC have been extracted, some of which correspond to the canonical uses described in the NGLE while, in contrast, others correspond to innovative uses. Many of the different uses have already been registered in other contexts in several investigations, such as Pfänder and Palacios (2013), Palacios Alcaine (2005, 2006, 2007), Bustamante (1991), Henderson (2006), Caravedo and Klee (2012), Jara Yupanqui (2009), de Araujo (2014), among others. However, in this paper, special attention will be paid to the forms of the PPC with aoristic value that appear in our corpus. 
In Example (1), the interviewee is an 18-year-old girl who had arrived in Genoa from Guayaquil during childhood. She uses the PPC while referring to her mother's partner who died the previous year, even though the preferred verbal form should be the simple one. According to the criteria that Azpiazu (2014) and Bermejo Calleja (2017) have established in order to recognize if the PPC has aoristic value, the verbal form in question is used in a narrative sequence with no experiential value and is preceded by a temporal delimitation, el año pasado ('last year'):

(1) De parte de mami no tengo hermanos, de parte de papá, pienso que sí ... O sea, mi papá se separó de mi mamá cuando yo ya estaba en la panza, me parece ... yo no lo conozco ... Sinceramente, no sé cómo fue, es que me da cosa preguntarle y hacerla sufrir. Ella se volvió a casar con otro señor, pero hace ... el año pasado se ha muerto ... Si, tenían juntos ... diez años ... Yo no me llevaba bien. Al inicio sí, cuando era chiquita sí, pero ya después, ya no me llevé porque ... digamos que la apartaba a mi mami de la familia. Entonces a mí eso no me gustaba. Porque la apartaba a ella y me apartaba a mí. $Y$ yo soy bastante unida con mi familia, entonces no me gustó. (Guayaquil, five years old when she arrived in Italy, 13 years in Italy.) ${ }^{4}$

It should be noted that the interviewee uses the simple form for her narrative sequence, but there was a kind of interruption in her story when she introduced the death of her mother's partner, to whom the interviewee did not feel very close. However, she probably recognized the pain that this event implied for her mother, or was expressing surprise, as her mother's partner was quite young when he died. In this way, the use of the PPC brings the story closer to the present and makes the speaker participate in some way in the narrated fact.

In Example (2), the speaker himself is involved in the narration of a pre-hodiernal event next to a temporal adverb which did not designate an interval but included the present. It is clear that context is also fundamental, because if there are other verbs then the tense they are conjugated in is important; the closer they are to the present, the more they tend to suggest the use of the PPC. In this case, we have two conjugated verbs in compound forms, but rather than the former influencing the latter there is rather a unique event of vital importance to the interviewee. He is the protagonist of what he narrates, and the agent of facts that radically changed his life: the move to Italy, a different school and the creation of new friendships during a stage in his life when everything was different:

(2) Yo he venido a Italia con trece años, aquí cumplí los catorce. Porque vine el veinte, vine el veinte de febrero, el 20 de febrero he llegado aquí, entonces yo tenía 13 años, y acá en julio cumplí ya los 14. Y para otra etapa (... ) otro colegio, todo diferente ... Pero igual las amistades siempre quedan, me gusta eso, desde que vine, ya son tres veces que voy de vacaciones a Ecuador. (Manta, 13 years old when he arrived in Italy, five years in Italy. $)^{5}$

The interviewee uses the compound form on two occasions, even referring to an event punctually located in the past thanks to the explicitation of the temporal marker con 13 años and el 20 de febrero. This event occurred six years ago, so it is concluded and temporarily distant with respect to the moment of enunciation (entonces yo tenía 13 años), but still very close emotionally to the speaker. The use of the simple form, repeated twice in a row (vine el 20, vine el 20 de febrero), should also be noted as a resource to give the story emphasis. In this selection, pragmatic variables have great influence: the interviewee

4 I do not have any siblings on my mom's side. I think I have some on my dad's side. I mean, my dad got separated from my mom when I was still in her belly, I think ... I do not know him ... Honestly, I do not know how it was. The fact is that I don't dare to ask and it pains me to make her suffer. She got married for the second time to another gentleman, but ... last year he has died ... Yes, they lived together ... 10 years ... I did not get along with him. I did at the beginning when I was little, yes, but later, I did not get along with him. Let's say he took my mom away from our family. So I did not like that. Because he took her away and he took me away from her. And I am quite close to my family, so I did not like it. (our translation).

5 When I have arrived in Italy I was 13, and I turned 14 here in July. As I arrived on the 20th, on February 20th I have arrived here, so I was 13, and I turned fourteen here in July. And then another step (...) a new school, everything different ... But anyway, friends are here to stay, since I have come here, I have been to Ecuador three times on holiday. (our translation). 
wants to bring the facts closer to the perspective of his interlocutor by making him a participant in his experience.

In Example (3), the interviewee remembers intense emotions evoked by his return to Lima in the company of his mother after 10 years of absence. The reunion with the whole family in his birthplace is a very strong experience, which the interviewee transmits through verbal selection and his words: casi se pone a llorar, feliz de la vida, abrazando a todos, tenían lágrimas en los ojos. Indeed, next to the temporal locator ese dia, although we expect the simple verbal form due to the fact that it is placed before the compound verbal form, the speaker chooses two verbal forms in the PPC, hemos viajado and hemos regresado. These are accompanied in both cases by the adjective juntos, which express his intention to bring the narrated event closer to the present and emotionally highlight how important it was not to leave his mother either going to or coming from Peru:

(3) Me recuerdo que mi mamá casi se pone a llorar, feliz de la vida, después de 10 años, porque ese día, ella regresaba junto conmigo, ese día hemos viajado juntos y hemos regresado juntos. Y... nada ... mi mamá estaba emocionada de ver de nuevo a toda la familia. Estaba abrazando a todos lo más que podia. Y también mi papá, igual, porque estaba ... nos esperaba en el aeropuerto, nos esperaba la familia de mi mamá, sus primos, sus tíos, la familia de mi papá, la mamá de mi papá, sus hermanas, sus hermanos. Y los dos se quedaron un poquito, ... o sea felices, ... tenían lágrimas en los ojos, pero estaban contentos. Esa vez nos quedamos un mes ... poquito, pero me gustó tanto ... porque estuve en la casa donde naci porque, yo naci, prácticamente me crie en la casa, o sea que vivía con mi abuelita y mi mamá y mis hermanos, porque mi papá ya había viajado acá. (Lima, six years old when he arrived in Italy, 12 years in Italy.) ${ }^{6}$

In Example (4), the interviewee narrates a significant personal fact: her father's despair when, on finding himself unable to manage his daughter's behavior, he feels helpless and cries, showing his weakness in a situation that is getting out of hand. The compound form se ha puesto a llorar, inserted in a narrative context preceded by the temporal marker en ese momento makes us think again of subjective aoristicization that shows how shocking it was for the daughter to discover that her father would cry for a reason attributable to her. It is very likely that this option is used as a means of highlighting the surprise of the speaker in front of the situation being described.

As said earlier, the linguistic context is also important, because there are other verbs conjugated in tenses closer to the present that are inserted into direct speech and which precede and follow the verbal phrase in the PPC to fully update the story of the interviewee in a natural way:

(4) No, porque ahorita ya he cambiado, ya ... Yo me iba ... Por ejemplo, hubo esa ocasión que justo mi mami se fue ... El tercer día mi novio,... yo hice una cosa a mi novio, y mi novio me dijo: mira, terminamos aquí. Y yo le dije: ok ... Y ahí él se metió con mi mejor amiga ... Decía que mi santo remedio para mi era irme a las discotecas, irme a tomar, irme a fiestas. Pero no paraba. Me fugué una semana del colegio. Mi papá vino acá a hablar y le dijo: Señora, ¿cómo está mi hija?, pero no le diga que yo vine... (y la profesora) Si su hija desde una semana que no viene... En ese momento mi papá se ha puesto a llorar y todo. Y después del llanto, ... creo que ... no me importa si mi papá llora, ... continuo a hacer lo mismo, y hacía lo mismo ... . (Quito, seven years old when he arrived in Italy, 13 years in Italy.) ${ }^{7}$

6 I remember when my mom almost started crying, she was very happy, after 10 years, because that day, she was returning with me, that day we have travelled together and we have come back together. And ... nothing ... my mom was excited to see the whole family again. She was hugging everyone as much as she could. And my dad, too, because he was ... he was waiting for us at the airport. My mom's family, her cousins, her uncles, my dad's family, my dad's mom, his sisters and his brothers were waiting for us. And they stared at each other for a while ... happy ... they had tears in their eyes, but they were happy. That time we stayed a month ... a short time, but I liked it so much ... because I was in the house where I was born, in the house where I grew up, where I lived with my grandma and my mom and my brothers, because my dad had already come here. (our translation).

7 No, because right now I have changed, already ... I was leaving ... For instance, just by coincidence my mom left ... The third day my boyfriend ... I did one thing to my boyfriend, and my boyfriend said "Look, we ended up here" and I said "ok 
In Example (5), the interviewee uses the compound verbal form ha divorciado followed by a temporal marker that locates the action in a punctual and concluded past moment ( 5 años atrás 'five years ago'), so we expect the simple verbal form. It is noteworthy that in the verbal context in which the form ha divorciado is expressed there are other verbal forms close to the present, and it is possible that they tend to suggest the use of the PPC to the interviewee:

(5) Sí... yo he vivido en la casa de mi abuelita siempre por parte de mi papa ... siempre, pero mi mamá, o sea, vivíamos ahí nosotras dos, porque mi mamá comunque tenía una buena relación con mi abuela ¿no?, con la familia de parte de mi papá, pero mi mamá ha divorciado de mi papá hace como 5 años atrás ... 6 años atrás ¿no? O sea, no eran legalmente divorciados porque los papeles recién ahorita han salido, el divorcio .... (Lima, 2 years old when she arrived in Italy, 13 years in Italy. $)^{8}$

However, the best hypothesis is that perhaps aoristicization occurs by assimilation to Italian. As pointed out in a previous study (Ariolfo 2018) the aoristicization of the PPC may be affected by an external factor in the Genoese migratory context (i.e., the period of residence in Genoa and the prolonged contact with the northern variety of Italian). It is known that the distinction between the PPC and the PPS is in clear regression in northern Italian in favor of the compound form, which suggests that the distinctive features of the PPS do not seem to be necessary for northern Italians. Indeed, in Genoa, the present perfect is used on contexts in which speakers from other areas of Italy use the simple past. In this regard, Squartini and Bertinetto (2000) point out that reference can be made to past pre-hodiernal and completely concluded events when the Italian PPC is used. In addition, it is usually used orally and informally to narrate past personal experiences. This use varies according to the region and the speakers, although it is most widespread in the north of the country. Therefore, it is possible that the interviewee who, after 13 years of residence in Italy (having emigrated at the age of two), and having been completely schooled there, used the PPC with an aoristic, aspectual value in a pre-hodiernal context due to a linguistic convergence between the two typologically close languages as a result of prolonged contact with the Italian spoken in Genoa. In this case, perhaps we might be facing an incipient phenomenon - the formation of a derivative, migratory, emergent or 'diasporic' verbal variety.

Another factor of no less importance that could support our hypothesis is the fact that the verb divorciarse, referring to a person (as in the case of the example), should be used in its pronominal form, that is, se ha divorciado. However, the interviewee uses a non-pronominal form ha divorciado, which suggests that she could have borrowed it from Italian that prefers the non-pronominal form with the auxiliary haber: mia mamma ha divorziato. On the other hand, the influence of Italian is proven by the presence of the form eran divorciados instead of estaban divorciados where the adjective divorziato is preceded by the verb ser (essere divorziato/a) and not estar, as in Spanish (estar divorciado/a).

Finally, Example (6) is a brief narration of a very unpleasant fact: a robbery at school. In the linguistic context, there is only one temporal locator, un dia, but we know that it is an episode that occurred in the previous schooling experience of the protagonist, who at the time of the interview was in the fourth year of secondary school; hence, we are facing a finished fact with no connection to the present. The story mainly highlights the use of two tenses: the imperfect to describe the context of the narrated event, and the PPC to sequence the order of the events (which is usually expressed by the PPS in a narration) and mark the emotional intensity with which the young woman lived that episode.

..." And he got involved with my best friend ... He said that the easiest way for me to get the problem solved was going to clubs, drinking, and going to parties. But this was not enough. I ran away from school one week. My dad came here to talk with my teacher and said, "Madam, how's my daughter doing? but do not tell her that I came ... " "Your daughter has not been coming for a week... " At that moment my dad has started crying. And after crying ... I believe ... "I do not care if my dad cries ... I continue to do the same," and did the same ... (our translation).

8 Yes ... I have lived in my grandma's house, always on my dad's side ... always, but my mom, that is, we lived there, both of us, because my mom comunque had a good relationship with my grandmother from my dad's side, right? but my mom and my dad has divorced about five years ago ... six years ago, right? That is, they were not legally divorced because the papers have come out just now, the divorce... (our translation). 
It is also interesting to note that the verbal sequences in the PPC lack a defined agent. As a matter of fact, verbs are either preceded by the indefinite pronoun alguien (alguien ha entrado, ha abierto ... y se ha llevado) or by implied subjects in indefinite plural form (han entrado y han abierto):

(6) Recuerdo un día que estábamos en el gimnasio de la escuela y ahí donde estaban los baños, al lado, habia una puerta de esas grandes, pesadas y unos bancos donde poníamos los bolsos. Ahí dejábamos todo. Entonces, mientras nosotros estábamos haciendo los ejercicios, alguien ha entrado, ha abierto la puerta y se ha llevado algunos bolsos jcon los celulares, el dinero, todo! Ha sido horrible porque han entrado y han abierto la puerta, jen nuestra escuela! Nosotros pasábamos horas y horas ahí ... (Quito, seven years when she arrived in Italy, 13 years in Italy.) ${ }^{9}$

It should be noted that in the examples commented upon, the verb forms in the PPC in bold type always appeared in relation to events that had great emotional impact, such as some culminating moments in the migratory history of the speakers (expressed by the verbs venir, llegar, viajar and regresar), weeping, death or separation from a person dear to the interviewee, or even the story of a robbery.

\section{Conclusions and Perspectives}

Given the scarcity of the available data - cases of the PPC in the pre-hodiernal context are very few in our corpus-and the fact that the majority of cases of the aoristic PPC were found only in five of the 16 interviewees, we view these results with caution and express the prudence towards any generalized explanation or final conclusion drawn.

Through the analysis of some fragments of the interviews, we have ascertained that the PPC is used by native Latin American speakers even in contexts in which the PPS would be used in the Iberian variation or in other American variations.

Although the nature and reduced extension of the corpus forced us a priori to discard socio-cultural clashes, as well as the influence of the variables of gender and age, as possible factors that could result in the use of the PPC in the narrative sequences in pre-hodiernal contexts, the research suggests the possibility that the use of the PPC in oral discourse may be related to internal and external factors which have arisen in the migratory context, as stated in a previous study (Ariolfo 2018). In other words, it could result from the speaker's desire or need for integration, or the effect of prolonged linguistic contact and formal learning of the local language (i.e., Italian). As we pointed out in Example (5), the fact of having completed primary and secondary studies in Italy and having been in prolonged contact with the characteristics of northern Italian could have in some way led to the aoristicization of the PPC. At the same time, we are aware that to better test our hypothesis, more empirical support should be provided through forthcoming research.

The fact that there were few speakers in the sample who used the aoristic PPC makes us think that the process of aoristicization was far from systematic in the speech of the interviewed students, and was probably linked to their ideolect. We agree with Azpiazu (2015) that the phenomenon is pragmatic rather than grammatical. It is typical of orality and contextually conditioning: the speaker chooses the verb form according to the context, possibly motivated by the wish to make their narration more current and, therefore, interesting for the interlocutor. Ultimately, we are facing a narrative technique that aims at updating the narrated events and bringing them closer or of greater similarity to the phenomenon, which occurs when using the conversational historical present tense or direct speech, as we highlighted in a previous study (Ariolfo 2018). Undoubtedly, the study of the pre-hodiernal PPC should be associated with these resources. Indeed, when the speaker narrates an event that is not temporally linked in any way to the present as if it were so, their goal is not to create new grammatical

9 I remember one day we were in the school sports hall, just inside the toilets, next to the toilets door, there was a big, heavy door and some benches where we put the bags. There we left everything. So while we were doing the exercises, someone has come in, has opened the door and has taken some bags with cell phones, money, everything! It has been horrible because they have entered and have opened the door, in our school! We spent hours and hours there ... (our translation). 
structures, but to draw the interlocutor's attention, express themselves effectively and bring the narration closer to the elocutionary moment by invigorating it and presenting it in a more vivid and expressive way. For this reason, as suggested by Azpiazu (2015), the study of the aoristicization of the PPC in Spanish must necessarily pass through a detailed analysis of the discursive and stylistic conditions of each of its occurrences.

As commented in the previous section, the analysis of the data shows that the phenomenon of aoristicization of the PPC is still not very stable, and that it is closely linked to stylistic preferences of speakers. It is also linked to the expressive values that it holds for the speaker's vision who selects one or another verbal form to structure the discourse (i.e., the circumstances that influence each form, as well as the semantic or pragmatic values that are hidden behind them). Indeed, what is actually recurrent in all the examples of our corpus is that the speaker tries to bring cases of their own or their relatives' experiences closer to the present. By doing this, they want to update and make a past experience they have directly witnessed, or that has been lived by a relative or a person close to them, more credible for the interlocutor. The compound form is then also narrative, and is used to relate events about which the speaker can in some way witness.

We agree with Soto (2014) that the decrease in restrictions on the use of the PPC seems to be associated with an increase in subjectivity. Although there are few samples of uses of the PPC with aoristic value to analyze, they all highlight situations that are meaningful to the speaker, who is not only talking about their life, but is sharing their point of view on the relevance that such episodes have at the moment of the narration.

Regarding extralinguistic context in cases of the PPC with aoristic value that appear in our corpus, we spotted the presence of a pre-hodiernal or past context with temporal locators that mostly precede the compound verbal form (except for Example (5), in which the temporal locator is located after the verbal form in the PPC) expressed in the first singular and plural person, and that refers to an event in which the speaker took part as the protagonist. The speaker presents themselves as the main source of the information provided and the guarantor of its truthfulness at the same time. Therefore, the occurrence of the first person in these instances may be an indication of a use that can be considered epistemic and evidential. In our corpus, there are also three cases of the aoristic PPC in the third singular person that refer to events that vitally affected the speaker, because it narrates events that they know well because they are emotionally close to the person affected by the incident. There is a single PPC example of aorist in the third plural person, whose agent is undefined and generic, whether expressed in singular or plural form.

As we previously pointed out, it is not possible to speak of functional grammaticalization of the PPC, since it is a very difficult phenomenon to cover in all its dialectal and diaphasic complexity and of which we still have an insufficient homogeneous vision, in spite of the numerous studies carried out. This is especially due to the absence of uniformity in data collection methods, which can lead to erroneous or hasty conclusions. Although the evocation test would allow easy control of some variables, it is a test in which to a certain extent the informant is obliged to explain their internal knowledge of the language, which they probably lack, as was the case with our interviewees. On the other hand, it is a decontextualized language test and, as we have seen, the PPC with aoristic value appears in real speech in very concrete and personal pragmatic conditions that are difficult to reproduce and systematize in an artificially created test. Since it is still a stylistic phenomenon that is more typical of the idiolect of some speakers than of others, studying it is very difficult. The aoristic drift of the PPC is still quite unsystematic and incipient, which makes it difficult to give a valid explanation for all cases without linking it to the specific context of each act of speech. Therefore, what has been reported up to now leads us to believe that the conclusions reached so far should be corroborated in future research, and we hope that this will be the case.

Funding: This research received no external funding.

Conflicts of Interest: The author declares no conflict of interest. 


\section{References}

Ariolfo, Rosana. 2012. Actitudes lingüísticas, inmigración y escuela. Un aporte para la reflexión y la práctica educativa. Lecce: Libellula.

Ariolfo, Rosana. 2014. Dalla parte degli insegnanti: Spunti per una riflessione sull'educazione plurale e multilingue. In Migrazione latinoamericana e discorsi istituzionali. Edited by Laura Mariottini and Alessandro Oricchio. Special Issue, Rivista RTSA-Rivista Trimestrale di Scienza dell'Amministrazione. vol. 2, pp. 40-53. [CrossRef]

Ariolfo, Rosana. 2018. El español de América en el paisaje lingüístico genovés. El pretérito perfecto compuesto en las narraciones de estudiantes latinoamericanos. In Paisajes lingüísticos de la migración. Contextos mediáticos, urbanos y formativos. Edited by Rosana Ariolfo and Laura Mariottini. Special Issue, Lingue e Linguaggi. vol. 25, pp. 323-45. Available online: http://siba-ese.unisalento.it/index.php/linguelinguaggi/article/view/18956/ 16217 (accessed on 15 December 2018).

Ariolfo, Rosana, and Paola Viterbori. 2016. Bilingüismo e inmigración: Actitudes lingüísticas y dificultades de aprendizaje en alumnos hispanohablantes. In Migraciones hispánicas: Discurso, sociedad y cognición. Edited by Rocío Caravedo and Francisco Moreno Fernández. Special Issue, Revista Cuadernos AISPI. vol. 8, pp. 51-73.

Azpiazu, Susana. 2012. El pretérito perfecto en el habla de Salamanca. Problemas metodológicos de las clasificaciones a la luz de una Lingüística de la Facticidad. RSEL 42: 5-33.

Azpiazu, Susana. 2014. Del pretérito perfecto al aoristo en el antepresente peninsular: Un fenómeno discursivo Formas simples y compuestas del pasado en español. Edited by Susana Azpiazu. Lugo: Axac, pp. 17-30.

Azpiazu, Susana. 2015. La variación Antepresente/Pretérito en dos áreas del español peninsular. Verba 42: 269-92. [CrossRef]

Bermejo Calleja, Felisa. 2017. Pretérito perfecto compuesto (PPC) en un corpus oral del español peninsular: Monólogos y conversaciones. In Pretérito perfecto simple y pretérito perfecto compuesto en español: Uso y gramatización. Edited by Susana Azpiazu and Carmen Quijada Van den Berghe. Special Issue, Orillas. vol. 6, pp. 405-26. Available online: http://orillas.cab.unipd.it/orillas/06_02bermejo_astilleros/ (accessed on 15 December 2018).

Bertinetto, Pier Marco, and Mario Squartini. 1996. La distribuzione del Perfetto Semplice e del Perfetto Composto nelle diverse varietà di italiano. Romance Philology XLIX 4: 384-419.

Burgo, Clara. 2008. Tense and Aspect Grammaticalization in Bilbao Spanish. Chicago: University of Illinois at Chicago. Bustamante, Isabel. 1991. El presente perfecto o pretérito perfecto compuesto en el español quiteño. LEXIS XV: 195-231.

Caravedo, Rocío, and Carol Klee. 2012. Migración y contacto en Lima: El pretérito perfecto en las cláusulas narrativas. Lengua y Migración 4: 5-24.

de Araujo, Leandro Silveira. 2014. A variação linguística no uso do pretérito perfecto compuesto espanhol: Ponderações sobre o estado da arte. Entretextos 14: 258-82.

De Jonge, Bob. 1999. El tiempo de todos los tiempos: El uso del presente perfecto en el español bonaerense. In Actas del XI Congreso Internacional de ALFAL. Las Palmas de Gran Canaria: Universidad de Las Palmas de Gran Canaria, pp. 297-304.

De Mello, George. 1994. Pretérito compuesto para indicar acción con límite en el pasado: Ayer he visto a Juan. Boletín de la Real Academia Española 74: 611-33.

Escobar, Ana María. 1997. Contrastive and Innovative Uses of the Present Perfect and the Preterite in Spanish in Contact with Quechua. Hispania 80: 859-70. [CrossRef]

Henderson, Carlos. 2006. Aspectos semánticos pragmáticos y discursivos del Pretérito Perfecto Compuesto. Available online: http://www.diva-portal.org/smash/get/diva2:283008/FULLTEXT01.pdf (accessed on 12 January 2019).

Hurtado, Silvia. 2009. El perfecto simple y el perfecto compuesto en Hispanoamérica: La inclusión o la exclusión del ahora de la enunciación. Estudios Filológicos 44: 93-106.

Jara Yupanqui, Margarita. 2009. El pretérito perfecto simple y el pretérito perfecto compuesto en las variedades del español peninsular y americano. Signo \& Seña 20: 253-81.

Jara Yupanqui, Margarita. 2011. Funciones discursivas y gramaticalización del pretérito perfecto compuesto en el español de Lima. Spanish in Context 8: 95-118. [CrossRef] 
Jara Yupanqui, Margarita. 2013. El perfecto en el español de Lima. Variación y cambio en situación de contacto lingüístico. Lima: Pontificia Universidad Católica del Perú.

Kempas, Ilpo. 2006. Estudio sobre el uso del pretérito perfecto prehodiernal en el español peninsular y en comparación con la variedad del español argentino hablada en Santiago del Estero. Ph.D. thesis, University of Helsinki, Helsinki, Finland. Available online: http://ethesis.helsinki.fi/julkaisut/hum/romaa/vk/kempas/ estudios.pdf (accessed on 3 January 2019).

Kempas, Ilpo. 2008. El pretérito perfecto compuesto y los pasados prehodiernales. In Tiempos compuestos y formas verbales complejas. Edited by Ángeles Carrasco Gutiérrez. Madrid: Iberoamericana, Frankfurt: Vervuert, pp. 231-73.

Kempas, Ilpo. 2014. Aportes empíricos a los estudios sobre el pretérito perfecto compuesto "aoristizado". In Formas simples y compuestas de pasado en el verbo español. Edited by Susana Azpiazu. Lugo: Axac, pp. 81-102.

Lorenzo, Fernando Trujillo, and José Manuel Vez. 2011. Educación bilingüe. Integración de contenidos y segundas lenguas. Madrid: Síntesis, pp. 26-27.

Montero Cádiz, Manuel Menardo. 2015. Acercamiento al empleo del pretérito perfecto compuesto del modo indicativo en la variedad cubana del español. Revista Nebrija de Lingüística Aplicada a la Enseñanza de Lenguas 18: 25-40. Available online: http://www.nebrija.com/revista-linguistica/numero-18-2015 (accessed on 3 January 2018).

Montoro del Arco, Esteban. 2017. El pretérito perfecto compuesto con valor aorístico en el habla urbana de Granada. In Pretérito perfecto simple y pretérito perfecto compuesto en español: Uso y gramatización. Edited by Susana Azpiazu and Carmen Quijada Van den Berghe. Special Issue, Orillas. vol. 6, pp. 455-70. Available online: http://orillas.cab.unipd.it/orillas/articoli/numero_6/05Montoro_astilleros.pdf (accessed on 4 January 2018)

Moreno Burgos, Juan. 2015. El pretérito perfecto compuesto en el ámbito hispánico. Anuario de Letras. Lingüística y Filología III: 87-130. [CrossRef]

Palacios Alcaine, Azucena. 2005. La influencia del quichua en el español andino ecuatoriano. In Variedades lingüísticas y lenguas en contacto en el mundo de habla hispana. Edited by C. Ferrero and N. Lasso-von Lang. Bloomington: AuthorHouse, pp. 44-52.

Palacios Alcaine, Azucena. 2006. Variedades del español hablado en América: Una aproximación educativa. In Las lenguas españolas: un enfoque filológico. Edited by Elena Miguel. Madrid: MEC, pp. 175-96.

Palacios Alcaine, Azucena. 2007. Cambios lingüísticos de ida y vuelta: Los tiempos del pasado en la variedad emergente de los migrantes ecuatorianos en España. Revista Internacional de Lingüística Iberoamericana 2: 109-25.

Pfänder, Stefan, and Azucena Palacios A. 2013. Evidencialidad y validación en los pretéritos del español andino ecuatoriano. Círculo de Lingüística Aplicada a la Comunicación 54: 65-98. [CrossRef]

RAE, and ASALE. 2009. Nueva gramática de la lengua española. Madrid: Espasa, p. 1721.

Rodrigues Parrihna, Silvia. 2014. Valores pragmáticos y discursivos en el uso del pretérito perfecto compuesto en el español de Buenos Aires. In Formas simples y compuestas de pasado en el verbo español. Edited by Susana Azpiazu. Lugo: Axac, pp. 103-15.

Rodríguez Louro, Celeste. 2009. Perfect Evolution and Change: A Sociolinguistic Study of Preterit and Present Perfect Usage in Contemporary and Earlier Argentina. Ph.D. thesis, The University of Melbourne, Melbourne, Australia. Available online: https://minerva-access.unimelb.edu.au/handle/11343/35140 (accessed on 30 December 2017).

Serrano, María José. 1994. Del pretérito indefinido al pretérito perfecto: Un caso de cambio y gramaticalización en el español de Canarias y Madrid. Lingüística Española Actual 16: 37-57.

Soto, Guillermo. 2014. El pretérito perfecto compuesto en el español estándar de nueve capitales americanas: Frecuencia, subjetivización y deriva aorística. In Formas simples y compuestas de pasado en el verbo español. Edited by Susana Azpiazu. Lugo: Axac, pp. 131-46.

Squartini, Mario, and Pier Marco Bertinetto. 2000. The simple and Compound Past in Romance languages. In Tense and Aspect in the Languages of Europe. Edited by Dahl Östen. Berlin: DeGruyter, pp. 403-39.

(C) 2019 by the author. Licensee MDPI, Basel, Switzerland. This article is an open access article distributed under the terms and conditions of the Creative Commons Attribution (CC BY) license (http://creativecommons.org/licenses/by/4.0/). 

Article

\title{
Revisiting the Use of the Proximity Lexicon in the Classroom for Immigrant Populations at Risk of Social Exclusion: Does It Really Help?
}

\author{
Antonio-Manuel Ávila-Muñoz \\ General Linguistics, Universidad de Málaga, 29071 Málaga, Spain; amavila@uma.es \\ Received: 22 April 2019; Accepted: 17 June 2019; Published: 19 June 2019
}

\begin{abstract}
This paper shows the convenience of using linguistic resources in foreign language teaching based on the proximity lexicon (dialectal and local) in order to facilitate the integration of socially vulnerable immigrant groups. The social barriers facing them intensify because of lack of knowledge of the linguistic varieties of the host countries and their functions. This study is a continuation of another one published in 2019 in which we presented a theoretical model of language teaching based on the gradual introduction of specific lexical material with the aim of facilitating sociocultural adaptation. The proximity lexicon associated to communal belonging meanings was considered a powerful social inclusion tool. We worked with two student samples to confirm the efficacy of the model. In a group, the dialectal strategy was employed in a programmed and conscious manner, whereas in the other one, the control group, the model was not followed. The results are based on the answers to questions in a wellbeing questionnaire designed ad hoc to evaluate the efficacy of the proposal. The group to which the proposed system was applied showed a greater degree of social wellbeing, satisfaction and adaptation.
\end{abstract}

Keywords: Proximity lexicon; teaching; immigrants; social vulnerability; (non) adaptation

\section{Introduction}

Population movements have been a constant throughout the history of mankind. Nevertheless, from the end of the XIX century, migratory flows have intensified and brought sociolinguistic, and unexpected, consequences which merit discussion and solution in case of emerging conflicts (Moreno-Fernández 2009; Fernández-Vítores 2013; Piller 2016; EUROSTAT 2017). In this paper, we present the early results of the application of a linguistic performance model, which aims, from the perspective of social dialectology, at facilitating the sociocultural integration of the more vulnerable immigrant groups by way of the teaching of the proximity lexicon (dialectal and local) in the Spanish as a foreign language (SFL) classroom. The epistemological foundation of this model was presented in Ávila-Muñoz (Forthcoming), although in that previous work, its practical efficacy was still to be demonstrated. The first section of this paper is dedicated to the synthesis of the more relevant theoretical fundamentals of the model and in the second one, the results of its application in the SFL classroom are submitted. This application took place in an NGO located in the city of Malaga working with migrants under risk of social exclusion. The results are based on the use and interpretation of wellbeing tests applied to a sample of students after their having completed their Spanish course. To insure the reliability of our proposal, we worked with two groups of informants to the first of which the proposed model was applied by way of showing the Proximity lexicon systematically and consciously, aiming at its transformation into a social integration tool. The second one-the control group-was not given language teaching based on the model. 


\section{The Linguistic Model of Social Integration Based on the Teaching of the Proximity Lexicon}

\subsection{Principles}

As shown in Ávila-Muñoz (Forthcoming), the proposed model is based on the following principles:

1. Principle of Group Belonging. Languages have units which function as solidarity links among members of speech communities because they connote sharing of cultural habits. These units are especially significative at the semantic-lexical level because of two well-documented motives in cognitive sociolinguistics (Moreno-Fernández 2013a). The first one being that each lexical variant carries associated underlying social meanings; in the case of localisms, this motive is linked to the history of the immediate sociocultural context. The second motive is that sociolinguistic conscience particularly sensible to these units, interprets them as symbols of social identity (Sheppard 2015; Regan et al. 2016; Dempster and Hargrave 2017; Stokes 2017).

2. The Integration Principle. If these units are identified systematically and consciously, without prejudices, in foreign language teaching to immigrants, or even in general language classes to migrants who speak the language of the host community, we would be providing a sociocultural integration tool. This tool might also modify attitudes of negation or rejection by members of the host community (Ariolfo 2012; CIS 2015; Dempster and Hargrave 2017; Wheeler 2019).

3. Principle of the usefulness of an entertaining multidimensional approach. The work with the specific vocabulary of the nearest social context assumes an additional motivation for both the teacher and the student. On the one hand, the teacher may know, respect and foster the use of this lexicon among his students. On the other hand, the characteristics of this lexicon lend support to the realisation of complementary workshops with the aim of backing the explanation of the connoted value of these linguistic units.

This approach can be applied to any foreign language teaching to migrants, but it acquires its whole dimension with those students who wish to remain and settle - either transiently or indefinitely - in a region of the host country. In addition to being an interesting approach to any situation involving the teaching of foreign languages or varieties of a language, we believe that these principles can lead to a pedagogical strategy of far-reaching sociocultural integration of vulnerable groups.

The proximity lexicon (dialectal and local) not registered in general dictionaries or marked as specific of concrete places, can be observed as complete forms (for example, in Andalusia, borrachuelo, 'fried dough eaten during the Christmas/Easter seasons') or as particular meanings of general forms (in Malaga, pitufo 'small bread roll'). The proposal goes beyond the classroom and becomes a space for debate that would help to diminish the negative effects of the social marginalisation to which the more unprotected migrants are subjected (Moreno-Fernández 2013b; Sancho-Pascual 2013; Johnson and Berry 2014; Bravo-García et al. 2014). Our ultimate objective is therefore, the creation of a theoretical model of language teaching that on the bases of description, explanation and understanding of the sociolinguistic situation caused by these population flows, becomes an integration tool, above all for the groups more likely to suffer social exclusion. It is a question of facilitating the access to the knowledge of the language and the connoted usages associated to the employment of some elements typical of the linguistic variety nearest to the area where the learning process takes place.

One of the main advantages of this model is the creation of a discussion space among the agents involved in the language teaching process to migrant populations. From the practical problems facing teachers, we aim at making our proposal the beginning of a debate on the need to create teaching models based on tools whose function will be to show the linguistic variety to its full extent with the objective of facilitating social integration (Mallows 2014; Egli and Höchle 2016; Devereaux and Palmer 2019). 


\subsection{Theoretical Approaches and Operational Areas}

The objective is the creation of a programming strategy which allows the incorporation of new resources to those normally used in language teaching. In order to achieve it, our model proposes procedures compatible with the elaboration of didactic programmings, which may even be in use. In sum, what is needed is the generation of a proposal with a verifiable efficacy easily put into practice by teachers, permitting both linguistic learning and the necessary social integration of the students.

Our proposal presupposes the convenience of using the Proximity lexicon in the language classroom, be it mother or foreign tongue, as a strategy for the social integration of migrants. However, this lexicon should be a reduced part of the whole lexicon; its verified social cohesion function, with the active connotations in the competence of the speakers of the local groups (Ávila-Muñoz 2017), makes its inclusion recommendable in the lexical selection models employed in the language teaching for vulnerable groups.

Our theoretical model with the inclusion of the Proximity lexicon in the language teaching classroom may be organised as a structure of concentrical crowns, built in five stages:

1. Adequate selection of the lexicon. The common basis is formed by the general lexicon of very frequent use, not dependent on the communicative situation (Frequency Lexicon: Davies 2005; Lonsdale and Bras 2009) and availability, habitually associated to concrete situations (Lexical Availability Ávila-Muñoz and Ponsoda 2010; Bombarelli 2005). From this common structure, our proposal assumes the introduction of some proximity elements, taking advantage of the linkage of contents of didactic units as presented in the system of concentrical crowns in Figure 1.

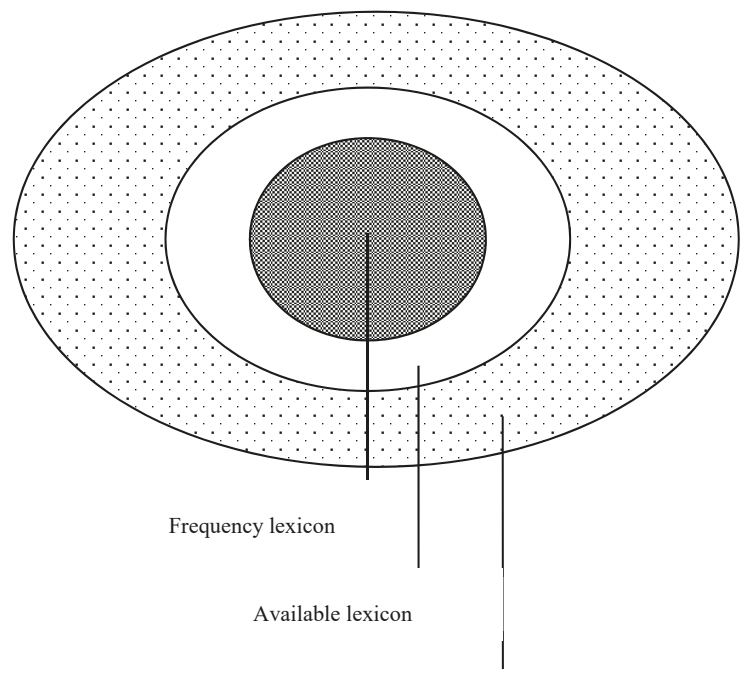

Proximity lexicon

Figure 1. Representation of the general lexical selection model based on the concentrical crowns. (Ávila-Muñoz 2017).

The always active nucleus present in the Frequency Lexicon is generally formed by grammatical words or those of scarcely precise semantic content: conjunctions, articles, prepositions and some nouns or verbs of polyvalent or ambiguous character (Ávila-Muñoz 1999). This nucleus is complemented as a function of the concrete communicative situation and of the words associated to it. Lexical availability refers to habitual vocabulary in concrete thematic contexts, for instance: family, human body, weather, and politics. The structure of the proximity lexicon can be observed as well as a wave system generated 
round a nucleus formed by this type of lexicon employed more often in the speech community. These waves distance themselves from the centre as the frequency of its terms diminishes as shown in Figure 2, which refers to the use of a series of localisms in the city of Malaga (Ávila-Muñoz 2017) whose gloss appears in Table 1.

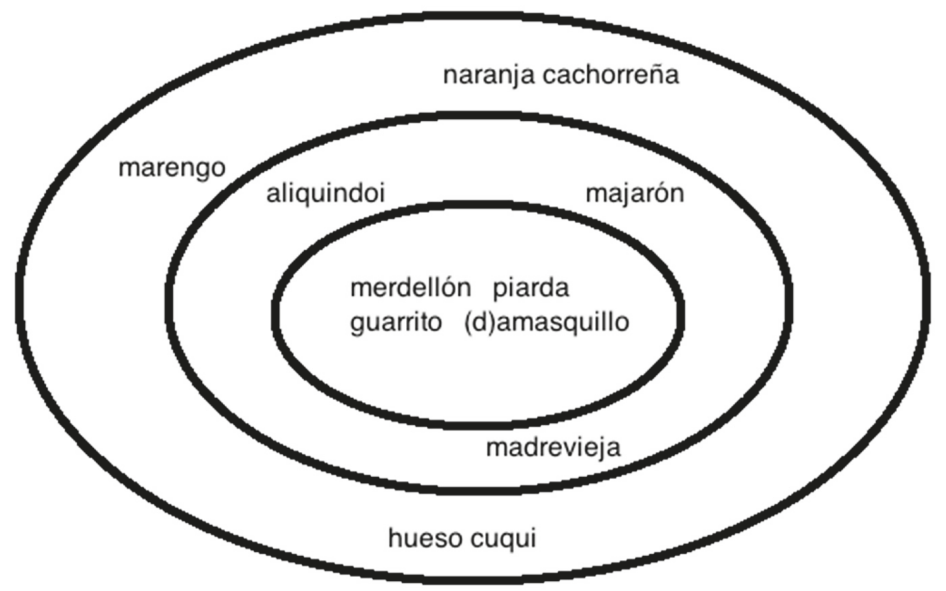

Figure 2. Representation of a sample of the local lexicon of Malaga based on concentrical waves according to frequency of use (Ávila-Muñoz 2017).

Table 1. Gloss of the localisms in Figure 2.

\begin{tabular}{ll}
\hline \multicolumn{1}{c}{ Localisms } & \multicolumn{1}{c}{ Gloss } \\
\hline $\begin{array}{l}\text { merdellón } \\
\text { piarda }\end{array}$ & 'not very fine, pretentions, vulgar' \\
guarrito & 'dlay truant' (UK), 'play hookey / hooky'(USA) \\
(d)amasquillo & 'apricot' \\
madrevieja & 'sewer' \\
aliquindoi & 'to be alert' \\
majarón & 'crazy, fool' \\
hueso cuqui & 'bone of the rump' \\
marengo & 'fish peddler' \\
naranja & 'bitter orange' \\
cachorreña & \\
\hline
\end{tabular}

From the model of general lexical representation suggested in Figure 1, the teacher should select the more appropriate words for each moment and social context in order to guarantee his students' learning and make their sociocultural integration easier according to each type of education:

a. On the one hand, in the case of the teaching of foreign languages, our proposal could be applied to those units related to all areas of communicative relevance proposed by the European Council in the European Common Frame of Reference for Languages (European Council 2002) or the oral linguistic recruitment guides presented by the American Council on the Teaching of Foreign Languages (ACTFL 2012).

b. On the other hand, the Spanish non-university educational system could adapt, with certain ease, our proposal to the subject of Lengua Española (or the corresponding co-official one in those autonomous communities in which it exists) in order to work with students, both in the primary and secondary levels, especially in the latter. 
Given the specificity of the proximity lexicon, an optimal selection of the communication domains or didactic units should be made, in which the proposal could be applied according to the most evident presence of this type of lexical items. For example, in the case of foreign language teaching, our experiment was done with the didactic unit related to the MCER proposal 'Food and drink'. Together with general elements such as agua 'water', refresco 'soft drink', or limonada 'lemonade', we included others more specific to the area, which are shown in Table 2. In our case, these words come from a previous study in which as mentioned before, the proximity lexicon had a clear importance as a local identifier factor (Ávila-Muñoz 2017).

Table 2. Proximity lexicon employed in the experiment (Ávila-Muñoz 2017).

\begin{tabular}{ll}
\hline \multicolumn{1}{c}{ Word } & \multicolumn{1}{c}{ Gloss } \\
\hline $\begin{array}{l}\text { agu< }<(j)>\text { apala }<(d)>a \\
\text { arenca }\end{array}$ & 'sword fish' \\
vitoriano & 'herring' \\
borrachuelo & 'small-sized anchovy' \\
$<(d)>$ amasquillo & 'Christmas / Easter sponge cakes covered with rum' \\
pitufo & 'apricot' \\
cachorreña & 'small piece of bread' \\
sombra & 'bitter orange' \\
nube & 'white coffee' coffee with some milk $(+$ coffee - milk $)$ \\
\hline
\end{tabular}

2. The selection of the proximity lexicon should be adjusted to the model of concentrical crowns shown in Figure 2. The more frequent form-known and used by a great part of speakers of the local speech community - would be included in the centre and as they distance themselves from the initial nucleus, other forms of a lesser frequency of use would appear. For the design of the "Food and drink" didactic unit employed in our experiment, the model was fixed as shown in Figure 3.

The words included in the central circles or "crowns" of Figure 3, thus being more frequent and representative of the active Malaga proximity lexicon (nube, sombra, pitufo, borrachuelo, <d >amasquillo, vitoriano, arenca) should become the first lexical social integration tools and could be used for the intermediate levels proposed by ECFR (A2-B1) or the descriptors of ACTFL (Lower Intermediate, Intermediate). The more peripheral agujapala $<(d)>a$ and cachorreña forms in Figure 3, are local meanings recognised by members of the Malaga speech community, but little or not used (passive lexicon), so that they could be assigned to higher levels although they were used in our experiment given the willing welcome by our students to the activity. In case the organisation of the thematic nuclei into expansion lexical waves should not be possible, the teacher could work with the more general model shown in Figure 2 and teach more widely used proximity elements without having to adjust obligatorily to a concrete didactic unit.

3. After an adequate vocabulary selection, activities may be proposed concerning cultural information exchange about habits related to the themes used for the introduction of the lexicon. In our experiment, activities were organised in which the students' gastronomic experiences and traditions were shared.

4. These practical activities with the students should be backed by seminars, informal discussions or debates, and diverse activities outside the classrooms or teaching environments were encouraged. In our case, participation in gastronomic fairs or cooking workshops were organised, where the students were allowed to apply in a practical way what had been presented theoretically.

5. Finally, it is necessary to share and put into practice the knowledge thus acquired so as to evaluate the real efficacy of the Proximity lexicon as a tool towards sociocultural integration. 


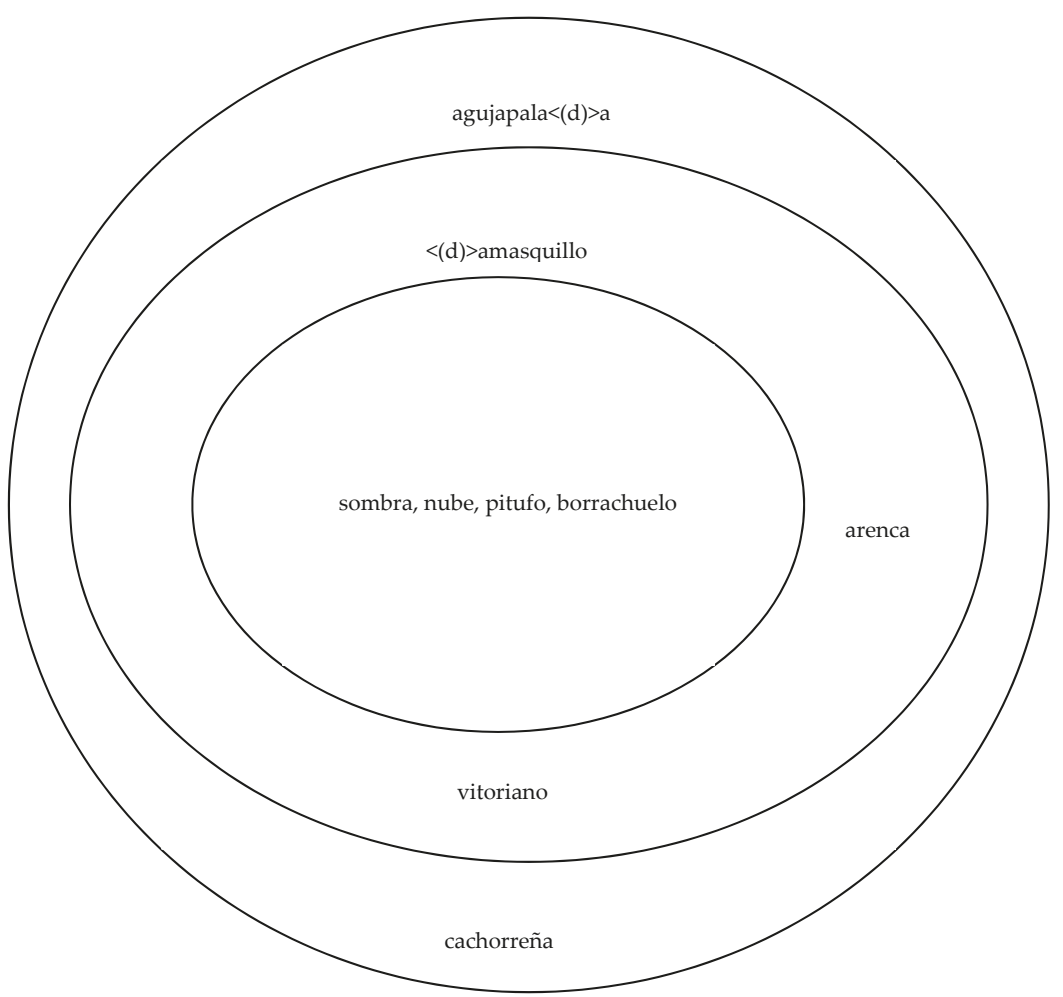

Figure 3. Model of crowns for the lexical proximity selection based on frequency of use (Food and drink) (Ávila-Muñoz 2017).

\section{Hypothesis and Design of Variables}

With the object of verifying the efficacy of our proposal, during 2018 we contacted several NGOs working with migrant groups under risk of social exclusion in the city of Malaga. We came to the conclusion that Málaga Acoge (Malaga Welcomes You) was the one that fulfilled all the requirements to implement our model:

1. It had active courses of Spanish as a foreign language.

2. The students were classified into groups according to their level of knowledge of the Spanish language. The criteria and proposals of ECFR were employed in the evaluation of their idiomatic command of the language.

3. Every level had a sufficient number of students.

4. Additionally, there was more than one group for each different level of knowledge of the language.

In a first approximation, we believed it convenient to work with Spanish B1 level students as the course had already started at the beginning of our research. We did not have more than a quarter of them to carry out our experiment and it seemed convenient to put our model into practice at that intermediate level. It was also important to keep a control group which during their learning process, did not receive any stimulus by way of the Proximity lexicon and if it did, the stimulus was not to be given in the systematic and controlled manner required by our research.

Both groups constitute the independent variable of our work and from its design, we were able to build the main hypotheses of the present research: 
1. Hypothesis of personal satisfaction. After the implementation of the didactic model which supports this work, there will be a statistically superior and significative difference in the experimental group in contrast with the control group in its perception of local integration, wellbeing and personal satisfaction.

2. Hypothesis of integration. Likewise, it is to be expected that the positive perception of vital wellbeing among the individuals which form the experimental group may lead them to formulate plans of possible plans of a future and integration in the host community to a greater degree than the members of the control group.

With the objective of confirming both hypotheses, we carried out an analysis of correlations between dependent and independent variables with the results which are presented in the following chapter. The dependent variables were built on the bases of the answers given by the informants to the items included in the sociological questionnaire of wellbeing (Appendix A). The results were correlated with the independent variable (group to which the individual belonged: experimental group, Group A; control group, Group B). The idea was to establish a cause-effect relation between the variables under study so that the belonging to each group should justify the level of satisfaction as formulated initially in the hypotheses.

We had a total sample of 40 students. Half of them $(\mathrm{N}=20)$ were offered the learning system which contained the "Food and drink" unit. We chose this unit because of its traditional use in foreign language teaching. In addition, a previous study gave us enough local terms connected with this unit. As we will mention later, it is important a previous study of specific situations to use the proposal model in other didactic units. At the same time, as mentioned, a control group of 20 students was kept to which the model was not applied (Group B), even though the rest of educational process was identical (same learning system, same didactic unit Food and drink). The main difference was the systematic way that the experimental group learnt local lexicon. As obvious, the teachers in the control group could use this lexical forms eventually. The difference was the systematic and conscious way that defines the experimental group.

Throughout the last quarter of the course (from March to June 2018), the teachers under contract to the NGO, were asked to apply the proximity-based model to the members of Group A. Naturally, the teachers were previously informed of the nature of the activity and the lexicon model methodology better suited to be implemented with Group A. Furthermore, a group of students who had been previously informed and trained, volunteered as auxiliary instructors during that quarter. The auxiliary group helped to organise workshops and activities related to the selected didactic unit: local cooking workshops, excursions to gastronomic provincial fairs and an end-of-course celebration, where local food and drinks were exchanged. The exchange also included food and drinks from the migrants' homelands. As mentioned before, the lexical items employed came from the previous study and selection (Ávila-Muñoz 2017) and were shown in Table 2.

At the end of the course, the students were asked to fill the wellbeing questionnaire shown as Appendix A. In the following section comments are given on the more significative results from the analysis of those questionnaires, that were created ad hoc to improve the actual research from previous studies (Diener et al. 1985; Atienza et al. 2000; Pons et al. 2002)

\section{Sample}

All subjects gave their informed consent for inclusion before they participated in the study. The study was conducted in accordance with the Declaration of Helsinki, and the protocol was approved by the Ethics Committee of ECOPASOS (FFI2015-68171-C5-1-P).

The main social and personal characteristics of our informants are synthesised in Tables 3-5 and provide the description of our sample. 
Table 3. Characteristics of the sample. Gender and origin.

\begin{tabular}{cccccccc}
\hline & \multicolumn{2}{c}{ Gender } & & Origin & \multirow{2}{*}{ Total } \\
\cline { 3 - 8 } & Male & Female & Europe & Africa & Asia & \\
\hline \multirow{2}{*}{ Group A } & 12 & 8 & 1 & 16 & 3 & 20 \\
\hline Total & 12 & 8 & 0 & 18 & 2 & 20 \\
\hline
\end{tabular}

Table 4. Characteristics of the sample. Completed studies.

\begin{tabular}{cccccccc}
\hline & \multicolumn{5}{c}{ Studies That Were Completed } & Total \\
\cline { 3 - 6 } & $\begin{array}{l}\text { No School } \\
\text { Attendance } \\
\text { Whatsoever }\end{array}$ & $\begin{array}{c}\text { No, but (s)he } \\
\text { Attended School }\end{array}$ & Primary & Secondary & Professional & \\
\hline & Group A & 4 & 1 & 14 & 1 & 0 & 20 \\
& Group B & 8 & 4 & 7 & 0 & 1 & 20 \\
\hline Total & 12 & 5 & 21 & 1 & 1 & 40 \\
\hline
\end{tabular}

Table 5. Recodified educational level. Distribution by groups.

\begin{tabular}{lcccc}
\hline & & \multicolumn{2}{c}{ Recodified Education } & \multirow{2}{*}{ Total } \\
\cline { 3 - 4 } & Level 0 & Level 1 & \\
\hline & Group A & 5 & 15 & 20 \\
& Group B & 12 & 8 & 20 \\
\hline Total & 17 & 23 & 40 \\
\hline
\end{tabular}

Most of the migrants came from Africa, although in both groups there were people from Asia and only one was from a European country in Group A (Table 3). The number of males was somewhat higher than that of females, but the imbalance was identical in both groups $(\mathrm{M}=12, \mathrm{~F}=8)$.

A recodified version more adjusted to the informants' educational reality was done based on the data in Table 4. Thus, the values were reorganised into two variants according to the degree of completion of some educational stages (Level 1, $N=23$ ) or not (Level 0, $N=17$ ). We believe that the reorganisation shown in Table 5 is a better representation of our informants' situation than that of Table 4 and it is more adjusted to the prevalent academic situation in the western world.

Most of the individuals in Group A fit in Level $1(\mathrm{~N}=15)$, the opposite situation occurring in Group B, since almost all its members belong to educational level 0. Table 6 shows that most males indicated that their study rank corresponded to Level 1 in our recodification $(\mathrm{N}=18)$, while most females belonged to Level $0(\mathrm{~N}=11)$.

Table 6. Educational level according to gender.

\begin{tabular}{ccccc}
\hline \multirow{2}{*}{ Gender } & \multicolumn{2}{c}{ Recodified Education } & \multirow{2}{*}{ Total } \\
\cline { 2 - 3 } & $\mathrm{M}$ & Level 0 & Level 1 & \\
\hline & $\mathrm{F}$ & 6 & 18 & 24 \\
& 11 & 5 & 16 \\
\hline Total & 17 & 23 & 40 \\
\hline
\end{tabular}

Most of the members of the sample had arrived to Malaga between a year and less than a year (Group A = 17; Group B = 15) and only one had been more than five years in the city. The rest had been between 1 and 5 years in Malaga (Group A = 3; Group B = 4). Almost all had had very frequent 
contact with their country (between two or more times every week and every day). Only 2 informants from Group A indicated that they kept very sporadic contact with their country (more than twice monthly). Half of the sample did not answer the questions related to the work they had (Group $\mathrm{A}=11$; Group B =9), which made us think they were unemployed or in an illegal situation at the time of the interview. It is relevant to point out that of those who answered those questions, almost all expressed that they were very little/little satisfied with their work and only one person of Group B stated that (s)he was very satisfied with her or his employment situation. Additionally, it was lamentable that 30 of our informants had suffered some racist or xenophobic incidents since the time they arrived in Spain (Group A = 16; Group B = 14), whereas 4 classified such incidents as grave and 26 as Not grave.

Most of the informants indicated that they shared their free time only with people of the same origin or culture (Group A = 13; Group B = 17). However, 6 people from Group A and only 1 from Group B also socialised with Spaniards. Almost none of the migrants belonged to associations or social groups (Group A = 18; Group B = 18) and only 4 participated in associations, which were anyway formed by people of their own origin or culture (Group A = 2; Group B = 2).

As can be appreciated by the data so far, the initial conditions of the members of Groups A and B were very similar, except for their educational level. Nonetheless, their education showed no correlation or a very weak one with the variables we will use further on to measure the wellbeing shown by the migrant towards the population and their host region or area (see below, regression analysis by steps).

\section{From Theory to Practice. Does the Model Work?}

It is important for the objectives of our work that 9 people from Group A indicated that since they began their study of Spanish, they had fewer integration problems in contrast with only 3 informants who chose the same answer in Group B. This part of our data may turn out to be very significative because until the implementation of the proximity model in March 2018, the learning conditions of both groups were the same: identical language learning procedures in so far as contents, teaching and methods (at any rate, without the systematic employment of the Proximity lexicon as a working tool). In Group B, only 2 people stated they had no integration problems in contrast with 7 who chose the same option in Group A. Likewise, we believe that data in Table 7 are relevant because we could interpret that the teaching method based on the Proximity lexicon as we propose it, could have some incidence on the social integration ease of the immigrants in the local communities.

Table 7. Integration difficulties with Malaganians *.

\begin{tabular}{|c|c|c|c|c|c|c|c|}
\hline & & \multicolumn{5}{|c|}{ Integration Difficulties with Malaganians } & \multirow[t]{2}{*}{ Total } \\
\hline & & 0 & 1 & 2 & 3 & 4 & \\
\hline & Group A & 7 & 9 & 0 & 3 & 1 & 20 \\
\hline & Group B & 2 & 3 & 8 & 6 & 1 & 20 \\
\hline Total & & 9 & 12 & 8 & 9 & 2 & 40 \\
\hline
\end{tabular}

0: I have no problems. 1: Since I study Spanish, it is easier for me to integrate. 2: No. I do not look for this type of contacts. 3: No. I just prefer to be with people who share my culture. 4: Yes, I have many problems to integrate.

* Data obtained from the answers to question number 25 in the questionnaire.

Notice how 8 members of Group B did not even look for contacts; no member of Group A chose this option. Besides, the number of people from Group B $(\mathrm{N}=6)$ doubles that of those in Group A $(\mathrm{N}=3)$ who prefer to be with members of the same culture. In Group A, we find 16 people who state they have no integration problems or that they have been reduced since they study Spanish (options $0+1, \mathrm{~N}=16$ ) in contrast with only 5 in Group B.

When we analyse the answers referring to students' integration with Malaga values and customs, the answers pointed in the same direction as shown in Table 8. 
Table 8. Integration in Malaga society *.

\begin{tabular}{lccccccc}
\hline & \multicolumn{5}{c}{ Degree of Integration in Malaga } & \multirow{2}{*}{ Total } \\
\cline { 3 - 7 } & None & Very Little & Little & Enough & Quite a Lot & \\
\hline \multirow{3}{*}{ Group A } & 0 & 3 & 11 & 5 & 1 & 20 \\
& Group B & 3 & 6 & 10 & 1 & 0 & 20 \\
\hline Total & 3 & 9 & 21 & 6 & 1 & 40 \\
\hline
\end{tabular}

* Data obtained from the answers to question number 31 in the questionnaire.

By adding the answers to None and Very little we observe that 9 people belong to Group B and only 3 to Group A (besides, in this group, nobody chose the option None). Additionally, 6 members of Group A indicated that they were between Enough and Quite a lot integrated in the Malaga society and only 1 person from Group B agreed with that position.

With regard to the migrants' intentions in the short and the medium term, the data again consolidate the tendencies indicated: the members of Group A are the ones who in the majority consider, as a probable option, to remain in Malaga both in the short term (less than 5 years: Group $\mathrm{A}=6$; Group $\mathrm{B}=1$ ) as well as in the medium one (more than 5 years: Group $\mathrm{A}=5$; Group $\mathrm{B}=0$ ). Nevertheless, the truth is that most of the migrants we have studied, either do not know what they will do in the short/medium term or have in mind to go to some other countries.

We have left for the end of our analysis some of the items which in our opinion, will be the most useful in the evaluation of the efficacy of the proposed teaching model based on the proximity lexicon as a social integrational tool. We are referring to the gradation migrants make of (A) their feelings towards the assertions shown in items 39-41 of our questionnaire (Tables 9-11) and (B) their level of wellbeing in Malaga (Table 12, item 42 of the questionnaire). To evaluate these 4 items, the informants had to place them in a continuous scale from less to more (0-6).

Table 9. Effect of the learning group in the subjective evaluation of life in Malaga *.

\begin{tabular}{lcccccc}
\hline & \multicolumn{2}{c}{ In the Majority of Things, My Life in Malaga Is Positive } & \multirow{2}{*}{ Total } \\
\cline { 3 - 6 } & $\mathbf{0}$ & $\mathbf{1}$ & $\mathbf{2}$ & $\mathbf{3}$ & \\
\hline & Group A & 2 & 5 & 8 & 5 & 20 \\
& Group B & 7 & 9 & 4 & 0 & 20 \\
\hline \multirow{2}{*}{ Total } & 9 & 14 & 12 & 5 & 40 \\
\hline
\end{tabular}

* Data from the answers to question number 39 in the questionnaire.

Table 10. Effect of the learning group on the subjective evaluation of life in Malaga.

\begin{tabular}{llc}
\hline & & Positive Evaluation of Life in Malaga \\
\hline \multirow{2}{*}{ Group A } & Mean & 2.8000 \\
& Typ. Dev. & 0.95145 \\
\hline \multirow{2}{*}{ Group B } & Mean & 1.8500 \\
& Typ. Dev. & 0.74516 \\
\hline Total Mean & & 2.3250 \\
Typ. dev. & & 0.85342 \\
\hline
\end{tabular}

Sig. 0.001 
Table 11. Effect of the learning group in the subjective evaluation of life conditions in Malaga *.

\begin{tabular}{lcccccc}
\hline & \multicolumn{4}{c}{ My life Conditions in Malaga Are Adequate } & \multirow{2}{*}{ Total } \\
\cline { 3 - 6 } & & $\mathbf{0}$ & $\mathbf{1}$ & $\mathbf{2}$ & $\mathbf{3}$ & \\
\hline & Group A & 2 & 4 & 12 & 2 & 20 \\
& Group B & 16 & 4 & 0 & 0 & 20 \\
\hline Total & & 18 & 8 & 12 & 2 & 40 \\
\hline
\end{tabular}

* Data obtained from answers to question number 40 in the questionnaire.

Table 12. Effect on the learning group on the subjective evaluation of life conditions in Malaga.

\begin{tabular}{llc}
\hline & & $\begin{array}{c}\text { Subjective Evaluation of Life } \\
\text { Conditions in Malaga }\end{array}$ \\
\hline \multirow{2}{*}{ Group A } & Mean & 2.7000 \\
& Typ. Dev. & 0.80131 \\
\hline \multirow{2}{*}{ Group B } & Mean & 1.2000 \\
& Typ. Dev. & 0.41039 \\
\multirow{2}{*}{ Total } & Mean & 1.9500 \\
& Typ. Dev. & 0.67436 \\
\hline
\end{tabular}

Sig. 0.000

The only grade 3 evaluations shown in Table 9 belong to Group A subjects $(N=5)$; notice that 16 people from Group B chose the lower levels of the scale (grades 0 and 1) in contrast to 7 of Group A. Additionally, only 4 people from Group B chose option 2, which was half of those in Group A $(\mathrm{N}=8)$.

The media analysis shows a weak signification index, although with an Eta ${ }^{2}$ of low intensity (Table 10).

The Mann-Whitney test was applied for differences of means in independent samples

\begin{tabular}{lcc}
\hline Measures of Association & Eta & Eta $^{2}$ \\
Group * Positive Evaluation of life in Malaga & 0.506 & 0.256 \\
\hline
\end{tabular}

Similar tendencies are observed when analysing the data from the evaluation of life conditions in Malaga (Table 11). Nevertheless, on this occasion, the values of the means and the measures of association are very significative (Table 12). It calls our attention that all members of Group B chose the lowest proposed grades $(\mathrm{N}=20$, grades 0 and 1$)$. Only 6 people from Group A opted for the same levels, in contrast with the 14, who chose 2 or 3.

The Mann-Whitney test was applied for mean differences in independent samples

\begin{tabular}{ccc}
\hline Measures of Association & Eta & Eta $^{2}$ \\
Group * Sentence2 & 0.789 & 0.622 \\
\hline
\end{tabular}

To think of moving dear relatives to a new country to start a new life is a very difficult decision, which requires a high degree of certainty and determination. However, as can be observed (Table 13) most of the subjects in Group A chose the highest option in this aspect (grade 2, N = 18), while the 20 subjects of Group B chose option $0(\mathrm{~N}=16)$ or $1(\mathrm{~N}=4)$. Nobody in this group chose option 3 in contrast with 1 person in Group A. 
Table 13. Effect of the learning group on expectations of moving the family to Malaga.

\begin{tabular}{ccccccc}
\hline & & \multicolumn{2}{c}{ If It Depended on $\mathbf{m e}$ I } & Would Bring My Family to Malaga & \multirow{2}{*}{ Total } \\
\cline { 2 - 6 } & & $\mathbf{0}$ & $\mathbf{1}$ & $\mathbf{2}$ & $\mathbf{3}$ & \\
\hline & Group A & 0 & 1 & 18 & 1 & 20 \\
& Group B & 16 & 4 & 0 & 0 & 20 \\
\hline Total & 16 & 5 & 18 & 1 & 40 \\
\hline
\end{tabular}

* Data obtained from the answers to question number 41 in the questionnaire.

The strong signification values obtained from the media analysis led to a possible positive effect of the proposed teaching model (Table 14).

Table 14. Expectations of moving the family to Malaga.

\begin{tabular}{llc}
\hline Group A & Mean & $\begin{array}{c}\text { Expectations of Moving } \\
\text { the Family to Malaga }\end{array}$ \\
\hline Group B & Typ. Dev. & 3.0000 \\
& Mean & 0.32444 \\
\hline \multirow{2}{*}{ Total } & Typ. Dev. & 1.2000 \\
& Mean & 0.41039 \\
\hline
\end{tabular}

Sig. 0.000

The Mann-Whitney test was applied for the media differences in independent samples

\begin{tabular}{lcc}
\hline Measures of association & Eta & Eta $^{2}$ \\
Group * Expectations of moving the family to Malaga & 0.959 & 0.920 \\
\hline
\end{tabular}

Table 15 shows very similar results, although in this occasion, the tendency towards a more positive evaluation of wellbeing in Malaga seems even more evident among members of Group A. Nobody in Group B indicated grade 4 and only one chose option 3. This option was selected by 6 members of Group A, who also indicated their preference for option 4 three times. More than half of the subjects of Group B opted for the lower grades of the scale ( 0 or $1, N=15)$ while only 6 did the same in Group A.

Table 15. Effect of the learning group on the general level of wellbeing in Malaga *.

\begin{tabular}{cccccccc}
\hline & \multicolumn{4}{c}{ General Level of Wellbeing in Malaga } & \multirow{2}{*}{ Total } \\
\cline { 3 - 6 } & & $\mathbf{0}$ & $\mathbf{1}$ & $\mathbf{2}$ & $\mathbf{3}$ & $\mathbf{4}$ & \\
\hline & Group A & 2 & 4 & 5 & 6 & 3 & 20 \\
& Group B & 4 & 11 & 4 & 1 & 0 & 20 \\
\hline \multirow{2}{*}{ Total } & 6 & 15 & 9 & 7 & 3 & 40 \\
\hline \multicolumn{4}{c}{} \\
\end{tabular}

As Table 16 shows, the signification and association measures were more moderate in this case. 
Table 16. Effect of the learning group on the sensation of general wellbeing.

\begin{tabular}{llc}
\hline & & General Wellbeing \\
\hline \multirow{2}{*}{ Group A } & Mean & 3.2000 \\
& Typ. Dev. & 1.23969 \\
\hline \multirow{2}{*}{ Group B } & Mean & 2.1000 \\
& Typ. Dev. & 0.78807 \\
\hline \multirow{2}{*}{ Total } & Media & 2.6500 \\
& Typ. Dev. & 0.98976 \\
\hline
\end{tabular}

Sig. 0.026

The Mann-Whitney test was applied for media differences in independent samples

\begin{tabular}{ccc}
\hline Measures of association & Eta & Eta $^{2}$ \\
Group * Wellbeing in Malaga & 0.515 & 0.265 \\
\hline
\end{tabular}

The signification index of the positive correlations in Table 17 is high enough in all cases so that the belonging to learning groups can be considered a relevant explanatory factor of the variables that measure the migrants' degree of wellbeing in their host community. The form of the variables correlated in Table 17 were recodified on the basis of a fictitious variable in which Group B $=0$ and Group A $=1$. Variables Sentence 1, Sentence 2, Sentence 3 and Wellbeing in Malaga were measured on a scale of gradation from 0 (completely in disagreement) to 6 (completely in agreement).

Table 17. Learning group and wellbeing indicators. Spearman correlations.

\begin{tabular}{|c|c|c|c|c|}
\hline & Sentence 1 & Sentence 2 & Sentence 3 & $\begin{array}{c}\text { Wellbeing in } \\
\text { Malaga }\end{array}$ \\
\hline \multirow[t]{2}{*}{ Group } & $0.491(* *)$ & $0.778(* *)$ & $0.934(* *)$ & $0.468\left(^{* *}\right)$ \\
\hline & Sig. 0.001 & Sig. 0.000 & Sig. 0.000 & Sig. 0.002 \\
\hline
\end{tabular}

Sentence 1: In most things, my life in Malaga is positive

Sentence 2: The conditions of my life are adequate

Sentence 3: If it depended on me, I would bring my family to live in Malaga

At the end, we made a recodification of some of the items of the questionnaire, whose scales were compatible and from them, two new variables were made in order to measure: (1) the informant's global subjective satisfaction (Individual Subjective Satisfaction, ISS) and (2) the individual sensation of general wellbeing (General Wellbeing Index, GWI).

The first case deals with the original questionnaire variables, which measure on a scale from minor to major ( 1 to 5 ) the integration and opening of the analysed migrants to the host region and its inhabitants. Variable 25 was recodified to adapt it to the new scale.

\section{You have meetings in your free time}

1. Only with members of my family

2. Only with people of my origin or culture

3. Never with people of my origin or culture, except with Spaniards

4. With every type of people, including Spaniards

\section{You participate in associations or groups in free time}


1. No

2. Yes, only with people of my origin or culture

3. Yes, but never with people of my origin or culture

4. Yes, with every type of people, except with Spaniards

5. Yes, with every type of people, including Spaniards

25. Do you have difficulties to integrate with Malaganians or groups of them? Think, for example. if you feel comfortable when you are with these people and consider you an equal or if, on the contrary, when you are with these people you feel a foreigner

1. Yes, I have many difficulties to integrate

2. No, but I only prefer to be with people of my zone or culture

3. No, I do not look for this type of contact

4. Since I study Spanish I find it easier to integrate

5. I do not have any problems

28. How do you evaluate the native population of Malaga?

1. Very negatively

2. Negatively

3. I am indifferent towards them

4. Positively

5. Very positively

31. In what way do you feel integrated with the customs of the Malaga society? (traditions like Easter, Carnival, etc.)

1. Not at all

2. Very little

3. Little

4. Enough

5. Quite a lot

\section{What are your intentions now?}

1. To make money and go back in less than a year

2. To make money to build a better life in my country of origin

3. To start a new life in another country

4. To go back and stay with my family

5. To stay in Malaga

34. What do you think you will do in the next 5 years?

1. Going back to my country

2. Moving to another country

3. Moving to another Spanish autonomous community

4. Moving to another city in Andalusia

5. Staying in Malaga

35. What do you think of doing after the next 5 years? (As a life project)

1. Going back to my country 
2. Moving to another country

3. Moving to another Spanish autonomous community

4. Moving to another city of Andalusia

5. Staying in Malaga

The resulting variable of the reformulation of the previous ones (ISS calculated as a function of the number of times informants opted for the values of the scale $1-5$ in all the considered variables) showed a normal distribution with some differences of means of a low potency (Table 18).

Table 18. Effect of the learning group in the Individual Subjective Sensation (ISS).

\begin{tabular}{llcc}
\hline & & ISS & Punctuation Z \\
\hline \multirow{2}{*}{ Group A } & Mean & 3.9500 & 0.5071618 \\
& Typ. Dev. & 1.46808 & 0.91260825 \\
\hline \multirow{2}{*}{ Group B } & Mean & 2.0500 & -0.3631248 \\
& Typ. Dev. & 1.05006 & 0.65275386 \\
\hline \multirow{2}{*}{ Total } & Mean & 3.2500 & 0.0720185 \\
& Typ. Dev. & 1.44559 & 0.89862964 \\
\hline & & Sig. 0.001
\end{tabular}

The Mann-Whitney test was applied for the differences of means in independent samples

\begin{tabular}{lcc}
\hline Measures of association & Eta & Eta $^{2}$ \\
ISS * Group & 0.490 & 0.240 \\
Z punctuation (ISS) * Group & 0.490 & 0.240 \\
\hline
\end{tabular}

The second recodification was done from the individual original variables, which measured on a 0-6 scale certain wellbeing parameters related to the informants'stay in Malaga (variables 39-42 in the questionnaire). In this occasion, the new recodified scale in three levels of intervals according to the informants' original answers $(0-2=$ Level $0 ; 3=$ Level $1 ; 4-6=$ Level 2$)$. The differences of means show results of very high significance, now with values de $\mathrm{Eta}^{2}$ of high potency (Table 19).

Table 19. Effect of the learning group in the General Wellbeing (GWI).

\begin{tabular}{lcc}
\hline GWI & Mean & Typ. Dev. \\
\hline Group A & 1.9500 & 0.22361 \\
Group B & 1.0000 & 0.00000 \\
Total & 1.4750 & 0.50574 \\
\hline
\end{tabular}

The Mann-Whitney test was applied for differences of means in independent samples

\begin{tabular}{ccc}
\hline \multicolumn{3}{c}{ Measures of Association } \\
\hline $\mathrm{GWI} *$ Group & Eta & $\mathrm{Eta}^{2}$ \\
& 0.872 & 0.761 \\
\hline
\end{tabular}

Test of independent samples 


\begin{tabular}{llllllll}
\hline \multirow{2}{*}{ GWI } & \multicolumn{2}{c}{$\begin{array}{c}\text { Levene Test for } \\
\text { Equality of Variances }\end{array}$} & \multicolumn{4}{c}{ T test for the Equality of Variances } \\
\cline { 2 - 8 } & F & Sig. & $\mathbf{t}$ & df & $\begin{array}{c}\text { Bilateral } \\
\text { Sig. }\end{array}$ & $\begin{array}{c}\text { Differences of } \\
\text { Means }\end{array}$ \\
\hline $\begin{array}{l}\text { Equal variances } \\
\text { have been assumed }\end{array}$ & 4.457 & 0.041 & -19.000 & 38 & 0.000 & -0.95000 \\
\hline $\begin{array}{l}\text { Equal variances } \\
\text { have not been } \\
\text { assumed }\end{array}$ & & & -19.000 & 19.000 & 0.000 & -0.95000 \\
\hline
\end{tabular}

Our significative results, and a final analysis of regression by steps, helped us to design a statistical model, which confirms: (1) the high correlation observed between group belonging and the variable GWI and (2) the weak correlation between the variables gender and education and the dependent variable (GWI, both variables were excluded from the model, Table 20). Thus, we discarded that the internal group imbalance with regard to the educational level of their members (Tables 5 and 6) was camouflaging a possible covert effect of this variable on the results.

Table 20. Regression analysis.

\begin{tabular}{|c|c|c|c|}
\hline \multicolumn{4}{|c|}{ Introduced/Eliminated Variables } \\
\hline Model & Introduced Variables & Eliminated Variables & Method \\
\hline 1 & Group & Gender Education & $\begin{array}{l}\text { By steps (criterion: Prob. of F to } \\
\text { enter }<=0.050 . \text { Prob. of } \mathrm{F} \text { to leave } \\
>=0.100) .\end{array}$ \\
\hline
\end{tabular}

Dependent Variable: IBG.

\begin{tabular}{|c|c|c|c|c|c|c|c|c|}
\hline \multicolumn{9}{|c|}{ Eliminated Variables } \\
\hline \multirow{2}{*}{\multicolumn{2}{|c|}{ Model }} & \multirow[b]{2}{*}{ Beta in } & \multirow[b]{2}{*}{$\mathbf{t}$} & \multirow[b]{2}{*}{ Sig. } & \multirow{2}{*}{$\begin{array}{c}\text { Partial } \\
\text { Correlation }\end{array}$} & \multicolumn{3}{|c|}{ Colinearity Statistics } \\
\hline & & & & & & Tolerance & VIF & $\begin{array}{l}\text { Minimal } \\
\text { Tolerance }\end{array}$ \\
\hline \multirow{2}{*}{1} & Gender & $0.041^{b}$ & 0.813 & 0.422 & 0.132 & 1.000 & 1.000 & 1.000 \\
\hline & $\begin{array}{l}\text { Recodified } \\
\text { Education }\end{array}$ & $-0.029^{b}$ & -0.536 & 0.595 & -0.088 & 0.875 & 1.143 & 0.875 \\
\hline
\end{tabular}

Dependent Variable: GWI. ${ }^{\mathrm{b}}$ Predictors in the model: (Constant), Group.

\begin{tabular}{cccccc}
\hline \multicolumn{6}{c}{ Summary of the Model } \\
\hline Model & $\mathbf{R}$ & R Square & $\begin{array}{c}\text { Corrected R } \\
\text { Square }\end{array}$ & $\begin{array}{c}\text { Standard Error } \\
\text { in the Estimate }\end{array}$ & Durbin-Watson \\
\hline 1 & $0.951^{\text {a }}$ & 0.905 & 0.902 & 0.15811 & 2.108 \\
\hline \multicolumn{4}{c}{ a Predictors: (Constant), Group. Dependent Variable: GWI. }
\end{tabular}

\begin{tabular}{ccccccc}
\hline \multicolumn{7}{c}{ ANOVA $^{\mathbf{a}}$} \\
\hline \multirow{2}{*}{ Model } & Sum of & df & Mean & F & Sig. \\
& Squares & & Square & & $0.000^{\mathrm{b}}$ \\
\multirow{2}{*}{1} & Regression & 9.025 & 1 & 9.025 & 361,000 & \\
& Residual & 0.950 & 38 & 0.025 & & \\
\hline
\end{tabular}

${ }^{\mathrm{a}}$ Dependent Variable: GWI, ${ }^{\mathrm{b}}$ Predictors: (Constant), Group. 


\begin{tabular}{|c|c|c|c|c|c|c|}
\hline \multicolumn{7}{|c|}{ Coefficients } \\
\hline & \multirow[t]{2}{*}{ Model } & \multicolumn{2}{|c|}{ Non-Standardised Coefficients } & $\begin{array}{c}\text { Typified } \\
\text { Coefficients }\end{array}$ & \multirow[t]{2}{*}{$\mathbf{T}$} & \multirow[t]{2}{*}{ Sig. } \\
\hline & & B & Standard Error & Beta & & \\
\hline \multirow{2}{*}{1} & (Constant) & 1.000 & 0.035 & & 28.284 & 0.000 \\
\hline & Group & 0.950 & 0.050 & 0.951 & 19.000 & 0.000 \\
\hline
\end{tabular}

Dependent Variable: GWI.

\section{Discussion and Final Reflections}

One of the major obstacles migrants have when they arrive at their destinations is their lack of knowledge of the local language and customs of the countries chosen for settlement. Nonetheless, in this work we have aimed at transforming this difficulty into the possibility of providing a better adaptation by way of a linguistic learning model backed by the following fundamentals, a consequence of what we have exposed so far:

1. There is an objective need to formulate proposals leading to the successful sociocultural integration of immigrants (particularly the more unprotected and vulnerable among them) from the language classrooms.

2. The challenge consists of supplying the lack of linguistic knowledge with inclusive programmes which, with respect to the nearest traditions, manage to promote the immigrants' sociocultural integration in a multidimensional way and their acceptance by the host communities.

3. Consequently, it is a question of promoting educational programmes based on respect for the rights of the more vulnerable groups, which also deepens mutual understanding and acceptance of cultures and values of both the host communities and of the immigrant groups.

4. Language has proved to be a powerful social connection between groups enjoying equality and that fact has been fully recognised by the main international institutions, which observe and study population and migratory flows (OECD/European Union 2015; Helke and Laczko 2015; Jahan 2016). Language teaching models should be adapted to include effective elements that facilitate this integration.

5. Social dialectology is aware of a dynamic convergence process which is generalised among varieties of the same language (Auer 2005; Auer et al. 2005; Hinskens 1996; Kerswill 2003; Trudgill 2002; Villena 2005, among many others). This process strengthens the idea-widely accepted in the foreign language teaching field — of employing the standard variety as the basis of learning. However, the divergence processes play an important role not to be underestimated (Braunmüller et al. 2014; Villena and Vida 2017): the divergent variants reinforce the social solidarity links and can be used as integration tools when working with vulnerable groups (Ávila-Muñoz Forthcoming).

6. Our proposal is compatible with the usual native and foreign language teaching processes. While complementing already elaborated didactic units, it could be also employed in the preparation of new ones. As the proximity vocabulary is restricted, the selection of the more adequate ones for each didactic unit will depend on each specific situation. The teachers are in charge of selecting and adding the relevant dialectal lexical elements to be introduced in the classroom gradually and adequately. The selection would have to be preceded by a study of the particular characteristics of each lexical units of the area for which glossaries and specialised dictionaries should be consulted. Furthermore, this study could also come from the knowledge teachers have of the sociolinguistic reality of the area in which they work. It is a question of trying to adjust the lexical selection to the model of concentrical crowns in each case as suggested in our proposal: 
a. Inclusion of the proximity lexicon associated to specific thematic units or communication spaces when sufficient material exists. In these cases, the proximity vocabulary is to be presented and structured according to the model of concentrical crowns model, with a nucleus formed by extensively used and recognised elements in the local community-and thus, with a strong connoted value of social integration and group belonging conscience-it would be used at the most elementary: A2-B1 or Lower Intermediate-Intermediate for foreign language teaching; primary education in the case of the general teaching regime. In the higher levels, less-used vocabulary could be introduced in the speech community, although with the same social cohesion function.

b. Should the number of lexical elements be insufficient to execute the proposal as structure in concrete didactic units, the teacher should appeal to the general model of lexical selection (frequent lexicon, lexical availability, proximity lexicon) and include dialectal elements from the peripheral crown containing units with the required social integration function.

c. Lastly, the use of the proximity lexicon in the language classroom facilitates the realisation of complementary practical activities (workshops, informal meetings, debates), which may prove attractive to the students.

The results which have been shown in this paper after the implementation of the proposed model with a group of migrants as students of SFL, give room great hope. If we compare the results from the wellbeing questionnaire as answered by students after the end of the course according to our model with the answers of the members of the control group-who as such were not asked to do that course-we can assert that the model seems to work. Those who enjoyed the course with our model, showed a significantly higher degree of social integration, personal wellbeing and subjective satisfaction than those who followed a different methodology. The former are individuals with a more positive perception of their life conditions in their host community than the members of the control group, to the point that they even plan to bring their relatives to their actual location. This very positive attitude envisages commencing a new life in Malaga together with their family, which definitely indicates a considerably greater index of general well-being.

Summing up we can assert that we have created a foreign language teaching programme for migrant populations from the basis of a deep knowledge of the difficulties for the social integration of these groups. This programme justifies the use of the proximity lexicon in the language classroom as a sociocultural integration tool for migrant populations, but above all, for the more unprotected groups, who may find the employment of the proximity lexicon an entertaining and flexible manner to attain inclusion in the community. Although it is true that teachers may have appealed to these strategies previously in a more or less sporadic and unsystematic manner, from this point onwards, a collective space for discussion and work has been created, which justifies, structures, endorses and recommends this practice.

Funding: This research was funded by DGICYT, grant number FFI2015-68171-C5-1-P.

Acknowledgments: This research was supported by DGICYT: Estudio Complementario de los Patrones sociolingüísticos del Español de Málaga (FFI2015-68171-C5-1-P).

Conflicts of Interest: The author declares no conflict of interest.

\section{Appendix A. Sociological Questionnaire of Wellbeing}

Subject number:

\section{Gender}

1. MALE

2. FEMALE 
Languages 2019, 4, 43

2. Age in years

3. Native country

\section{Year of arrival in Spain}

\section{Year of arrival in Andalusia}

\section{Year of arrival in Malaga}

\section{Completed studies}

0. Subject did not attend school

1. None, although (s)he attended school

2. Primary

3. Secondary

4. Professional

5. University

\begin{tabular}{|c|c|}
\hline $\begin{array}{l}\text { 8. Do you keep in contact with your relatives in } \\
\text { your native country? }\end{array}$ & 9. How frequently?? \\
\hline 0. Never & 0. Very sporadically \\
\hline 1. Yes, by mail & 1. Once a month \\
\hline 2. Yes, by videoconference & 2. More than twice a month \\
\hline 3. Yes, by Internet (e-mail, chat, Skype ... ) & 3. Twice or more times a week \\
\hline 4. Yes, by telephone & 4. Every day \\
\hline
\end{tabular}

Degree of satisfaction with the following aspects of your work at present or the last one you had in Spain. (If you have had no work, continue with question 22) 


\begin{tabular}{|c|c|c|c|c|c|}
\hline & $\begin{array}{c}\text { Very } \\
\text { Unsatisfied }\end{array}$ & Little Satisfied & $\begin{array}{l}\text { Satisfied } \\
\text { Enough }\end{array}$ & Very Satisfied & $\begin{array}{c}\text { Do Not Know. } \\
\text { No Answer }\end{array}$ \\
\hline 10. The type of work you do & 1 & 2 & 3 & 4 & \\
\hline 11. The position you have & 1 & 2 & 3 & 4 & \\
\hline $\begin{array}{l}\text { 12. Possibilities of } \\
\text { promotion }\end{array}$ & 1 & 2 & 3 & 4 & \\
\hline 13. Timetable & 1 & 2 & 3 & 4 & \\
\hline $\begin{array}{l}\text { 14. Relation with bosses or } \\
\text { superiors }\end{array}$ & 1 & 2 & 3 & 4 & \\
\hline 15. Rhythm & 1 & 2 & 3 & 4 & \\
\hline 16. Working conditions & 1 & 2 & 3 & 4 & \\
\hline $\begin{array}{l}\text { 17. Degree of harshness of } \\
\text { work }\end{array}$ & 1 & 2 & 3 & 4 & \\
\hline 18. Level of risks & 1 & 2 & 3 & 4 & \\
\hline $\begin{array}{l}\text { 19. Psychological pressure } \\
\text { caused by work }\end{array}$ & 1 & 2 & 3 & 4 & \\
\hline 20. Income & 1 & 2 & 3 & 4 & \\
\hline $\begin{array}{l}\text { 21. Adjustment to your life } \\
\text { according to culture and } \\
\text { religion }\end{array}$ & 1 & 2 & 3 & 4 & \\
\hline $\begin{array}{l}\text { 22. Does it adjust to your } \\
\text { studies? }\end{array}$ & 1 & 2 & 3 & 4 & \\
\hline
\end{tabular}

\section{Who do you meet in your free time?}

1. Only with members of my family

2. Only with people of my native country or my culture

3. Never with people of my native country or culture

4. With every type of people, except with Spaniards

5. With very type of people, including Spaniards
24. Participation in associations or free time groups

1. No

2. Yes, only with people of my native country or culture

3. Yes, but never with people of my native country or culture

4. Yes, with every type of people, except with Spaniards

5. Yes, with all types of people, including Spaniards

\section{Do you have difficulties to integrate? Do you have difficulties to integrate with Malaganians or groups of them? Think for example if you feel comfortable with these people and consider youself as an equal or on the contrary, when you are with them, you feel a foreigner}

0. I do not have a problem

1. Since I study Spanish, it is easier to integrate

2. No, I do not look for this type of contacts

3. No, but I prefer to be with people from my area or culture

4. Yes, I have many difficulties to integrate
26. Do you have difficulties to integrate with people or groups of immigrants?

0 . I do not have problems.

1. No, I do not look for that type of contacts

2. No, but I only prefer to be with people from my area or culture

3. Yes, I have many difficulties to integrate 


\section{Do you participate or are affiliated or registered in associations or groups?}

0. No

1. Informal groups of immigrants

2. Organisations of support

3. Associations or sport clubs

4. Educational or sport groups

5. Religious entities or groups

6. Neighbourhood groups

7. Labour unions

8. Political parties

9. Brotherhoods, confraternities, coteries

\begin{tabular}{|c|c|}
\hline $\begin{array}{l}\text { 28. How do you evaluate the Malaga native } \\
\text { population? }\end{array}$ & $\begin{array}{l}\text { 29. How do you evaluate the immigrant population } \\
\text { resident in Malaga? }\end{array}$ \\
\hline Very negatively & Very negatively \\
\hline Negatively & 2. Negatively \\
\hline Indifferent towards them & 3. Indifferent towards them \\
\hline 4. Positively & 4. Positively \\
\hline 5. Very positively & 5. Very positively \\
\hline
\end{tabular}

\begin{tabular}{|c|c|c|c|c|}
\hline \multicolumn{4}{|c|}{ 30. Have you experienced incidents in Malaga related to } & $\begin{array}{l}\text { 31. To what degree do you } \\
\text { feel integrated into } \\
\text { customs in Malaga society? } \\
\text { (traditions such as Easter, } \\
\text { carnival, the fair, etc.?) }\end{array}$ \\
\hline $\begin{array}{l}\text { Racism/xenofobia? } \\
\text { Describe the } \\
\text { incidents: }\end{array}$ & $\begin{array}{l}\text { Grave } \\
2\end{array}$ & $\begin{array}{l}\text { Not grave } \\
1\end{array}$ & $\begin{array}{l}\text { No } \\
0\end{array}$ & $\begin{array}{ll}\text { 1. } & \text { Not at all } \\
\text { 2. } & \text { Very little } \\
\text { 3. } & \text { Little } \\
\text { 4. } & \text { Enough } \\
\text { 5. } & \text { Quite a lot }\end{array}$ \\
\hline
\end{tabular}

\section{What were your intentions}

\begin{tabular}{|c|c|}
\hline 32. When you started your trip? & 33. Now? \\
\hline To make money and return in less than a year & To make money and return in less than a year \\
\hline $\begin{array}{l}\text { 2. To make money to build a better life in my } \\
\text { native country }\end{array}$ & $\begin{array}{l}\text { 2. To make money and build a better life in my } \\
\text { native country }\end{array}$ \\
\hline To start a new life in another country & To start a new life in another country \\
\hline To go back to the company of my family & 4. To be in the company of my family \\
\hline & 5. To stay in Malaga \\
\hline
\end{tabular}

\section{What do you think you will do}




\begin{tabular}{|lccccc|}
\hline & $\begin{array}{c}\text { Going back to } \\
\text { my country }\end{array}$ & $\begin{array}{c}\text { Moving to } \\
\text { another } \\
\text { country }\end{array}$ & $\begin{array}{c}\text { Moving to } \\
\text { another } \\
\text { Autonomous } \\
\text { Community in } \\
\text { Spain }\end{array}$ & $\begin{array}{c}\text { Moving to } \\
\text { another } \\
\text { Andalusian } \\
\text { city }\end{array}$ & $\begin{array}{c}\text { Staying in } \\
\text { Malaga }\end{array}$ \\
\hline $\begin{array}{l}\text { 34. In the next } \\
\text { 5 years? }\end{array}$ & 1 & 2 & 3 & 4 & 5 \\
\hline $\begin{array}{l}\text { 35. Beyond 5 } \\
\text { years, as a life } \\
\text { project? }\end{array}$ & 1 & 2 & 3 & 4 & 5 \\
\hline
\end{tabular}

Expectations of those who think of staying in Malaga for the next 5 years or beyond:

\begin{tabular}{|c|c|c|}
\hline 36. Dwelling & 37. Employment & 38. Social relations \\
\hline $\begin{array}{ll}\text { 1. } & \text { To stay in my } \\
\text { 2. } & \text { Share another dwellling } \\
\text { 3. } & \text { Rent a a dwelling } \\
\text { 4. } & \text { To finish paying my } \\
& \text { actual dwelling }\end{array}$ & $\begin{array}{ll}\text { 1. To continue as until now } \\
\text { 2. To find employment } \\
\text { (whichever I find) } \\
\text { 3. To find stable employment } \\
\text { 4. To find employment in a } \\
\text { different sector or activity } \\
\text { 5. To find employment } \\
\text { according to my formation }\end{array}$ & $\begin{array}{l}\text { 1. To continue as until now } \\
\text { 2. To relate myself more with } \\
\text { people of my area or culture } \\
\text { 3. To relate myself more } \\
\text { with Malaganians } \\
\text { 4. To distance myself from } \\
\text { people of my area or culture }\end{array}$ \\
\hline
\end{tabular}

The following five sentences reflect how people can think and feel about their life. By way of the following scale from 0 (completely in disagreement) to 6 (completely in agreement), indicate sincerely at what point of your life you find yourself and how you feel about it.

\begin{tabular}{|c|c|c|c|c|c|c|c|c|}
\hline 39 & $\begin{array}{l}\text { In most things, my life in Malaga is } \\
\text { positive }\end{array}$ & 0 & 1 & 2 & 3 & 4 & 5 & 6 \\
\hline 40 & $\begin{array}{l}\text { The conditions of my life in Malaga } \\
\text { are adequate }\end{array}$ & 0 & 1 & 2 & 3 & 4 & 5 & 6 \\
\hline 41 & $\begin{array}{l}\text { If it were up to me, I would bring } \\
\text { my family to live in Malaga. }\end{array}$ & 0 & 1 & 2 & 3 & 4 & 5 & 6 \\
\hline
\end{tabular}

42. What is your actual general wellbeing in Malaga? Consider, for instance, if you feel comfortable in the city, if you feel a foreigner among the people when you go out for a stroll, if you like the city and the way of being of Malaganians.

\begin{tabular}{|l|l|l|l|l|l|l|}
\hline 0 & 1 & 2 & 3 & 4 & 5 & 6 \\
\hline
\end{tabular}

\section{References}

American Council on the Teaching of Foreign Languages. 2012. Performance Descriptors for Language Learners. Alexandria: ACTFL, Available online: https://www.actfl.org/sites/default/files/pdfs/ PerformanceDescriptorsLanguageLearners.pdf (accessed on 1 March 2019).

Ariolfo, Rosana. 2012. Actitudes lingüísticas, inmigración y escuela: Un aporte para la reflexión y la práctica educativa. Lecce: Libellula Edizioni.

Atienza, Francisco Luis, Diana Pons, Isabel Balaguer, and Marisa Garcia-Merita. 2000. Propiedades psicométricas de la escala de satisfacción con la vida en adolescentes. Psicothema 12: 331-36.

Auer, Peter. 2005. Europe's sociolinguistic unity; or: A typology of European dialect/standard constellations. In Perspectives on Variation. Edited by Nicole Delbecque, Johan van der Auwera and Dirk Geeraerts. Berlin and Nueva York: Mouton de Gruyter, pp. 7-42. 
Auer, Peter, Frans Hinskens, and Paul Kerswill, eds. 2005. Dialect Change: Convergence and Divergence in European Languages. Cambridge: Cambridge University Press.

Ávila-Muñoz, Antonio Manuel. 1999. Léxico de frecuencia del español hablado en la ciudad de Málaga. Málaga: Universidad.

Ávila-Muñoz, Antonio Manuel. 2017. Entre limonetis y malaguitas: Estudio del léxico divergente de proximidad. Nuevos datos del Proyecto CONVERLEX-Málaga. Hispania 100: 538-53. [CrossRef]

Ávila-Muñoz, Antonio Manuel, and Juan Andrés Villena Ponsoda, eds. 2010. Variación social del léxico disponible en la ciudad de Málaga. Malaga: Sarriá.

Ávila-Muñoz, Antonio Manuel. Forthcoming. La integración sociocultural de los grupos vulnerables de inmigrantes desde el aula de lenguas. Propuesta de actuación desde la dialectología social en la ciudad de Málaga. Lengua y migración/Language and Migration. Forthcoming.

Bombarelli, Ángela. 2005. La disponibilidad léxica como herramienta didáctica: una propuesta de selección del vocabulario para un nivel umbral de ELE. Degree-Granting Salamanca. Salamanca: Universidad.

Braunmüller, Kurt, Steffen Höder, and Karoline Kühl, eds. 2014. Stability and Divergence in Language Contact. Factors and Mechanisms. Amsterdam and Philadelphia: John Benjamins.

Bravo-García, Eva, Emilio Gallardo-Saborido, Inmaculada Santos de la Rosa, and Antonio Gutiérrez, eds. 2014. Investigaciones sobre la enseñanza del español y su cultura en contextos de inmigración. Helsinki: University of Helsinki, Seville: University of Seville.

CIS. 2015. Estudio número 3119. Actitudes hacia la Inmigración (VIII). Available online: http://www.cis.es/cis/opencm/ ES/1encuestas/estudios/ver.jsp?estudio $=14249 \&$ cuestionario $=17109 \&$ muestra $=22655$ (accessed on 1 March 2019).

Davies, Mark. 2005. A Frequency Dictionary of Spanish: Core Vocabulary for Leaners. London: Routledge.

Dempster, Helen, and Karen Hargrave. 2017. Understanding Public Attitudes towards Refugees and Migrants. London: Overseas Development Institute, Available online: http://www.odi.org/publications/10826 (accessed on 1 April 2019).

Devereaux, Michelle D., and Chris C. Palmer, eds. 2019. Teaching Language Variation in the Classroom. Strategies and Models from Teachers and Linguists. New York and London: Routledge.

Diener, Ed, Robert A. Emmons, Randy J. Larsen, and Sharon Griffin. 1985. The satisfaction with life scale. Journal of Personality Assessment 49: 71-75. [CrossRef] [PubMed]

Egli, Mirjam, and Katharina Höchle. 2016. PluriMobil meets DYLAN_Practical resources for supporting plurilingual and intercultural learning in vocational students' mobility. In Managing Plurilingual and Intercultural Practices in the Workplace. Edited by Georges Lüdi, Katharina Höchle Meier and Patchareeart Yanaprasart. Amsterdam and Philadelphia: John Benjamins, pp. 294-313.

European Council. 2002. European Common Frame of Reference for Languages. Madrid: MECD, Available online: http://cvc.cervantes.es/ensenanza/biblioteca_ele/marco/ (accessed on 1 March 2019).

EUROSTAT. 2017. Statistics Explained. Estadísticas de migración y población migrante. Available online: http://ec.europa.eu/eurostat/statistics-explained/index.php/Migration_and_migrant_population_ statistics/es\#Principales_resultados_estad.C3.ADsticos (accessed on 1 March 2019).

Fernández-Vítores, David. 2013. El papel de la lengua en la configuración de la migración europea: tendencias y desencuentros. Lengua y migración/Language and Migration 5: 51-66.

Helke, Jill, and Frank Laczko. 2015. Informe sobre las migraciones en el mundo 2015. Los migrantes y las ciudades: Nuevas colaboraciones para gestionar la movilidad. Ginebra: Organización Internacional para las Migraciones, Available online: http://www.publications.iom.int/system/wmr2015_sp.pdf (accessed on 15 March 2019).

Hinskens, Frans. 1996. Dialect Levelling in Linburg: Structural and Sociolinguistic Aspects. Tübingen: Niemeyer.

Jahan, Selim. 2016. Informe Sobre Desarrollo Humano 2016. Desarrollo humano para todas las personas. Nueva York: Programa de las Naciones Unidas para el Desarrollo, Available online: http://www.undp.org/content/dam/ HDR16OverviewSpanish.pdf (accessed on 1 March 2019).

Johnson, Trev, and Simon Berry. 2014. Beyond the ESOL classroom. In Language issues in Migration and Integration: Perspectives from Teachers and Learners. Edited by Davis Mallows. London: British Council, pp. 79-95.

Kerswill, Paul. 2003. Dialect levelling and geographical diffusion in British English. In Social Dialectology. In Honour of Peter Trudgill. Edited by David Britain and Jenny Cheshire. Amsterdam: John Benjamins, pp. 223-43.

Lonsdale, Deryle, and Yvon Le Bras. 2009. A Frequency Dictionary of French: Core vocabulary for Leaners. London: Routledge. 
Mallows, Davis, ed. 2014. Language Issues in Migration and Integration: Perspectives from Teachers and Learners. London: British Council.

Moreno-Fernández, Francisco. 2009. Integración sociolingüística en contextos de inmigración: marco epistemológico para su estudio en España. Lengua y migración/Language and Migration 1: 121-56.

Moreno-Fernández, Francisco. 2013a. Sociolingüística Cognitiva: Proposiciones, Escolios y Debates. Madrid and Frankfurt: Iberoamericana/Vervuert.

Moreno-Fernández, Francisco. 2013b. Lingüística de las migraciones hispánicas. Lengua y migración/Language and Migration 5: 67-89.

OECD/European Union. 2015. Indicators of Immigrant Integration 2015: Settling In. Paris: OECD Publishing, Available online: http://dx.doi.org/10.1787/9789264234024 (accessed on 1 March 2019).

Piller, Ingrid, ed. 2016. Language and Migration. Critical Concepts in Linguistics. I-IV vols. London and New York: Routledge.

Pons, Diana, Francisco Luis Atienza Isabel Balaguer, and Marisa Garcia-Merita. 2002. Propiedades psicométricas de la escala de satisfacción con la vida en personas de la tercera edad. Revista Iberoamericana de Diagnóstico Evaluación Psicológica 13: 71-82.

Regan, Vera, Chloé Diskin, and Jennifer Martin, eds. 2016. Language, Identity and Migration. Voices from Transnational Speakers and Communities. Bern: Peter Lang.

Sancho-Pascual, María. 2013. La integración sociolingüística de la inmigración hispana en España: lengua, percepción e identidad social. Lengua y migración/Language and Migration 5: 91-110.

Sheppard, Jill. 2015. Australian Attitudes towards National Identity: Citizenship, Immigration and Tradition. Canberra: ANU.

Stokes, Bruce. 2017. Refugees in the Mind of the West. Washington: Pew Research Center for the People \& the Press. Trudgill, Peter. 2002. Sociolinguistic Variation and Change. Edinburgh: Edinburgh University Press.

Villena, Juan Andrés. 2005. How similar are people who speak alike? An interpretive way of using social networds in social dialectology research. In Dialect Change: Convergence and Divergence in European Languages. Edited by Peter Auer, Frans Hinskens and Paul Kerswill. Cambridge: Cambridge University Press, pp. 303-34.

Villena, Juan Andrés, and Matilde Vida. 2017. Between local and standard varieties. Horizontal and vertical convergence and divergence of dialects in Southern Spain. In Language Variation-European Perspectives VI, I. Edited by Isabelle Buchstaller and Beat Siebenhaar. Amsterdam and Philadelphia: John Benjamins, pp. $125-40$.

Wheeler, Rebecca. 2019. Attitude Change is Not Enough: Changing teacher practice to disrupt dialect prejudice un the classroom. In Teaching Language Variation in the Classroom. Strategies and Models from Teachers and Linguists. Edited by Michelle D. Devereaux and Chris C. Palmer. New York and London: Routledge, pp. 109-19.

(C) 2019 by the author. Licensee MDPI, Basel, Switzerland. This article is an open access article distributed under the terms and conditions of the Creative Commons Attribution (CC BY) license (http://creativecommons.org/licenses/by/4.0/). 
MDPI

St. Alban-Anlage 66

4052 Basel

Switzerland

Tel. +41616837734

Fax +41 613028918

www.mdpi.com

Languages Editorial Office

E-mail: languages@mdpi.com

www.mdpi.com/journal/languages

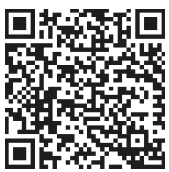



MDPI

St. Alban-Anlage 66

4052 Basel

Switzerland

Tel: +41 616837734

Fax: +41 613028918

www.mdpi.com 